\title{
A AVALIAÇÃO ECONÔMICO-FINANCEIRA DE INVESTIMENTOS SOB CONDIÇÃO DE INCERTEZA: UMA COMPARAÇÃO ENTRE O MÉTODO DE MONTE CARLO E O VPL FUZZY
}

\section{Mário Henrique da Fonseca Oliveira}

\author{
Dissertação apresentada à Escola de Engenharia de São \\ Carlos, da Universidade de São Paulo, como parte dos \\ requisitos para obtenção do título de Mestre em \\ Engenharia de Produção
}

ORIENTADORA: Profa. Associada Daisy Aparecida do Nascimento Rebelatto

São Carlos

2008 
A minha esposa Francine, meu filho

Guilherme e minha mãe Luzia. 


\section{AGRADECIMENTOS}

A Deus por todas as oportunidades e realizações que tem me abençoado em toda minha vida.

A orientadora, professora Daisy Aparecida do Nascimento Rebelatto, pela oportunidade e pela sábia maneira com que conduziu este trabalho. Obrigado pelo valor inestimável de seu exemplo pessoal e profissional.

A minha esposa Francine Guidugli Bartoletti, pela amada companhia e maneira atenciosa com que dispôs de seu tempo para me ajudar na construção textual e conceitual deste trabalho.

A minha mãe, Luzia Darci da Fonseca, que em todos os momentos de minha vida sempre incentivou meus estudos e pelo seu exemplo de dedicação e força de vontade.

Aos professores da Escola de Engenharia de São Carlos, Marcelo Seido Nagano e Ivan Nunes da Silva, pelas sugestões que aperfeiçoaram e engrandeceram este trabalho.

Ao professor Carlos Roberto Azzoni por honrar-me com presença na participação da banca examinadora.

Ao estimado amigo Ronaldo Justo Santoro pela ajuda neste trabalho e por nossas intermináveis discussões que nos acompanham desde os tempos de graduação. 
Aos companheiros de Tecumseh, Orlando Falanghe Carneiro, Marcos Roberto Perez de Oliveira e Valter Kenji Okada, pelos esforços para disponibilizar horários para minha participação no programa de pós-graduação.

Aos amigos do programa de pós-graduação em Engenharia de Produção, uma geração estimada de novos pesquisadores. 
"Mire o céu para acertar o horizonte".

(Renato Nunes Faria de Aquino) 


\section{SUMÁRIO}

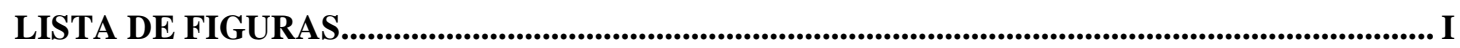

LISTA DE QUADROS.......................................................................................................

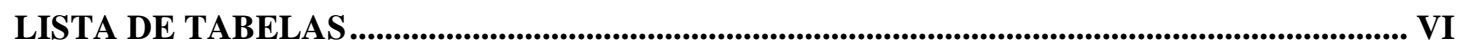

LISTA DE SÍMBOLOS ............................................................................................................. VII

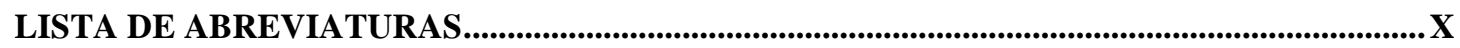

RESUMO

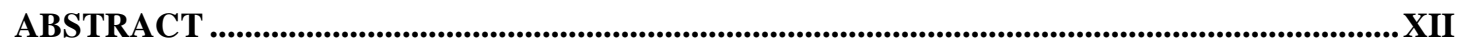

1 APRESENTAÇÃO ............................................................................................................................................

1.1 OBJETIVO

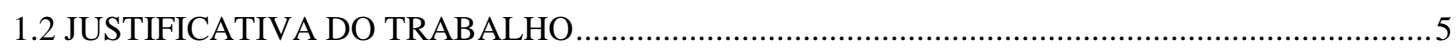

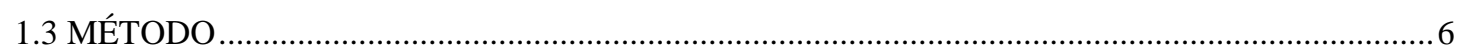

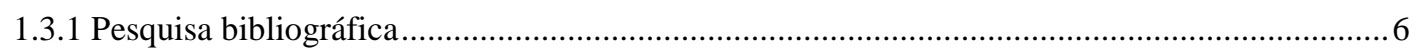

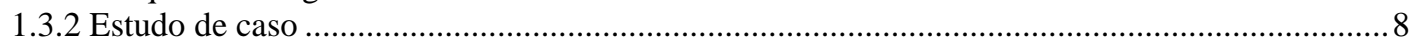

1.4 A COMPARAÇÃO ENTRE O MÉTODO DE MONTE CARLO E O VALOR PRESENTE

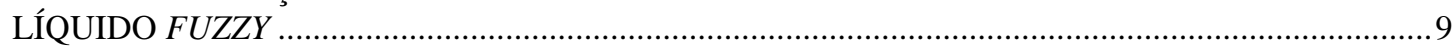

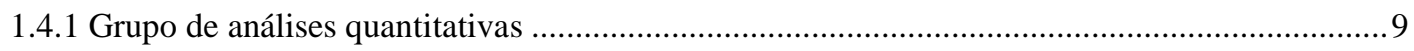

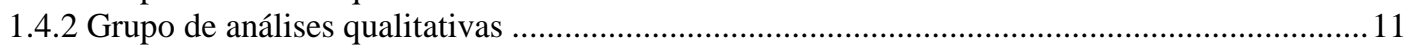

1.5 LOCALIZAÇÃO DO TEMA NO CONTEXTO DA ENGENHARIA DE PRODUÇÃO..................11

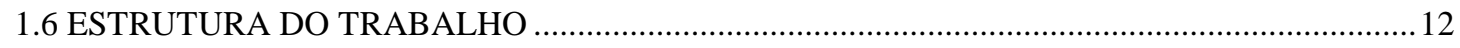

2 A ANÁLISE DE INVESTIMENTOS E AS INCERTEZAS NA TOMADA DE DECISÕES ....14

2.1 MÉTODOS QUANTITATIVOS NA ANÁLISE DE INVESTIMENTOS ……………....................15

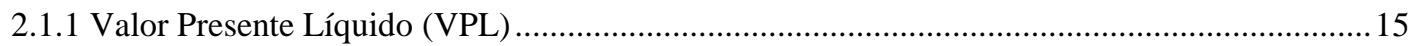

2.1.2 Taxa Mínima De Atratividade (TMA) ............................................................................. 17

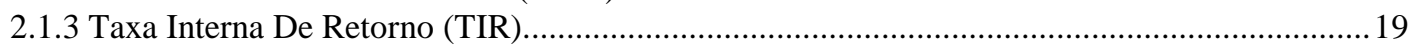

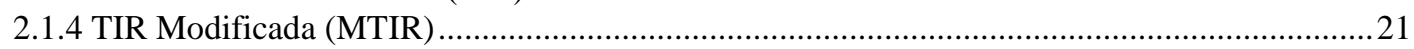

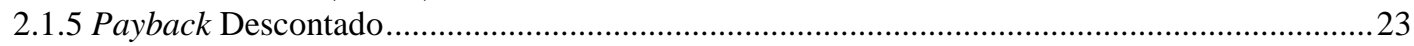

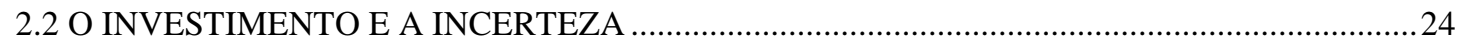

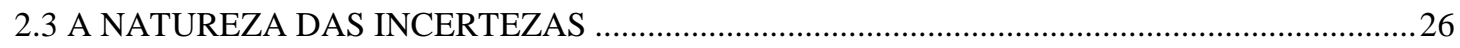




\section{A SIMULAÇÃO DE MONTE CARLO NA ANÁLISE DE INVESTIMENTO SOB}

CONDIÇÕES DE INCERTEZA..............................................................................................................30

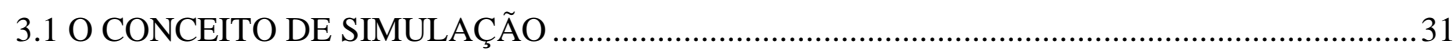

3.2 A CONSTRUÇÃO DE UM MODELO PROBABILÍSTICO E O USO DA SIMULAÇÃO DE

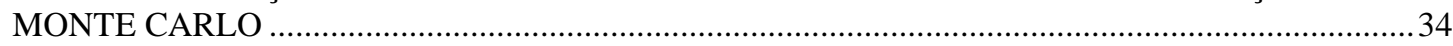

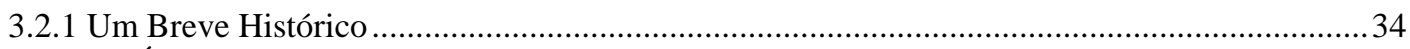

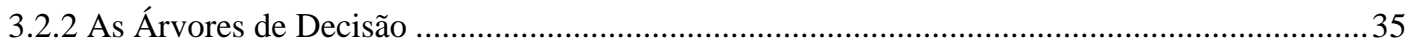

3.2.3 O Conceito da Simulação de Monte Carlo aplicado ao VPL ....................................................... 38

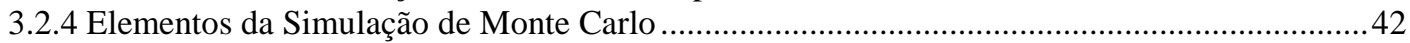

3.2.5 Alguns tipos importantes de distribuição de probabilidade ......................................................46

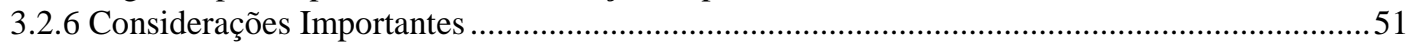

4 O USO DE NÚMEROS FUZZY NA ANÁLISE DE INVESTIMENTOS SOB CONDIÇÕES DE

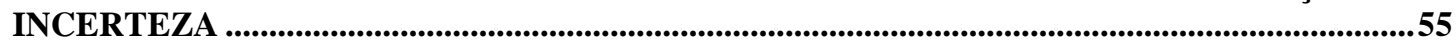

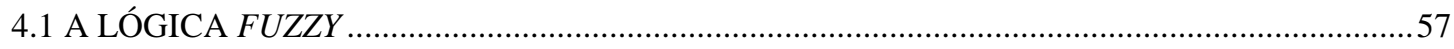

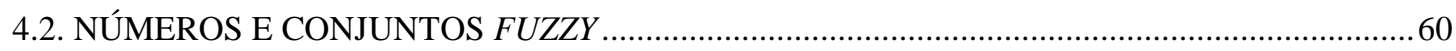

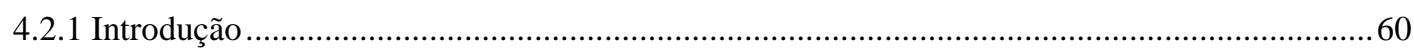

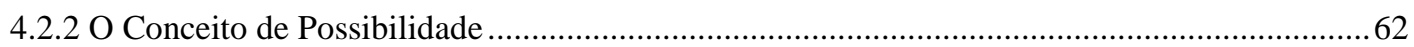

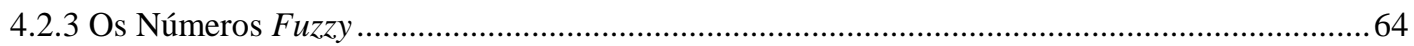

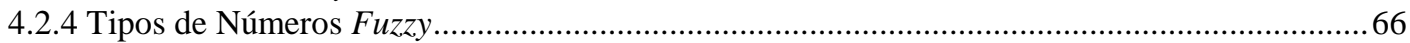

4.2.5 Operações com Números Triangulares Fuzzy ................................................................ 71

4.3 A ESTRUTURA LÓGICA EM SISTEMAS E MODELOS FUZZY …………………....................76

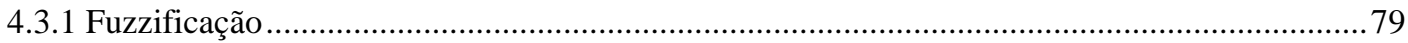

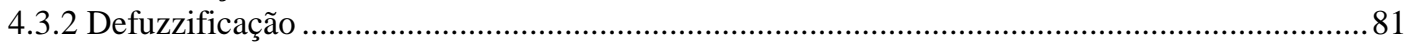

4.4 A APLICAÇÃO DA LÓGICA FUZZY EM UM SISTEMA DE CONTROLE ……….......................86

4.5 A APLICAÇÃO DO VALOR PRESENTE LÍQUIDO FUZZY NA AVALIAÇÃO ECONÔMICO-

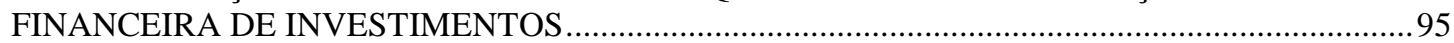

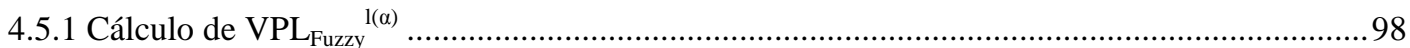

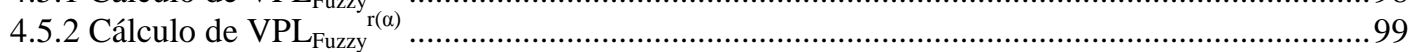

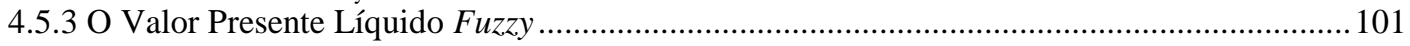

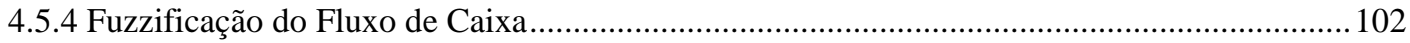

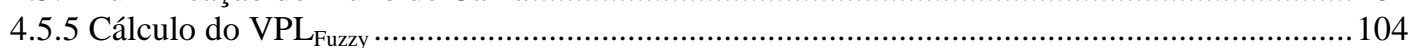

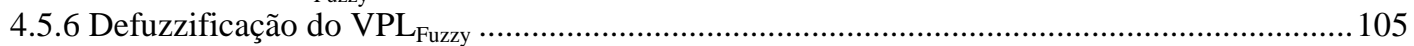

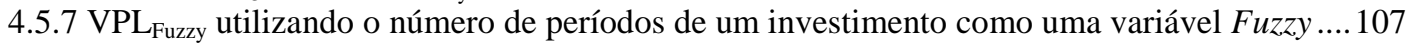

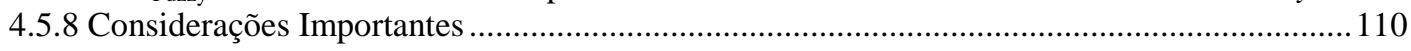

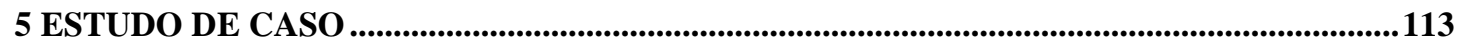

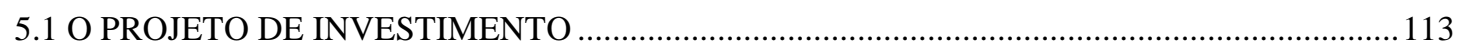

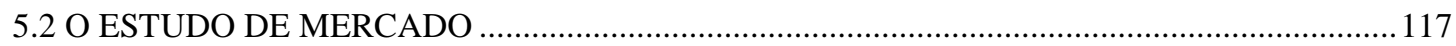

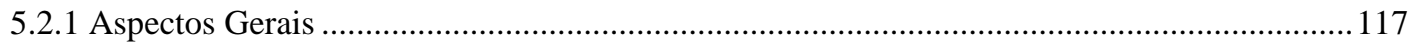

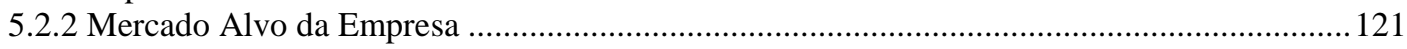

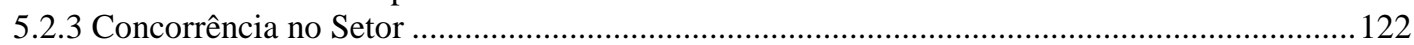

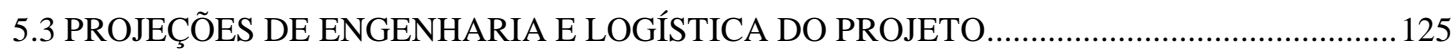




\subsection{A ESTIMATIVA DE CUSTOS E RECEITAS DO PROJETO}

5.6 O CÁLCULO DO VPL DETERMINÍSTICO PARA A AVALIAÇÃO ECONÔMICOFINANCEIRA DO PROJETO DE INVESTIMENTO

5.6.1 O Investimento Total

5.6.2 Receita Anual Total

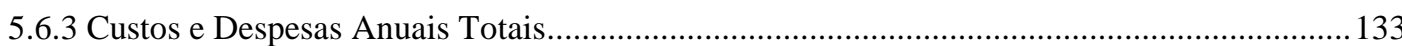

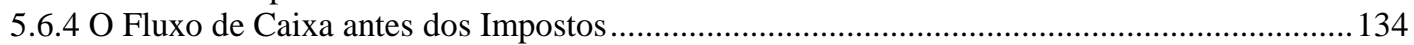

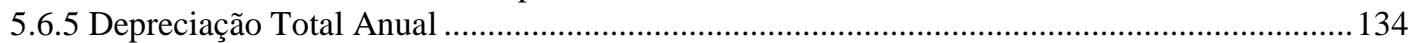

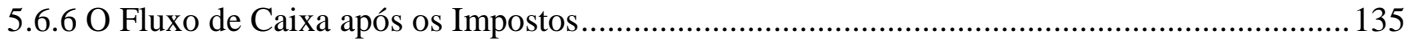

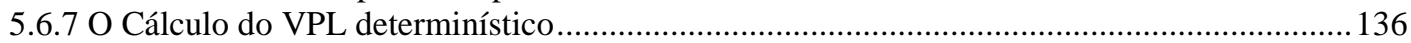

5.7 A AVALIAÇÃO ECONÔMICO-FINANCEIRA DO PROJETO DE INVESTIMENTO UTILIZANDO A SIMULAÇÃO DE MONTE-CARLO.

5.7.1 Atribuição de distribuições de probabilidades junto às variáveis independentes.

5.7.2 Atribuição dos números aleatórios e execução da simulação

5.7.3 Resultados da simulação

\subsection{A AVALIAÇÃO ECONÔMICO-FINANCEIRA DO PROJETO DE INVESTIMENTO} UTILIZANDO VPL FUZZY

5.7.1 A fuzzificação das variáveis

5.9 A COMPARAÇÃO ENTRE O VPL OBTIDO PELA SIMULAÇÃO DE MONTE CARLO E O VPL FUZZY

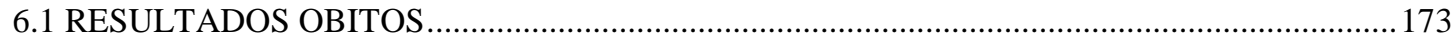

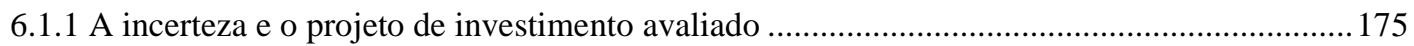

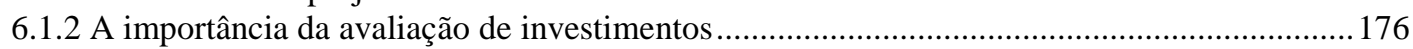

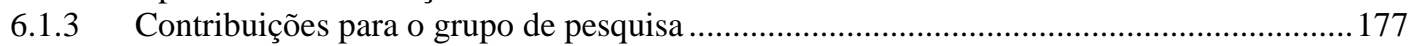

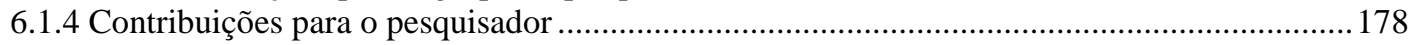

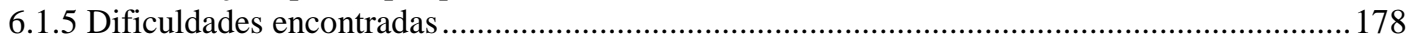

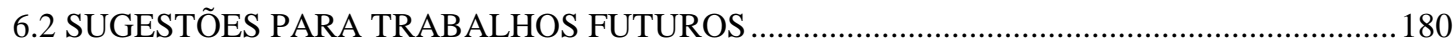

6.2.1 Melhorias na composição do Valor Presente Líquido Fuzzy .............................................. 180

6.2.2 Melhorias na quantificação de incertezas ........................................................................... 181

6.2.3 Estruturação de softwares ou planilhas de cálculo para maior facilidade de aplicação ........... 183

6.2.4 Sistemas de apoio a decisão para decisões de curto e curtíssimo prazo................................... 184

6.2.5 Sistema de apoio a decisão para a análise de crédito ............................................................. 185

6.2.6 Sistema de avaliação social de projetos ........................................................................ 186

6.2.7 A utilização da Lógica Fuzzy para precificação de opções .................................................. 187

6.2.8 Possíveis aplicações da lógica Fuzzy em outras áreas da engenharia de produção.................. 187 
APÊNDICE A ..

APÊNDICE B 



\section{LISTA DE FIGURAS}

$\begin{array}{ll}\text { Figura } 1 \text { - O conceito de VPL } & 16\end{array}$

Figura 2 - Ilustração Gráfica da TIR 20

Figura 3 - A Incerteza nos Fluxos de Caixa 25

Figura 4 - Formas de Estudo de um Sistema

Figura 5 - Processo simples de modelagem 33

Figura 6 - Uso da Árvore de Decisão 36

Figura 7 - Árvore de Decisão para Comparação de Investimentos 37

Figura 8 - Uma comparação entre o uso da Árvore Decisão e a Simulação de Monte

$\begin{array}{ll}\text { Carlo } & 39\end{array}$

Figura 9 - Função densidade de probabilidade uniforme contínua 47

Figura 10 - Função densidade de probabilidade da distribuição normal. 49

Figura 11 - Função densidade de probabilidade de Weibull para valores selecionados

$\begin{array}{lr}\text { de } \delta \text { e } \beta . & 50\end{array}$

Figura 12 - A estrutura da Simulação de Monte Carlo. 52

$\begin{array}{lr}\text { Figura } 13 \text { - Lógica booleana } & 58\end{array}$

Figura 14 - Lógica Fuzzy $\quad 59$

Figura 15 - Número Real $0 \quad 61$

Figura 16 - O conceito de Quase zero $\quad 61$

Figura 17 - Próximo de Zero $\quad 62$

Figura 18 - A Intensidade da Chuva $\quad 64$

Figura 19 - Função de pertinência não normalizada 65

$\begin{array}{ll}\text { Figura } 20 \text { - Função de pertinência normalizada } & 65\end{array}$

Figura 21 - Função de pertinência normalizada, porém não convexa 66 
Figura 22 - Número Trapezoidal Fuzzy

Figura 23 - Número Triangular Fuzzy

Figura 24 - Representação de $\alpha-c u t=0.25$ e $\alpha-c u t=0.75$ em um número triangular Fuzzy

Figura 25 - Representação gráfica do número Fuzzy $\mathrm{A}=(-1,2,5)$

Figura 26 - Número Fuzzy em formato de Sino

Figura 27 - Soma entre os números Fuzzy A e B

Figura 28 - A Imagem Simétrica de A

Figura 29 - Subtração entre os números Fuzzy A e B

Figura 30 - Multiplicação entre os números Fuzzy A e B

Figura 31 - Divisão entre os números Fuzzy A e B

Figura 32 - Sistemas e Modelos Fuzzy

Figura 33 - Variável Lingüística Taxa de Juros Selic Alta

Figura 34 - Possíveis valores Taxa de Juros Selic

Figura 35 - Valor de entrada $13 \%$

Figura 36 - Método de defuzzificação pelo Centro da Área

Figura 37 - Método de Defuzzificação pela Média do Máximo

Figura 38 - Possibilidade Cumulativa

Figura 39 - Transporte para cargas portuárias

Figura 40 - Estrutura de Controle

Figura 41 - Entrada da variável angle

Figura 42 - Entrada da variável distance

Figura 43 - Conjunto de regras para o sistema

Figura 44 - Potência pos_medium com pertinência 0.70

Figura 45 - Resultado fuzzificado da Power 
Figura 46 - Valor defuzzificado de power : $14.0500 \mathrm{~kW}$

Figura 47 - VPL obtido em um investimento onde fora utilizado taxas de descontos e

$\begin{array}{ll}\text { fluxos caixa Fuzzy } & 97\end{array}$

$\begin{array}{lr}\text { Figura } 48 \text { - Investimento fuzzificado } & 102\end{array}$

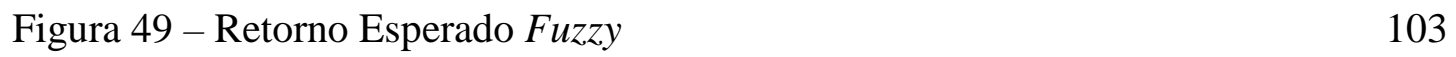

$\begin{array}{ll}\text { Figura 50 - A TMA fuzzificada } & 104\end{array}$

$\begin{array}{ll}\text { Figura } 51-\mathrm{VPL}_{\text {Fuzzy }} \text { aplicado ao exemplo apresentado } & 105\end{array}$

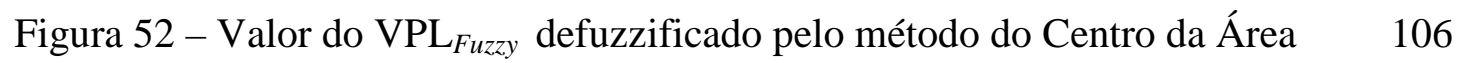

Figura 53 - Vida econômica do investimento representada por um número Fuzzy 108

$\begin{array}{ll}\text { Figura } 54 \text { - Resultados do VPL para cada período } & 109\end{array}$

Figura 55 - Defuzzificação proposta por Sanches (2003) 109

Figura 56 - Defuzzificação proposta por Omitaou e Badiru (2007) 110

Figura 57 - Esquema de funcionamento de uma caldeira aquatubular $\quad 115$

Figura 58 - Esquema de funcionamento de uma caldeira aquatubular $\quad 116$

Figura 59 - Produção de cana-de-açúcar em tonelada 120

$\begin{array}{ll}\text { Figura } 60 \text { - Estimativa da distribuição atual do mercado } & 123\end{array}$

$\begin{array}{ll}\text { Figura 61- O teorema de Tchebichev ou regra empírica } & 139\end{array}$

Figura 62- Definição da variável Galpão na simulação utilizando o Crystall Ball 142

Figura 63 - VPL obtido como resultado da simulação 144

Figura 64 - Indicadores estatísticos obtidos através da simulação 145

Figura 65 - Fluxo de caixa Fuzzy para o período de 1 a 10 anos 155

Figura 66 - Fluxo de caixa Fuzzy para o período de 11 a 15 anos 156

Figura 67 - Valor Presente Líquido Fuzzy do projeto de investimento 158

Figura 68 - Defuzzificação do Valor Presente Líquido Fuzzy do projeto de investimento 
Figura 69 - Valor Presente Líquido fuzzy obtido por aproximação 


\section{LISTA DE QUADROS}

Quadro 1 - Grandes Áreas da Engenharia de Produção

Quadro 2 - Fatores que contribuem para Incerteza

Quadro 3 - Fatores e Tratamentos para as Incertezas

Quadro 4 - Uma representação Fuzzy para chuva

Quadro 5 - Grandes produtores mundiais de etanol 


\section{LISTA DE TABELAS}

Tabela 1 - Diferenças básicas entre Cálculos e Inferências Fuzzy 78

$\begin{array}{ll}\text { Tabela } 2 \text { - Inferência do sistema } & 92\end{array}$

$\begin{array}{ll}\text { Tabela } 3 \text { - Estimativas Iniciais do Projeto } & 128\end{array}$

$\begin{array}{ll}\text { Tabela } 4 \text { - Estimativa de receitas e custos anuais do projeto } & 129\end{array}$

Tabela 5 - Variáveis independentes para execução da Simulação de Monte Carlo 141

Tabela 6 - Resultados obtidos pela aplicação da Simulação de Monte Carlo 145

Tabela 7 - Variáveis fuzzificadas para o cálculo do Valor Presente Líquido Fuzzy 149

Tabela 8 - Resultados obtidos pela aplicação do Valor Presente Líquido Fuzzy 161

Tabela 9 - Análise numérica comparativa entre os valores obtidos pela aplicação da

simulação de Monte Carlo e Valor Presente Líquido Fuzzy

Tabela 10 - Comparação numérica entre valores obtidos pela simulação de Monte

$\begin{array}{ll}\text { Carlo em duas diferentes situações } & 164\end{array}$

Tabela 11 - Comparação numérica entre valores obtidos pelo cálculo do Valor Presente Líquido Fuzzy efetuado sem aproximação e com aproximação matemática 


\section{LISTA DE SÍMBOLOS}

$a$ - Limite Inferior da Distribuição de Probabilidade Uniforme

$a_{1}$ - Representação Genérica do Primeiro Elemento do Número Fuzzy A

$a_{2}$ - Representação Genérica do Segundo Elemento do Número Fuzzy A

$a_{3}$ - Representação Genérica do Terceiro Elemento do Número Fuzzy A

$a_{4}$ - Representação Genérica do Quarto Elemento do Número Fuzzy A

$a^{l(\alpha)}$ - Lado Esquerdo de Pertinência do Número Fuzzy A

$a^{r(\alpha)}$ - Lado Direito de Pertinência do Número Fuzzy A

$\alpha$ - Indicador de Representação por $\alpha-c u t$

$b$ - Limite Superior da Distribuição de Probabilidade Uniforme

$b_{1}$ - Representação Genérica do Primeiro Elemento do Número Fuzzy B

$b_{2}$ - Representação Genérica do Segundo Elemento do Número Fuzzy B

$b_{3}$ - Representação Genérica do Terceiro Elemento do Número Fuzzy B

$b^{l(\alpha)}$ - Lado Esquerdo de Pertinência do Número Fuzzy B

$b^{r(\alpha)}$ - Lado Direito de Pertinência do Número Fuzzy B

$B$ - Montante Capital de Terceiros

$\beta$ - Parâmetro de Forma

$c$ - Constante de Incremento

$C_{j}$ - Fluxos de Caixa Negativos

$d$ - Constante Multiplicadora

$E(X)$ - Valor Médio para Distribuição de Probabilidade Uniforme

$f(x)$ - Função Densidade de Probabilidade 
$f_{1}^{a}(x)$ - Função de Pertinência 1

$f_{2}^{a}(x)$ - Função de Pertinência 2

$F C_{0}$ - Fluxo de caixa verificado no momento zero (momento inicial)

$F C_{j}$ - Fluxo de caixa em cada período $j$

$F C^{l(\alpha)}$ - Lado Esquerdo de Pertinência do número Fuzzy FC

$F C^{r(\alpha)}$ - Lado Direito de Pertinência do número Fuzzy FC

$\delta$ - Parâmetro de Escala

$i$ - Taxa de Desconto

$i_{B}$ - Custo de Capital de Terceiros

$i_{c}$ - Taxa Correspondente ao Custo de Capitação

$i_{s}$ - Custo de Capital Próprio

$i_{r}$ - Taxa de Aplicação de Recursos Ociosos

$i^{l(\alpha)}$ - Lado Direito de Pertinência do número Fuzzy $i$

$i^{r(\alpha)}$ - Lado Direito de Pertinência do número Fuzzy $i$

$l(\alpha)$ - Lado Esquerdo de uma Função de Pertinência

$m$ - Constante Módulo

$\mu$ - Média

$\mu_{\text {Galpão }}$ - Média da Variável Galpão

$\mu_{\text {saída }}(x)$ - Função de Pertinência da Variável Saída

$\mu_{A}(x)$ - Função de Pertinência para o Número Fuzzy A

$\mu^{*}\left(V P L_{f u z z y}<0\right)$ - Possibilidade Cumulativa de $V P L_{f u z z y}$ menor do que 0

$n$ - Período de Tempo

$N$ - Quantidade de Iterações utilizadas 
$N_{\text {Galpão }}$ - Distribuição Normal de Probabilidade da Variável Galpão $P$ - Probabilidade

$r(\alpha)$ - Lado Direito de uma Função de Pertinência

$R_{j}$ - Fluxos de Caixa Positivos

$\Gamma$ - Função Auxiliar da Distribuição de Probabilidade de Weibull

$S$ - Montante da Capital Próprio

$\sigma$ - Desvio-padrão

$\sigma_{\text {Galpão }}$ - Desvio-padrão da Variável Galpão

$\sigma^{2}$ - Variância

$U$ - Universo de Discurso

$V P L *$ - Valor Presente Líquido Defuzzificado

$V P L_{f u z z y}$ - Valor Presente Líquido Fuzzy

$V P L_{f u z z y}{ }^{l(\alpha)}$ - Lado Esquerdo de Pertinência da função VPL Fuzzy

$V P L_{f u z z y}^{r(\alpha)}$ - Lado Direito de Pertinência da função VPL Fuzzy

$x$ - Valor que o VPL pode assumir

$x_{0}$ - Semente ou seed

$x_{m}$ - m-ésimo Valor no Universo de Discurso com Pertinência Máxima

$x_{n+1}$ - Número aleatório $x$ Gerado

$x *$ - Valor da Variável $x$ Defuzzificado

(+) - Adição Fuzzy

(-) - Subtração Fuzzy

(×) -Multiplicação Fuzzy

$(\div)$ - Divisão Fuzzy 


\section{LISTA DE ABREVIATURAS}

BNDES - Banco Nacional de Desenvolvimento Econômico e Social

CAD - Computer Aided Design (Desenho Auxiliado por Computador)

CNAA - Companhia Nacional de Açúcar e Álcool

CIL - Coeficiente de Incerteza Léxica

IBGE - Instituto Brasileiro de Geografia e Estatística

IPEA - Instituto de Pesquisa Econômica Aplicada

MTIR - Taxa Interna De Retorno Modificada

PROINFA - Programa de Incentivo às Fontes Alternativas

SELIC - Sistema Especial de Liquidação e Custódia

TIR - Taxa Interna De Retorno

TMA - Taxa Mínima de Atratividade

VPL - Valor Presente Líquido

VPL $_{f u z z y}$ - Valor Presente Líquido Fuzzy

WACC - Weighted Average Cost of Capital (Custo Médio Ponderado de Capital) 


\section{RESUMO}

OLIVEIRA, M. H. F. (2008). A avaliação econômico-financeira de investimentos sob condição de incerteza: uma comparação entre o método de Monte Carlo e o VPL fuzzy. São Carlos, 2008, 209p. Dissertação (Mestrado) - Escola de Engenharia de São Carlos, Universidade de São Paulo.

Os métodos determinísticos utilizados para avaliação econômico-financeira de projetos de investimentos, como o Valor Presente Líquido (VPL) e a Taxa Interna de Retorno (TIR), contemplam exatidão do comportamento futuro das varáveis inerentes ao projeto. Porém, as imprevisibilidades futuras acrescidas da alta volatilidade da economia e tecnologia mundial tornam as análises determinísticas frágeis em situações onde existam incertezas, o que pode levar gestores e investidores a tomar decisões equivocadas quanto à alocação de capital. O presente trabalho tem como objetivo geral a comparação entre dois métodos que podem ser utilizados para avaliação de investimentos que abordam a condição de incerteza. O método de Monte Carlo, em seu caráter estatístico, permite que as variáveis presentes sejam consideradas por meio de distribuições de probabilidade, as quais associadas a geração de números aleatórios fornecem uma resposta que considera as incertezas presentes. O Valor Presente Líquido Fuzzy constitui-se em um método alternativo para análise, o qual considera as variáveis incertas como números nebulosos, ou seja, concepções matemáticas que não apresentam fronteiras rígidas. Por meio da aplicação dos métodos em uma situação real de investimento, buscou-se realizar uma análise comparativa, que levasse em conta os resultados numéricos obtidos e a conceituação teórica envolvida.

Palavras-chave: VPL Fuzzy, Incerteza, Análise de Investimentos. 


\begin{abstract}
OLIVEIRA, M. H. F. (2008). The financial and economic evaluation of investments under uncertainly: a comparison between the Monte Carlo method and NPV fuzzy. São Carlos, 2008, 209p. Dissertação (Mestrado) - Escola de Engenharia de São Carlos, Universidade de São Paulo.
\end{abstract}

The deterministic methods used for economical and financial evaluation of investments projects, such as Net Present Value (NPV) and Internal Rate Return (IRR) consider the future comportment of the project variables as exact values. Nevertheless, the future unpredictability and the high volatility of world economy and technology make fragile the deterministic analysis under situations that uncertainty is present, what may lead managers and investors to take bad decisions about capital allocation. The main objective of this assignment is two compare two different methods used to evaluate investments under uncertainty. The Monte Carlo Method is its statistical character, allows to associate probability distributions with random numbers and this application provides that includes uncertainty. The Fuzzy Net Present Value is an alternative method to analyze investments, which consider uncertainty variable as Fuzzy numbers, i.e., mathematics conceptions that do not present absolute borders. Two different kinds of comparisons were produced by applications of both methods in a real investment situation: the first was developed based on numeric analysis; the second is based on a theory that involves those methods.

Key-words: NPV Fuzzy, Uncertainty, Investments Analysis. 


\section{APRESENTAÇÃO}

A partir da década de 90 grandes transformações foram observadas no mundo; a crescente tecnologia na informática, a intensificação das relações comerciais e maior integração dos meios de informação propiciaram a criação de um mercado global, onde a variedade de produtos e empresas contribuiu para o aumento da volatilidade econômica e a concorrência empresarial.

O mundo é um lugar menor para se fazer negócio. Muitas empresas médias estão buscando fornecedores e vendendo seus produtos e serviços globalmente. Um website bem desenhado pode transformar mesmo pequenas empresas em atores globais (SLACK et al, 2002).

A facilidade comercial e de comunicação fez com que o acesso a novos produtos, marcas e serviços se tornassem accessíveis. Os objetivos de desempenho como qualidade, flexibilidade e custo tornaram-se mais importantes, agindo como diferenciais competitivos na concorrência empresarial. Em um cenário volátil fora possível observar grandes empresas como a IBM, reduzirem seu faturamento acentuadamente, enquanto novas empresas surgiam no mercado internacional.

O governo brasileiro inseriu o país neste cenário ao desvencilhar-se de uma política comercial protecionista em pró da abertura econômica. Segundo Meireles (2004) a redução das tarifas de importação sem uma contrapartida de financiamentos voltados a modernização, acentuou ainda mais as diferenças competitivas entre as empresas, segundo a origem de capital e segundo o tamanho.

A dificuldade inicial das empresas brasileiras em se desenvolver neste novo cenário internacional também era advinda do grande descontrole que a economia nacional apresentou desde a década 80. Os altos índices de inflação dificultavam a 
gestão financeira e empresarial, altos estoques assim como o overnight eram incisivos no sucesso das empresas.

O ambiente complexo da globalização forçou a evolução da estratégia empresarial e os investimentos e modernização passaram a ser fundamentais (MEIRELES, 2004). O uso de métodos quantitativos para a avaliação econômicofinanceira de investimentos passaram a ter mais visibilidade, isto não só pela necessidade dos investidores em avaliar seus passos futuros, mas também pela evolução do sistema financeiro nacional, informatizado e bastante lucrativo.

A análise das alternativas de investimento é o estudo dos fluxos de caixa - desembolsos de capital (saídas de caixa) e retornos de investimentos (entradas de caixa) - de um projeto para avaliar a sua viabilidade econômica. A viabilidade econômica de um investimento exige sua recuperação de capital (retorno do investimento) e sua remuneração (retorno sobre o investimento) (Rebelatto, 2004).

As avaliações econômico-financeiras dos investimentos contribuem diretamente para a tomada de decisão de gestores e investidores. Através de tais análises é possível projetar o sucesso ou insucesso econômico de um investimento, já que consideram como entradas, as variáveis que compõem o fluxo de caixa do investimento, e oferece como resposta ou saída a viabilidade do investimento em termos financeiros.

É evidente que análises podem conduzir a prejuízos; o cenário projetado para o investimento pode modificar-se ao longo do tempo e as premissas assumidas no início do projeto podem não ocorrer, já que na grande maioria dos casos existem incertezas sobre qual será o comportamento do projeto analisado no futuro. 
As informações disponíveis para elaborar uma análise de investimento não são lineares ou absolutas, visto que a economia e o mercado financeiro mundial historicamente apresentam variações que podem ser imprevisíveis e também podem atingir economias diversas. Mesmo com as agências de rating e diversos sistemas de informações on-line, parte dos títulos mobiliários americanos estiveram supervalorizados no primeiro semestre de 2007. Surpresas e variações de natureza diversas são bastante presentes na economia.

A dificuldade dos gestores e investidores em prever com exatidão os resultados de suas decisões é existente devido a inúmeros fatos desconhecidos, como mudanças de tecnologia, modificações na preferência, incertezas em função da legislação, flutuação de preços e câmbio (Thompson Júnior, 1995).

A incerteza é um componente imutável da vida empresarial tal qual impostos e acionistas. Cabe à empresa, no entanto, decidir quais as incertezas que deseja assumir e quais prefere evitar. Para tanto, é preciso um método para descobrir e avaliar as incertezas inerentes aos seus projetos de investimento (Brandão, 2007).

Uma das grandes dificuldades ao se elaborar uma análise de um projeto de investimento é a de concernir os dados presentes de modo com que as variações futuras em custos, receitas e horizonte de planejamento, entre outras, sejam consideradas na análise.

O presente trabalho visa comparar dois métodos para a análise de investimentos: o primeiro deles está associado à simulação de Monte Carlo e o segundo é baseado na teoria dos números e conjuntos Fuzzy. A opção por essa 
comparação está associada à capacidade que eles apresentam de representar riscos e incertezas, presentes em grande parte dos investimentos correntes.

A simulação de Monte Carlo é um método de simulação estocástico, que se baseia na geração de números aleatórios para sua execução. Em síntese, pode-se dizer que os números aleatórios gerados representam cenários possíveis do investimento em questão. A geração de números aleatórios é associada a distribuições de probabilidade de maneira a simular os valores futuros de receitas e custos.

A Lógica Fuzzy é conhecida por ser factível ao uso em situações incertas e de difícil mensuração. Em vários momentos de uma análise de investimentos, as informações encontram-se vagas e imprecisas, sendo necessário interpretar as variáveis de maneira qualitativa. A Lógica Fuzzy permite manipular informações que se encontram imprecisas, traduzindo expressões verbais, vagas, imprecisas e qualitativas, de categoria subjetiva, comuns na comunicação humana, em valores numéricos (MEDEIROS, 2003).

\subsection{OBJETIVO}

O objetivo geral deste trabalho consiste em avaliar a aplicabilidade do Valor Presente Líquido Fuzzy como instrumento de avaliação de projetos de investimento, a partir da comparação que será feita junto ao método de Monte Carlo. Os objetivos específicos deste trabalho são:

- Discutir a incerteza na análise econômico-financeira de investimentos e sua influência na tomada de decisão; 
- Estruturar de maneira clara os principais conceitos que envolvem o uso da Lógica Fuzzy, representando-os segundo a óptica da Engenharia de Produção;

- Estruturar os conceitos que envolvem o Valor Presente Líquido Fuzzy e sua aplicabilidade;

- Verificar as possíveis vantagens do uso do Valor Presente Líquido Fuzzy para a avaliação de investimentos onde a incerteza está presente;

- Apresentar as limitações e as principais dificuldades para o uso da Lógica Fuzzy como método para avaliação de investimentos.

\subsection{JUSTIFICATIVA DO TRABALHO}

A necessidade de se considerar a variação dos parâmetros de entrada é fundamental para realização de uma avaliação concisa de um investimento, já que é impossível saber quais os valores exatos que o fluxo de caixa do projeto assumirá no futuro. Assim é necessário buscar métodos que consigam representar a imprevisibilidade futura (MALERBA, 2003).

Apesar de difundida em outras áreas do conhecimento, a Lógica Fuzzy ainda carece de estudos quando sua aplicação diz respeito à área financeira. A quantidade de trabalhos que visam aprimorar e divulgar métodos baseados neste princípio é bastante escassa, sendo também poucas as fontes bibliográficas que estruturam de forma acessível e fundamentada as aplicações presentes na Engenharia de Produção.

A comparação de novas teorias (Lógica Fuzzy) junto a métodos já aceitos pela comunidade científica (simulação de Monte Carlo) pode trazer informações e discussões relevantes ao processo decisório nas análises de investimentos. 
Mesmo sendo conceitualmente diferente da matemática tradicional, os conceitos para utilização da Lógica Fuzzy não apresentam grande complexidade, sendo viável sua aplicação em diversos softwares no mercado. Aliado a isso, softwares específicos para manipular sistemas Fuzzy têm sido desenvolvidos, fazendo com que sua operacionalização em diversas instituições e empresas seja bastante factível.

\subsection{MÉTODO}

Segundo Gil (1987) quando no objeto de estudo deseja-se confrontar de maneira empírica os dados teóricos com a realidade, torna-se necessário traçar um modelo conceitual e operativo para pesquisa, que recebe o nome de delineamento.

O mesmo autor define dois grandes tipos de delineamento: o que se vale das chamadas fontes de "papel" e aqueles cujo os dados são fornecidos por "pessoas". No primeiro grupo estão a pesquisa bibliográfica e a pesquisa documental. O segundo grupo está compreendido pela pesquisa experimental, a pesquisa ex-post-facto, o levantamento e o estudo de caso.

A presente dissertação foi elaborada com a combinação de duas etapas distintas. A primeira, de caráter conceitual, foi desenvolvida com base em uma pesquisa bibliográfica. A segunda, de caráter complementar e adicional, consistiu na execução de um estudo de caso, que permitiu a explanação dos conceitos à luz de uma situação real de investimento.

\subsubsection{Pesquisa bibliográfica}


Uma pesquisa bibliográfica consiste no levantamento da bibliografia já publicada que apresente relação com o assunto. Sua finalidade é colocar o pesquisador em contato com muito do já foi escrito sobre determinado assunto (MARCONI e LAKATOS, 1982).

O ponto de partida para o desenvolvimento conceitual foi a crítica aos métodos tradicionais para a avaliação de investimentos, que em muitas de suas aplicações, não permitem explorar as variações futuras nas receitas e dispêndios de um projeto. Tal crítica fortalece a hipótese do uso Valor Presente Líquido Fuzzy como uma alternativa aos problemas correntes na avaliação de investimentos.

\footnotetext{
Enquanto não testadas empiricamente, e mesmo após isto, as conclusões e raciocínios lógicos não passam de hipóteses. Mesmo após serem submetidas com sucesso a uma bateria de testes empíricos jamais perderão seu caráter precário. A qualquer momento, podem ser postas em xeque, diante da apresentação de novos indícios ou explicações (Meireles, 2004).
}

Para confecção de uma revisão bibliográfica compactuada ao tema, fez-se necessária a pesquisa e estudo de variados textos. A discussão sobre os métodos quantitativos tradicionais de análises e as incertezas presentes nos investimentos foi realizada através de pesquisas em trabalhos sobre finanças corporativas, o mercado financeiro e a engenharia econômica.

Em uma segunda etapa fez-se necessário conceituar o método de Monte Carlo, levando em conta os principais conceitos sobre simulação. Também foi necessária a pesquisa em publicações sobre estatística, característica marcante ao método, já que é 
necessária tanto para estipular as variações nas entradas da análise como para interpretação de seu resultado final.

A construção da revisão sobre a Lógica Fuzzy e do método do Valor Presente Líquido Fuzzy é subsidiada por trabalhos da área de automação, sistemas de apoio de decisão, matemática aplicada e da análise de investimentos. Esta parte da revisão visa atender objetivos importantes deste trabalho; como o de estruturar a Lógica Fuzzy segundo a óptica da Engenharia de Produção e o de apresentar os principais conceitos da ferramenta central da pesquisa.

\subsubsection{Estudo de caso}

A opção pela realização de uma experimentação foi de explicitar a pesquisa vigente, já que traz à tona a aplicação prática de constatações importantes realizadas na revisão bibliográfica.

Um estudo de caso é caracterizado pelo estudo profundo de um ou poucos objetos, de maneira que permita o seu amplo e detalhado conhecimento, tarefa praticamente impossível mediante os outros tipos de delineamento (GIL, 1987).

A aplicação em questão consiste na avaliação de um projeto de investimento referente a criação de um centro fabril para produção máquinas e equipamentos industriais utilizados no setor sucroalcooleiro. O estudo é fundamentado nas seguintes etapas:

- Coleta dos dados referentes ao projeto, como receitas, despesas, custos, prazos e demais fatores considerados importantes ao estudo; 
- Coleta e pesquisa de informações econômicas e financeiras referentes ao setor em que a empresa está inserido, considerados o caráter micro e macroeconômico, possibilitando contextualizar a incerteza presente no projeto;

- Elaboração de planilhas eletrônicas para o uso da simulação do método de Monte Carlo;

- Elaboração de planilhas eletrônicas para o uso do Valor Presente Líquido Fuzzy;

- Análise comparativa dos resultados obtidos pelos modelos aplicados.

\subsection{A COMPARAÇÃO ENTRE O MÉTODO DE MONTE CARLO E O VALOR PRESENTE LÍQUIDO FUZZY}

O trabalho tem entre seus objetivos a comparação entre dois métodos para a avaliação econômico-financeira de investimentos. Através da experimentação (estudo de caso) acredita-se que será possível realizar análises comparativas baseadas na aplicação prática.

A fim de evitar que as conclusões e considerações apresentem algum tipo de viés, faz-se necessário estruturar alguns possíveis itens de comparação antes mesmo da realização do experimento. Dois grupos de análise foram criados: o primeiro se refere à análises quantitativas e o segundo a análises qualitativas.

\subsubsection{Grupo de análises quantitativas}

O método de Monte Carlo e o Valor Presente Líquido Fuzzy apresentam respostas de caráter matemático, o que torna possível confrontar diretamente os 
valores obtidos pelos dois métodos. Em resumo, as respostas dos métodos se apresentam como uma faixa de valores prováveis (ou possíveis) do capital que será ganho ou perdido caso o investimento seja realizado. Baseando-se nos valores obtidos como resposta, os seguintes itens de comparação serão trabalhados nesta dissertação:

- Comparação entre o retorno esperado mais provável (método de Monte Carlo) e os mais possível (Lógica Fuzzy) se realizado o investimento;

- Análise comparativa entre os limites numéricos (melhor e pior situações) de retorno de capital obtidos pela aplicação dos métodos;

- Uma das respostas obtidas pelo aplicação do método de Monte Carlo é a probabilidade de insucesso de um investimento, já o Valor Presente Líquido Fuzzy informa possibilidade de sucesso ou insucesso de um investimento. Apesar de conceitualmente distintos, os dois conceitos podem ser comparados numericamente;

- A simulação de Monte Carlo tem sua execução é baseada em números aleatórios, fazendo com que cada vez que o método seja aplicado, mesmo que mantidas as mesmas entradas, as respostas apresentem alguma alteração (neste trabalho chamado de erro de reaplicação). No caso da Valor Presente Líquido Fuzzy as funções geradas muitas vezes podem ser trabalhadas com aproximações (gerando um erro por aproximação). Tem-se então o intuito de comparar o erro matemático presente nos dois métodos (reaplicação e aproximação).

Embora na parte inicial deste trabalho os itens citados para a comparação quantitativa possam parecer pouco claros, ao decorrer do trabalho e principalmente no 
capítulo final, ter-se-á o intuito de deixá-los mais perceptíveis, visto que toda a revisão bibliográfica e aplicação dos métodos já terão sido efetuadas.

\subsubsection{Grupo de análises qualitativas}

Além da comparação por resultados numéricos obtidos como resposta da aplicação dos dois métodos, uma série de análises qualitativas será efetuada para confrontá-los:

- A facilidade em representar a incerteza presente no investimento como uma entrada para o modelo de cálculo;

- Viabilidade de execução dos cálculos pertinentes a cada método;

- Facilidade de assimilação da resposta calculada pelos modelos matemáticos;

- Aplicabilidade junto ao estudo de caso efetuado.

\subsection{LOCALIZAÇÃO DO TEMA NO CONTEXTO DA ENGENHARIA DE PRODUÇÃO}

A Comissão de Diretrizes Curriculares da ABEPRO (Associação Brasileira de Engenharia de Produção), cumprindo resolução da Sessão Plenária Final do IX ENCEP (Encontro Nacional de Coordenadores de Cursos de Engenharia de Produção), realizado entre os dias 28 e 30 de maio de 2003, no Centro Universitário da FEI em São Bernardo do Campo - SP relata dez diferentes áreas do conhecimento compreendidas pela Engenharia de Produção: 


\begin{tabular}{|c|l|}
\hline 1 & Gestão da Produção \\
\hline 2 & Gestão da Qualidade \\
\hline 3 & Gestão Econômica \\
\hline 4 & Ergonomia e Segurança do Trabalho \\
\hline 5 & Gestão do Produto \\
\hline 6 & Pesquisa Operacional \\
\hline 7 & Gestão Estratégica e Organizacional \\
\hline 8 & Gestão do Conhecimento Organizacional \\
\hline 9 & Gestão Ambiental \\
\hline 10 & Educação em Engenharia de Produção \\
\hline
\end{tabular}

Quadro 1 - Grandes Áreas da Engenharia de Produção Fonte: ABEPRO (2007).

O presente trabalho se enquadra na área denominada Gestão Econômica, que por sua vez inclui a Engenharia Econômica, a Gestão de Custos, a Gestão Financeira de Projetos e a Gestão de Investimentos.

\subsection{ESTRUTURA DO TRABALHO}

Este trabalho será estruturado em 6 capítulos. No primeiro é colocada em pauta uma breve apresentação do trabalho, bem como a definição do objetivo, justificativas a respeito do tema e da linha metodológica utilizada.

O capítulo 2 caracteriza-se pela apresentação de conceitos sobre análise de investimentos, trazendo a tona os principais métodos determinísticos utilizados para avaliar investimentos, como o Valor Presente Líquido e Taxa Interna de Retorno, 
além de considerações sobre o custo de capital em empresas. Na seqüência são apresentados conceitos sobre as incertezas e riscos presentes nos projetos de investimentos, bem como suas principais fontes e como tratá-las.

O terceiro capítulo refere-se à Simulação de Monte Carlo. Este método tem como foco central a geração de números aleatórios associados a distribuições de probabilidade para representação do risco em um investimento, fazendo com que a interpretação de resultados seja realizada de maneira estatística. Desta forma, faz-se necessário a apresentação de conceitos de como são gerados os números aleatórios, algumas distribuições de probabilidade e como estruturar a Simulação para uso na avaliação de um projeto de investimento.

A Lógica Fuzzy é apresentada no capítulo 4 como método alternativo para formulação de problemas onde a incerteza está presente. O capítulo traz em sua parte inicial o estado da arte desta lógica, seguindo para os conceitos fundamentais para aplicação. Um exemplo de sistema de automação Fuzzy é mostrado; por fim apresenta-se o método do Valor Presente Líquido Fuzzy e um exemplo de sua aplicação.

O capítulo 5 destina-se à apresentação do estudo de caso; sua descrição em âmbito geral, o cenário do projeto de investimento, a ponderação sobre as incertezas e a aplicação da Simulação de Monte Carlo e do Valor Presente Líquido Fuzzy para avaliação quantitativa do investimento.

O sexto capítulo é dedicado às conclusões e recomendações finais, assim como propostas para trabalhos futuros. Os apêndices A e B os conceitos básicos para a estruturação de cálculos no Microsoft Excel® em aplicações da simulação de Monte Carlo e da Lógica Fuzzy. 


\section{A ANÁLISE DE INVESTIMENTOS E AS INCERTEZAS NA TOMADA DE DECISÕES}

Pode-se definir investimento como sendo o ato de incorrer em gastos imediatos na expectativa de obter futuros benefícios. São esses benefícios que promovem ganhos de capital para empresa, propiciando crescimento, novas alternativas ou, em alguns casos, sua sobrevivência. Diversos são os fatores que justificam um investimento; a pesquisa em uma nova tecnologia, investimentos em manufatura, substituição de equipamentos, troca de fonte energética, a possibilidade de ganho de capital em aplicações financeiras, etc. O capital é um recurso escasso, por isso seleção do investimento correto é questão fundamental para os gestores.

A decisão de investir envolve um conjunto particularmente complexo de questões e alternativas que devem ser solucionadas pela administração (PACÍFICO, 2003). Durante a análise do investimento deve-se considerar as possíveis vantagens competitivas que a empresa poderá obter, tempo limite de espera do retorno do investimento, perspectivas da empresa dentro do setor que está inserido e demais fatores que interferem na sua decisão de investir (LIMA, 2007).

O processo decisório de uma empresa é complexo, sobretudo porque as decisões refletem muitas vezes características para longo prazo. As estimativas e cálculos devem refletir informações disponíveis de maneira ampla e concisa, a partir daí deve-se lançar uso de um método para análise do investimento em questão.

Os métodos de análise de investimentos são utilizados pelas empresas para a seleção de projetos que visam aumentar a riqueza de seus proprietários ou acionistas (Rebelatto, 2004). 
Dentre os métodos utilizados para análise de investimentos cita-se como determinísticos o Valor Presente Líquido (VPL) e Taxa Interna de Retorno (TIR), Taxa Interna de Retorno Modificada (MTIR) e o Payback Descontado, os quais serão apresentados nos próximos itens.

Prosseguindo na discussão em questão, a análise de investimentos em sua essência lida com expectativas, premissas de custos e receitas futuras. O que foi definido como certo no projeto realmente se confirmará? A própria experiência do ser humano sugere dificuldade em lidar com esses assuntos futuros e incertos. Assim, conhece-se a incerteza, a qual não pode ser ignorada em grande parte das análises de investimentos. O item 2.2. fornece um panorama sobre o assunto e como pode ser tratado.

\subsection{MÉTODOS QUANTITATIVOS NA ANÁLISE DE INVESTIMENTOS}

\subsubsection{Valor Presente Líquido (VPL)}

O Valor Presente Líquido (VPL) apresenta-se como um dos métodos mais utilizados pela engenharia econômica, sendo de grande valia para avaliar investimentos. Seu intuito é fornecer qual seria o ganho monetário que se teria na realização de um investimento a uma determinada taxa de juros.

De acordo com Rebelatto (2004), o VPL de um projeto de investimento é o valor atual das entradas de caixa (retornos de capital esperados), incluindo o valor residual (se houver) menos o valor atual das saídas de caixa (investimentos realizados). 
Por considerar explicitamente o valor do dinheiro no tempo, o valor presente líquido é considerado uma técnica sofisticada para a análise de investimentos. Este tipo de técnica de uma forma ou de outra, desconta os fluxos de caixa de uma empresa a uma taxa especificada. Essa taxa, freqüentemente chamada de taxa de desconto ${ }^{1}(\mathrm{i})$, custo de oportunidade de capital ou custo de capital (GITMAN, 2002).

A Figura 1 ilustra um fluxo de caixa qualquer. A função do VPL consiste em trazer as entradas e saídas de capital para a data zero do investimento.

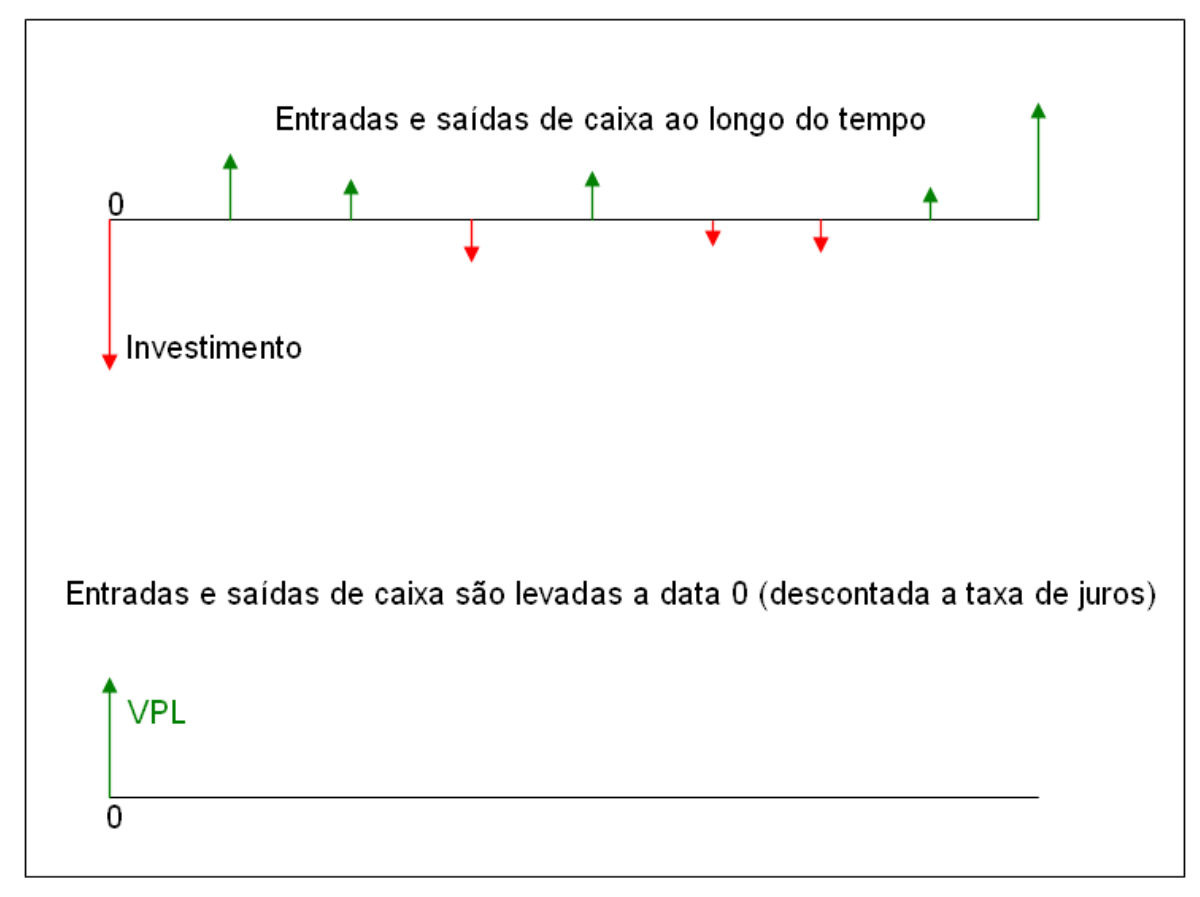

Figura 1 - O conceito de VPL

O cálculo do $V P L$ é descrito pela seguinte função:

$$
V P L=\sum_{j=1}^{n} \frac{F C_{j}}{(1+i)^{j}}-F C_{0}
$$

\footnotetext{
${ }^{1}$ A taxa de desconto é taxa de juros aplicadas sobre os valores futuros. Ao analisar seus investimentos os gestores utilizam-se da chamada Taxa Mínima de Atratividade (TMA) a qual será abordada no próximo item deste capítulo.
} 
Em que:

$F C_{0}$ : fluxo de caixa verificado no momento zero (momento inicial), podendo ser um investimento, empréstimo ou financiamento;

$F C_{j}$ : representa o valor de entrada (ou saída) de caixa previsto para cada intervalo de tempo;

$i$ : é a taxa de desconto;

$n$ : período de tempo.

No caso de uma única alternativa de investimento:

Se o $V P L>$ aceita-se o projeto;

Se o $V P L<$ rejeita-se o projeto;

Se o $V P L=0$, é indiferente investir ou não nesse projeto.

Considerando duas ou mais alternativas de investimento utiliza-se a de maior VPL positivo. A grande vantagem para o uso VPL do como indicador para avaliação de investimentos sustenta-se na revelação do quanto o projeto enriquecerá a empresa, representado pelo próprio valor do VPL.

\subsubsection{Taxa Mínima De Atratividade (TMA)}

Como o dinheiro tem valor no tempo, alguns métodos de análise de investimentos de projetos econômicos sugeridos pela engenharia econômica requerem a necessidade de uma taxa de juros para equacionamento (REBELATTO, 2004). 
A mesma autora diz ser necessária a definição prévia de uma taxa para servir como parâmetro de aceitação ou rejeição de um determinado projeto de investimento. Essa taxa de aceitação recebe o nome de Taxa Mínima de Atratividade (TMA) e deve ser a taxa mínima alcançada pelo investimento para que ele seja viável economicamente, isto é, a taxa mínima de retorno de capital aceitável para que um projeto econômico seja implementado. Assim, deve-se considerar a TMA é taxa de desconto a ser utilizada no cálculo do VPL.

Existem grandes controvérsias quanto a como calcular esta taxa. Alguns autores afirmam que taxa de juros a ser usada pela engenharia econômica é a taxa de juros equivalente à maior rentabilidade das aplicações correntes e de pouco risco. Uma proposta de investimento deve render, no mínimo, esta taxa de juros para ser atrativa.

Outro enfoque dado à TMA é a de que deve ser o custo de capital investido na proposta em questão, ou ainda, o custo de capital da empresa mais o risco envolvido em cada alternativa de investimento. Naturalmente, haverá disposição de investir se a expectativa de ganhos, já deduzido o valor do investimento, for superior ao custo médio de capital (PAMPLONA e MONTEVECHI 2006).

O custo médio de capital é uma média ponderada do custo de capital próprio e do custo de capital de terceiros e também costuma ser chamado de Custo Médio Ponderado de Capital ou Weighted Average Cost of Capital (WACC) (ROSS et al, 2000):

$$
W A C C=\left(\frac{S}{S+B}\right) \times i_{S}+\left(\frac{B}{S+B}\right) \times i_{B} \times\left(1-T_{C}\right)
$$

Em que: 
$i_{s}:$ custo de capital próprio;

$i_{B}:$ custo de capital de terceiros;

$T_{C}$ : alíquota de imposto de renda da empresa;

$S:$ montante da capital próprio;

$B:$ montante capital de terceiros.

Observa-se que todas as fontes de capital da empresa são consideradas levando em conta a proporção de que cada um constitui o investimento, Dessa forma um investimento que tenha um retorno percentual superior ao WACC propicia a empresa lucro econômico, pois permite ao gestor saldar suas obrigações, sejam elas de capital próprio ou de terceiros, e o excedente de capital adquirido aumenta a riqueza da empresa.

\subsubsection{Taxa Interna De Retorno (TIR)}

A taxa interna de retorno de um projeto é a taxa de desconto para a qual o valor presente das receitas torna-se igual ao valor presente dos desembolsos. Isto significa dizer que a TIR é aquela que torna nulo o valor presente líquido do projeto. Pode ainda ser entendida como a taxa de remuneração do capital. Um investimento onde a TIR apresenta um valor superior ao da TMA é viável economicamente, pois sua taxa de remuneração é maior do que o mínimo exigido pela empresa.

A Figura 2 apresenta a relação ente TIR e VPL: 


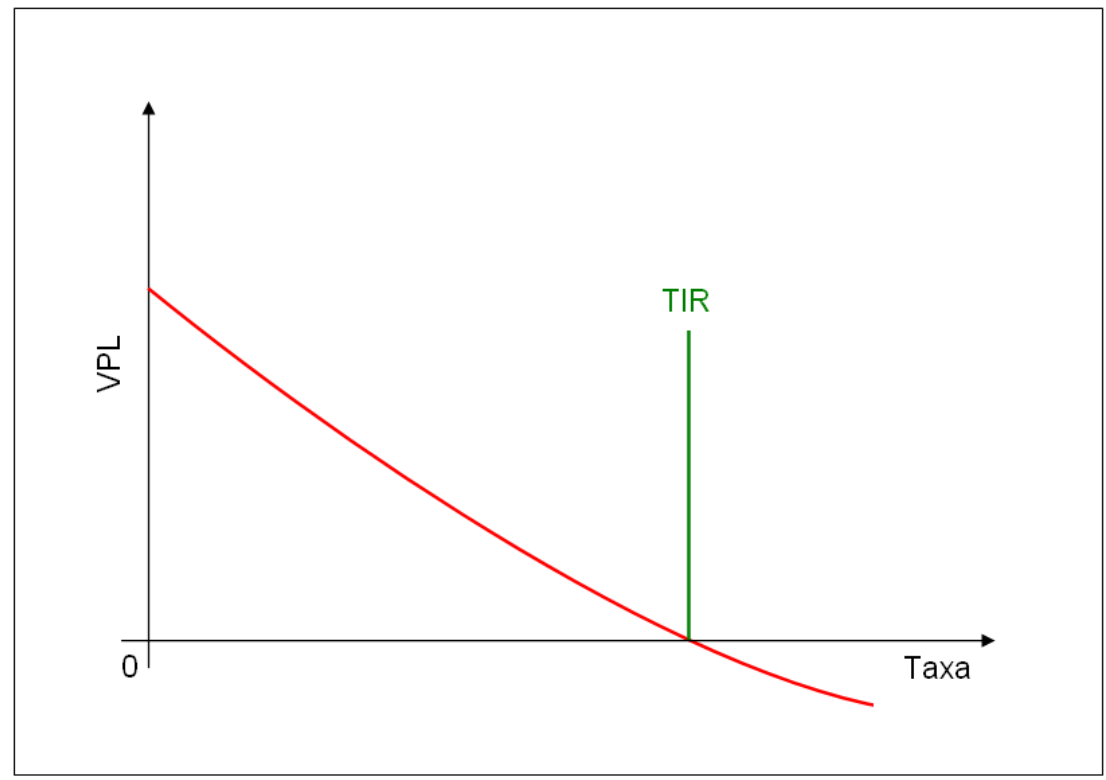

Figura 2 - Ilustração Gráfica da TIR Fonte: BARREIROS (2004).

Matematicamente a TIR é obtida resolvendo-se a equação:

$$
\begin{aligned}
& V P L=\sum_{j=1}^{n} \frac{F C_{j}}{(1+i)^{j}}-F C_{0} \\
& 0=\sum_{j=1}^{n} \frac{F C_{j}}{(1+T I R)^{j}}-F C_{0} \\
& F C_{0}=\sum_{j=1}^{n} \frac{F C_{j}}{(1+T I R)^{j}}
\end{aligned}
$$

A TIR pode ser usada pelo executivo para tomar decisões entre diferentes alternativas de investimentos. Para isso determina-se a TMA e a TIR de cada uma das alternativas. A vencedora é aquela que tiver maior TIR, desde que seja maior que a TMA. Caso contrário, nenhuma das alternativas é viável (BARREIROS, 2003) 
Deve-se ressaltar que a comparação entre duas ou mais TIRs é estritamente percentual e deixa de lado valores monetários. Por exemplo, dois investimentos de prazo de um ano são colocados em questão; o investimento A requer um desembolso inicial de $\mathrm{R} \$ 10.000$ e o retorno é de $\mathrm{R} \$ 12.000,00$. Já o desembolso em $\mathrm{B}$ é de $\mathrm{R} \$ 20.000$, e seu retorno é de $\mathrm{R} \$ 23.000,00$. Nesta situação $\mathrm{TIR}_{\mathrm{A}}$ é $20 \%$ e $\mathrm{TIR}_{\mathrm{B}}$ é $15 \%$, porém o ganho de capital em A é de $\mathrm{R} \$ 2.000,00$ e em B de $\mathrm{R} \$ 3.000,00$. Qual seria o investimento escolhido?

Uma alternativa para esta situação é a da utilização do capital excedente do investimento A em relação B, no caso $\mathrm{R} \$ 10.000,00$, e estimar sua aplicação em outro investimento corrente (investimento C). A TIR $\mathrm{AC}_{\mathrm{C}}$ seria resultado da composição de A e de C; esta taxa seria comparada com a TIR $_{\mathrm{B}}$.

Casarotto Filho e Kopittke (2000) consideram a Taxa Interna de Retorno (TIR) como um método determinístico para a análise de investimentos equivalente ao VPL. Apesar de apresentarem diferenciações, vantagens e desvantagens, grande parte dos investimentos a serem realizados podem ser avaliados pelas duas técnicas.

\subsubsection{TIR Modificada (MTIR)}

A TIR, apesar da facilidade de entendimento como uma taxa, requer alguns cuidados em sua interpretação que muitas vezes podem vir a serem desprezados.

Segundo Kassai (1996) quando um projeto é representado por um fluxo de caixa não tradicional em que há várias inversões de sinais entre fluxo de caixas positivos e negativos, esse mesmo projeto pode apresentar mais de uma TIR (positivas ou negativas) ou até inexistir solução. 
Outro fator negativo é que na confecção do cálculo da TIR pressupõe-se que todos os fluxos de caixa, sejam eles recebimentos ou desembolsos, são financiados ao longo do tempo. No entanto, normalmente a taxa de captação (custo financeiro) é maior do que a taxa de remuneração para aplicações dos saldos de caixa (BALARINE, 2004)

O método da TIR Modificada (MTIR) leva em consideração essas diferentes taxas, através da seguinte solução:

$$
M T I R=\left(\frac{\sum_{j=0}^{n} R_{j}\left(1+i_{r}\right)^{n-j}}{\sum_{j=0}^{n}\left|C_{j}\right| /\left(1+i_{c}\right)^{j}}\right)^{1 / n}-1
$$

Em que:

$i_{r}$ é a taxa de atratividade (taxa de aplicação de recursos ociosos);

$i_{c}$ é taxa correspondente ao custo de capitação (custo financeiro);

$R_{j}$ representa os fluxos de caixa positivos (recebimentos);

$C_{j}$ representa os fluxos de caixa negativos (custos ou dispêndios de capital);

$n$ : período de tempo.

A utilização de planilhas eletrônicas e calculadoras financeiras torna bastante funcionais técnicas como TIR, MTIR e VPL, pois propicia velocidade de execução, além de dispor de ferramentas para análises subseqüentes. 


\subsubsection{Payback Descontado}

O método do Payback consiste em mostrar quanto tempo (n) um investimento leva para ser ressarcido, porém a taxa de desconto é ignorada. O conceito do Payback Descontado atua justamente nessa falha, pois considera uma taxa de juros para realizar o cálculo do período gasto.

O Payback Descontado é obtido pela função abaixo:

$$
V P L=-F C_{0}+\sum_{j=1}^{n} \frac{F C_{j}}{(1+i)^{j}}
$$

Em que:

$i$ é a taxa de desconto;

$j$ é um índice genérico que representa os períodos $j=1 \mathrm{a} n$;

$V P L$ é o Valor Presente Líquido;

$F C_{j}$ : representa o valor de entrada (ou saída) de caixa até o instante $n$;

$F C_{0}$ : fluxo de caixa verificado no momento zero (momento inicial).

Quando ocorrer VPL $=0, n$ é o Payback Descontado, com $n$ inteiro. Se ocorrer VPL $<0$ em $j-1$ e VPL $>0$ em $j$, interpola-se para determinar um $n$ fracionário (LIMA, 2007).

A grande informação que o Payback Descontado oferece é qual o período necessário para que o investidor retome o dinheiro que fora investido, e a partir daí, comece a obter ganhos de capital. 
O tempo é sem dúvida importante para análise de investimentos, quanto maior o horizonte de planejamento do projeto, maior a chance da avaliação ficar sujeita as oscilações, mudanças econômicas, alterações no preço da energia ou outras alterações nas estimativas e premissas assumidas no início do projeto.

\subsection{O INVESTIMENTO E A INCERTEZA}

Na tomada de decisão sobre um investimento são aceitas algumas previsões, que podem não se concretizar, ou se apresentarem de forma diferente, refletindo diretamente no sucesso ou insucesso de um projeto. O conceito de incerteza reflete as dúvidas sobre o investimento corrente.

A intensidade da incerteza em um dado investimento aumenta proporcionalmente à variável tempo (n), ou seja, quanto mais distante o fluxo de caixa, maiores são as incertezas a seu respeito.

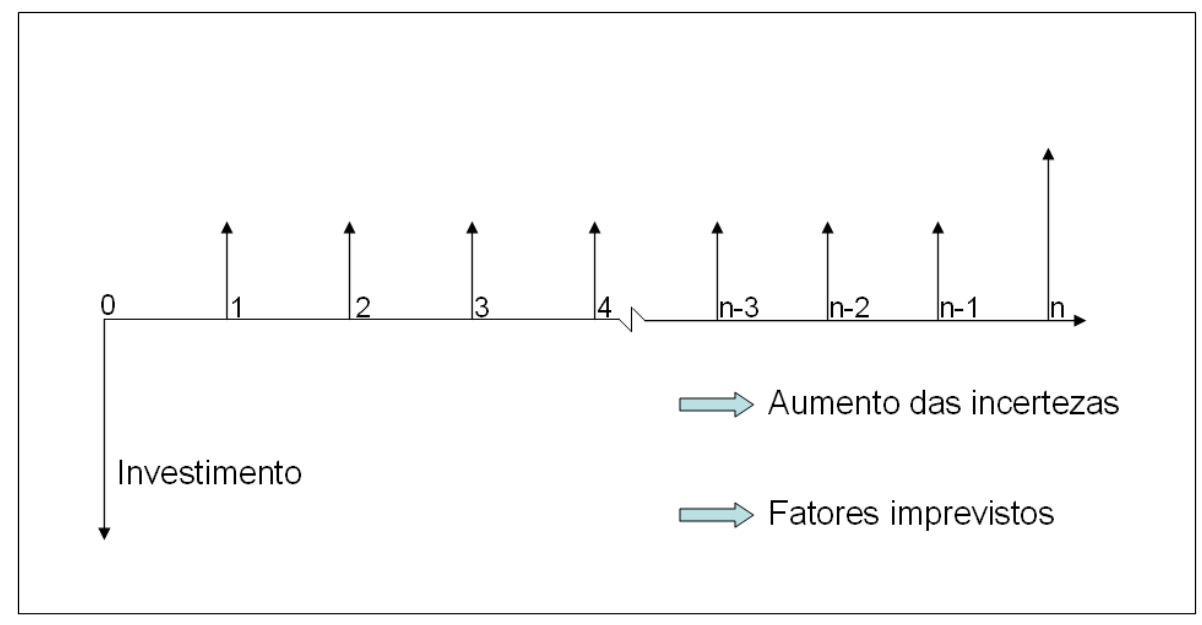

Figura 3 - A Incerteza nos Fluxos de Caixa

Fonte: PAMPLONA E MONTEVECHI (2006) 
A Figura 3 apresenta um fluxo de caixa esquemático. Nos períodos próximos da data zero, normalmente se tem boas estimativas do investimento necessário para o projeto, com algumas pequenas incertezas, as estimativas para esse cenário próximo refletem a realidade mais próxima da empresa e da economia. Entretanto variações ao longo do tempo ocorrem nos fatores que compõem as receitas e despesas caixa. Os valores a priori estimados como manutenção, mão-de-obra, matéria prima, energia elétrica, impostos, depreciação, financiamentos, etc. podem não se comportar da maneira prevista. Na maioria das vezes, ao se analisar e construir os fluxos de caixa, a consideração sobre os dados é determinística, sendo que na realidade isso pode gerar falhas em algumas análises. Existem variações imprevisíveis sobre os diversos elementos que compõem o fluxo de caixa, que precisam ser considerados para a correta avaliação do projeto.

A "incerteza", esporadicamente confundida com "risco", pode ser definida segundo Von Altrock (1995) como dúvidas sobre eventos futuros que independem da ação tomada no presente, podendo ser "Estocástica" ou "Léxica". A "Estocástica" está associada à probabilidade de um evento ocorrer, enquanto a "Léxica" está associada à intensidade com que o evento ocorre. Já o "Risco" é definido segundo Pamplona e Montevechi (2006), como um valor conhecido de dispersão associado à distribuição de probabilidade com que o evento ocorre, o que está, logicamente, associado à incerteza Estocástica (SANCHES, 2003).

Em suma, num ambiente de incertezas, devem ser calculadas as possíveis conseqüências dessas incertezas, de forma que o projeto tenha uma possibilidade de sucesso adequada, como objetivo de maximizar a riqueza da empresa. Quando as incertezas são ignoradas numa análise, esta pode ficar comprometida. A avaliação de investimentos em um ambiente que não seja sujeito a incertezas é bastante 
conveniente, porém são poucos os fatores que podem ser tratados efetivamente como certos. Na economia isso é evidente, pois existem variáveis que estão ligadas a parâmetros de grande incerteza como: mercado, inflação, guerras, eleições, etc.

Em um caso genérico de investimento em equipamentos, devem ser consideradas as seguintes variáveis: o "Investimento Fixo", que representa o custo de aquisição e instalações do equipamento, o "Capital de Giro", que é o capital necessário para a compra de matéria prima e implementos em geral, o "Horizonte de Planejamento", que é a vida útil esperada para o empreendimento, a "Previsão de Vendas", o "Custo Fixo", o "Custo Variável”, a “TMA” representando a taxa de

desconto a ser utilizada nos cálculos de VPL (custo de capital da empresa), as “Alíquotas de Imposto de Renda", a "Taxa de Depreciação" (regulamentada pela Receita Federal) e finalmente o "Valor Residual do Equipamento" (SANCHES, 2003).

\subsection{A NATUREZA DAS INCERTEZAS}

Como já mostrado esquematicamente na Figura 3, "O futuro pode revelar surpresas" (PAMPLONA e MONTEVECHI, 2006). Quanto maior a vida do projeto, maiores as chances de se ter problemas com estimativas feitas na época da análise econômica do projeto. Vários são os fatores que podem contribuir para a incerteza. Alguns destes fatores estão sintetizados na Quadro 2. 


\begin{tabular}{|c|c|c|c|}
\hline Econômicos & Financeiros & Técnicos & Outros \\
\hline $\begin{array}{c}\text { Oferta } \\
\text { Subdimensionada }\end{array}$ & $\begin{array}{c}\text { Insuficiência de } \\
\text { capital }\end{array}$ & $\begin{array}{l}\text { Inadequabilidade do } \\
\text { processo utilizado }\end{array}$ & $\begin{array}{l}\text { Fatores } \\
\text { Políticos }\end{array}$ \\
\hline $\begin{array}{c}\text { Oferta } \\
\text { Superdimensionada }\end{array}$ & $\begin{array}{c}\text { Falta de capacidade } \\
\text { de pagamento }\end{array}$ & $\begin{array}{l}\text { Inadequabilidade das } \\
\text { matérias-primas }\end{array}$ & $\begin{array}{c}\text { Fatores } \\
\text { Institucionais }\end{array}$ \\
\hline $\begin{array}{c}\text { Dimensionamento } \\
\text { Incorreto }\end{array}$ & & $\begin{array}{l}\text { Inadequabilidade da } \\
\text { tecnologia empregada }\end{array}$ & Greve \\
\hline $\begin{array}{c}\text { Alteração de } \\
\text { produtos e } \\
\text { subprodutos }\end{array}$ & & & Inflação \\
\hline $\begin{array}{c}\text { Aumento dos } \\
\text { custos de matéria- } \\
\text { prima }\end{array}$ & & & \\
\hline $\begin{array}{c}\text { Investimentos } \\
\text { imprevistos }\end{array}$ & & & \\
\hline
\end{tabular}

Quadro 2 - Fatores que contribuem para Incerteza Fonte: PAMPLONA e MOTEVECHI (2006)

Fatores como o aumento de investimento ou impostos podem afetar a todas as empresas e são os chamados sistemáticos. Outros fatores como o aumento de preço de uma matéria-prima específica, atingem empresas em casos isolados e são os não sistemáticos.

Na realidade a distinção de fatores sistemáticos ou não sistemáticos nunca é tão exata. Mesmo eventos mais limitados e peculiares a um tipo de empresa têm repercussão na economia (ROSS et al, 2002).

Cada projeto é concebido e desenvolvido com base em um conjunto de hipóteses. Esta é uma técnica que explora as incertezas do projeto pela existência de algumas premissas que foram assumidas e podem não ser verdadeiras. Essas 
premissas incertas podem, ainda, ser imprecisas, inconsistentes ou incompletas e deverão ser identificadas e descritas, conforme suas origens, para posteriormente poderem ser avaliadas (SANHCES, 2003).

As incertezas possuem diferentes fontes e formas de tratamento e podem ser ilustradas segundo no Quadro 3:

\begin{tabular}{|c|c|c|}
\hline Fonte/Tipo & Exemplo de Origem & Tratamento Analítico \\
\hline Física & Conhecimento limitado & Simulação de Monte Carlo \\
\hline Estatística & Amostragem & Desvio padrão, erro médio, \\
limites de confiança
\end{tabular}

Quadro 3 - Fatores e Tratamentos para as Incertezas Fonte: SANCHEZ(2003) apud KREUZER (2000) 
Nesta visão, cada tipo de incerteza deveria receber um tratamento específico, porém este tipo de abordagem torna-se impraticável, pois o número de possíveis fatores fontes de incerteza é muito abrangente na avaliação de investimentos.

Dessa maneira, a escolha do tratamento que se adéqüe de forma abrangente ao tipo de análise é um caminho a ser usado. Na análise de investimentos a Simulação de Monte Carlo destaca-se como um método utilizado. A Lógica Fuzzy, devido a sua flexibilidade, considera as incertezas de várias fontes distintas, não sendo rígida a forma como se chega a incerteza, propiciando uma análise conjunta dos fatores presentes. 


\section{A Simulação de MONTE CARLO NA ANÁllSE DE INVESTIMENTO SOB CONDIÇÕES DE INCERTEZA}

A Simulação é uma ferramenta que permite a reprodução de um sistema real através da criação de um modelo matemático. Diversa é sua utilização na engenharia, dada sobretudo, pela evolução da informática ao longo dos últimos vinte anos, que propiciou softwares de custo acessível e fácil uso, seja pela melhoria de interface, ou pelo grande ganho na capacidade para efetuar cálculos.

Na engenharia mecânica, softwares atuais relacionados ao Desenho Auxiliado por Computador (CAD - Computer Aided Design), como SolidWorks ${ }^{\circledR}$ e Cathia®, apresentam funções integradas ${ }^{2}$ para simulação de, por exemplo, esforços em estruturas metálicas, propiciando aos projetistas captar informações representativas, evitando possíveis problemas na fase de execução do projeto. Na engenharia de produção, softwares como o Arena proporcionam observação virtual de sistemas de manufatura, possibilitando as mais diversas alterações, contribuindo para tomada de decisão.

A evolução computacional proporcionou também a disseminação de modelos chamados estocásticos, que são baseados na geração de números aleatórios. A Simulação de Monte Carlo utiliza a geração destes números aleatórios, os quais estão associados a distribuições de probabilidade pré-definidas. Softwares amplamente encontrados como Statistica® ou Microsoft ${ }^{\circledR}$ Excel oferecem este recurso de aplicação vasta.

\footnotetext{
${ }^{2}$ Este tipo de função presente nesses softwares recebe a denominação de CAE - Computer Aided Engineering www.numa.org.br/conhecimento
} 
$\mathrm{Na}$ avaliação de investimentos a Simulação de Monte Carlo é muito utilizada como ferramenta para análise de riscos e incertezas. Em um dado investimento ao invés de se tratar uma variável, como a demanda, assumindo um valor fixo, considerase que esta demanda pode assumir qualquer valor, obedecendo a uma distribuição de probabilidade estipulada pelo analista, o que dá uma conotação mais ampla do cenário analisado.

A primeira parte deste capítulo apresenta o conceito de Simulação; enquanto a segunda visa mostrar a Simulação utilizando o método de Monte Carlo, focando sua aplicação na criação de modelos probabilísticos para a análise de investimentos em condições de risco e incertezas.

\subsection{O CONCEITO DE SIMULAÇÃO}

A Simulação, de acordo do com Shamblin (1979), é uma ferramenta muito valiosa por permitir obter uma resposta a um problema particular, principalmente quando se trata de um sistema complexo.

Uma Simulação é a imitação da operação de um sistema ou de um processo do mundo real. Feita a mão (estudando) ou em um computador, a simulação envolve a geração de uma história artificial do sistema, e a partir desta história artificial a inferência de como o sistema real funcionaria. O comportamento do sistema é estudado pela construção de um Modelo de Simulação (SANTOS, 1999). A Figura 4 exprime o conceito de simulação junto a um sistema. 


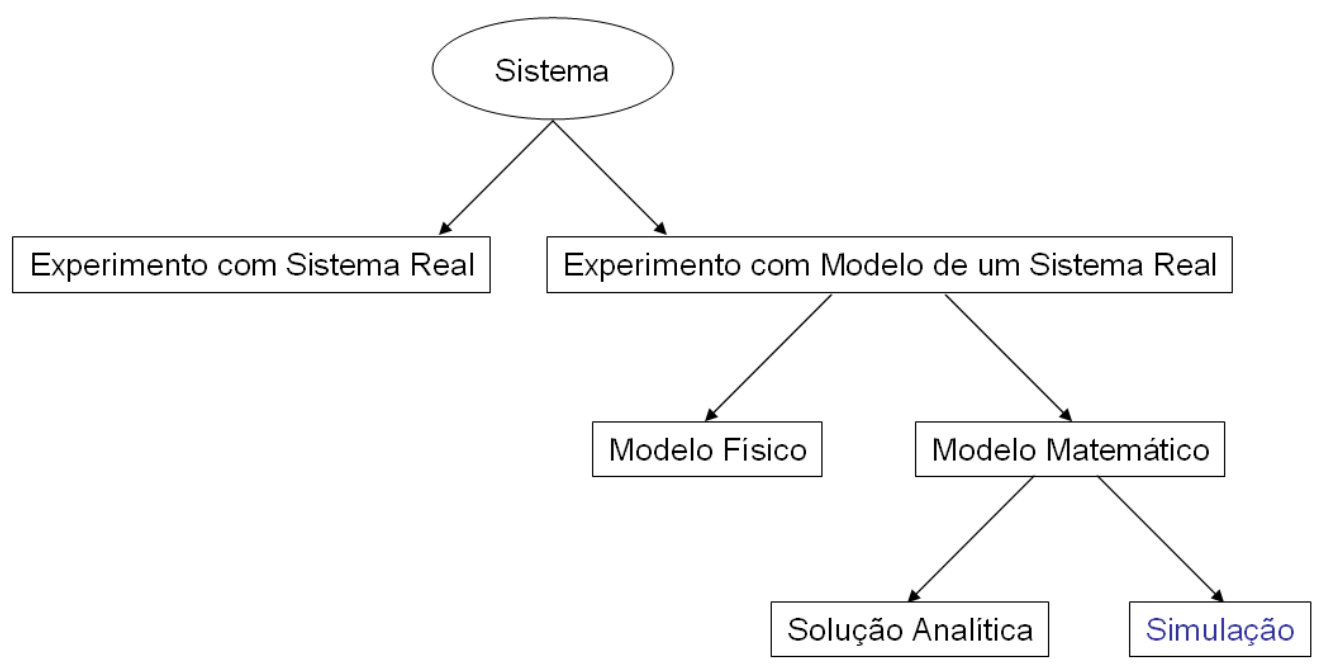

Figura 4 - Formas de Estudo de um Sistema

Fonte: GAVIRA (2003) apud LAW e KELTON (2000)

O uso da Simulação busca representar de maneira próxima um evento real. A partir daí uma série de prévias considerações podem ser feitas, sem que seja necessário a implementação ou alteração do sistema real. Por exemplo, que efeitos poderiam ser observados em uma célula de manufatura caso um equipamento fosse substituído por um mais produtivo?

Segundo Pinto (2001) a simulação é uma ferramenta versátil que permite as companhias responder questões do tipo "what if" (o que aconteceria se...) sobre mudanças em seus sistemas sem ser necessário efetuar mudanças na prática. 

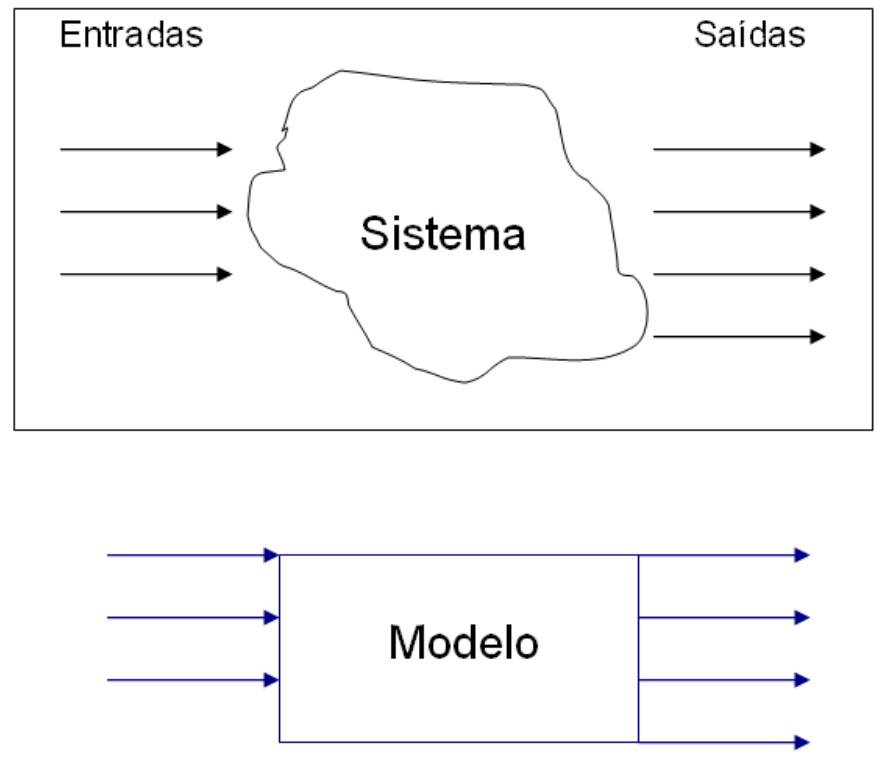

Figura 5 - Processo simples de modelagem Fonte: GAVIRA (2003)

A Figura 5 apresenta uma noção dos princípios utilizados no processo de modelagem. Imaginando um projeto de investimento com duração de 10 anos, onde deseja-se utilizar o VPL para sua avaliação. Qual associação poderia ser feita entre a figura e a análise de investimento desse projeto? Neste caso, o "Sistema" engloba toda a situação real do investimento a ser realizado. Desde o início do investimento até o seu final, todas as receitas e dispêndios reais que ocorrerem no período irão contribuir para o sucesso ou insucesso do investimento. É evidente que não há como saber realmente quais serão tais receitas e dispêndios de capital ao longo do projeto, já que se tratam de eventos futuros, ou seja, não há como saber o VPL exato deste "Sistema". Desta forma, a ato de simular este problema está associado a criação de um "Modelo" matemático, onde através do uso da "Simulação" os valores utilizados para cálculo do fluxo de caixa sofrem variações, as quais representam alterações que irão ocorrer com os valores entrada e saída de capital ao decorrer do projeto. 
Segundo Santos (1999) um modelo de simulação pode ser "Determinístico" ou "Estocástico". Modelos de simulação que não contém nenhuma variável aleatória são classificados como determinísticos, ou seja, para um conjunto conhecido de dados de entrada teremos um único conjunto de resultados de saída.

O mesmo autor define que modelos estocásticos de simulação aqueles têm uma ou mais variáveis aleatórias como entrada. Estas entradas aleatórias levam a saídas aleatórias que podem somente ser consideradas como estimativas das características verdadeiras de um modelo. Assim, por exemplo, a simulação (estocástica) do funcionamento de uma agência bancária envolve variáveis aleatórias como o intervalo entre chegadas e a duração dos serviços prestados. Logo, medidas como o número médio de clientes esperando e o tempo médio de espera de um cliente, devem ser tratadas como estimativas estatísticas das medidas reais do sistema.

\subsection{A CONSTRUÇÃO DE UM MODELO PROBABILÍSTICO E O USO DA SIMULAÇÃO DE MONTE CARLO}

\subsubsection{Um Breve Histórico}

O Método de Monte Carlo é uma ferramenta para modelagem de problemas estocásticos. Leva este nome devido ao comportamento aleatório das roletas, principal atração da cidade de Monte Carlo, capital do principado de Mônaco. Tal método tem como base a geração de valores aleatórios para criar um cenário de um problema (PLLANA, 2007). Estes valores aleatórios são selecionados dentro de uma 
determinada faixa de valores que seguem uma determinada distribuição de probabilidades (CORREA NETO et al, 2002).

A aparição do método e seu desenvolvimento ocorreram por volta de 1944, na época da segunda guerra mundial no projeto Manhattan, relacionado a construção da bomba atômica. O intuito do estudo na ocasião era obter soluções aproximadas para problemas referentes à difusão randômica de nêutrons no material nuclear através de simulações (PLLANA, 2007). O nome Monte Carlo foi dado por um dos seus criadores o matemático austríaco Stanislaw Uslam (CORREA NETO et al, 2002).

Segundo Brealey e Myers (1998) a aplicação da Simulação de Monte Carlo na análise de investimentos está associada a David Hertz ${ }^{3}$ e a McKinsey and Company, consultores associados. Sua aplicação consistia em simular a taxa de retorno dos investimentos.

\subsubsection{As Árvores de Decisão}

Diagramas de decisão ou árvores de decisão são representações gráficas das relações e seus possíveis resultados. Seu conceito, embora simples, tem ampla relação com o uso da Simulação de Monte Carlo.

As árvores de decisão tem uma convenção simples, onde as decisões e incertezas do projeto são representadas por nós na árvore, com os galhos representando as alternativas escolhidas ou o resultado da resolução da incerteza (BRANDÃO, 2007).

3 D. B. HERTZ, Investment Policies that Pay Off. Harvard Business Review, 46:96-108. janeiro/fevereiro 1968. 
Um exemplo explica o conceito: suponha que um uma empresa esteja analisando um projeto que apresenta $70 \%$ de chances de sucesso, e consequentemente $30 \%$ de probabilidade de fracasso. Se o investimento resultar em sucesso, o retorno será um VPL de $\$ 10.000,00$, caso seja um fracasso acarretará um prejuízo de $\$ 12.000,00$.

A Figura 6 ilustra o exemplo utilizando uma árvore de decisão. No início do projeto pode-se tomar a decisão de se investir ou não, representada pelo $\square$. Caso o investimento seja realizado encontra-se uma bifurcação na árvore, representada na incerteza, simbolizada por $\bigcirc$. A partir daí as duas situações possíveis são ilustradas; a de sucesso e a de insucesso.

$$
\text { DECISÃO RESULTADO }
$$

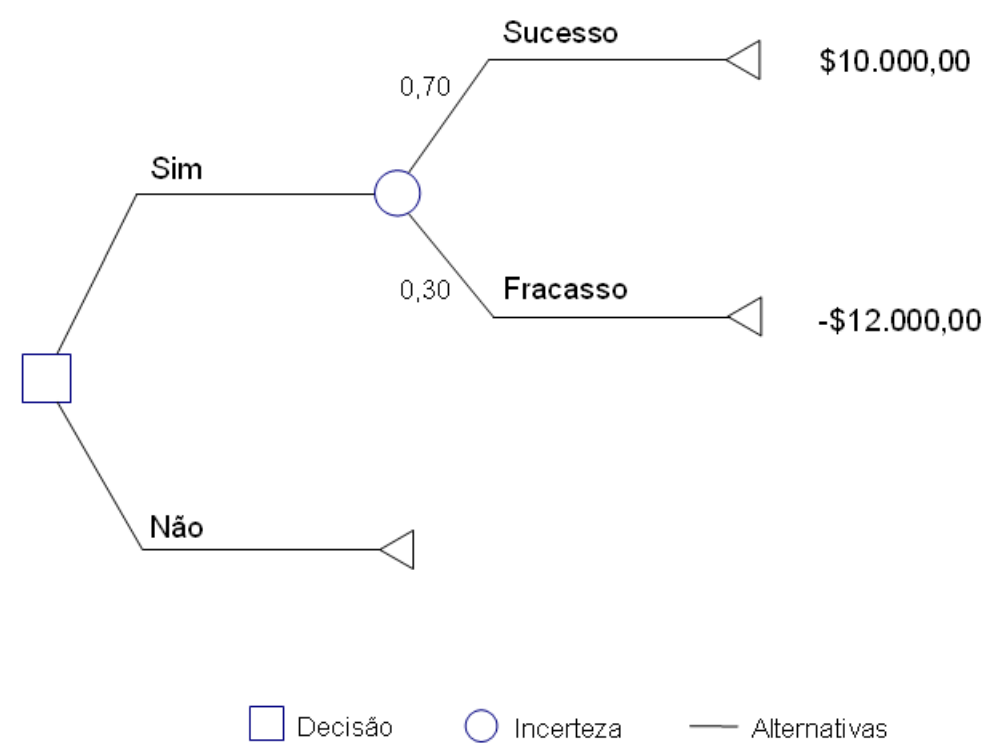

Figura 6 - Uso da Árvore de Decisão Fonte: Adaptado de BRANDÃO (2007)

A resolução da árvore de decisão se dá do final para o início. As incertezas envolvidas são resolvidas utilizando-se os valores esperados do VPL de cada uma. 
Não se sabe qual será o resultado do projeto, mas pode-se calcular o valor equivalente através da média ponderada entre os VPLs de sucesso e insucesso:

$$
\begin{aligned}
& V P L=\sum_{i=1}^{k}\left(V P L_{i} \times p_{i}\right) \\
& V P L=\$ 10.000,00 \times(0,7)-\$ 12.000,00 \times(0,3) \\
& V P L=\$ 3.400,00
\end{aligned}
$$

Em que:

$V P L_{i}$ : Valor presente líquido para a situação $i$

$p_{i}$ : Probabilidade de ocorrência de $i$;

$k:$ Situações totais.

O exemplo é meramente ilustrativo, porém este conceito pode ser utilizado aumentando o número de alternativas e incertezas ao longo do projeto. A Figura 7 apresenta um investimento hipotético, onde dois projetos são analisados.

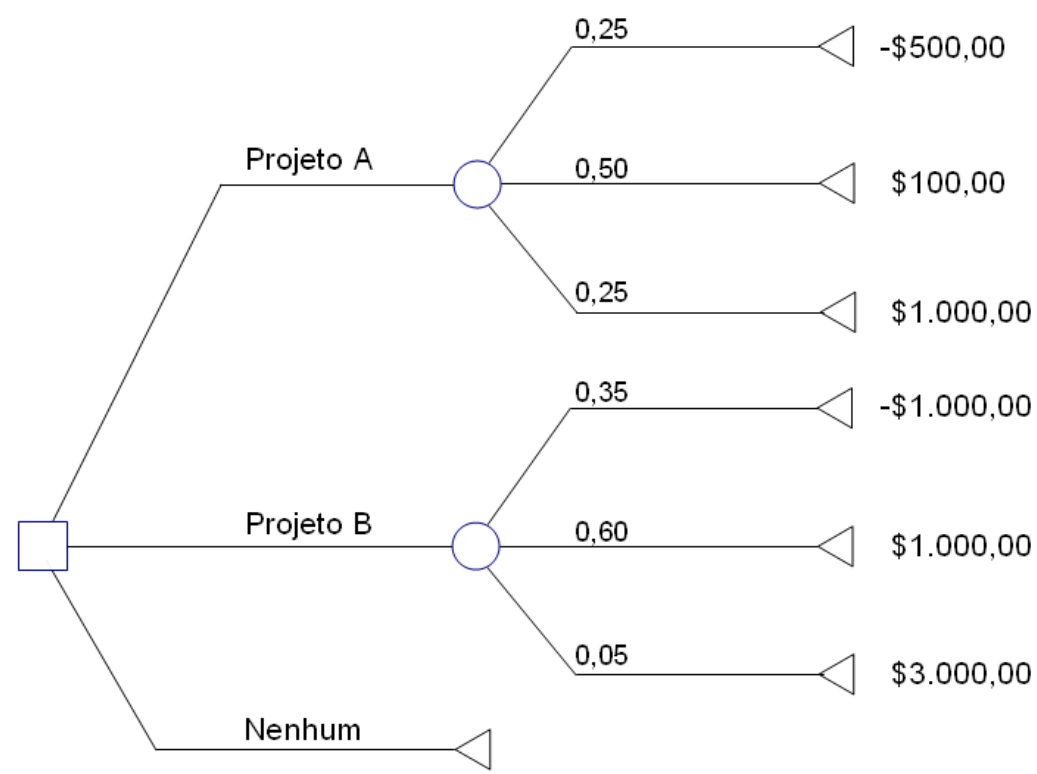

Figura 7 - Árvore de Decisão para Comparação de Investimentos Fonte: Adaptado de BRANDÃO (2007) 
Segundo Brandão (2007) as árvores de decisão têm a vantagem de representarem graficamente as interações de maneira simples e intuitiva. Elas devem ser mantidas simples, pois se desdobram facilmente, se tornando complexas e de difícil manejo. Diversas ferramentas computacionais foram desenvolvidas nos últimos anos com o intuito de facilitar e automatizar a construção das árvores de decisão, facilitando seu manejo e permitindo a construção de árvores complexas.

\subsubsection{O Conceito da Simulação de Monte Carlo aplicado ao VPL}

A análise de cenário, utilizando a árvore de decisão, permite na prática, apenas um número limitado de alternativas. A simulação de Monte Carlo é uma ferramenta que possibilita considerar uma quantidade muito grande de alternativas possíveis, fornecendo uma distribuição estatística do VPL do projeto (BRANDÃO, 2007), contribuindo para redução do viés do analista, muito presente no uso de árvores de decisão.

O método gera continuamente e aleatoriamente números, que estão ligados nas entradas e/ou saídas de caixa, usadas no cálculo do VPL. Tais alterações no fluxo de caixa funcionam como cenários aleatórios. Os números gerados aleatoriamente obedecem a distribuições de probabilidade pré-definidas pelo analista, baseando-se em dados obtidos da análise de eventos passados ou usando projeções para o futuro.

A definição das distribuições de probabilidades é feita sobre fatores que compõe o cálculo do VPL, como demanda e custo fixo; sendo assim o ato de gerar aleatoriamente esses fatores faz com que o VPL assuma diversos valores. 


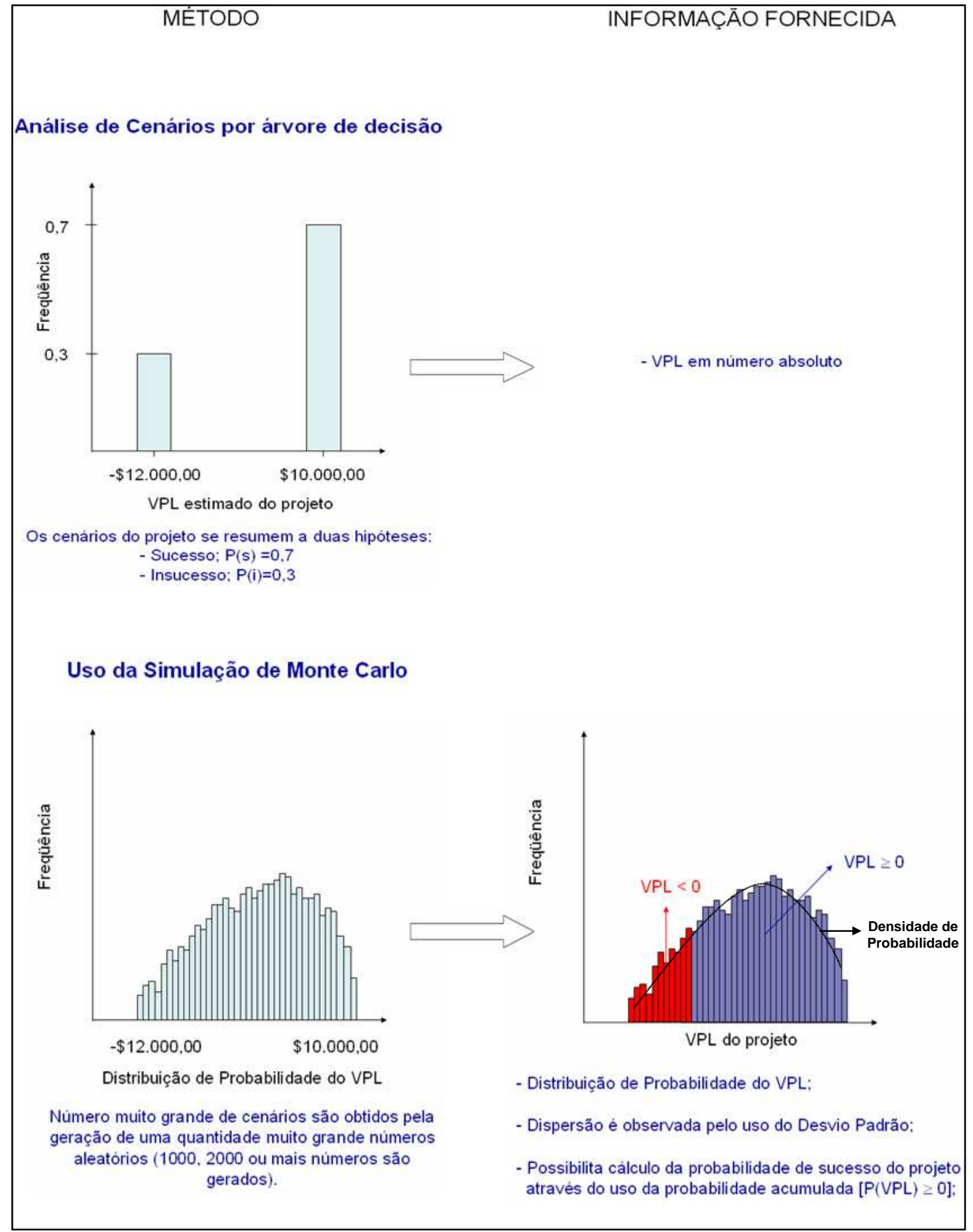

Figura 8 - Uma comparação entre o uso da Árvore Decisão e a Simulação de Monte Carlo

Segundo Torres (2006) a simulação de Monte Carlo executa o projeto muitas vezes, criando cenários aleatórios que permitem uma distribuição estatística das variáveis, permitindo uso de ferramentas da estatística descritiva, como média, desvio-padrão e probabilidade acumulada. 
A Figura 8 ilustra o cálculo do VPL do exemplo do item 3.2.2. O uso da árvore de cenários leva em conta um número reduzido de hipóteses, fornecendo uma informação direta, porém ela mostra pouco sobre qual a probabilidade de haver insucesso. O uso da Simulação de Monte Carlo permite que um grande número de alternativas sejam inclusas no cálculo do VPL, fornecendo uma informação de cunho estatístico, propiciando análises dos tipos: qual a probabilidade de haver sucesso no investimento? Qual a probabilidade do retorno superar $\$ 7.000,00$ ? Qual projeto apresenta mais risco (no caso de comparação entre projetos)?

A definição de "Risco" foi apresentada no capítulo 2 e está relacionada com a dispersão dos valores obtidos pela simulação. O desvio-padrão é usado como ferramenta para obtenção do risco, quanto maior o desvio-padrão, maior a variabilidade dos dados, conseqüentemente maior o risco do projeto.

“O indicador estatístico mais comum para o risco de um ativo é o desvio-padrão, o qual mede a dispersão em torno de um valor esperado. $\mathrm{O}$ valor esperado de um retorno é o retorno mais provável de um ativo" (Gitman, 2004, p.207).

A função do desvio-padrão ${ }^{4}$ (s) é expressa por:

$$
\sigma=\sqrt{\left(\frac{\left.\sum_{j=1}^{N}\left(x_{j}-\mu\right)^{2}\right)}{N}\right)}
$$

\footnotetext{
${ }^{4}$ A função representa o desvio-padrão (raiz quadrada da variância) para distribuições normais de probabilidades, porém outros tipos de distribuições geradas pela simulação podem ser transformadas em normais, assim pode-se fazer uso da função apresentada.
} 
Em que:

$N$ é relacionado a quantidade de números aleatórios gerados;

$\mu$ é valor esperado do VPL (obtido pela média dos retornos de cada situação simulada i);

$x_{j}$ é o retorno apresentado pelo VPL para cada situação simulada j;

A partir do momento em que é analisada uma distribuição estatística pode-se fazer considerações de quão prováveis são determinados valores; assim é possível efetuar o cálculo de qual a probabilidade do VPL ter um valor maior que 0 , o que torna viável um investimento. Para este cálculo usa-se o conceito de probabilidade cumulativa, também conhecido como probabilidade acumulada.

O cálculo da probabilidade cumulativa do VPL é apresentado pela função:

$$
\begin{aligned}
& P(X>x)=1-\int_{-x}^{X} f(u) d u \\
& \text { para }-\infty<x<\infty
\end{aligned}
$$

Em que:

$P(X>x)$ é a probabilidade cumulativa do valor do VPL desejado;

$x$ é o valor mínimo que o VPL desejado pode assumir;

$f(u)$ é função densidade de probabilidade do VPL (representada pela curva de probabilidades geradas pelo VPL simulado).

De maneira geral, os softwares que permitem o uso da Simulação de Monte Carlo apresentam grande quantidade de ferramentas da estatística descritiva, o que faz 
com que o gestor não tenha que se preocupar com os cálculos, porém a interpretação correta dos indicadores é fundamental.

Ao decorrer do capítulo serão mostrados alguns elementos ainda não bem definidos sobre a Simulação de Monte Carlo; como a geração de números aleatórios e a possibilidade de criar variações em variáveis independentes (demanda, preço, custos, etc.) de maneira a gerar um VPL simulado (variável dependente).

\subsubsection{Elementos da Simulação de Monte Carlo}

\section{- Variáveis Dependentes e Independentes}

O ponto de partida para a construção da simulação é a definição de qual método matemático estará envolvido no cálculo. Todos os métodos citados no capítulo 2 (VPL, TIR, MTIR e Payback Descontado) são passíveis de simulação, sendo chamados de "Variáveis Dependentes" do modelo, já que seu cálculo depende do fluxo de caixa do composto pela interação matemática de valores constituintes do projeto, como receita bruta, TMA, preço de venda de determinado produto, custo de mão-de-obra direta, etc.; considerados "Varáveis Independentes".

A Simulação de Monte Carlo ocorre variando continuamente as variáveis independentes. Dessa forma a cada novo valor dessas variáveis, uma variável dependente nova é calculada (neste trabalho o VPL), representando um cenário diferente.

Para execução da simulação o analista define a quantidade de números aleatórios que serão gerados. A cada nova geração de números aleatórios durante a 
simulação, as variáveis independentes assumem um novo valor. Desta forma, quantidade de números aleatórios está relacionada a quantidade de cenários aleatórios.

\section{- Números Aleatórios}

Para geração de tais números diversas técnicas foram utilizadas ao longo da história. A priori métodos manuais eram utilizados para sua geração, como o sorteio de valores através do uso de urnas. Depois foram desenvolvidas as tabelas de números aleatórios, que apresentam uma série muito grande de números, cumprindo a condição de igualdade de probabilidade de ocorrência de cada número. Máquinas mecânicas e elétricas analógicas também foram desenvolvidas com o intuito de reproduzir eventos aleatórios para geração dos números (NOVA, 1980).

O mesmo autor cita que com a evolução da eletrônica teve-se o surgimento dos chamados métodos eletrônicos. Existem muitas máquinas eletrônicas para geração de números aleatórios, um exemplo interessante é a ERNIE, que seleciona os prêmios da loteria da Grã-Bretanha. Nessas máquinas os números são gerados com base no ruído produzido por uma fonte (material radioativo, lâmpadas de néon, diodos termoinônicos). Os ruídos apresentados por essas fontes, não apresentam padrões harmônicos, o que dá caráter aleatório.

$\mathrm{Na}$ informática, os números aleatórios são obtidos através de geradores de números aleatórios, que tem o propósito de através do cálculo numérico, produzir uma seqüência de números gerados aleatoriamente dentro de uma distribuição de probabilidade específica. Usualmente, um gerador básico de números aleatórios produz números que imitam variáveis aleatórias independentes da distribuição uniforme sobre o intervalo [0;1]. As variáveis aleatórias de outras distribuições 
(normal, qui-quadrado, exponencial, poisson, etc.) são simuladas empregando-se transformações apropriadas aos números aleatórios uniformes gerados (VIEIRA et al, 2004).

$\mathrm{Na}$ literatura os números aleatórios gerados por computador também são conhecidos como número pseudo-aleatórios, já que ainda não se consegue gerar por esse advento seqüências totalmente aleatórias, pois após certos números gerados percebe-se padrões de repetição. Muitas empresas de software têm investido nesse recurso, o software $S_{a s}^{5}$, por exemplo, pode gerar rapidamente milhões de números com correlação relativamente baixa a algum tipo de padrão matemático de repetição.

Segundo Torres (2006), a grande maioria dos algoritmos dos softwares utiliza o método da congruência linear do cálculo numérico, representado pela função abaixo:

$$
x_{n+1}=\left(d x_{n}+c\right) \bmod m
$$

Em que:

$x_{0}$ é chamado de semente (seed), que pode ser definida pelo usuário do software;

$d$ é a constante multiplicadora;

$c$ é a constante incremento;

$m$ é a constante módulo.

Rosa e Pedro Júnior (2002) salientam que tais constantes devem ser convenientemente escolhidas, pois estes valores afetam drasticamente o comprimento

\footnotetext{
${ }^{5}$ www.sas.com/offices/latinamerica/brazil/technologies/ai/forecasting.html
} 
do período da seqüência de números aleatórios. Existem softwares que permitem ao usuário alterar ou fixar o valor da semente.

A planilha Excel apresenta a função ALEATORIO( ), que permite gerar valores entre 0 e 1 . O Minitab permite geração de números aleatórios usando o comando CALC $\backslash$ RANDOM DATA; esse recurso permite ao usuário definir quantos números deseja gerar e qual a distribuição de probabilidade que tais números irão assumir.

\section{- Distribuições de Probabilidade}

Na Simulação de Monte Carlo as distribuições de probabilidade têm a função de delinear as varáveis independentes, ou seja, são elas que definem quais são as fronteiras que os números aleatórios gerados irão pertencer; evitando o aparecimento de valores fora da realidade do investimento.

"Uma distribuição de probabilidades dá a probabilidade de cada valor de uma variável aleatória" (Triola, 1999, p.94).

O intuito de se atribuir uma distribuição a determinada variável independente é reproduzir o comportamento das variáveis durante todo o período do projeto de investimento. Dessa forma, na construção de um modelo onde há uso do método de Monte Carlo faz-se necessário conhecer; não somente o valor mais provável de uma variável, mas todos os valores em questão, ou pelo menos uma estimativa de como eles se comportam. Assim lança-se uso das distribuições que visam reproduzir o comportamento da variável independente. 
Segundo Silva (2004) uma forma comum de estabelecer a distribuição de probabilidades para uma dada variável é através da consulta de dados históricos ou estimativas. Quando se utiliza dados históricos, vale o pressuposto de que estes dados poderão descrever adequadamente o futuro, se isto não for correto, o recomendável é que se trabalhe com estimativas.

Devido à relevância do uso das distribuições para a aplicação da simulação de Monte Carlo, o item 3.2.5 trata sobre alguns tipos importantes de distribuições para a aplicação do método.

\subsubsection{Alguns tipos importantes de distribuição de probabilidade}

\section{- Distribuição de Probabilidade Uniforme}

Neste tipo de distribuição considera-se que todos os eventos que podem ocorrer são equiprováveis. Essa distribuição remete ao velho exemplo do uso de dados; a probabilidade de se obter um número entre seis é a mesma para qualquer evento do espaço amostral. Apesar do exemplo em um caso discreto, usualmente são usadas distribuições contínuas para uma simulação.

Uma variável aleatória discreta admite um número finito de valores ou tem uma quantidade enumerável de valores. Uma variável aleatória contínua pode tomar um número infinito de valores, e esses valores podem ser associados a mensurações em uma escala contínua, de tal forma que não haja lacunas ou interrupções (Triola, 1999). 
A Figura 9 apresenta a função densidade de probabilidade de uma distribuição de probabilidade uniforme contínua:

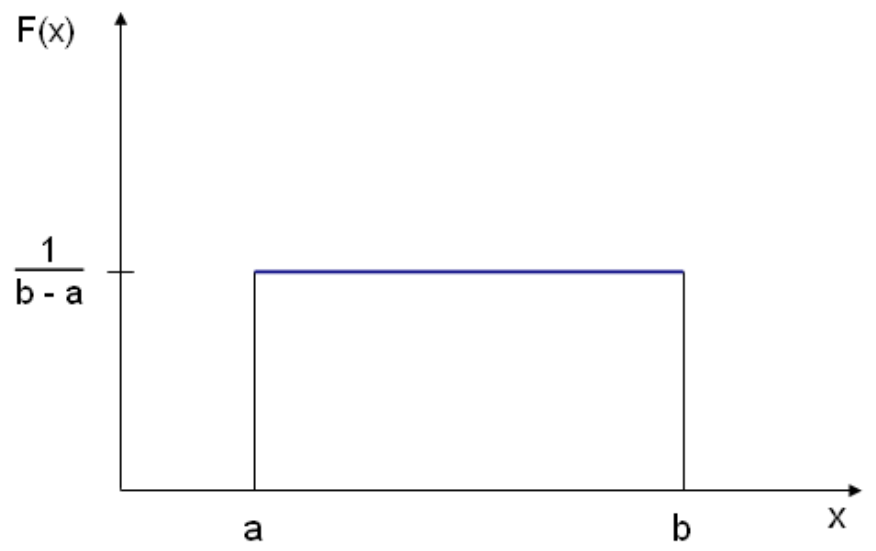

Figura 9 - Função densidade de probabilidade uniforme contínua Fonte: MONTGOMERY e RUNGER (2003)

A variável aleatória contínua $\mathrm{X}$ tem distribuição uniforme contínua com parâmetros reais $a$ e $b$; sua função densidade de probabilidade é denotada por:

$$
f(x)=1 /(b-a), \quad a \leq x \leq b
$$

Em que:

$a$ é o limite inferior da distribuição;

$b$ é o limite superior da distribuição.

O valor médio em uma distribuição uniforme contínua denotado por:

$$
E(X)=\int_{a}^{b} \frac{x}{b-a} d x=\left.\frac{0,5 x^{2}}{b-a}\right|_{a} ^{b}
$$


A variância é denotada por:

$$
\begin{aligned}
\sigma^{2} & =\int_{a}^{b} \frac{\left(x-\left(\frac{a+b}{2}\right)\right)^{2}}{b-a} d x=\left.\frac{\left(x-\frac{a+b}{2}\right)^{3}}{3(b-a)}\right|_{a} ^{b} \\
\sigma^{2} & =(b-a)^{2} / 12
\end{aligned}
$$

Segundo Kalatizs (2006) essa distribuição é usada quando se tem informação sobre os limites de variação da variável em estudo. O fato é que nesta distribuição o responsável pela construção do modelo probabilístico para simulação define somente os limites $a$ e $b$.

\section{- Distribuição de Probabilidade Normal}

Indubitavelmente, o modelo mais largamente usado para a distribuição de uma variável aleatória é a distribuição normal” (MONTGMOREY e RUNGER et al, 2003). Seu formato é definido por uma função gaussiana; simétrico em relação a média $(\mu)$, onde o desvio-padrão $(\sigma)$ é maneira usual de representear sua dispersão.

A Figura 10 ilustra uma particular curva normal, determinada por valores de $\mu \mathrm{e} \sigma:$ 


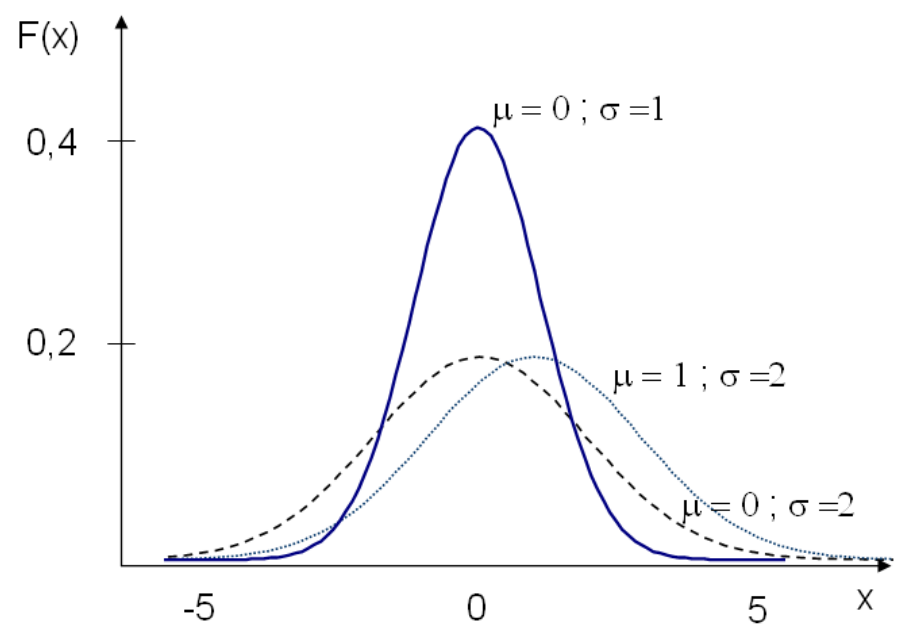

Figura 10 - Função densidade de probabilidade da distribuição normal. Fonte: KALATIZS (2006)

A função densidade de probabilidade é denotada por:

$$
f(x)=\frac{1}{\sqrt{2 \pi \sigma}} e^{\frac{-(x-\mu)^{2}}{2 \sigma^{2}}} \text { para }-\infty<x<\infty
$$

A média pode ser obtida através da média aritmética de todos os valores que compõe o estudo. Já o desvio-padrão foi apresentado pela equação 3.4.

Kalatizs (2006) cita que a distribuição normal deve ser utilizada quando não se tem informação sobre os limites de variação da variável em estudo ou, não se quer fixar os limites para a variável em estudo.

\section{- Distribuição de Probabilidade de Weibull}

A distribuição de Weibull pode apresentar formatos variados, apresentando grande flexibilidade para modelar diferentes tipos de sistemas físicos. Tal 
flexibilidade da distribuição de Weibull é ilustrada pelos gráficos das funções densidade de probabilidade selecionadas na Figura 11:

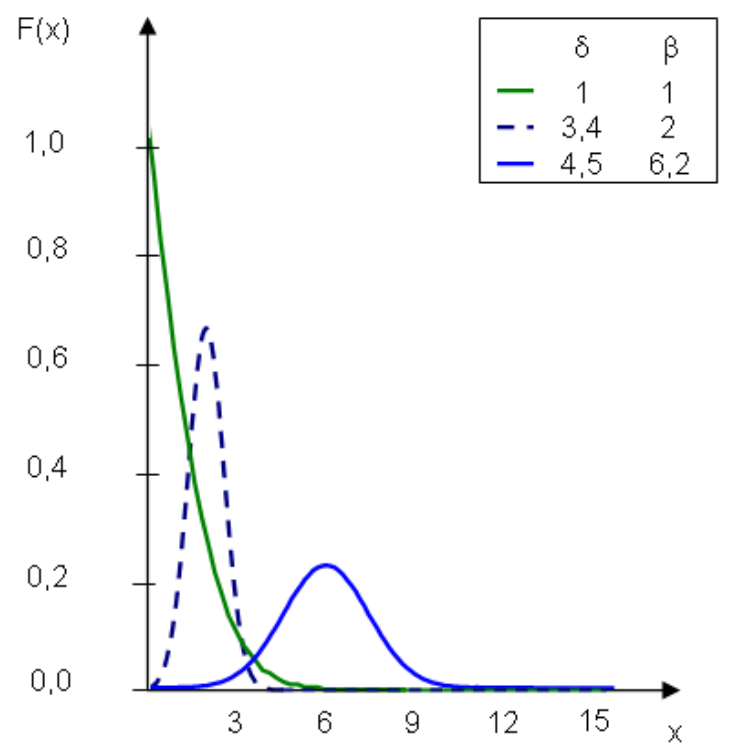

Figura 11 - Função densidade de probabilidade de Weibull para valores selecionados de $\delta$ e $\beta$.

Fonte: MONTGOMERY e RUNGER (2003)

A função densidade de probabilidade dessa função é descrita por:

$$
f(x)=\frac{\beta}{\delta}\left(\frac{x}{\delta}\right)^{\beta-1} e^{-(x / \delta)^{\beta}}, \text { para } \quad x>0, \delta>0 \text { e } \beta>0
$$

Em que:

$\delta$ é o parâmetro de escala;

$\beta$ é o parâmetro que dá forma a distribuição.

A média e a variância são descritas pelas funções abaixo: 


$$
\begin{aligned}
& \mu=\delta \Gamma\left(1+\frac{1}{\beta}\right) \\
& \sigma^{2}=\delta^{2} \Gamma\left(1+\frac{2}{\beta}\right)-\delta^{2}\left[\Gamma\left(1+\frac{1}{\beta}\right)\right]^{2} \\
& \Gamma(r)=(r-1) !
\end{aligned}
$$

Este tipo de distribuição deve ser usado quando se tem idéia da assimetria da variável independente, de forma que possa ser estipulado seu limite inferior e a curvatura da distribuição de probabilidades.

\subsubsection{Considerações Importantes}

Depois de apresentada a conceituação sobre a Simulação de Monte Carlo, fazse necessário apresentar de maneira lógica e seqüencial a construção do modelo probabilístico e o uso da simulação. O fluxograma apresentado na Figura 12 exprime os conceitos: 


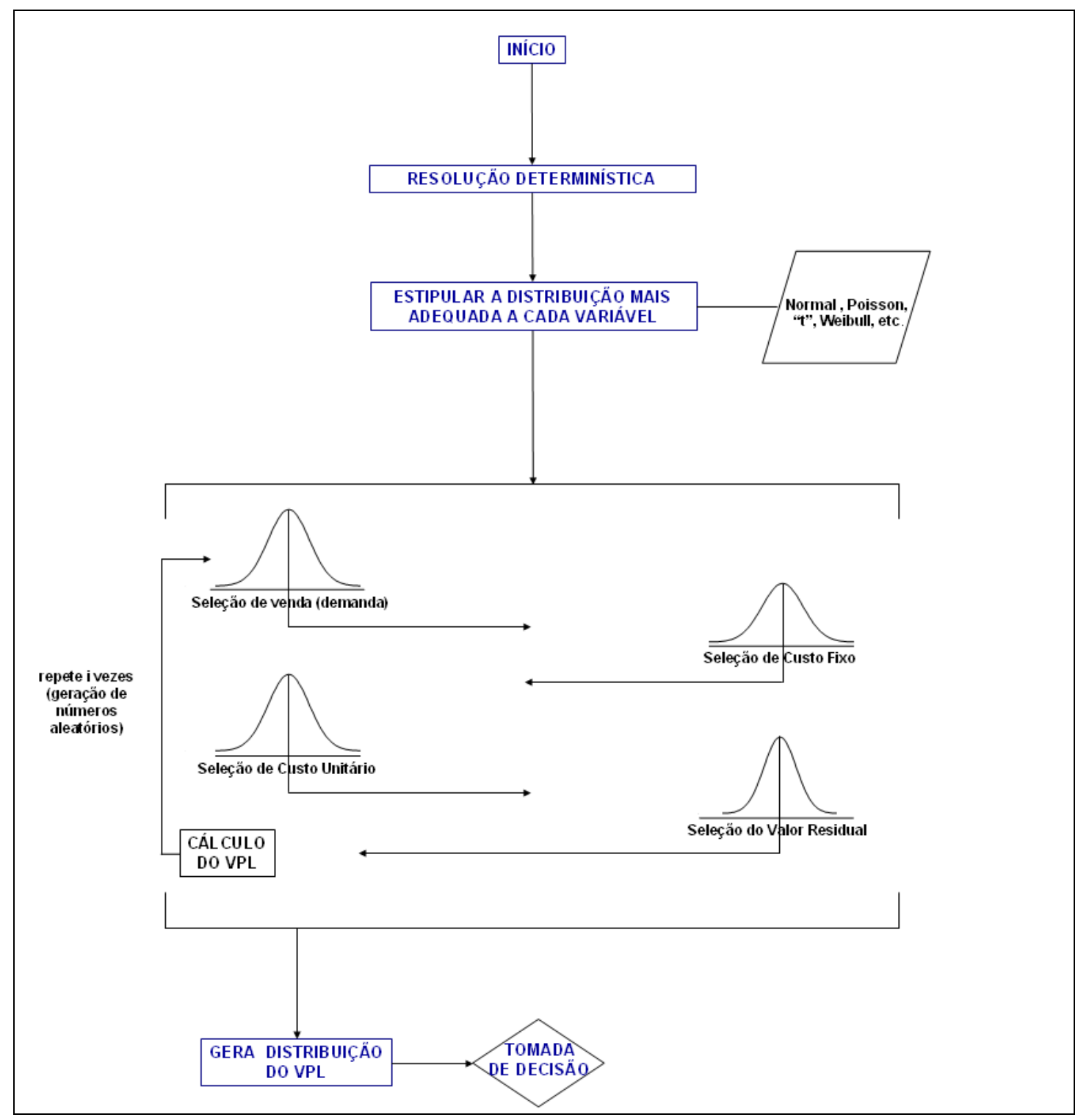

Figura 12 - A estrutura da Simulação de Monte Carlo.

Fonte: adaptado de CASAROTTO FILHO e KOPITTKE. (2000)

Após construído o modelo probabilístico, a cada nova situação i as variáveis independentes (venda, custo fixo, custo unitário e valor residual) assumem um valor diferente, desta forma a cada situação tem-se um novo VPL. O conjunto de VPLs calculados formará a distribuição de probabilidade para a tomada de decisão.

Outra consideração que deve ser feita é sobre a relação do método com os tipos de incerteza vistos no capítulo 2. A Simulação de Monte Carlo é fundamentada para efetuar análises de "Risco", onde o cenário do projeto permite a formulação de distribuições estatística para uso nas variáveis dependentes. Em um investimento em 
um título público, por exemplo, informações históricas do valor deste título podem ser relevantes e suficientes para o investidor, o que faz com que as distribuições de probabilidade sejam facilmente obtidas e reflitam a confiança do investidor nos dados. O mesmo pode ocorrer com algumas expansões de manufatura de uma indústria, na formulação de uma carteira com muitos ativos, etc.

Nas situações de análise de "Incerteza" as informações sobre os cenários financeiros e econômicos são vagas e pouco mensuráveis, ou seja, não se conhece a distribuição estatística dos componentes do fluxo de caixa e usa-se como alternativa trabalhar com opiniões e sugestões de especialistas que tem a função de decidir as condições do projeto do ponto de vista econômico. Infelizmente, é esta situação mais freqüente e também a qual os especialistas estão menos preparados para enfrentar. Como responder as seguintes perguntas: qual será a inflação daqui três anos? Qual o valor do $\mathrm{kW} / \mathrm{h}$ se as companhias de distribuição forem privatizadas? Qual o valor do petróleo daqui cinco anos? (PAMPLONA e MONTEVECHI, 2005).

Segundo Casarotto Filho e Kopittke (2000) quando se dispõe de alguma informação é possível considerar a incerteza como risco, propiciando o uso da Simulação de Monte Carlo. Intuitivamente, pode-se criar distribuições de probabilidade para representar situações de incerteza, porém o mesmo autor salienta o cuidado que deve ser dado na definição de parâmetros de distribuição de cada variável, sob pena de obter resultados totalmente inúteis.

O conceito do método de Monte Carlo trata a incerteza como estritamente "Estocástica", onde os limites das incertezas presentes na análise são bastante visíveis e bem definidos pelas distribuições de probabilidade. No capítulo 4, avalia-se a incerteza em seu caráter "Léxico", assim lança-se uso da teoria de conjuntos fuzzy e sua utilização em sistemas que apresentam incerteza e subjetividade. 
O Apêndice A apresenta a construção uma breve conceituação de como Microsoft ${ }^{\circledR}$ Excel em conjunto com software Crystal Ball pode ser utilizado para executar uma Simulação de Monte Carlo. 


\section{O USO DE NÚMEROS FUZZY NA ANÁLISE DE INVESTIMENTOS SOB CONDIÇÕES DE INCERTEZA}

Os "Sistemas Inteligentes" são ferramentas computacionais aplicáveis em diversas áreas do conhecimento. Suas principais estruturas são baseadas em novos conceitos matemáticos, que permitem a trabalhar na resolução de problemas onde a programação ou formulação tradicional é muito difícil ou até mesmo impraticável. Tais sistemas são utilizados desde automação de sistemas de manufatura, previsões temporais e na tomada de decisão, entre outras inúmeras aplicações.

Grande parte destes Sistemas Inteligentes é bastante conhecida e utilizada em aplicações na chamada "Inteligência Artificial”, definida por Shaw e Simões (1999) como a área do conhecimento que estuda como as pessoas resolvem problemas e como as máquinas podem emular esse comportamento humano de solução de problemas, em outras palavras, como fazer com que as máquinas sejam mais atribuídas de características da inteligência humana.

A concepção lógica dos diversos tipos de Sistemas Inteligentes é bastante variada; as "Redes Neurais Artificiais", por exemplo, são técnicas computacionais que apresentam um modelo matemático inspirado na estrutura neural de organismos inteligentes que adquirem conhecimento com a experiência. Porém enquanto uma rede neural artificial pode ter centenas ou milhares de unidades de processamento, $\mathrm{o}$ cérebro de um mamífero pode ter muitos bilhões de neurônios (SANCHES, 2003).

Os “Algoritmos Genéticos" são uma família de modelos computacionais inspirados na evolução, que incorporam uma solução potencial para um problema específico numa estrutura semelhante a de um cromossomo e aplicam operadores de seleção e "cross-over" a essas estruturas de forma a preservar informações críticas 
relativas à solução do problema. Normalmente os algoritmos genéticos são vistos como otimizadores de funções, embora a quantidade de problemas para o qual os algoritmos genéticos se aplicam seja bastante abrangente (ARAÚJO, 2008).

A "Lógica Fuzzy", também conhecida como difusa ou nebulosa, tem o intuito de emular o pensamento humano, baseando-se na forma incerta e imprecisa com que os seres humanos raciocinam (SHAW e SIMÕES, 1999). Sua aplicação é crescente na engenharia, sendo comuns estudos e aplicações em conjunto com as redes neurais artificiais, culminando nos "Sistemas Neuro-Fuzzy".

Segundo Oliveira Júnior (1999) o aspecto mais notável dos métodos baseados na Lógica Fuzzy é a possibilidade de capturar em um modelo matemático, conceitos intuitivos como grau de satisfação, conforto e adequação.

O mesmo autor cita um exemplo para ilustrar a idéia. Supõe-se que em uma determinada cidade a temperatura varia anualmente entre 15 e $42^{\circ} \mathrm{C}$. Ao questionar-se um grupo de habitantes sobre sua sensação térmica, escolhida entre diferentes alternativas $\left\{\right.$ Fria, Neutra, Quente\}, provavelmente haveria consenso que a $15^{\circ} \mathrm{C}$ a sensação térmica é Fria, a $42^{\circ} \mathrm{C}$ seria Quente e a $25^{\circ} \mathrm{C}$ tal sensação poderia ser considerada Neutra.

Mas em que temperaturas a sensação Fria se torna Neutra e esta se transforma em Quente?

Dificilmente haverá coincidência de opiniões na resposta a essa pergunta, tendo em vista que os conceitos envolvidos são subjetivos e apresentam áreas "sombrias", onde não se consegue escolher entre duas alternativas mutuamente exclusivas simplesmente porque ambas podem estar parcialmente presentes.

Através da Lógica Fuzzy o problema poderia ser interpretado de maneira em que as temperaturas não apresentem fronteiras rígidas entre os limites de Fria, Neutra 
e Quente. Isto seria possível representado, por exemplo, a concepção de Frio como um número ou conjunto Fuzzy, que conteria uma faixa de valores possíveis para as temperaturas consideradas frias. Tal conceito é expresso ao longo deste capítulo.

\subsection{A LÓGICA FUZZY}

O surgimento da Lógica Fuzzy está associado ao professor Loft A. Zadeh, da Universidade de Berkley na Califórnia, que em 1965 publicou o artigo Fuzzy Sets. Na época Zadeh havia observado que os recursos tecnológicos disponíveis eram incapazes de automatizar problemas de natureza industrial que compreendessem situações ambíguas, não passíveis de processamento através da lógica computacional fundamentada na lógica booleana.

$\mathrm{Na}$ lógica booleana ou binária, um elemento $x$ pertence ou não pertence a um determinado conjunto $A$. Apenas duas hipóteses lógicas sobre a pertinência de $x$ ao conjunto $A$ são possíveis, sendo representadas em um conjunto binário $\{0,1\}$.

$$
\begin{aligned}
& \mu_{A}(x)=1 \text { se e somente se } x \in A ; \\
& \mu_{A}(x)=0 \text { se somente se } x \notin A ;
\end{aligned}
$$

Em que:

$\mu_{A}(x)$ é a função de inclusão do elemento ao conjunto.

A Figura 13 exprime o conceito: 


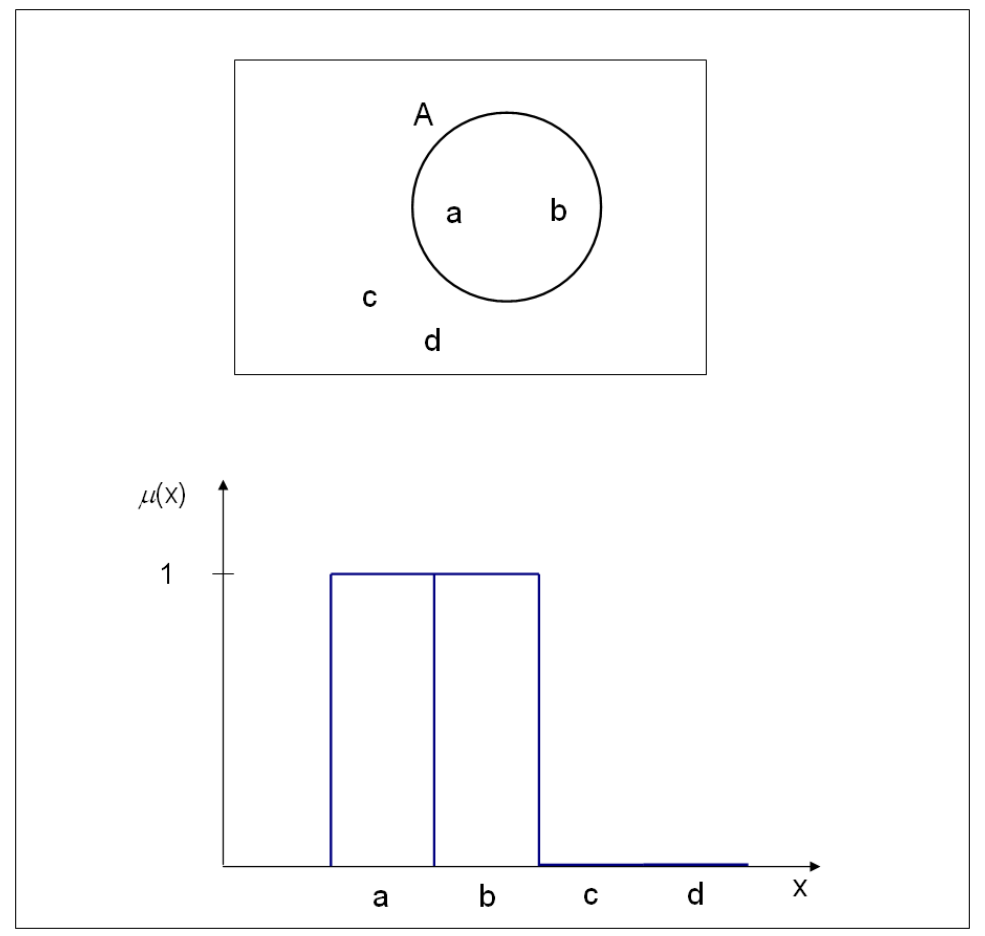

Figura 13 - Lógica booleana

Fonte: adaptado de SANCHEZ(2003)

A lógica booleana é na verdade a estruturação da lógica clássica proposta por Aristóteles, baseada no princípio da bivalência, o qual permeia o pensamento ocidental. Espera-se sempre que uma afirmação seja verdadeira ou falsa, branco ou preto, um ou zero. Nada está entre ambas e o meio está excluído.

Há um considerável descompasso entre o mundo real e a visão bivalente do mesmo, a começar pelo fato de que o mundo real contém um número infinito de graus de cinza entre as cores pretas e brancas. Verdade e precisão existem apenas em casos extremos. Desta forma a Lógica Fuzzy tem o objetivo de capturar os tons de cinza ou graus de verdade (Shaw e Simões, 1999).

Na lógica proposta por Zadeh (1965), existe a possibilidade dos termos pertencerem parcialmente ao conjunto $A$, ou seja, um termo qualquer $x$ pode ter uma 
"Função Pertinência" ou "Membership" que assuma qualquer valor no intervalo [0,1]. Segundo Shaw e Simões (1999) este princípio é chamado de multivalência.

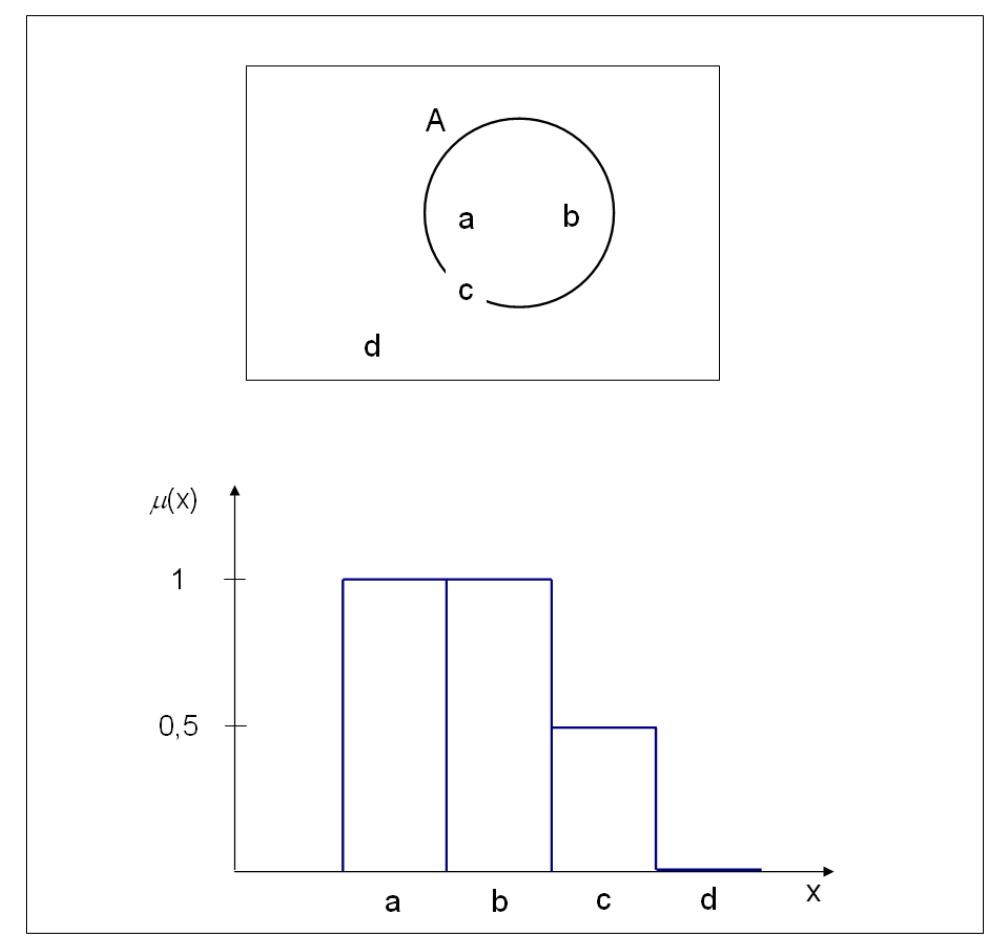

Figura 14 - Lógica Fuzzy

Fonte: adaptado de SANCHEZ(2003).

"Um conjunto Fuzzy A é caracterizado por um membership $\mu(x)$ que associa cada ponto em $x$ a um número real no intervalo [0,1], onde cada valor da função $\mu(x)$ representa o 'grau de pertinência' de $x$ em $A$ " (Zadeh, 1965 p.339).

Pela Figura 14 é possível observar que na Lógica Fuzzy pode existir um elemento $c$ que pertence parcialmente ao conjunto $A(0 \leq$ grau de pertinência $\leq 1)$.

O "grau de pertinência" de um elemento a um conjunto Fuzzy expressa o grau de compatibilidade do elemento com o conceito representado (NICOLETTI e CAMARGO, 2004). 
Inicialmente a função pertinência associada a um elemento $x$ qualquer pode apresentar semelhança com o conceito de uma função de probabilidade, porém existem diferenças essenciais entre esses dois conceitos que ficam mais claras ao apresentar-se a seqüência de regras de combinação entre funções pertinência e suas propriedades básicas. Na verdade, a noção de um conjunto Fuzzy é de natureza não estatística (ZADEH, 1965).

\subsection{NÚMEROS E CONJUNTOS FUZZY}

\subsubsection{Introdução}

Embora na matemática clássica exista uma distinção entre a noção de elemento e a de um conjunto, na Lógica Fuzzy esta noção se aproxima bastante, isso porque um número Fuzzy representa uma faixa de números possíveis e não um valor absoluto.

Segundo Sanches (2003) os números Fuzzy são subconjuntos dentro dos números reais, representando valores incertos. Todos os números Fuzzy estão relacionados ao grau de pertinência que expressam o quanto é verdadeira uma informação.

Por exemplo, numericamente o número "Zero" poderia ser representado em um eixo cartesiano simplesmente por um ponto único (Figura 15). 


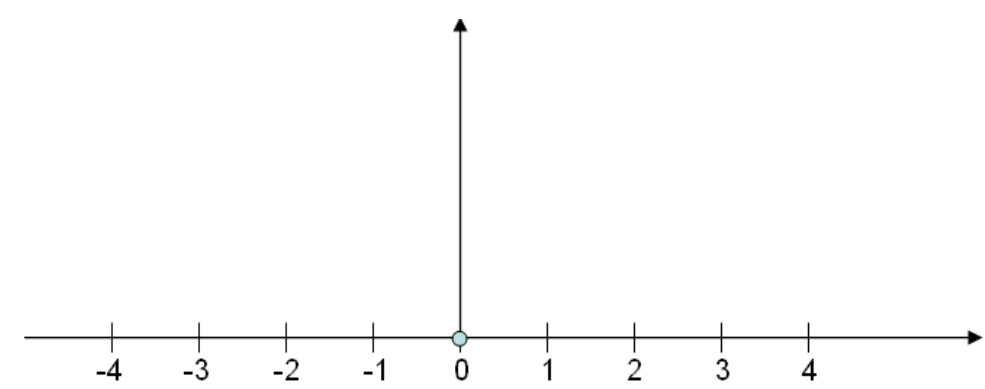

Figura 15 - Número Real 0 Fonte: SHAW e SIMÕES (1999)

O número Fuzzy mostrado na Figura 16 expressa o conceito de "Quase Zero". Neste conceito observa-se que existe uma área coberta no eixo horizontal. O conceito matemático de "Zero" tem uma abstração matemática de área nula, enquanto o conjunto "Quase Zero" desfruta de uma faixa de valores no eixo horizontal, denominada Universo de Discurso $(U)$.

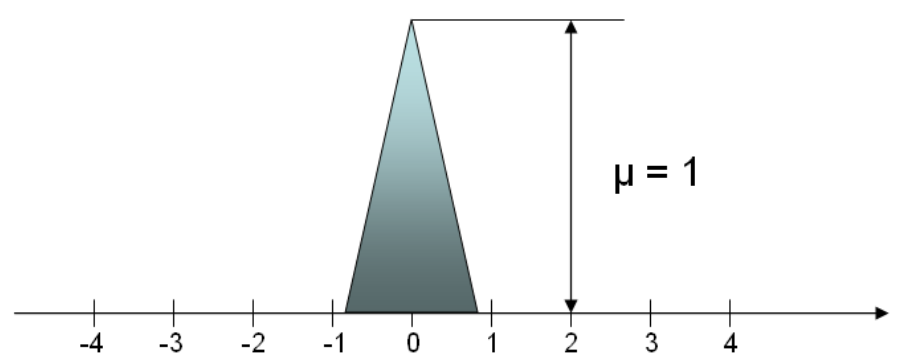

Figura 16 - O conceito de Quase zero Fonte: Adaptado de SHAW e SIMÕES (1999)

Observa-se que o para todos os valores compreendidos no número Fuzzy "Quase Zero" existe uma relação com a função pertinência. Onde 0 tem pertinência máxima 1.

Os termos "números Fuzzy" e "conjuntos Fuzzy" podem nesse caso representar a mesma coisa, há no entanto definições matemáticas mais rigorosas que apresentam diferenciação entre os termos (Shaw e Simões, 1999). 
A Figura 17 apresenta outro conceito; o de "Próximo de Zero". Neste caso a área de valores compreendidos é maior do que "Quase Zero", o que permite dizer que este novo número é mais Fuzzy do que o número que representa “Quase Zero”.

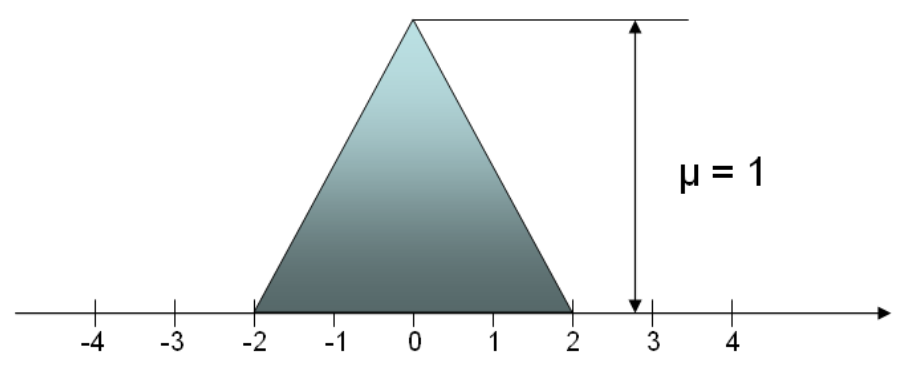

Figura 17 - Próximo de Zero

Fonte: Adaptado de SHAW e SIMÕES (1999)

A representação de uma grandeza ou evento por um número Fuzzy permite que através da matemática, conceitos que poderiam ser considerados qualitativos sejam representados de maneira quantitativa.

\subsubsection{O Conceito de Possibilidade}

A teoria dos conjuntos Fuzzy é baseada no fato de que os conjuntos existentes no mundo real não possuem limites precisos. Um conjunto Fuzzy é um agrupamento impreciso e indefinido, onde a transição da não-pertinência para a pertinência é gradual e não abrupta. A característica Fuzzy implica em existência de imprecisão, incerteza e definições qualitativas. A teoria dos conjuntos Fuzzy provê um método para manipulação dos conjuntos, onde os limites são imprecisos ao invés de restritos. A incerteza de um elemento, isso é, seus graus fracionário de pertinência pode ser concebida por uma "medida de possibilidade", ou seja, a "possibilidade" de que um elemento seja membro de um conjunto. $\mathrm{O}$ conceito de possibilidade não é o mesmo de 
probabilidade que se refere a "chance" de que um elemento seja membro de um conjunto (SHAW e SIMÕES, 1999).

Os mesmos autores apresentam um exemplo que ajuda a compreender o conceito. Em um relatório de metrologia a chance de chuva é de 0,8. Essa é uma expressão probabilística, pois o que está sendo levado em conta é se haverá chuva ou não. No conceito de possibilidade a representação do evento chuva poderia ser obtida através da construção de uma escala de possibilidades, como na Quadro 4:

\begin{tabular}{|c|c|}
\hline Grau de Pertinência & Intensidade da Chuva \\
\hline 1,0 & Tempestade (T) \\
\hline 0,8 & Chuva Forte (CF) \\
\hline 0,6 & Garoa (G) \\
\hline 0,4 & Garoa Fina (GF) \\
\hline 0,2 & \\
\hline
\end{tabular}

Quadro 4 - Uma representação Fuzzy para chuva

Neste caso uma possibilidade de chuva 0,8 indica que a chuva será forte, o que difere conceitualmente de dizer que amanhã existe uma probabilidade $80 \%$ de que haja chuva.

Através de um conjunto Fuzzy em forma de trapézio pode-se representar a intensidade de chuva expressa pela quadro anterior: 


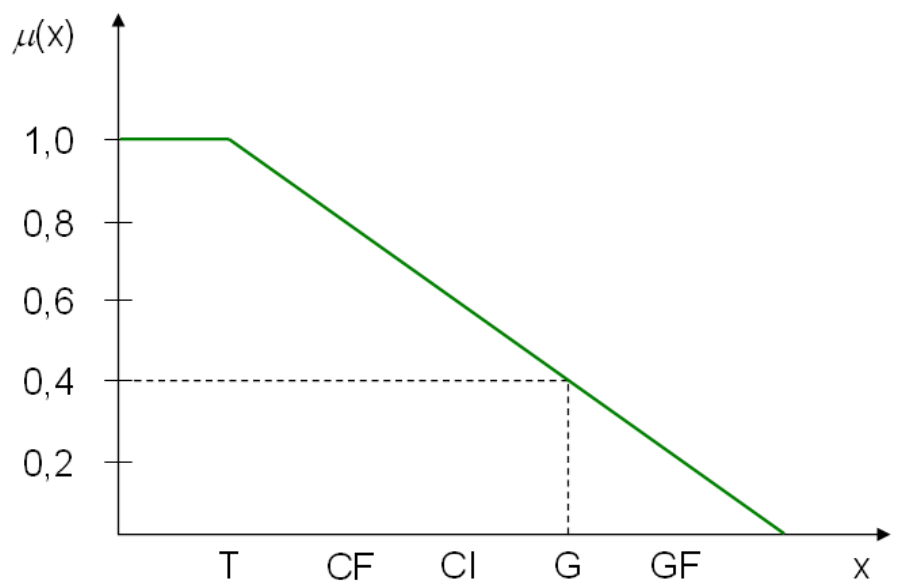

Figura 18 - A Intensidade da Chuva

Na Figura 18 o segmento em verde que representa a função $\mu(x)$ é também chamado de distribuição de possibilidades (FEITOSA e PAULOVICH, 2005).

\subsubsection{Os Números Fuzzy}

Até o presente momento nenhuma diferenciação entre um número Fuzzy e um conjunto Fuzzy foi apresentada, porém faz-se necessário explorar esses conceitos para que a matemática utilizada no trabalho fique mais clara.

Segundo Chiu e Park (1994) um número Fuzzy é um subconjunto Fuzzy caracterizado por uma função pertinência que satisfaz as seguintes condições:

- Normalidade: $\mu_{A}(x)=1$, pelo menos em um ponto $x \in U$ :

As Figuras 19 e 20 mostram o conceito: 


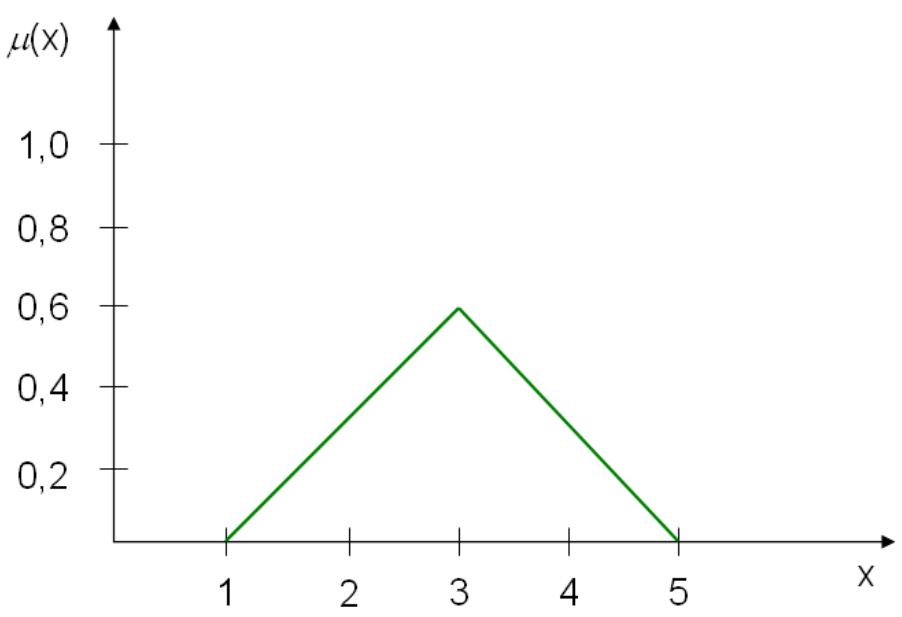

Figura 19 - Função de pertinência não normalizada. Fonte: Adaptado de OLIVEIRA JÚNIOR (1999).

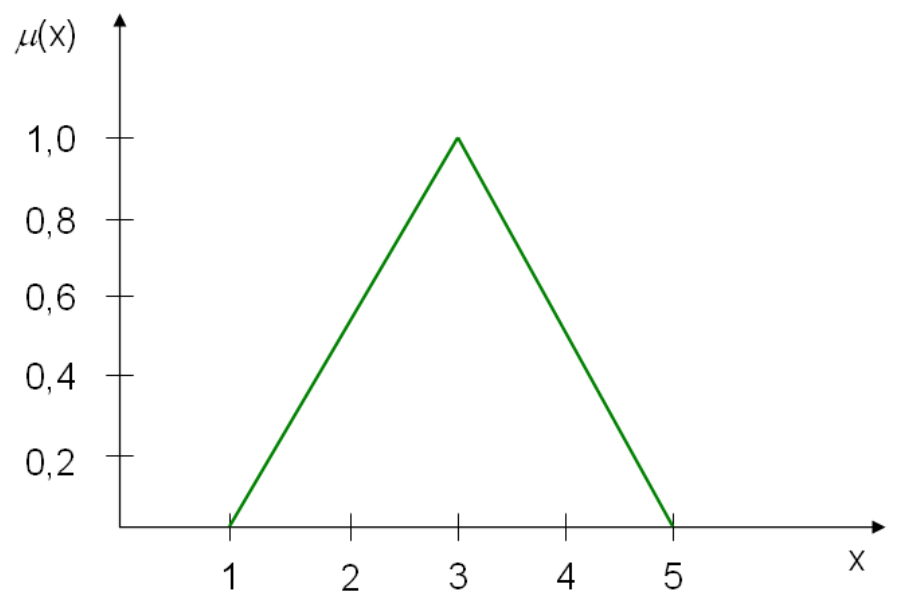

Figura 20 - Função de pertinência normalizada Fonte: Adaptado de OLIVEIRA JÚNIOR (1999)

- Convexidade: $\mu_{A}\left(x^{\prime}\right) \geq \mu_{A}\left(x_{1}\right) \wedge \mu_{A}\left(x_{2}\right)$, onde: $\mu_{A}(x) \in[0,1]$ e $\forall \quad x^{\prime} \in\left[x_{1}, x_{2}\right]$

As Figuras 19 e 20 apresentam funções pertinências convexas, já a Figura 21 apresenta uma não convexa: 


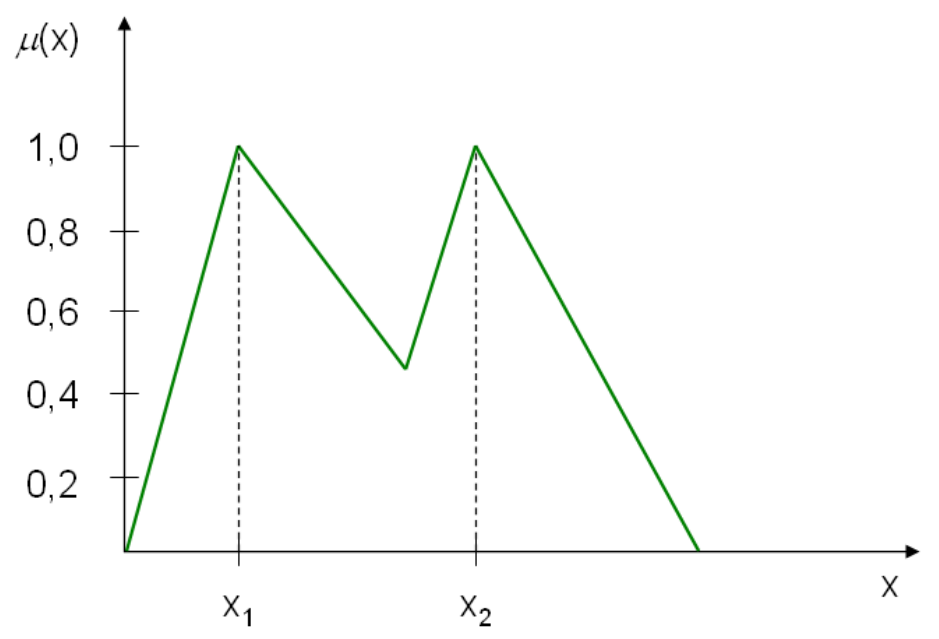

Figura 21 - Função de pertinência normalizada, porém não convexa

\subsubsection{Tipos de Números Fuzzy}

Diversos tipos de números Fuzzy são aplicados na engenharia, usualmente são denominados em função do formato de funções de pertinência e podem ser aplicados para representar conceitos ou eventos diversos. Na automação, são utilizados para representar entradas incertas em sistemas de controle. Nos sistemas de apoio à decisão, podem representar incertezas como, por exemplo, comportamento cambial ou variação diária da quantidade produzida de um produto.

\section{- Número Trapezoidal Fuzzy}

Neste caso a função pertinência assume um formato de trapézio como na Figura 22 que representa um número trapezoidal Fuzzy qualquer denominado A: 


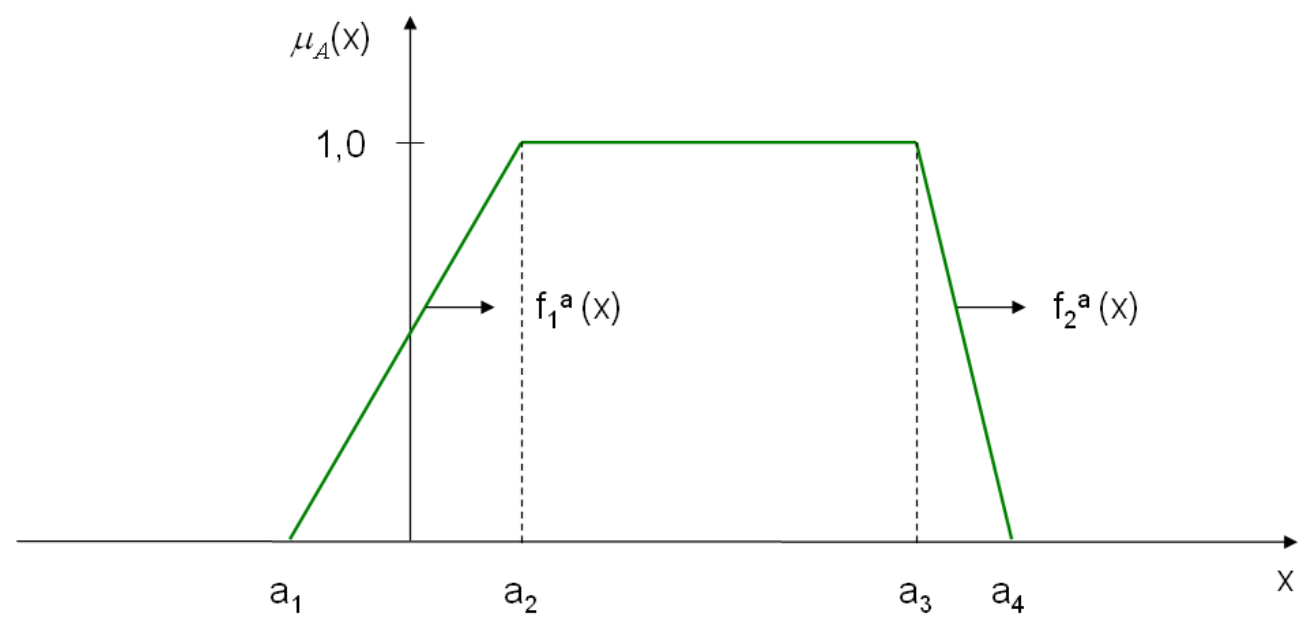

Figura 22 - Número Trapezoidal Fuzzy

Fonte: Adaptado de SANCHEZ (2003)

Matematicamente o número acima pode ser representado por:

$$
A=\left(a_{1}, a_{2}, a_{3}, a_{4}\right)
$$

Onde $f_{1}^{a}(x)$ e $f_{2}^{a}(\mathrm{x})$ são funções que representam os seguimentos de reta, definindo a função pertinência como:

$$
\mu_{A}(x)=\left\{\begin{array}{cl}
0, & x<a_{1} \\
\frac{x-a_{1}}{a_{2}-a_{1}}, & a_{1} \leq x \leq a_{2} \\
1 & a_{2} \leq x \leq a_{3} \\
\frac{a_{4}-x}{a_{4}-a_{3}}, & a_{3} \leq x \leq a_{4} \\
0, & x>a_{4}
\end{array}\right.
$$

\section{- Número Triangular Fuzzy}

Um número triangular Fuzzy é constituído por dois segmentos de reta, o que faz com que sua função pertinência assuma a seguinte forma: 


$$
\mu_{A}(x)=\left\{\begin{array}{cl}
0, & x<a_{1} \\
\frac{x-a_{1}}{a_{2}-a_{1}}, & a_{1} \leq x \leq a_{2} \\
\frac{a_{3}-x}{a_{3}-a_{2}}, & a_{2} \leq x \leq a_{3} \\
0, & x<a_{3}
\end{array}\right.
$$

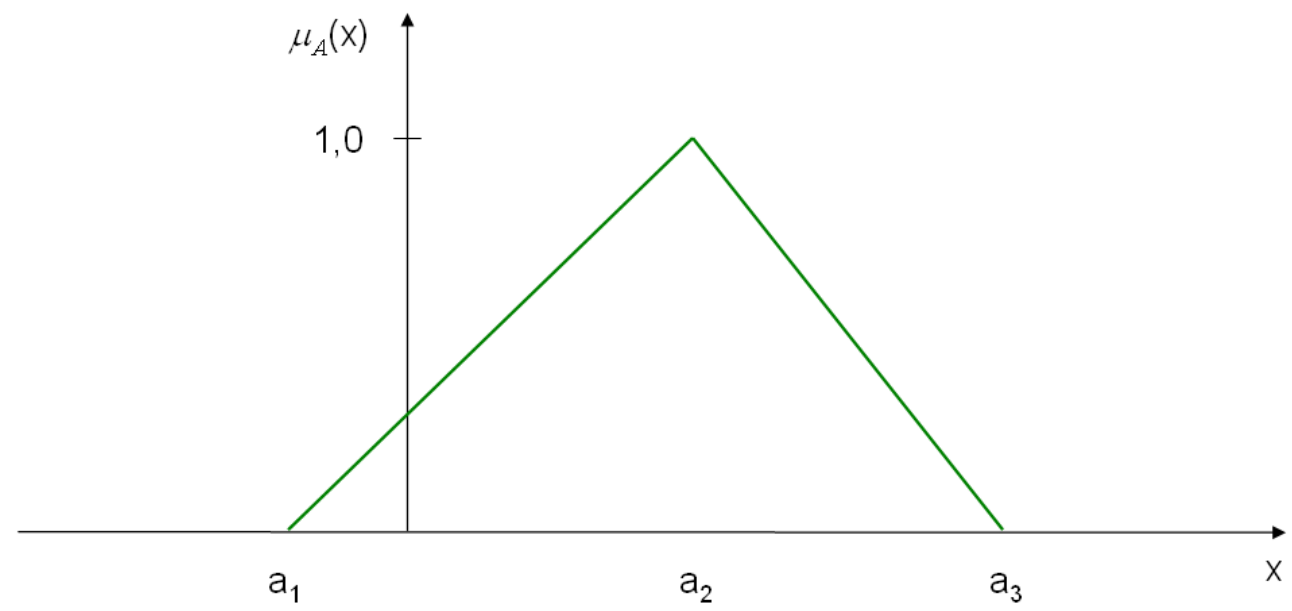

Figura 23 - Número Triangular Fuzzy

Fonte: Adaptado de SANCHEZ (2003)

Uma representação matemática simples do número apresentado na Figura 23 pode ser expressa por:

$$
A=\left(a_{1}, a_{2}, a_{3}\right)
$$

$\mathrm{Na}$ literatura a denominação $\alpha$-cuté muito utilizada quando deseja-se representar um número Fuzzy em função de determinada pertinência. Em termos práticos o $\alpha$-cut nada mais é do que os infinitos valores que uma função de pertinência pode assumir dentro do intervalo [0,1]. A Figura 24 exprime esta representação para um número triangular Fuzzy e em seguida é apresentada sua representação matemática. 


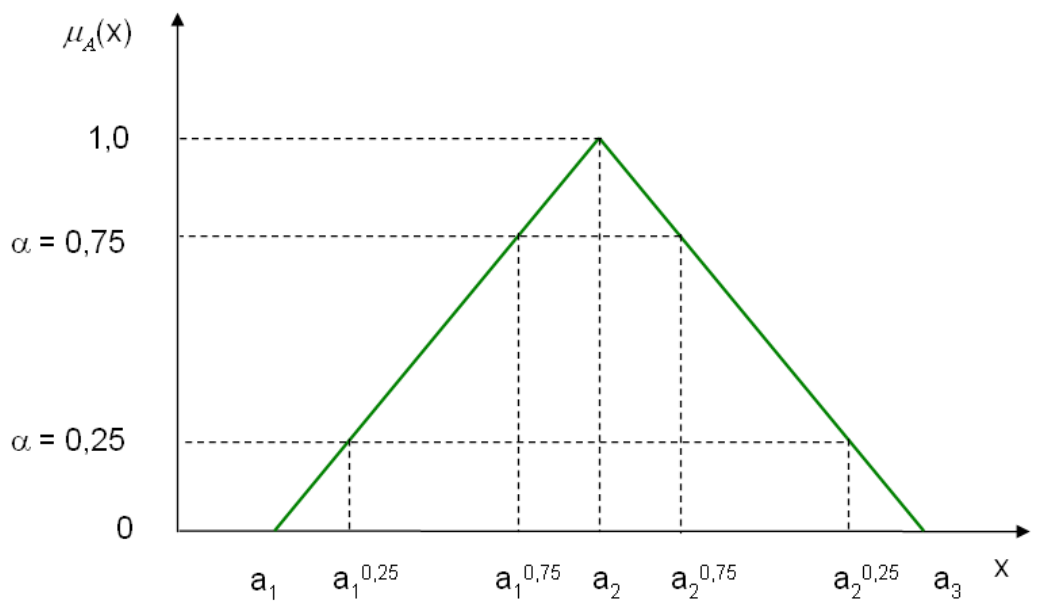

Figura $24-$ Representação de $\alpha-c u t=0.25$ e $\alpha-c u t=0.75$ em um número triangular Fuzzy

$$
A=\left[a^{l(\alpha)}, a^{r(\alpha)}\right]
$$

Onde, $l(\alpha)$ é função inversa do seguimento de reta à esquerda do referido número Fuzzy e $r(\alpha)$ é função inversa que representa o seguimento da direita (BANHOLZER, 2005). Desta forma:

$$
\forall \alpha \in[0,1]
$$

$$
A=\left[a^{l(\alpha)}, a^{r(\alpha)}\right]=\left[\left(a_{2}-a_{1}\right) \times \alpha+a_{1},-\left(a_{3}-a_{2}\right) \times \alpha+a_{3}\right]
$$

Um exemplo ajuda na melhor compreensão dos conceitos. Supõe-se que um número triangular Fuzzy A seja definido por $(-1,2,5)$, ilustrado na Figura 25. Sua função de pertinência é expressa por: 


$$
\mu_{A}(x)=\left\{\begin{array}{cl}
0, & x<-1 \\
\frac{x+1}{3}, & -1 \leq x \leq 2 \\
\frac{5-x}{3}, & 2 \leq x \leq 5 \\
0, & x>5
\end{array}\right.
$$

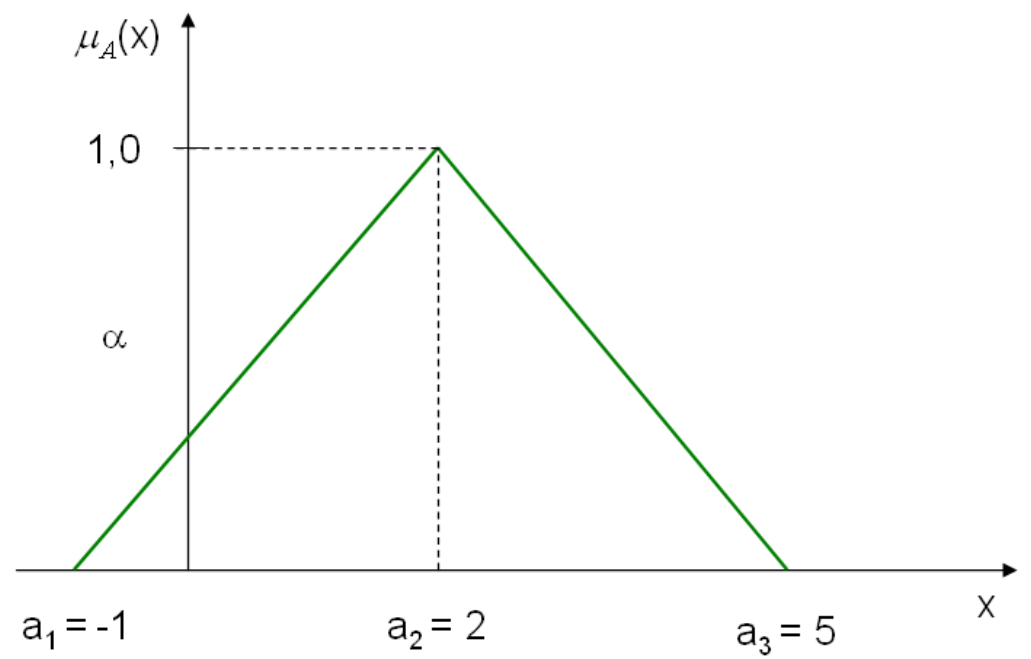

Figura 25 - Representação gráfica do número Fuzzy $\mathrm{A}=(-1,2,5)$

Utilizando a representação por $\alpha-$ cut :

$$
\forall \alpha \in[0,1]
$$

$$
A=\left[a^{l(\alpha)}, a^{r(\alpha)}\right]=[3 \times \alpha-1,-3 \times \alpha+5]
$$

\section{- Número Fuzzy em formato de Sino}

As funções pertinência em formato de sino são representadas pela seguinte função:

$$
\mu_{A}(x)=e^{-(x-a)^{2} / b}
$$




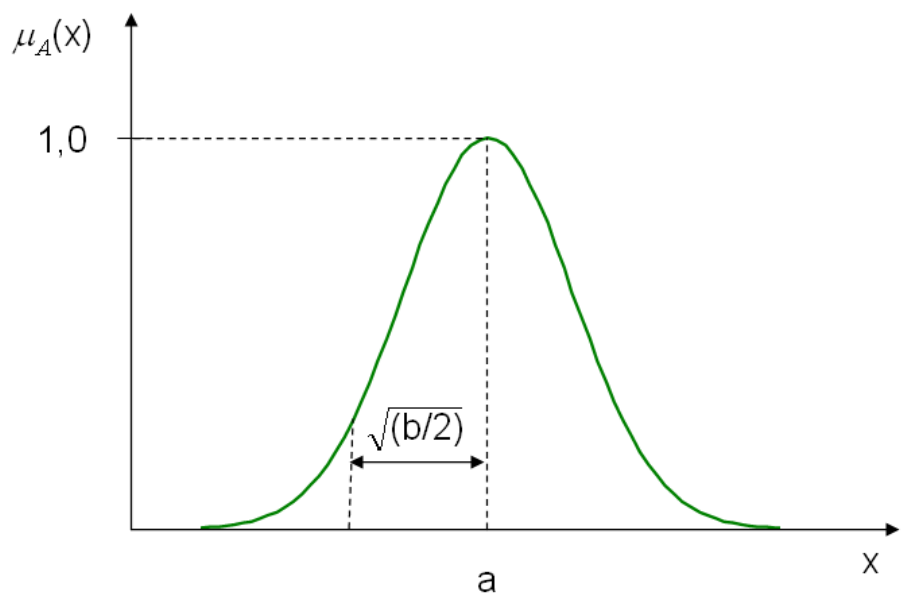

Figura 26 - Número Fuzzy em formato de Sino Fonte: NICOLETTI e CAMARGO (2004)

Os números Fuzzy podem assumir formatos diversos, isto porque uma função qualquer que apresente os princípios de normalidade e convexidade pode caracterizar um número Fuzzy.

Neste trabalho o intuito principal é o de representar parâmetros que compõe um fluxo de caixa através de números Fuzzy. Visto que tais parâmetros são incertos e, de certa forma, de difícil mensuração, atear-se-á aos números de formato geométrico mais simples como os triangulares, pois a opção por funções mais complexas pode ser pouco representativa. À medida que a complexidade da função aumenta, mais difícil se torna adequá-las as informações vagas e muitas vezes intuitivas presentes nas análises de investimento onde não se sabe claramente o comportamento futuro das variáveis dependentes.

\subsubsection{Operações com Números Triangulares Fuzzy}

- A Adição Fuzzy (+) 
Segundo Chiu e Park (1994) a adição entre dois números Fuzzy A e B pode ser expressa por:

$$
A(+) B=\left[a^{l(\alpha)}+b^{l(\alpha)}, a^{r(\alpha)}+b^{r(\alpha)}\right]
$$

Para a soma entre dois números Fuzzy $\mathrm{A}=(-10,4,5)$ e $\mathrm{B}=(7,10,15)$. Temse:

$$
\begin{gathered}
A=[-10+14 \times \alpha, 5-\alpha] \text { e } B=[7+3 \times \alpha, 15-5 \times \alpha] \\
A(+) B=[-3+17 \times \alpha, 20-6 \times \alpha]
\end{gathered}
$$

Para $\alpha=0: A(+) B=[-3,20]$

Para $\alpha=1: A(+) B=[14,14]$

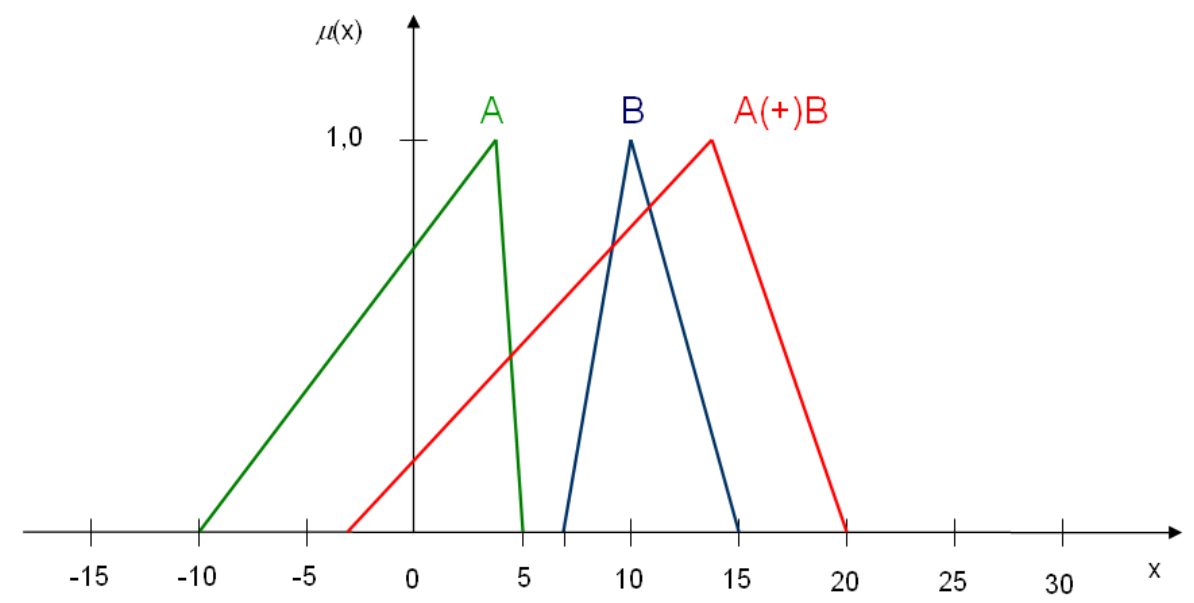

Figura 27 - Soma entre os números Fuzzy A e B Fonte: BANHOLZER (2005).

\section{- A Imagem Simétrica}


A Imagem Simétrica de um número triangular Fuzzy $A=\left(a_{1}, a_{2}, a_{3}\right)$ pode ser definida como:

$$
-A=\left(-a_{3},-a_{2},-a_{1}\right)
$$

A representação gráfica da imagem simétrica de um número Fuzzy pode ser visualizada através da Figura 28:

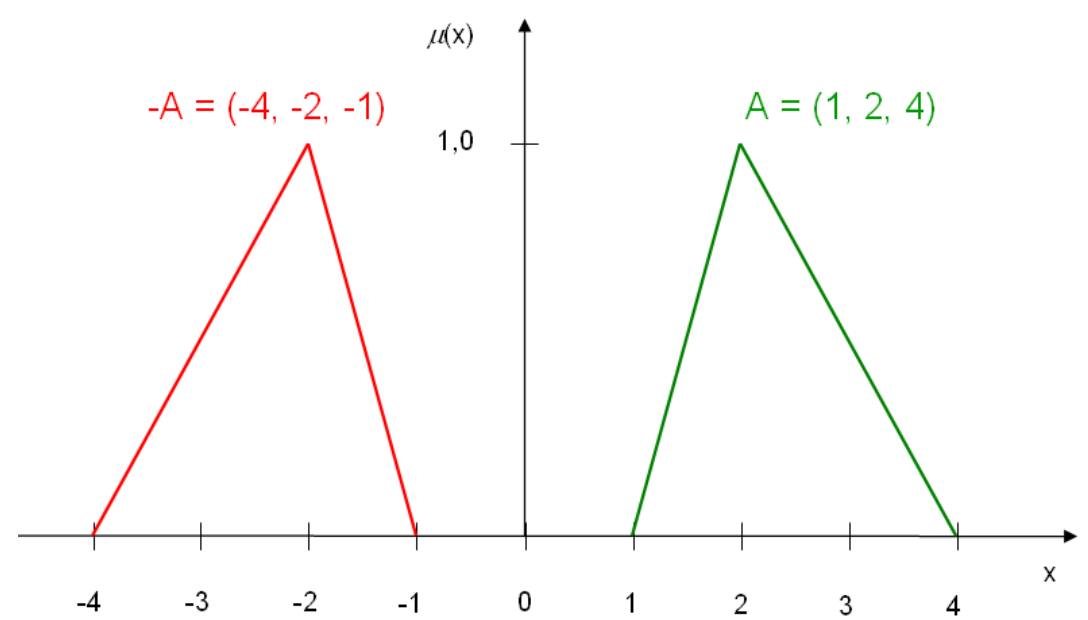

Figura 28 - A Imagem Simétrica de A

Pela concepção por $\alpha-c u t$;

$$
-A=\left[-a^{r(\alpha)},-a^{l(\alpha)}\right]
$$

- A Subtração Fuzzy (-)

A subtração Fuzzy na verdade é a soma de um número Fuzzy A com a imagem simétrica do número Fuzzy B que se pretende subtrair: 


$$
A(-) B=\left[a^{l(\alpha)}-b^{r(\alpha)}, a^{r(\alpha)}-b^{l(\alpha)}\right]
$$

Considerando os números Fuzzy $\mathrm{A}=(-2,0,3)$ e $\mathrm{B}=(2,4,5)$ tem-se:

$$
\begin{gathered}
A=[-2+2 \times \alpha, 3-3 \times \alpha] \text { e } B=[2 \times \alpha+2,-\alpha+5] \\
A(-) B=\left[\begin{array}{ll}
-7+3 \times \alpha, & 1-5 \times \alpha]
\end{array}\right.
\end{gathered}
$$

Para $\alpha=0: A(-) B=[-7,1]$

Para $\alpha=1 A(-) B=[-4,-4]$

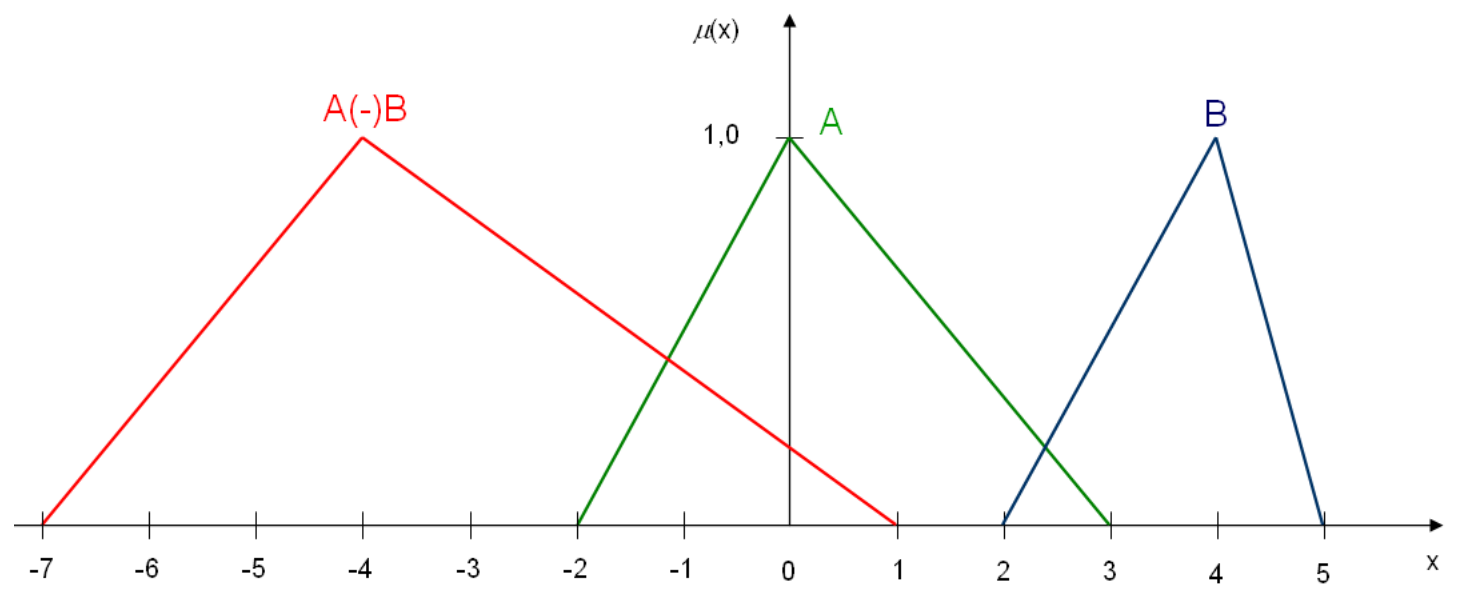

Figura 29 - Subtração entre os números Fuzzy A e B

\section{- A Multiplicação Fuzzy $(\times)$}

Segundo Chiu e Park (1994) a multiplicação entre dois números Fuzzy A e B pode ser expressa por: 


$$
A(\times) B=\left[a^{l(\alpha)} \times b^{l(\alpha)}, a^{r(\alpha)} \times b^{r(\alpha)}\right]
$$

Utilizando os valores dos números Fuzzy do exemplo anterior (subtração Fuzzy) tem-se:

$$
A(\times) B=\left[4-4 \times \alpha^{2}, 3 \times \alpha^{2}-18 \times \alpha-15\right]
$$

Desta forma o número Fuzzy resultante da multiplicação poderia ser representado pela Figura 30. Onde $l(\alpha)$ e $r(\alpha)$ de $A(\times) B$ não são segmentos de reta.

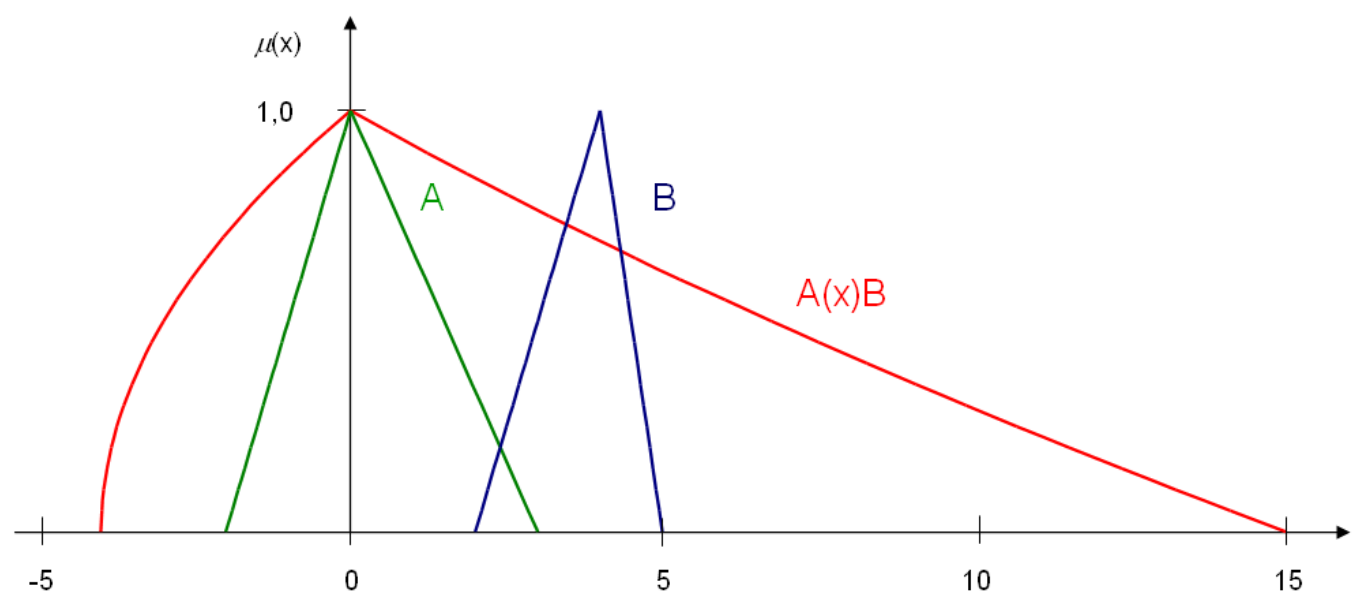

Figura 30 - Multiplicação entre os números Fuzzy A e B

- A Divisão Fuzzy $(\div)$

Segundo Banholzer (2005) a divisão de dois números Fuzzy A e B pode ser expressa por: 


$$
\begin{gathered}
A(\div) B=\left[\min \left(a^{l(\alpha)} / b^{l(\alpha)}, a^{l(\alpha)} / b^{r(\alpha)}, a^{r(\alpha)} / b^{l(\alpha)}, a^{r(\alpha)} / b^{r(\alpha)}\right) ;\right. \\
\left.\max \left(a^{l(\alpha)} / b^{l(\alpha)}, a^{l(\alpha)} / b^{r(\alpha)}, a^{r(\alpha)} / b^{l(\alpha)}, a^{l(\alpha)} / b^{r(\alpha)}\right)\right]
\end{gathered}
$$

O mesmo autor apresenta um exemplo usando números $F u z z y \mathrm{~A}=(-10,4,5)$ e $\mathrm{B}=(7,10,5)$ :

$$
\begin{aligned}
& A=[-10+14 \times \alpha, 5-\alpha] \\
& B=[7+3 \times \alpha, \quad 15-5 \times \alpha]
\end{aligned}
$$

(Eq.4.25)

$$
\begin{gathered}
A(\div) B=[\min ((-10+14 \times \alpha) /(7+3 \times \alpha),(-10+14 \times \alpha) /(15-5) \times \alpha,(5-\alpha) /(7+3 \times \alpha), \\
(5-\alpha) /(15-5 \times a)) ; \max ((-10+14 \times \alpha) /(7+3 \times \alpha),(-10+14 \times \alpha) /(15-5 \times \alpha), \\
(5-\alpha) /(7+3 \times \alpha),(5-\alpha) /(15-5 \times \alpha))]
\end{gathered}
$$

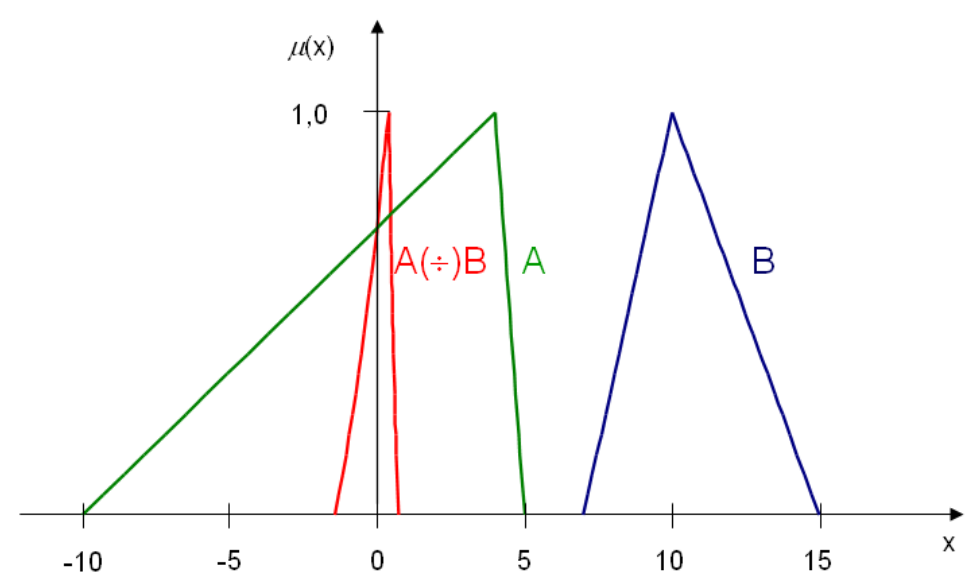

Figura 31 - Divisão entre os números Fuzzy A e B Fonte: BANHOLZER (2005)

\subsection{A ESTRUTURA LÓGICA EM SISTEMAS E MODELOS FUZZY}

A partir dos primeiros conceitos propostos por Zadeh até os dias atuais, muito se desenvolveu da Lógica Fuzzy, o que fez com que suas aplicações se estendessem à diversos tipos de sistemas e modelos. Este capítulo enfatiza sua utilização, em um 
primeiro momento, em um Sistema de Controle Fuzzy automático; a posteriori é apresentado um exemplo na avaliação de um investimento, que serve como base conceitual para modelo proposto no Estudo de Caso.

Como ponto de partida para sua aplicação, alguns conceitos utilizados na estruturação de modelos e sistemas Fuzzy devem ser ressaltados. A Figura 32 ilustra conceitos importantes do método e faz uma referência à Figura 5 do capítulo 2:
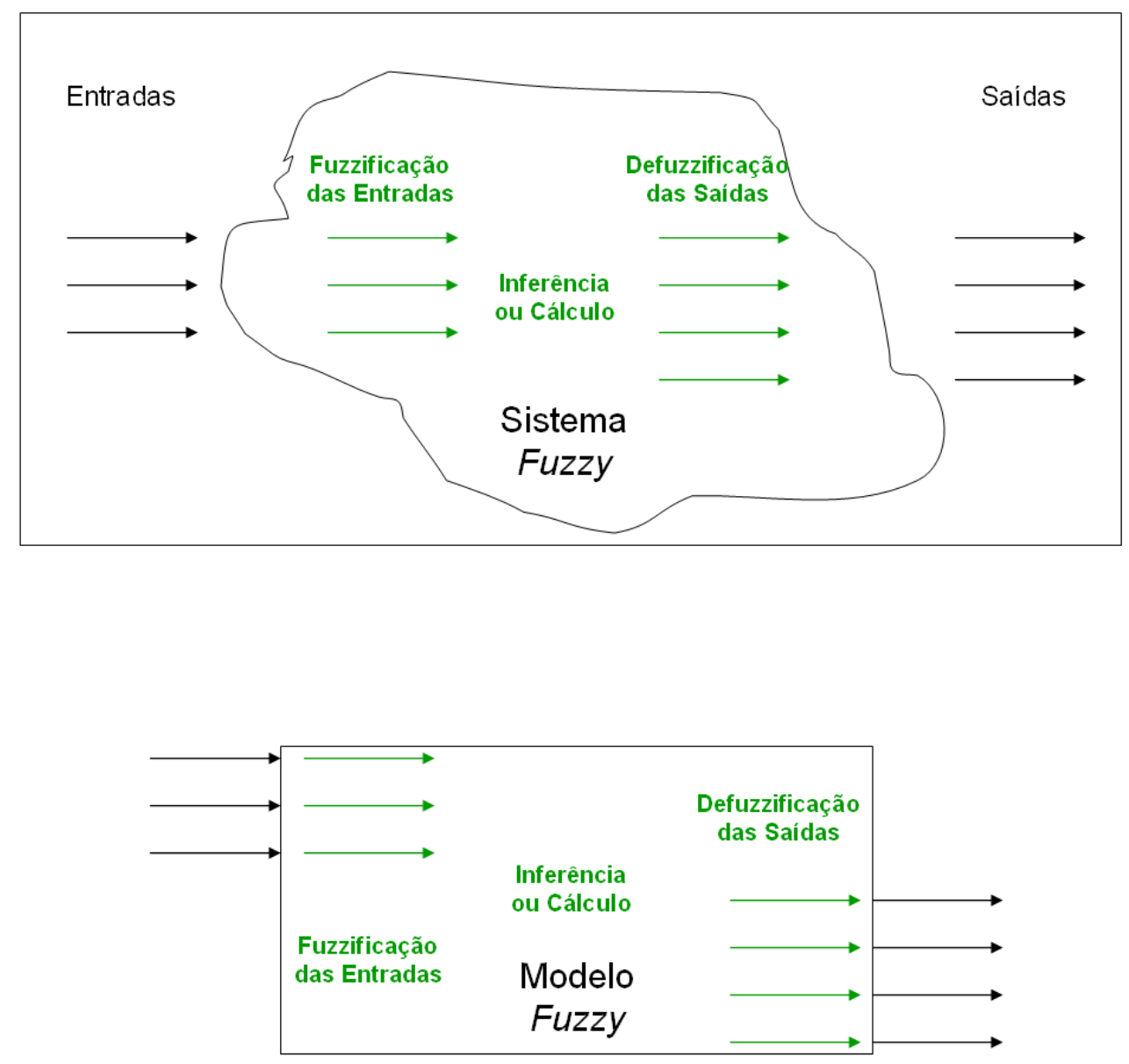

Figura 32 - Sistemas e Modelos Fuzzy

A "Fuzzificação" torna variáveis de entrada reais em variáveis Fuzzy. Estas variáveis fuzzificadas são utilizadas por meio de "Cálculos ou Inferências" baseados na matemática Fuzzy, que resultam em saídas para o sistema ou modelo. Por fim é realizada a "Defuzzificação", que torna as variáveis Fuzzy de saída obtidas em saídas 
reais, de maneira que possam ser interpretadas e utilizadas em ações ou aplicações subseqüentes.

A utilização de estruturas Fuzzy para "Inferência" apresenta diferenças significativas quando comparada a utilizações em "Cálculos". Desta forma uma breve diferenciação sobre as duas aplicações é exposta na Tabela 1; melhor esclarecida nos itens seguintes:

Tabela 1 - Diferenças básicas entre Cálculos e Inferências Fuzzy

\begin{tabular}{|c|c|c|}
\hline & Cálculo & Inferência \\
\hline Estrutura Principal & Operações Matemáticas Fuzzy. & $\begin{array}{l}\text { Estruturas lógicas: } \\
\text { - Se; } \\
\text { - Então. }\end{array}$ \\
\hline Fuzzificação & $\begin{array}{l}\text { Números Fuzzy representam } \\
\text { evento incerto. }\end{array}$ & $\begin{array}{l}\text { - Conjuntos numéricos Fuzzy } \\
\text { delimitam todos os valores } \\
\text { possíveis de entrada; } \\
\text { - Qualquer valor real pode } \\
\text { representar entrada no } \\
\text { Sistema. A partir daí ocorre a } \\
\text { fuzzificação, que transforma a } \\
\text { variável real em um vetor } \\
\text { Fuzzy. }\end{array}$ \\
\hline Defuzzificação & \multicolumn{2}{|c|}{$\begin{array}{l}\text { Resultado Fuzzy obtido é passível de interpretação ou serve } \\
\text { como resposta do sistema ou modelo. }\end{array}$} \\
\hline
\end{tabular}




\subsubsection{Fuzzificação}

Segundo Oliveira Júnior et al (2007) a Fuzzificação é feita para incorporar percepções a elementos ordinários, sendo realizada por meio de funções de pertinência que modelam a análise. Nesta etapa todas as informações relativas à imprecisão ou incertezas associadas devem ser consideradas.

Por exemplo, a variável linguiística, "Taxa de juros Selic Alta” poderia ser utilizada em Cálculo financeiro na forma de um número triangular Fuzzy, como na Figura 33. Neste caso, baseando-se nas informações econômicas e financeiras vigentes, o investidor supõe que a variação desta taxa de juros ao longo do investimento será representada pela função de pertinência triangular exposta na figura.

A Fuzzificação corresponde simplesmente em tornar o conceito "Taxa de Juros Selic Alta” em um número Fuzzy.

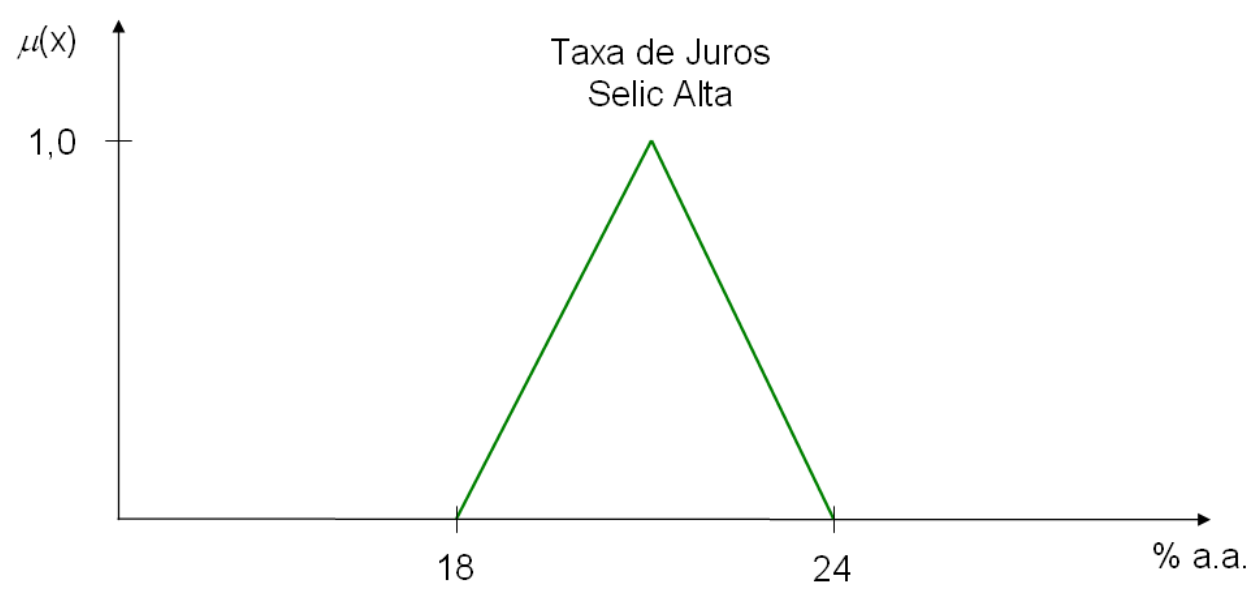

Figura 33 - Variável Lingüística Taxa de Juros Selic Alta. 
De maneira diferente das aplicações Fuzzy baseadas em cálculo, nos sistemas Fuzzy baseados em Inferência, usualmente representa-se uma determinada variável lingüística através de um conjunto de funções de pertinência, o qual representa todos os valores possíveis de entrada. A Figura 34 apresenta o conceito:

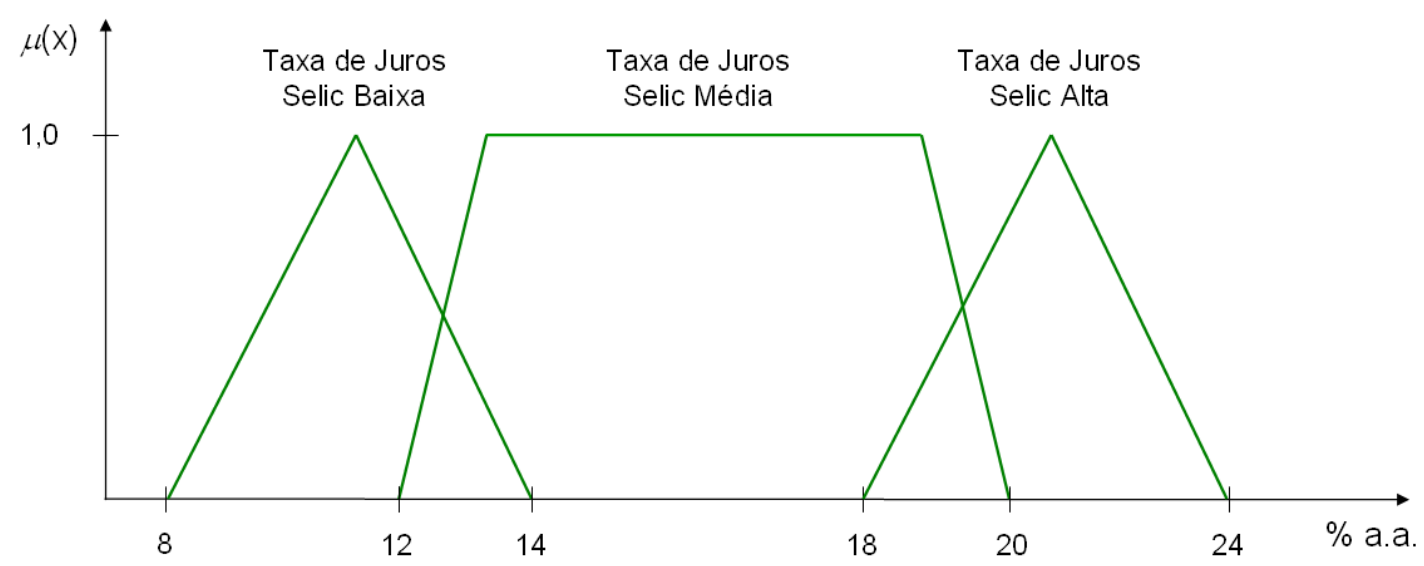

Figura 34 - Possíveis valores Taxa de Juros Selic

A Figura 34 serve como universo de discurso para qualquer entrada do sistema, ou seja, qualquer variável real possível no intervalo de $8 \%$ a $24 \%$ é passível de fuzzificação. Supõe-se que as estruturas apresentadas na figura sejam componentes de um software que faz inferências baseado no valor diário da Taxa de Juros Selic de Mercado, além de outras entradas, como valores de títulos e ações. A saída do software indica a melhor composição de um portifólio para um investidor em ativos para curtíssimo prazo.

Neste tipo de aplicação, a alimentação do sistema seria feita com valores diários da Taxa Selic no Mercado Financeiro. A cada dia um novo valor de entrada corresponderia à essa variável. A Figura 35 mostra a entrada no sistema quando a taxa referente é $13 \%$ a.a. 


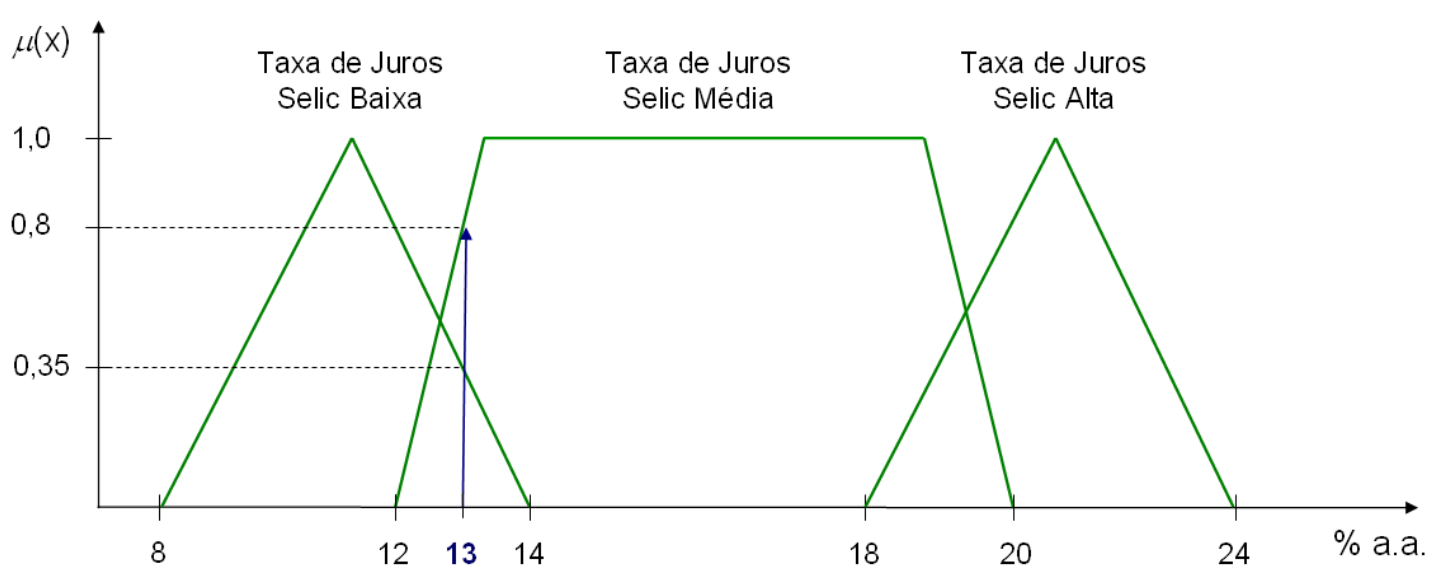

Figura 35 - Valor de entrada $13 \%$

O valor $13 \%$ pertence a dois dos números Fuzzy da Figura 35; o primeiro que se refere a "Taxa de Juros Selic Baixa", com pertinência 0.35 e o segundo referente a “Taxa de Juros Selic Média” com pertinência 0.8. Nota-se que a pertinência do valor 13\% ao número Fuzzy “Taxa de Juros Selic Alta” é igual a 0.

Assim, um "Vetor de Possibilidades" equivalente ao número discreto 13\% poderia ser representado por $\{0.35 ; 0.8 ; 0\}$ (SHAW e SIMÕES, 1999). Em suma, nos sistemas de Inferência, usualmente as entradas são Fuzzificadas através deste tipo de vetor.

\subsubsection{Defuzzificação}

Na Defuzzificação o valor da variável de saída inferida ou calculada será traduzida em um valor discreto. O objetivo é obter-se um único valor numérico discreto que melhor represente os valores Fuzzy obtidos da variável de saída, ou seja, da distribuição de possibilidades gerada. Assim a Defuzzificação é uma transformação inversa que traduz a saída do domínio Fuzzy para o domínio discreto (SHAW e SIMÕES, 1999). 
O mundo físico não "entende" números e conjuntos difusos, logo é necessário gerar grandezas abruptas que representem ou resumam da melhor maneira possível a informação contida nesses resultados (Oliveira Júnior, 1999).

Existem inúmeros métodos para realização da Defuzzificação, onde sua aplicabilidade varia de acordo com os tipos de aplicações em que a Lógica Fuzzy está sendo utilizada.

\section{- Defuzzificação pelo Centro da Área}

Este método também é conhecido como método do Centro de Gravidade, pois sua utilização se dá pelo cálculo do centróide da área composta que representa o termo Fuzzy obtido como saída sistema ou modelo (SHAW e SIMÕES, 1999).

A Figura 36 apresenta a saída de um controlador Fuzzy de potência de um motor em um sistema automático. Este exemplo será detalhado no item 4.4 deste capítulo. 


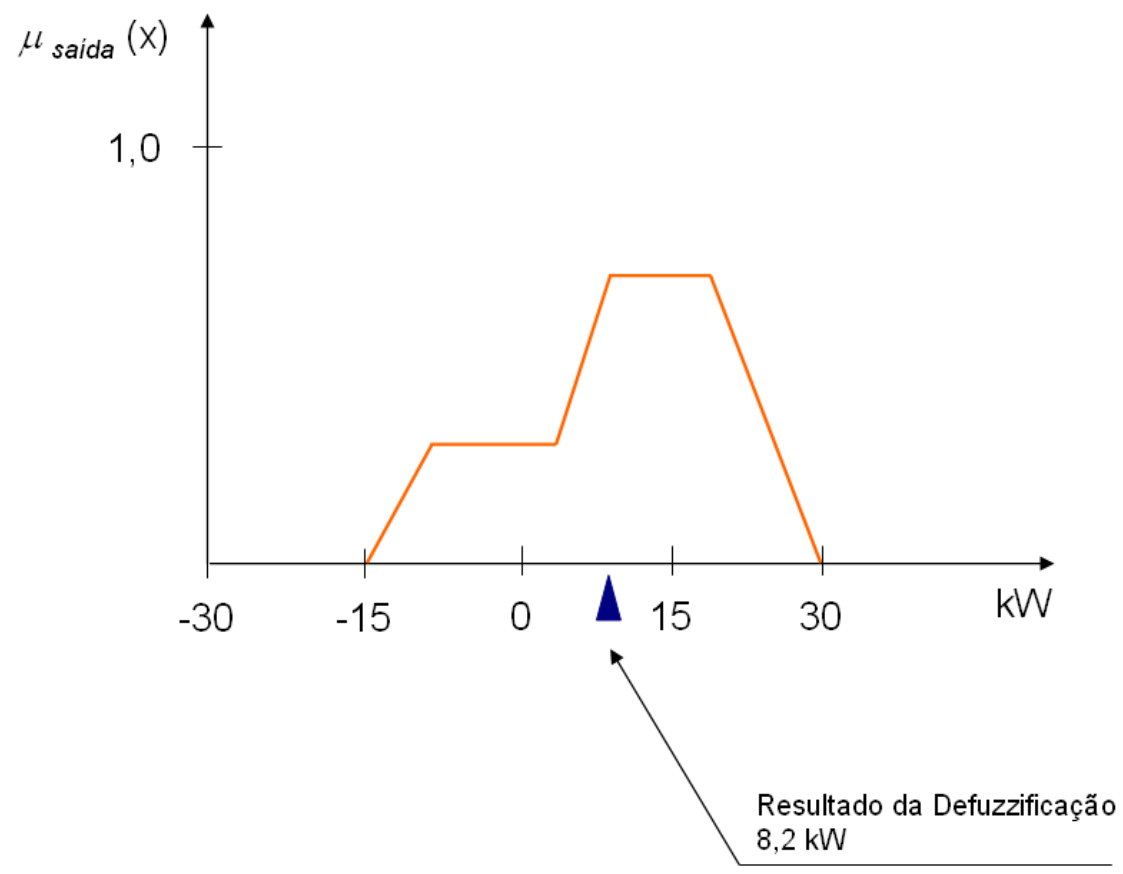

Figura 36 - Método de defuzzificação pelo Centro da Área

Fonte: Adaptado de SHAW e SIMÕES (1999).

O cálculo do centróide da área pode expresso da seguinte forma:

$$
x^{*}=\frac{\sum_{j=1}^{N} x_{j} \times \mu_{\text {saida }}(x)}{\sum_{j=1}^{N} \mu_{\text {saida }}(x)}
$$

Em que:

$x_{j}$ é o valor do valor real da variável em cada em cada situação $j$;

$\mu_{\text {saida }}(x)$ é o valor função de pertinência para valor real os cada valor real $x_{j}$; $N$ é o número de iterações utilizadas.

\section{- Defuzzificação pela Média dos Máximos}


Neste método os picos máximos das funções de pertinência são utilizados, enquanto a área é ignorada. Matematicamente é expresso por (SHAW e SIMÕES, 1999):

$$
x^{*}=\sum_{m=1}^{M} \frac{x_{m}}{M}
$$

Em que:

$x_{m}$ é o m-ésimo valor no inverso de discurso com pertinência máxima;

$M$ é o número total de valores com pertinência máxima.

A mesma saída fuzzificada, mostrada no item anterior, resultaria em uma menor potência do motor quando utilizando o método da Média dos Máximos, representado na Figura 37:

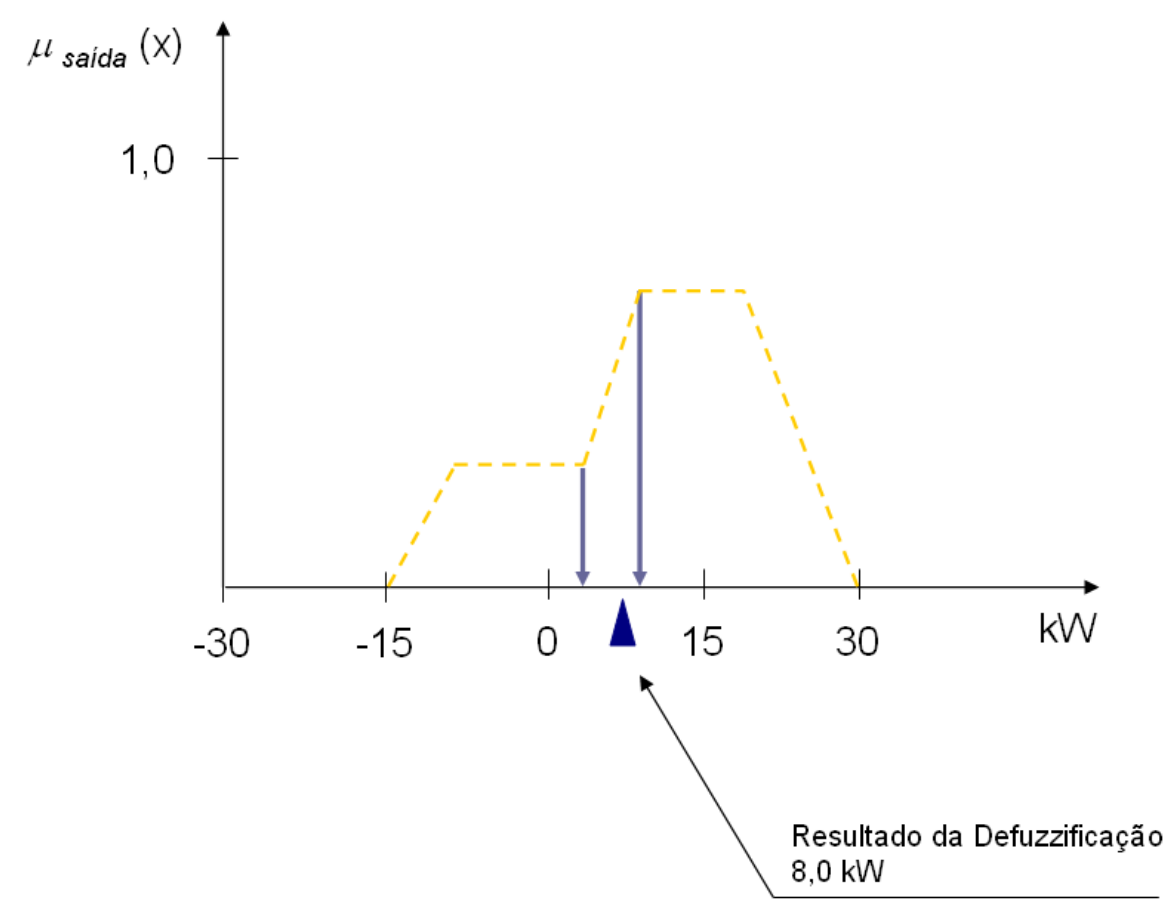

Figura 37 - Método de Defuzzificação pela Média do Máximo Fonte: Adaptado de SHAW e SIMÕES (1999) 


\section{- Defuzzificação pela Distribuição de Possibilidades Cumulativa}

Chiu e Park (1994) defendem o uso do cálculo de áreas para calcular a possibilidades da saída. Utilizando a saída fuzzificada apresentada nos exemplos anteriores poderia ser calculada a possibilidade do motor atuar em reverso, ou seja, apresentar potência negativa. Assim o valor seria obtido pela divisão da área que compreende os valores negativos na Figura 38 divididos pela área total.

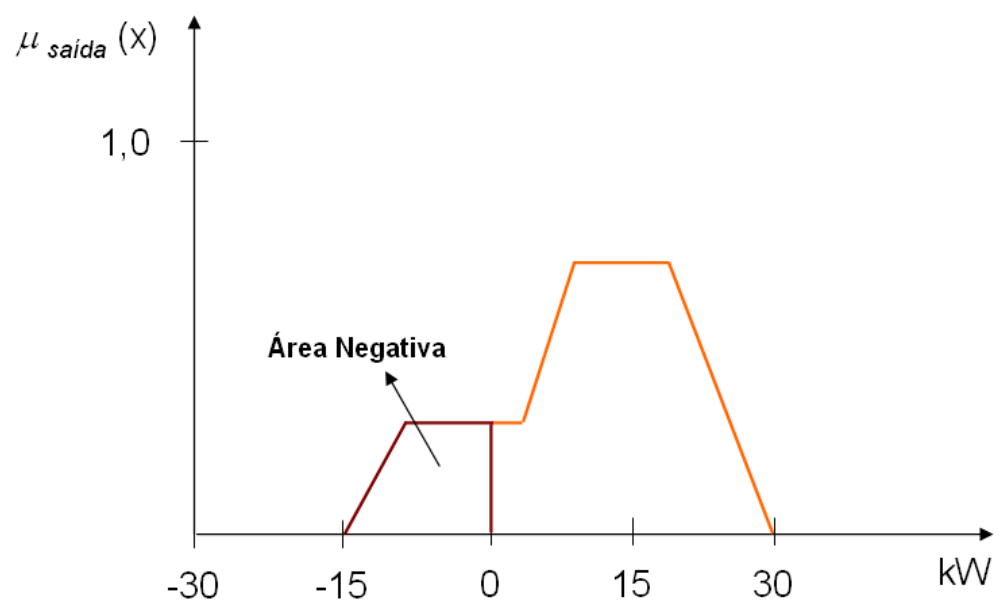

Figura 38 - Possibilidade Cumulativa

Desta forma:

$$
\mu *(x<0)=\frac{\int_{-15}^{0} \mu_{\text {saida }}(x)}{\int_{-15}^{30} \mu_{\text {saida }}(x)}
$$


Apesar de parecer pouco representativa, se aplicada no controle de um motor elétrico, a utilização da possibilidade cumulativa pode ser muito útil em aplicações onde se deseja fazer uso do VPL, pois através dela é possível calcular a possibilidade de sucesso ou insucesso de um investimento. Já os métodos do centróide e do centro do máximo podem ser úteis no cálculo do valor mais possível, ou seja, no caso do VPL, o retorno de maior possibilidade.

A escolha do método de Defuzzificação nos sistemas de apoio a decisão depende do contexto dessa decisão. Nas decisões qualitativas como alocação de recursos ou priorização de projetos é recomendado o uso centro do máximo (Shaw e Simões, 1999).

Apresentado os conceitos de Fuzzificação e Defuzzificação, uma lacuna surge no que diz respeito a maneira que cálculos ou inferências Fuzzy são efetuados. Pretende-se apresentar esses conceitos ainda inexplorados nos próximos tópicos do capítulo, onde são apresentados exemplos da aplicação da lógica.

\subsection{A APLICAÇÃO DA LÓGICA FUZZY EM UM SISTEMA DE CONTROLE}

Nas aplicações industriais e na engenharia de controle a Lógica Fuzzy ganhou aplicabilidade desde seu surgimento. Fora utilizada no controle automático de máquinas de lavar, controle de freios ABS, direção automática de trens, sistemas de transmissão automática de veículos, controle de tráfego urbano e rodoviário, sistemas de reconhecimento de voz e imagem, entre inúmeras outras aplicações (OLIVEIRA JÚNIOR, 1999). 
A ampla utilização industrial e em produtos de bens de consumo culminou no desenvolvimento de softwares para aplicação e equipamentos para automação. Na Europa e na Ásia principalmente, e com menor intensidade nos EUA, diversos fabricantes como Siemens, Allen-Bradley, AEG desenvolveram Controladores Lógicos Programáveis (CLP) com módulos específicos para a Lógica Fuzzy (SHAW e SIMÕES, 1999).

Os Controladores Lógicos Programáveis são dispositivos eletrônicos utilizados em sistemas de automação flexível. São ferramentas de trabalho muito úteis e versáteis para aplicações em sistemas de acionamentos e controle, e por isso são utilizados em grande escala no mercado industrial. Permitem desenvolver e alterar facilmente a lógica para acionamento das saídas em função das entradas. Desta forma, podese associar diversos sinais de entrada para controlar diversos atuadores ligados nos pontos de saída (Silva Filho, 2007).

O sistema de controle que será apresentado é aplicado em uma situação de automação. Trata-se de uma ponte rolante para contêineres, usada para carga e descarga em embarcações navais. A Figura 39 ilustra a situação: 


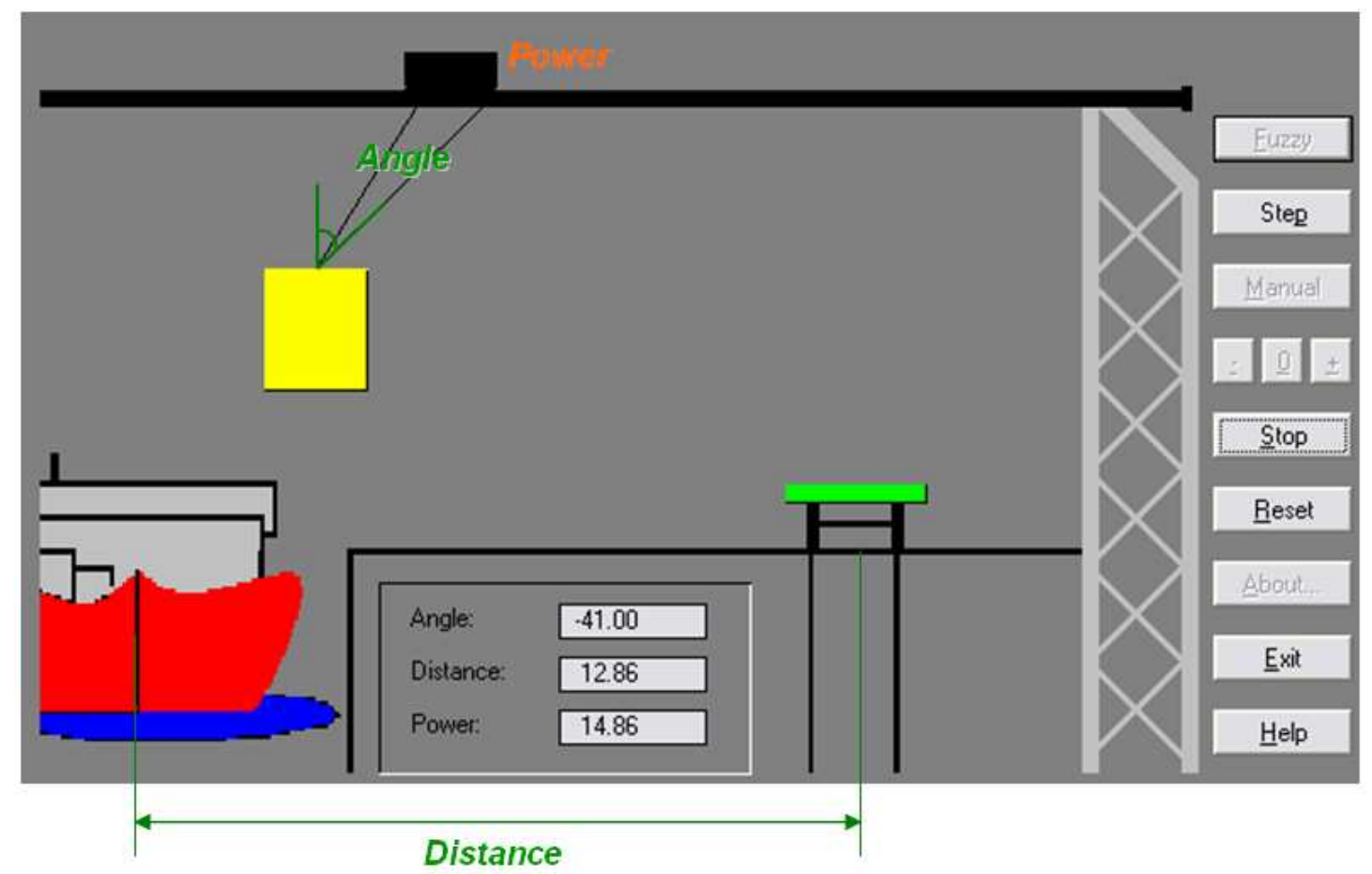

Figura 39 - Transporte para cargas portuárias Fonte: Adaptado de FUZZYTECH (2006)

A operação consiste em transportar contêineres ao longo da distância (distance) compreendida entre o navio e área de descarregamento. A dificuldade desta tarefa é que o contêiner é suspenso através de um cabo e a medida que há movimentação; forma-se um ângulo de abertura (angle) durante o transporte, gerando oscilação no sistema. À medida que a carga ganha velocidade, mais difícil se torna controlá-la, o que pode culminar em graves acidentes.

Deve-se levar em conta que trata-se de uma aplicação largamente usada em zonas portuárias, dessa forma a velocidade de descarregamento desses contêineres é um fator primordial, visto que afeta diretamente a produtividade logística e os custos operacionais. A velocidade do sistema está ligada à potência (power) do motor em operação.

Devido à dificuldade de automação por modelos físicos, usualmente esta tarefa era realizada manualmente por operadores humanos, o que também apresentava 
riscos, pois os mesmos caminhavam com os controladores em mãos, estando sujeitos a quedas ou algum deslize.

A aplicação da Lógica $F u z z y$ na automação desta operação é baseada na experiência humana neste controle. Subsidiada pelo raciocínio humano, a automação é realizada considerando apenas duas variáveis de entrada: distance e angle. Pela observação das entradas o operador controla power buscando velocidade no descarregamento.

O sistema Fuzzy para esse controle é baseado em inferências. A Figura 40 representa as entradas e saídas do sistema.

\section{Container Crane Controller}

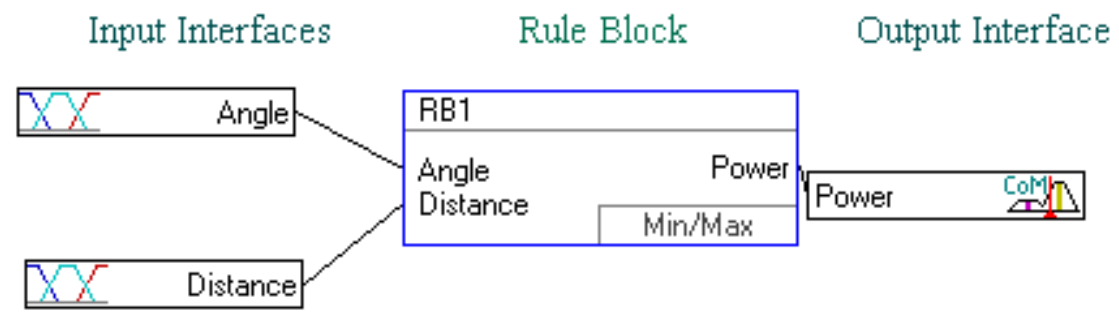

Figura 40 - Estrutura de Controle Fonte: FUZZYTECH (2006)

\section{- Fuzzificação das Variáveis}

Para fuzzificação das variáveis utiliza-se o conceito de vetor de possibilidades.

A Figura 41 representa a entrada da variável angle em graus. 


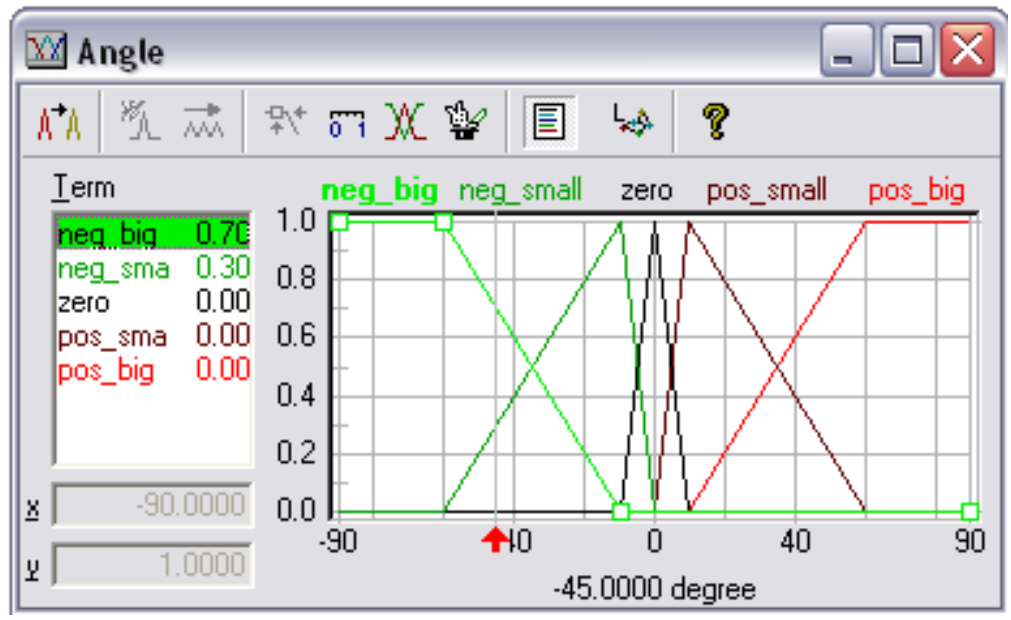

Figura 41 - Entrada da variável angle Fonte: FUZZYTECH (2006).

A seta vermelha representa a entrada angle em $-45^{\circ}$ que é fuzzificada em um vetor de possibilidades $\{0.70 ; 0.30 ; 0.00 ; 0.00 ; 0.00\}$. A pertinência do valor real ao número Fuzzy neg_big (negativo alto) é 0.70, sua pertinência à neg_small é 0.30 , enquanto a pertinência é nula quando considerado os outros números Fuzzy da figura.

A entrada distance com valor de 13.27 jardas é expressa pelo vetor Fuzzy $\{0.00 ; 0.00 ; 0.00 ; 0.73 ; 0.27\}$. Os números Fuzzy neg_close, zero, close, medium e far representam respectivamente os conceitos de perto à esquerda, na posição adequada, perto à direita, distância média à direita e longe à direita. A Figura 42 apresenta esta entrada.

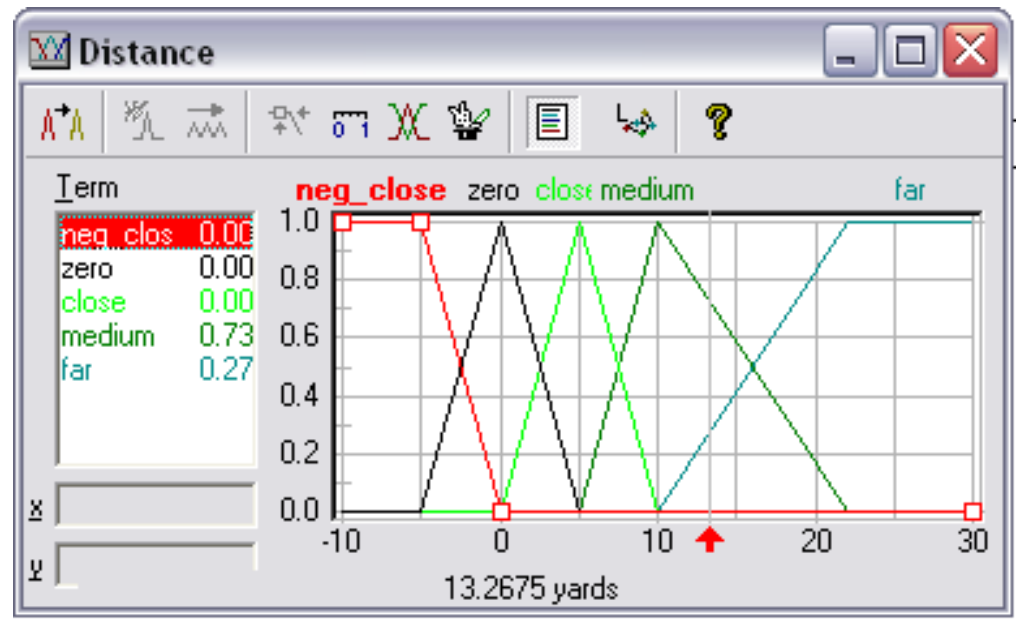

Figura 42 - Entrada da variável distance Fonte: FUZZYTECH (2006). 


\section{- A Inferência Fuzzy no Sistema}

$\mathrm{O}$ ato da inferência está relacionado ao processamento das variáveis de entrada de maneira a obter uma saída ou reposta fuzzyficada. Tal inferência é realizada através dos conectivos lógicos SE, E e ENTÃO. A Figura 43 exprime o conjunto de regras de inferência necessárias para o controle.

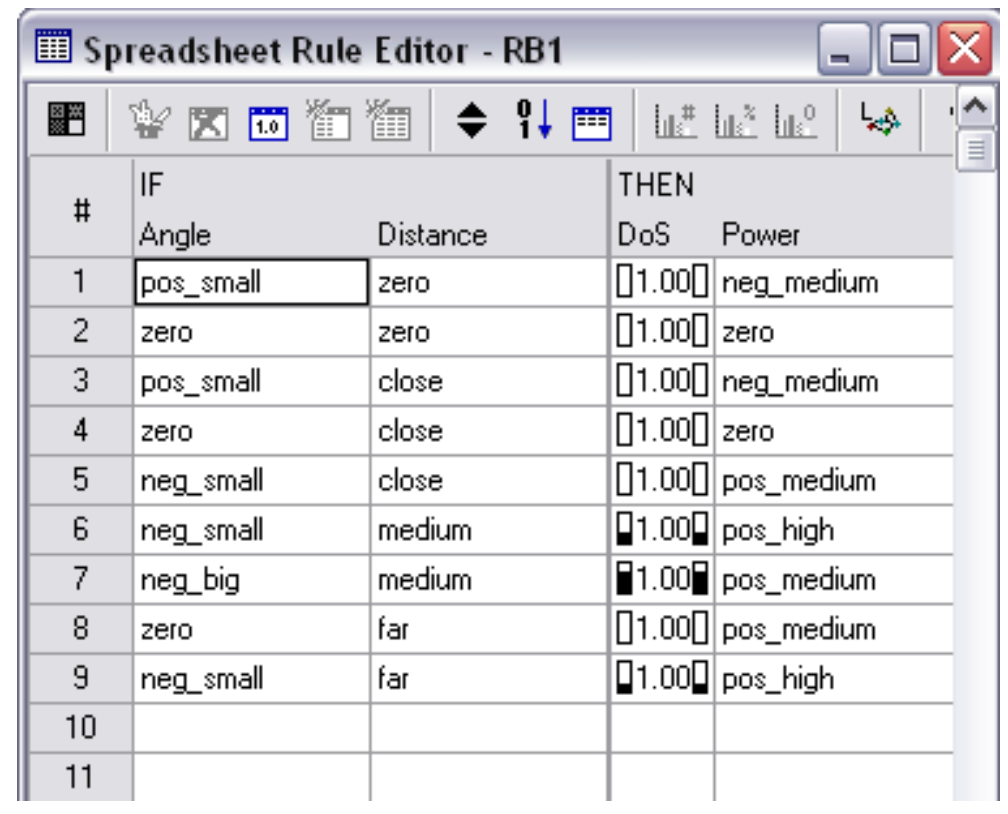

Figura 43 - Conjunto de regras para o sistema Fonte: FUZZYTECH (2006)

Nesta aplicação, em uma situação em que o sistema apresenta um ângulo levemente negativo e o contêiner está próximo do ponto de descarregamento, a saída do sistema power é levemente negativa, conforme a regra 5.

Para que a inferência seja feita, considera-se os valores dos vetores de possibilidade onde a combinação entre seus mínimos resultam em saídas fuzzificadas. Quando a entrada angle é $-45^{\circ}$, esta apresenta possibilidade 0.70 em neg_small e 0.30 em neg_big. Trata-se então das possibilidade separadamente: 
- o ângulo de abertura $-45^{\circ}$ é pequeno e negativo (neg_small). Sua intensidade é 0.30 ;

- o ângulo de abertura $-45^{\circ}$ é grande e negativo (neg_big). Sua intensidade é 0.70 .

A outra entrada mostra a distância em que o contêiner está do ponto de descarregamento. Conforme Figura 41, quando a distância é 13.27 jardas o vetor de possibilidades representa que:

- a distância 13.27 jardas é média (medium) com intensidade 0.73 ;

- a distância 13.27 jardas é longa (far) com intensidade 0.27 .

Desta forma, o resultado Fuzzy da potência do motor é obtido combinando as duas entradas, onde a pertinência resultante é obtida pelo menor valor de pertinência entre elas. Utilizando o bloco de regras da Figura 43 obtêm-se a resposta do sistema:

Tabela 2 - Inferência do sistema

\begin{tabular}{|c|c|c|c|c|c|c|}
\hline \multirow{2}{*}{ Regras } & \multicolumn{2}{|c|}{ SE } & \multicolumn{2}{c|}{$\mathrm{c}$} & \multicolumn{2}{c|}{ ENTÃO } \\
\cline { 2 - 7 } & Angle & $\mu_{\text {angle }}$ & Distance & $\mu_{\text {distance }}$ & Power & $\mu_{\text {power }}$ \\
\hline 6 & neg_small & 0.30 & medium & 0.73 & pos_high & 0.30 \\
\hline 7 & neg_big & 0.70 & medium & 0.73 & pos_medium & 0.70 \\
\hline 9 & neg_small & 0.70 & far & 0.27 & pos_high & 0.27 \\
\hline
\end{tabular}


Apenas 3 entre 9 regras presentes na Figura 43 foram utilizadas, isto porque, $\mu_{\text {power }}$ é obtida pelo menor valor entre $\mu_{\text {angle }}$ e $\mu_{\text {distance }}$. Assim quando alguma destas pertinências é nula, $\mu_{\text {power }}$ também é.

Quando não há regra para uma situação corrente, não há saída no sistema e a potência permanece inalterada.

Assim como para as entradas angle e distance, a saída Fuzzy é realizada através de uma série de números Fuzzy (neg_high, neg_medium, zero, pos_medium e pos_high) que representam a potência do motor. Observando-se a Tabela 2 na regra 7; a saída inferida é uma potência pos_medium com pertinência é 0.70 , visualizada geometricamente pela Figura 44:

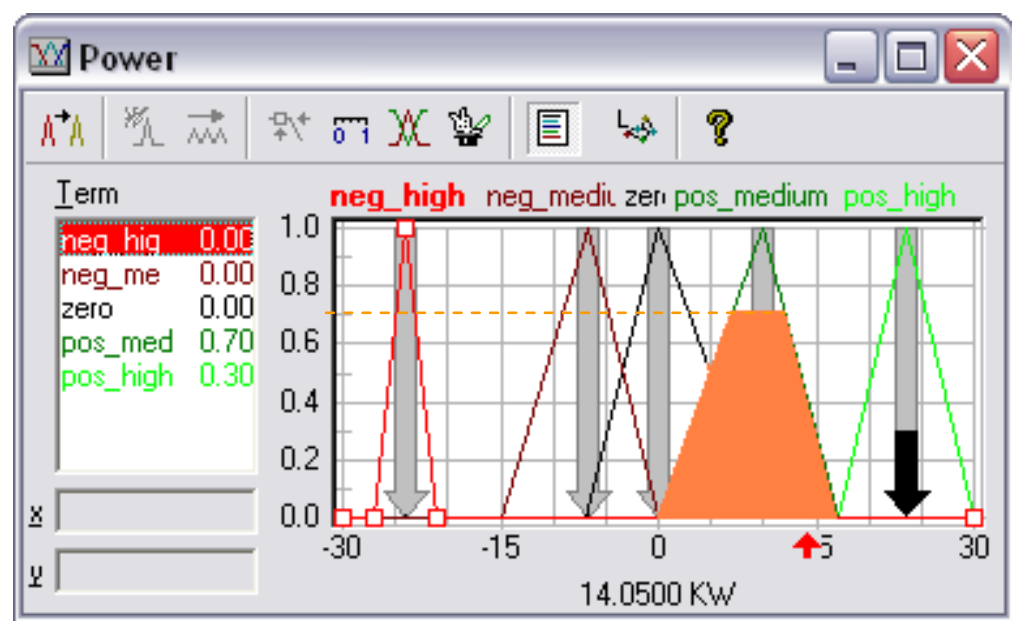

Figura 44 - Potência pos_medium com pertinência 0.70 Fonte: Adaptado de FUZZYTECH (2006).

Na realidade a resposta da inferência precisa ser composta pela combinação de todas as regras. Assim, a figura geométrica resultante da inferência é composta pela união das áreas geradas nas regras 6,7 e 9. Tal saída é conhecida como resposta fuzzificada, apresentada na Figura 45: 


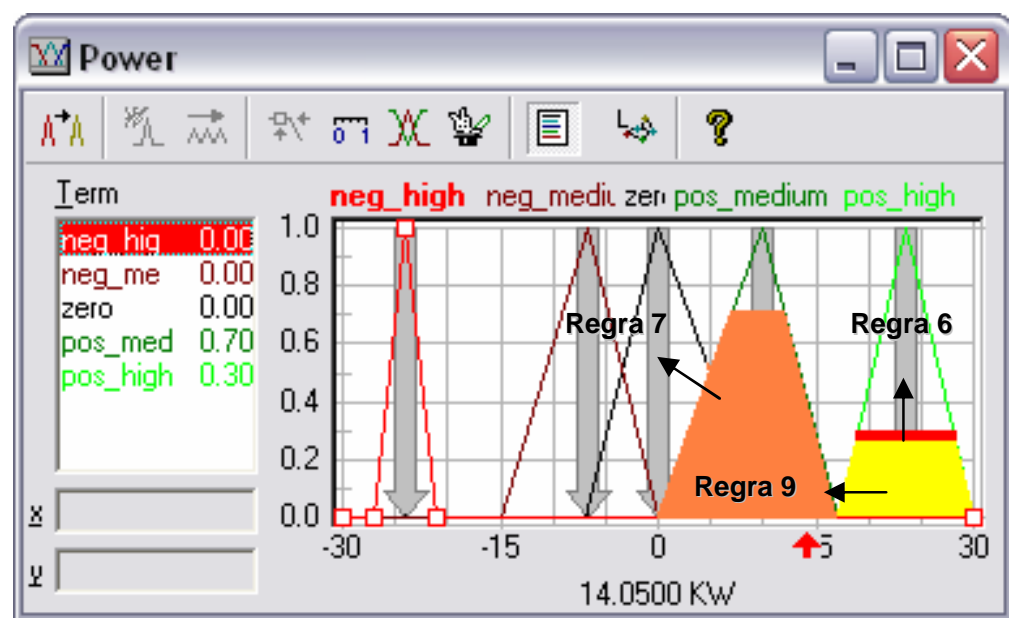

Figura 45 - Resultado fuzzificado da power" Fonte: Adaptado de FUZZYTECH (2006).

Este método de inferência é denominado por Shaw e Simões (1999) como de Mínimo-Máximo (Min-Max).

\section{- A Defuzzificação das Variáveis}

Obtida a saída fuzzificada faz-se necessário torna-lá uma variável real para que seja emitido o sinal de saída do controlador para o atuador. O método de defuzzificação é o da Média dos Máximos, que resulta um valor de 14.0500 kW.

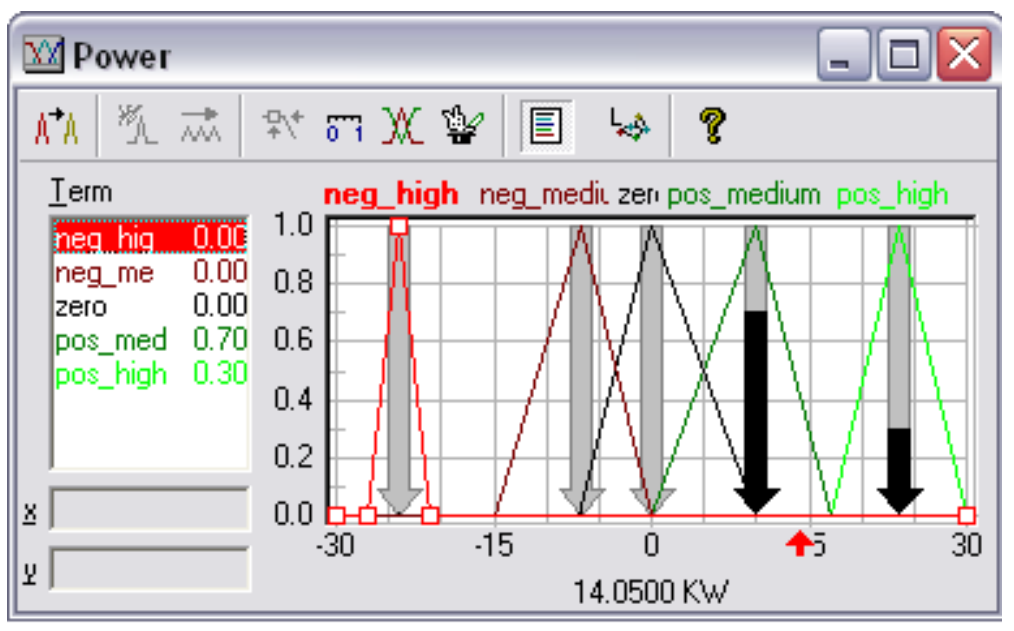

Figura 46 - Valor defuzzificado de power : $14.0500 \mathrm{~kW}$ Fonte: Adaptado de FUZZYTECH (2006). 
A cada instante os valores de angle e distance se alteram devido a movimentação, a cada variação nas entradas a inferência é realizada, o que resulta em um novo valor para power, ou seja, o controle é contínuo.

A aplicação apresentada faz parte de exemplos presentes nos software Fuzzytech 5.60, que apresenta versão demonstrativa para download no site $^{6}$ do fabricante.

Apesar de não ser tratada diretamente no estudo de caso, a utilização da Lógica Fuzzy para inferências é amplamente utilizada, seja em aplicações de controle, como em sistemas de apoio a decisão, portanto fez-se necessária sua apresentação no trabalho.

\subsection{A APLICAÇÃO DO VALOR PRESENTE LÍQUIDO FUZZY NA AVALIAÇÃO ECONÔMICO-FINANCEIRA DE INVESTIMENTOS}

A capacidade de relacionar a incerteza fez com que os conceitos Fuzzy ganhassem notoriedade e aplicabilidade em outras áreas do conhecimento. $\mathrm{Na}$ área financeira é crescente a quantidade de trabalhos e aplicações, a literatura internacional contempla livros específicos do uso da Lógica Fuzzy em finanças. Von Altrock (1995) e Gil-Lafuente (2005) apresentam aplicações diversas, como o uso na concessão de crédito e na detecção de fraudes.

No Brasil ainda são escassos os trabalhos que promovem o uso da Lógica Fuzzy na área financeira, porém este cenário está mudando. Borba e Dill (2007) mostram sua aplicação na análise de rentabilidade de empresas, onde o balanço patrimonial das mesmas é o objeto de estudo. Banholzer (2005) propõe o cálculo da

\footnotetext{
${ }^{6}$ www.fuzzytech.com
} 
Taxa Interna de Retorno através do cálculo Fuzzy. Medeiros (2003) apresenta em sua dissertação um estudo para avaliação de viabilidade de um projeto de um campo de golfe público, levando em conta a ordenação de fatores ambientais, econômicos e sociais.

Neste trabalho o intuito é calcular o VPL através da Lógica Fuzzy de modo com que as incertezas presentes no investimento sejam incorporadas ao cálculo. Gutiérrez (1989) apresenta a primeira formulação para a aplicação de números Fuzzy para o cálculo do Valor Presente Líquido. Em seu trabalho os fluxos de caixa por período $(F C)$ e a taxa de desconto de um investimento por período( $i$ ) são representados por números triangulares Fuzzy, tratando a incerteza presente como léxica.

$$
\begin{gathered}
F C=\left[F C^{l(\alpha)} ; F C^{r(\alpha)}\right] \\
{ }_{i}=\left[i^{l(\alpha)} ; i^{r(\alpha)}\right]
\end{gathered}
$$

Como resultado dos cálculos, fora apresentado um número Fuzzy de formato próximo a um triangular que constituía a função Valor Presente Líquido Fuzzy (VPL $\left.L_{F u z z y}\right)$. No entanto o trabalho de Gutierréz (1989) apresentava certa dificuldade para interpretação dos resultados, já que a saída do modelo era na verdade um valor fuzzificado. 


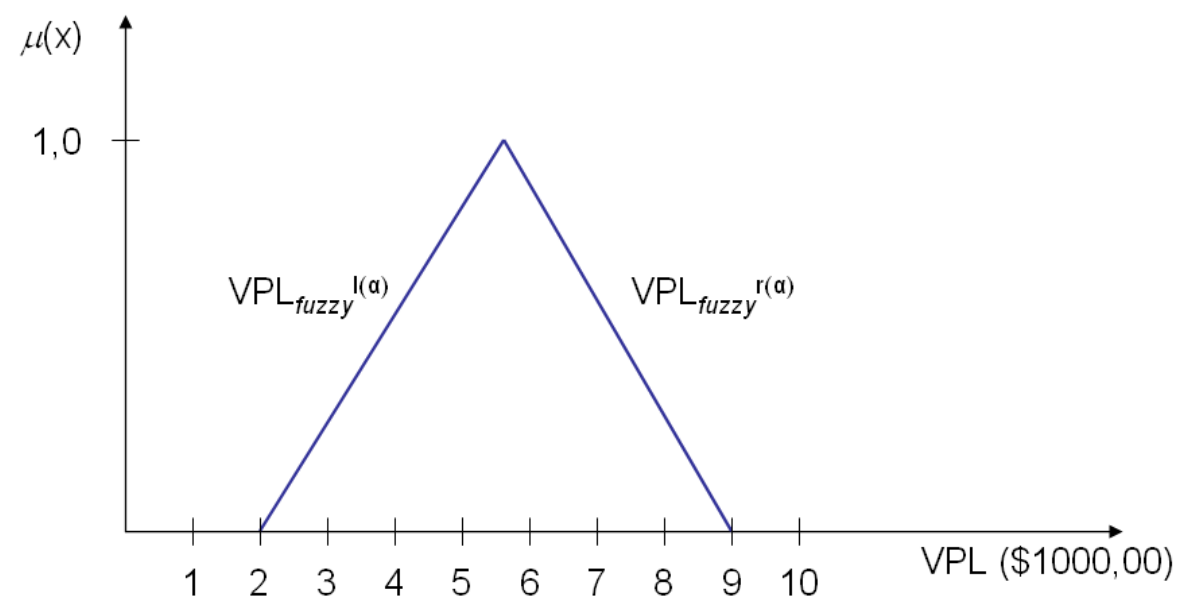

Figura 47 - VPL obtido em um investimento onde fora utilizado taxas de descontos e fluxos caixa Fuzzy

Fonte: Adaptado de GUTIERRÉZ(1989)

A dificuldade de interpretação do VPL resultante na Figura 47 é acentuada quando se deseja a comparação entre vários investimentos, visto que o ato de comparar valores fuzzificados pode exigir certo cuidado matemático.

Chiu e Park (1994) apresentam um método para defuzzificação para o VPL $_{F u z z y}$, além de reestruturar a formulação proposta por Guiterréz (1989), tornandose um dos trabalhos mais conceituados para a aplicação da Lógica Fuzzy como instrumento para avaliação de investimentos. A formulação de Chiu e Park (1994) éapresentada em duas etapas distintas; a primeira refere-se ao cálculo do lado esquerdo da função $\left(V P L_{f u z z y}^{l(\alpha)}\right)$ e posteriormente o lado direito $\left(V P L_{f u z z y}^{r(\alpha)}\right)$, de maneira que:

$$
V P L_{f u z z y}=\left\lfloor V P L_{f u z z y}^{l(\alpha)} ; V P L_{f u z z y}^{r(\alpha)}\right\rfloor
$$


A função $\operatorname{VPL}_{F u z z y}^{l(\alpha)}$ representa os piores resultados possíveis para o investimento em questão. Para seu cálculo é necessário considerar três situações possíveis para o fluxo de caixa:

I. Para $F C_{j}^{l(\alpha)}>0$ em $n$ períodos;

$$
\begin{gathered}
V P L_{f u z z y}^{l(\alpha)}=F C_{0}^{l(\alpha)}+\frac{F C_{1}^{l(\alpha)}}{\left(1+i_{1}^{r(\alpha)}\right)}+\frac{F C_{2}^{l(\alpha)}}{\left(1+i_{2}^{r(\alpha)}\right)}+\ldots+\frac{F C_{n}^{l(\alpha)}}{\left(1+i_{n}^{r(\alpha)}\right)} \\
V P L_{f u z z y}^{l(\alpha)}=\sum_{j=0}^{n}\left(\frac{F C_{j}^{l(\alpha)}}{\prod_{j^{\prime}=0}^{j}\left(1+i_{j}^{r(\alpha)}\right)}\right), \text { onde } i_{0}^{r(\alpha)}=0
\end{gathered}
$$

II. Para $F C_{j}^{l(\alpha)}<0$ em $n$ períodos;

$$
\begin{gathered}
V P L_{f u z z y}^{l(\alpha)}=F C_{0}^{l(\alpha)}+\frac{F C_{1}^{l(\alpha)}}{\left(1+i_{1}^{l(\alpha)}\right)}+\frac{F C_{2}^{l(\alpha)}}{\left(1+i_{2}^{l(\alpha)}\right)}+\ldots+\frac{F C_{n}^{l(\alpha)}}{\left(1+i_{n}^{l(\alpha)}\right)} \\
V P L_{f u z z y}^{l(\alpha)}=\sum_{j=0}^{n}\left(\frac{F C_{j}^{l(\alpha)}}{\prod_{j^{\prime}=0}^{j}\left(1+i_{j}^{l(\alpha)}\right)}\right), \text { onde } i_{0}^{l(\alpha)}=0
\end{gathered}
$$

III. Para $F C_{j}^{l(\alpha)}=0$ em $n$ períodos; 


$$
\begin{aligned}
& V P L_{f u z z y}^{l(\alpha)}=\frac{0}{\left(1+i_{n}^{r(\alpha)}\right)} \Rightarrow V P L_{f u z z y}{ }^{l(\alpha)}=0 \\
& V P L_{f u z z y}^{l(\alpha)}=\frac{0}{\left(1+i_{n}^{l(\alpha)}\right)} \Rightarrow V P L_{f u z z y}^{l(\alpha)}=0
\end{aligned}
$$

Ou seja, esta situação não influencia o cálculo.

Representando-se I e II na mesma função:

$$
V P L_{f u z z y}^{l(\alpha)}=\sum_{j=0}^{n}\left(\frac{\max \left(F C_{j}^{l(\alpha)}, 0\right)}{\prod_{j^{\prime}=0}^{j}\left(1+i_{j}^{r(\alpha)}\right)}+\frac{\min \left(F C_{j}^{l(\alpha)}, 0\right)}{\prod_{j^{\prime}=0}^{j}\left(1+i_{j}^{l(\alpha)}\right)}\right)
$$

\subsubsection{Cálculo de VPL ${ }_{\text {Fuzzy }}{ }^{\mathbf{r}(\alpha)}$}

O intuito do $\operatorname{VPL}_{F u z z y}{ }^{r(\alpha)}$ é representar as possíveis combinações das funções Fuzzy $F C$ e $i$, de maneira a função gerada represente os melhores resultados para o investimento em questão. Sua estruturação é realizada pelas situações IV, V e VI:

IV. Para $F C_{j}^{r(\alpha)}>0$ em $n$ períodos;

$$
V P L_{f u z z y}^{r(\alpha)}=F C_{0}^{r(\alpha)}+\frac{F C_{1}^{r(\alpha)}}{\left(1+i_{1}^{l(\alpha)}\right)}+\frac{F C_{2}^{r(\alpha)}}{\left(1+i_{2}^{l(\alpha)}\right)}+\ldots+\frac{F C_{n}^{r(\alpha)}}{\left(1+i_{n}^{l(\alpha)}\right)}
$$




$$
V P L_{f u z z y}^{r(\alpha)}=\sum_{j=0}^{n}\left(\frac{F C_{j}^{r(\alpha)}}{\prod_{j^{\prime}=0}^{j}\left(1+i_{j}^{l(\alpha)}\right)}\right), \text { onde } i_{0}^{l(\alpha)}=0
$$

V. Para $F C_{j}^{r(\alpha)}<0$ em $n$ períodos;

$$
\begin{gathered}
V P L_{f u z z y} r(\alpha)=F C_{0}^{r(\alpha)}+\frac{F C_{1}^{r(\alpha)}}{\left(1+i_{1}^{r(\alpha)}\right)}+\frac{F C_{2}^{r(\alpha)}}{\left(1+i_{2}^{r(\alpha)}\right)}+\ldots+\frac{F C_{n}^{r(\alpha)}}{\left(1+i_{n}^{r(\alpha)}\right)} \\
V P L_{f u z z y}^{r(\alpha)}=\sum_{j=0}^{n}\left(\frac{F C_{j}^{r(\alpha)}}{\prod_{j^{\prime}=0}^{j}\left(1+i_{j}^{r(\alpha)}\right)}\right), \text { onde } i_{0}^{r(\alpha)}=0
\end{gathered}
$$

VI. Para $F C_{j}^{r(\alpha)}=0$ em $n$ períodos;

$$
\begin{aligned}
& V P L_{f u z z y}^{r(\alpha)}=\frac{0}{\left(1+i_{1}^{l(\alpha)}\right)} \Rightarrow V P L_{f u z z y}^{r(\alpha)}=0 \\
& V P L_{f u z z y}^{r(\alpha)}=\frac{0}{\left(1+i_{1}^{r(\alpha)}\right)} \Rightarrow V P L_{f u z z y}^{r(\alpha)}=0
\end{aligned}
$$

Também não há influência sobre o cálculo.

Representando IV e V na mesma função tem-se: 


$$
V P L_{f u z z y}^{r(\alpha)}=\sum_{j=0}^{n}\left(\frac{\max \left(F C_{j}^{r(\alpha)}, 0\right)}{\prod_{j^{\prime}=0}^{j}\left(1+i_{j}^{l(\alpha)}\right)}+\frac{\min \left(F C_{j}^{r(\alpha)}, 0\right)}{\prod_{j^{\prime}=0}^{j}\left(1+i_{j}^{r(\alpha)}\right)}\right)
$$

\subsubsection{O Valor Presente Líquido Fuzzy}

Através da combinação entre as funções $V P L_{f u z z y}^{l(\alpha)}$ e $V P L_{f u z z y}^{r(\alpha)}$ no intervalo de pertinência de 0 a 1 tem-se:

(Eq.4.46)

$V P L_{f u z z y}=\left[\sum_{j=0}^{n}\left(\frac{\max \left(F C_{j}^{l(\alpha)}, 0\right)}{\prod_{j^{\prime}=0}^{j}\left(1+i_{j}^{r(\alpha)}\right)}+\frac{\min \left(F C_{j}^{l(\alpha)}, 0\right)}{\prod_{j^{\prime}=0}^{j}\left(1+i_{j}^{l(\alpha)}\right)}\right) ; \sum_{j=0}^{n}\left(\frac{\max \left(F C_{j}^{r(\alpha)}, 0\right)}{\prod_{j^{\prime}=0}^{j}\left(1+i_{j}^{l(\alpha)}\right)}+\frac{\min \left(F C_{j}^{r(\alpha)}, 0\right)}{\prod_{j^{\prime}=0}^{j}\left(1+i_{j}^{r(\alpha)}\right)}\right)\right]$

Para ilustrar sua aplicação um exemplo simplificado é mostrado a seguir. Através da opinião de especialistas e análise mercadológica tem-se estimativas dos componentes de caixa de um determinado investimento:

- Investimento: $\mathrm{R} \$ 280.000,00$, com variação estimada entre $-10 \%$ a $+15 \%$;

- Retorno Esperado: $\mathrm{R} \$ 240.000,00$, com variação estimada entre $\pm 15 \%$;

- Taxa mínima de Atratividade: $15 \%$ a.a., variando $\pm 2 \%$;

- Valor residual: nulo para este exemplo;

- Vida econômica: 3 anos. 


\subsubsection{Fuzzificação do Fluxo de Caixa}

Realizar a fuzzificação significa escrever as variáveis em números Fuzzy. O Investimento pode ser transformado em um número triangular Fuzzy conforme as Figura 48:

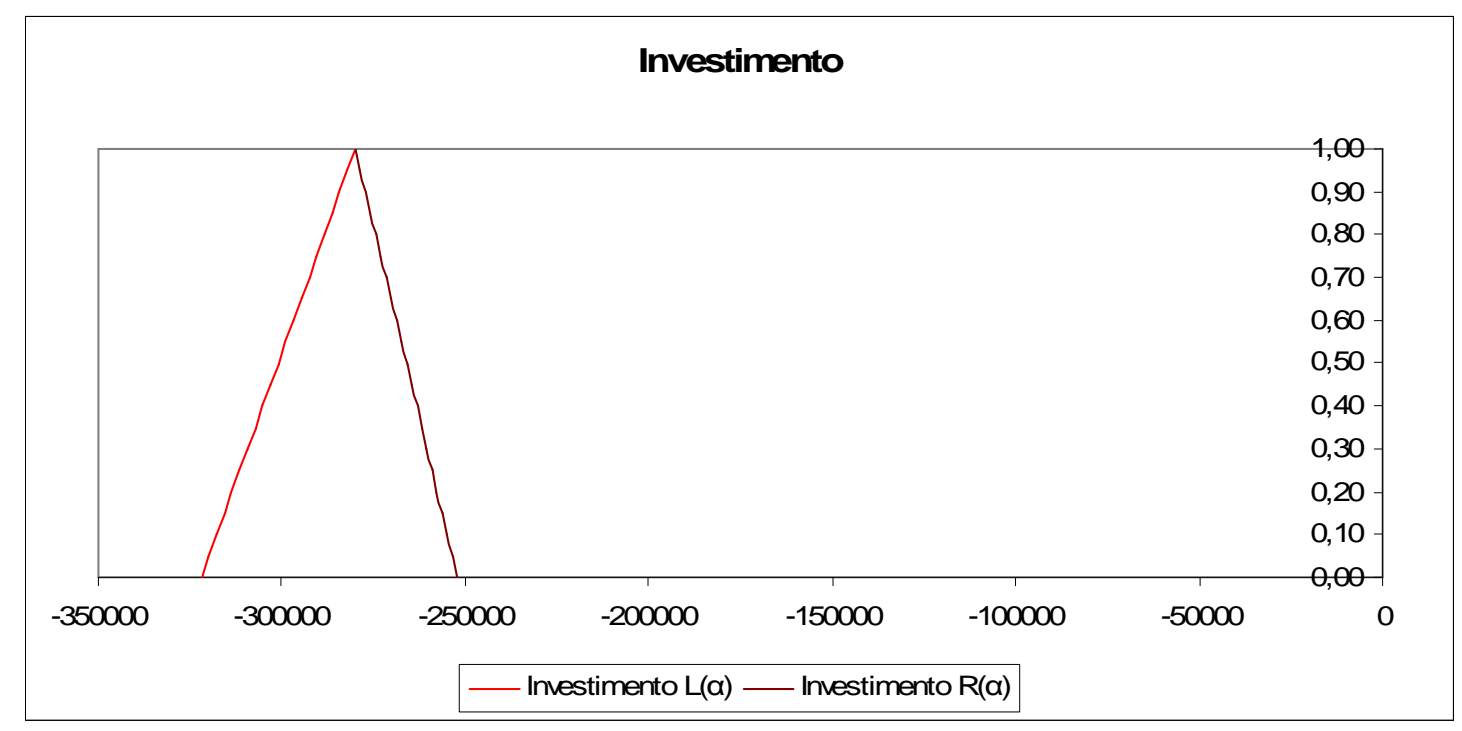

Figura 48 - Investimento fuzzificado

Matematicamente o Investimento pode ser representado da seguinte forma:

$$
\text { Investimento }=(-322000,-280000,-252000)
$$

Utilizando-se da representação por $\alpha$-cut tem-se:

$$
\text { Investimento }=[-322000+42000 \times \alpha ; \quad-28000 \times \alpha-252000]
$$

O Retorno Esperado pode ser representado matematicamente por: 
Retorno Esperado $=[204000+36000 \times \alpha ;-36000 \times \alpha+276000] \quad($ Eq.450)

Graficamente as funções que definem o Retorno Esperado Fuzzy são mostradas na Figura 49:

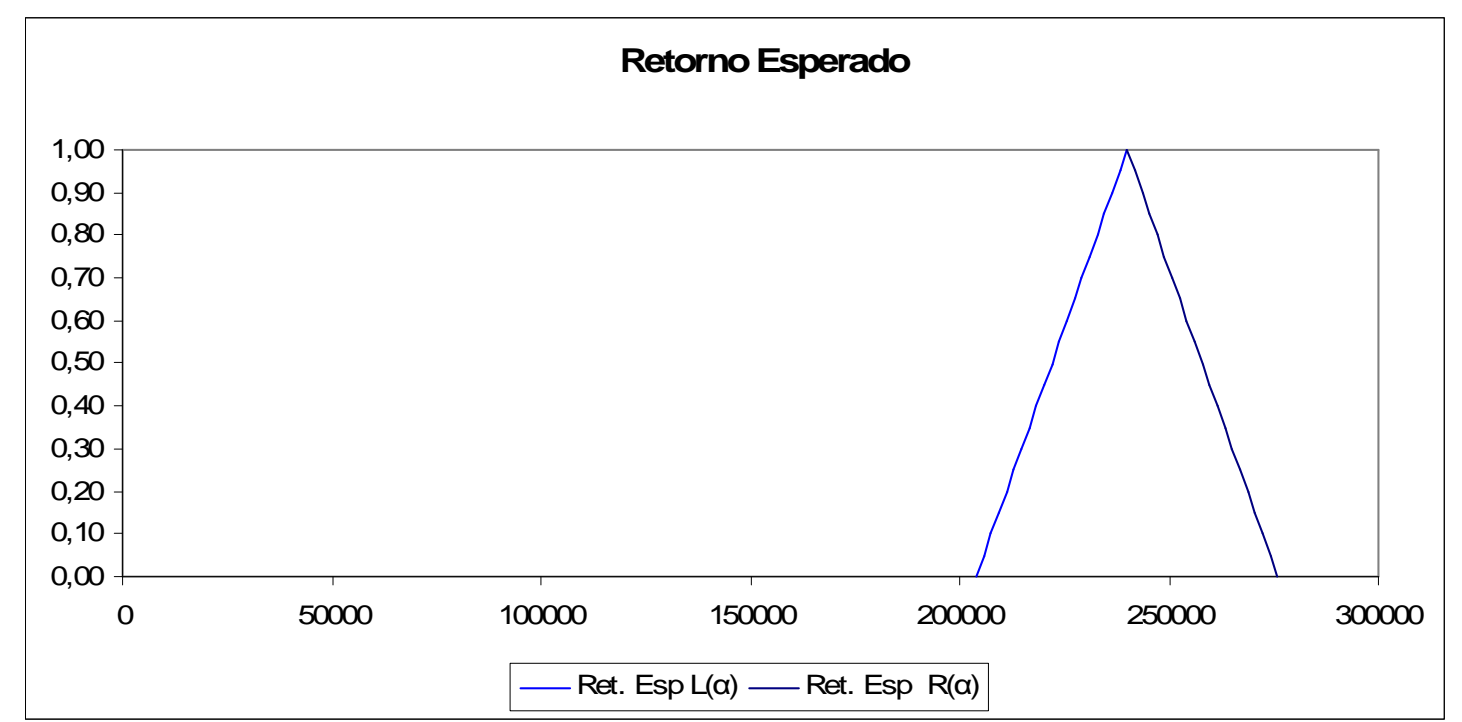

Figura 49 - Retorno Esperado Fuzzy

A Taxa Mínima de Atratividade a ser utilizada para o cálculo do $V P L_{F u z z y}$ é expressa matematicamente por:

$$
\begin{gathered}
T M A=(0.130,0.150,0.170) \\
T M A=[0.130+0.020 \times \alpha ;-0.020 \times \alpha+0.170]
\end{gathered}
$$

A Figura 50 mostra sua representação como um número triangular Fuzzy: 


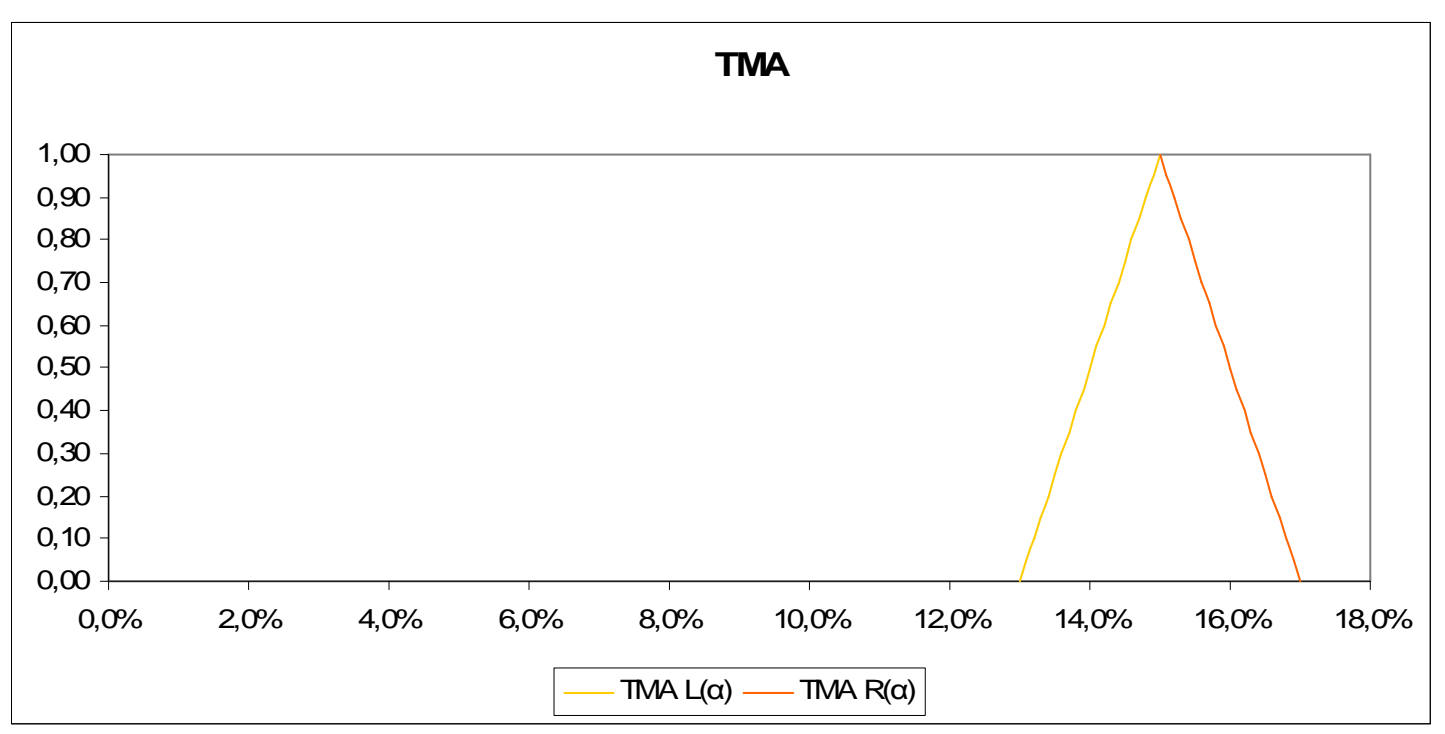

Figura 50 - A TMA fuzzificada

\subsubsection{Cálculo do VPL Fuzzy}

Uma vez obtidas as variáveis Fuzzy presentes no investimento, dá-se a etapa de cálculo do $V P L_{f u z z y}$. Utilizando a formulação proposta por Chiu e Park (1994), tem-se:

(Eq.4.53)

$$
\begin{gathered}
V P L_{f u z z y}^{l(\alpha)}=(-322000+42000 \times \alpha)+(204000+36000 \times \alpha) /(1.170-0.020 \times \alpha)+ \\
(204000+36000 \times \alpha) /(1.170-0.020 \times \alpha)^{2}+(204000+36000 \times \alpha) /(1.170-0.020 \times \alpha)^{3}
\end{gathered}
$$

(Eq.4.54)

$$
\begin{gathered}
V P L_{f u z z y}^{r(\alpha)}=(-252000-28000 \times \alpha)+(276000-36000 \times \alpha) /(1.130+0.02 \times \alpha)+ \\
(276000-36000 \times \alpha) /(1.130+0.02 \times \alpha)^{2}+(276000-36000 \times \alpha) /(1.130+0.02 \times \alpha)^{3}
\end{gathered}
$$


A Figura 51 mostra a representação vetorial do VPL, obtida no intervalo de $\alpha$ entre 0 e 1.

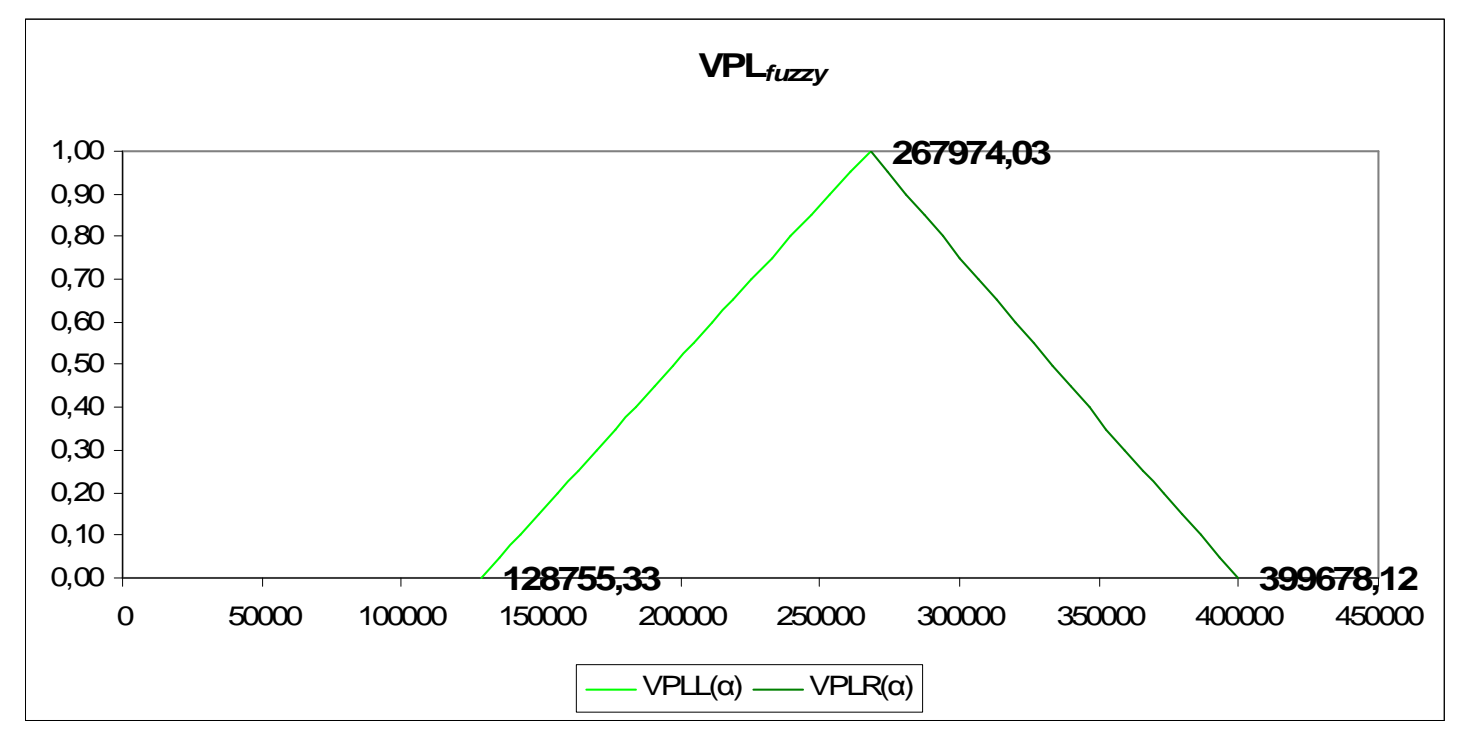

Figura $51-\mathrm{VPL}_{F u z z y}$ aplicado ao exemplo apresentado

\subsubsection{Defuzzificação do VPL Fuzzy}

As funções $V P L_{f u z z y}^{l(\alpha)}$ e $V P L_{f u z z y}^{r(\alpha)}$ aparentemente lembram seguimentos de reta, o que levaria a pensar que trata-se de um número triangular. Entretanto, trata-se de um equívoco. Isso deve-se ao fato de haver potenciação em $\alpha$. Como seu domínio é pequeno (entre 0 e 1), a curvatura das funções geradas é muito pouco acentuada. Assim, caso haja necessidade de se trabalhar com algum tipo de aproximação junto ao $V P L_{f u z z y}$, esta apresenta resultados bastante satisfatórios.

No exemplo apresentado, o $V P L_{f u z z y}$ obtido como saída apresenta somente valores positivos, ou seja, para todos os valores de pertinência o investimento é viável. Não é necessário, à priori, lançar-se uso do cálculo da possibilidade cumulativa $\left[\mu^{*}\left(V P L_{f u z z y}<0\right)\right]$. Já o valor que apresenta maior possibilidade no 
domínio Real é obtido pelo uso do método de defuzzificação pelo Centro da Área (CHIU e PARK, 1994):

$$
V P L^{*}=\frac{\sum_{j=1}^{N} V P L_{f u z z y} \times \mu\left(V P L_{f u z z y}\right)}{\sum_{j=1}^{N} \mu\left(V P L_{f u z z y}\right)}
$$

Em que:

$N$ é o número de iterações a serem realizadas;

$\mu\left(V P L_{F u z z y}\right)$ é função que descreve a pertinência do $V P L_{f u z z y}$

Neste exemplo foi utilizado $N=40$, sendo o intervalo entre cada iteração uma valor em 0,05 de $\mu\left(V P L_{F u z z y}\right)$, obtendo-se:

$$
V P L^{*}=\mathrm{R} \$ 266.270,57
$$

A Figura 52 faz referência ao valor defuzzificado:

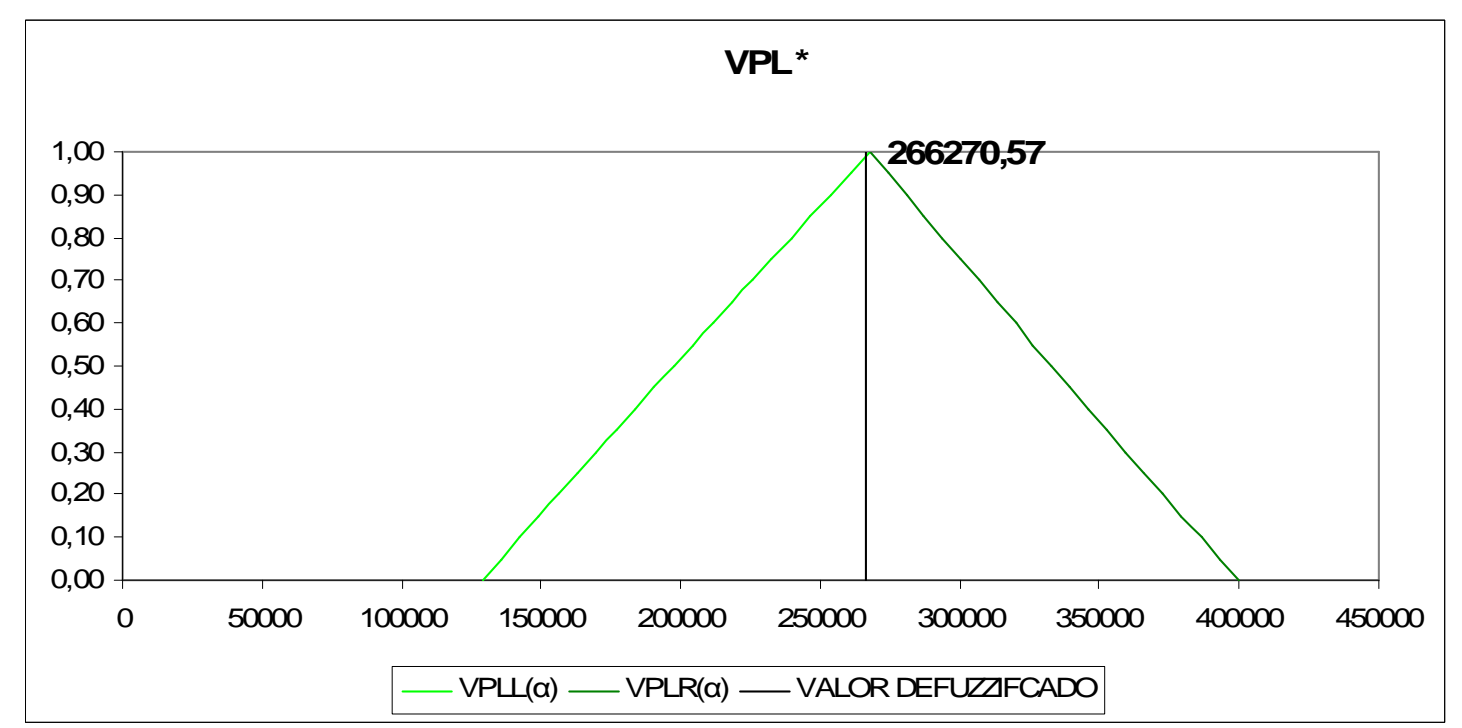

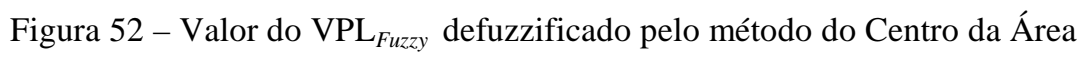


O valor obtido pela defuzzificação pode ser utilizado para comparação econômico-financeira entre projetos de investimento, uma vez que o valor defuzzificado representa o valor mais possível para cada investimento.

Esta dissertação apresenta um indicador complementar para comparação entre projetos de investimentos. O nome escolhido é coeficiente de incerteza léxica $(C I L)$ representado pela função:

$$
C I L=\frac{V P L_{f u z z y}^{r(1)}-V P L_{f u z z y}^{l(1)}}{V P L^{*}}
$$

Quanto mais próximo de 0 for o valor de CIL, menos incerto é o investimento.

Para o exemplo apresentado tem-se:

$$
\begin{gathered}
C I L=\frac{399 \cdot 678,12-128.755,33}{266.270,57} \\
C I L=1,02
\end{gathered}
$$

\subsubsection{VPL Fuzzy utilizando o número de períodos de um investimento como uma variável Fuzzy}

O uso da Lógica Fuzzy pode ser bastante flexível em representar as incertezas, Sanchez (2003) assim como Omitaou e Badiru (2007) propõem em seus trabalhos o uso de números Fuzzy para representar a vida econômica de um investimento. 
Desta forma, explorando o exemplo apresentado, o número de períodos do investimento poderia ser considerado um valor entre 2 e 4 anos, ao invés do valor absoluto de 3 anos. A Figura 53 apresenta o conceito.

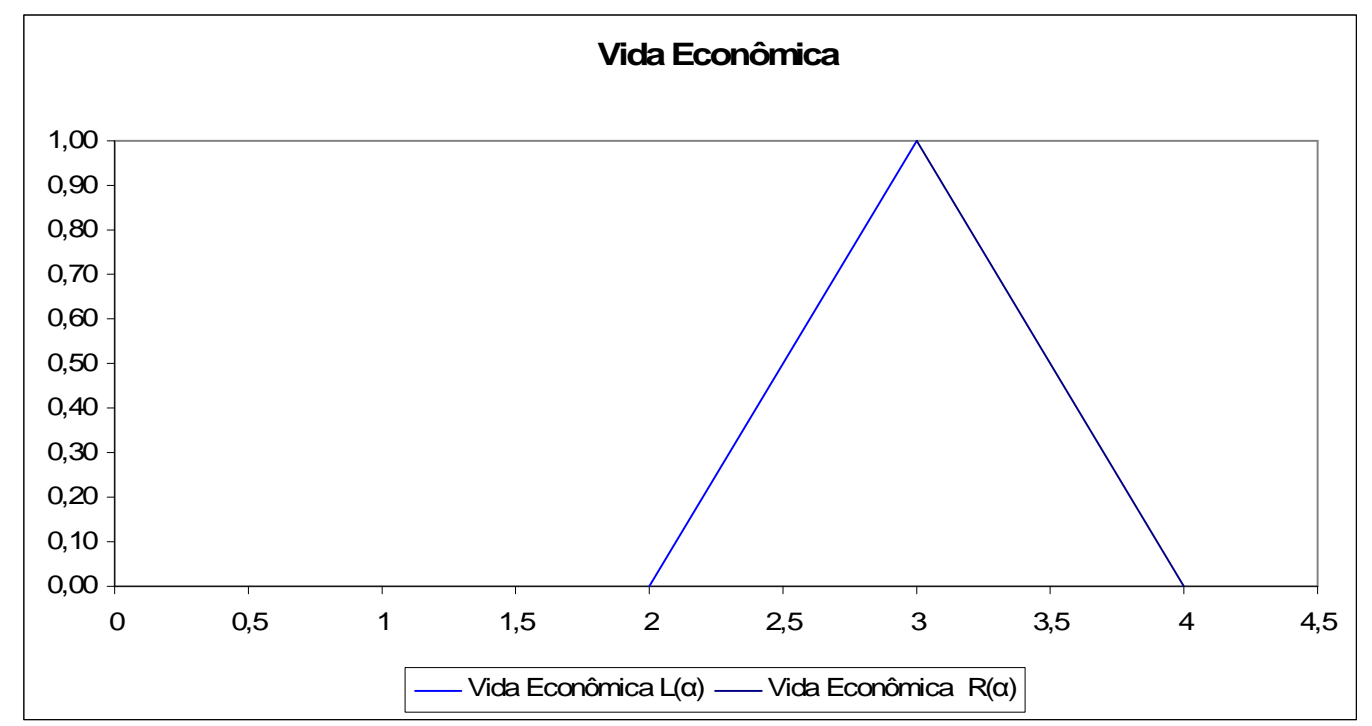

Figura 53 - Vida econômica do investimento representada por um número Fuzzy

Para obtenção do Vapor Presente Líquido Fuzzy em períodos variáveis, é necessário calcular individualmente o $V P L_{f u z z y}$ do investimento em cada uma das três principais situações que definem o número triangular Fuzzy Vida Econômica: 2, 3 e 4 anos. A combinação entre os três $V P L s_{f u z z y}$ obtidos representa o $V P L_{f u z z y}$ para períodos variáveis, expresso na Figura 54: 


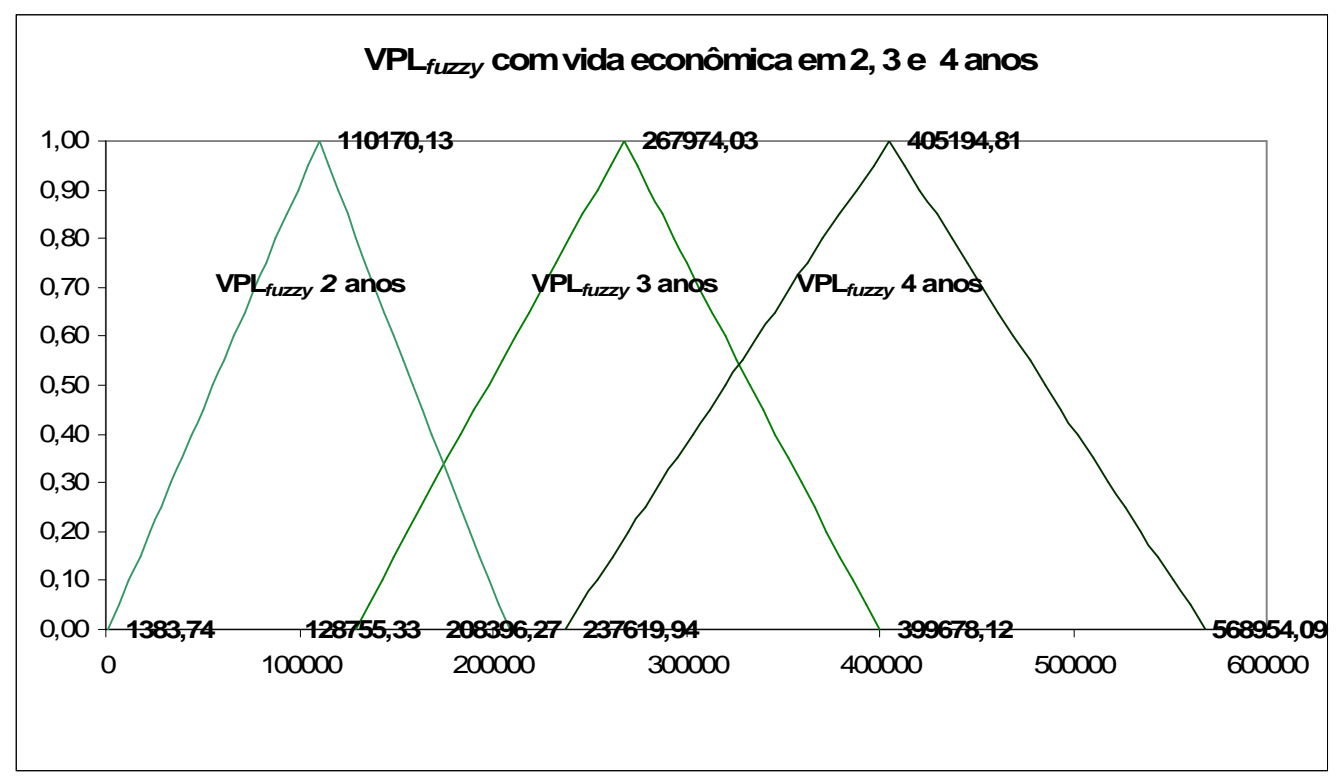

Figura 54 - Resultados do VPL para cada período

Para realizar a defuzzifação, Sanches (2003) propõe a aproximação das funções geradas para um número triangular Fuzzy e a partir daí utiliza-se do método do centro da área para obter o valor defuzzificado. A Figura 54 exprime o conceito e apresenta o valor defuzzificado de $\mathrm{R} \$ 273.419,07$ :

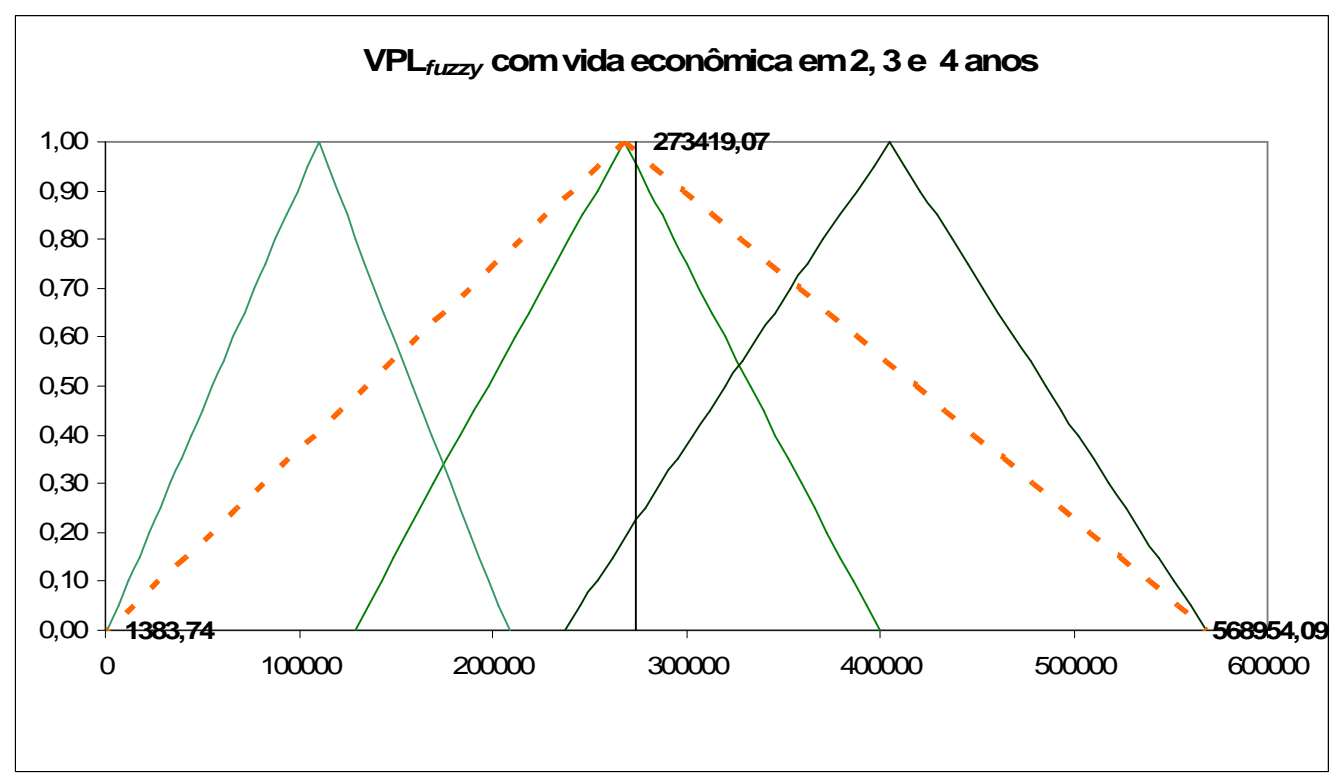

Figura 55 - Defuzzificação proposta por Sanches (2003) 
Omitaou e Badiru (2007) sugerem para interpretação do Vapor Presente Líquido Fuzzy em períodos variáveis, o uso do conceito de máximo Fuzzy, representado pela união das funções de pertinência do $V P L_{f u z z y}$ com vida econômica de 2, 3 e 4 anos, mostrado pelo tracejado na Figura 56.

A defuzzificação também é realizada pelo método do centro da área e resulta em um valor líquido de $\mathrm{R} \$ 256.301,39$. Percebe-se que neste exemplo, que a diferença do valor presente líquido em períodos variáveis utilizando-se dos métodos apresentados é relativamente pequena; $\mathrm{R} \$ 17.117,68$ (um valor próximo a 7\% do resultado total do investimento).

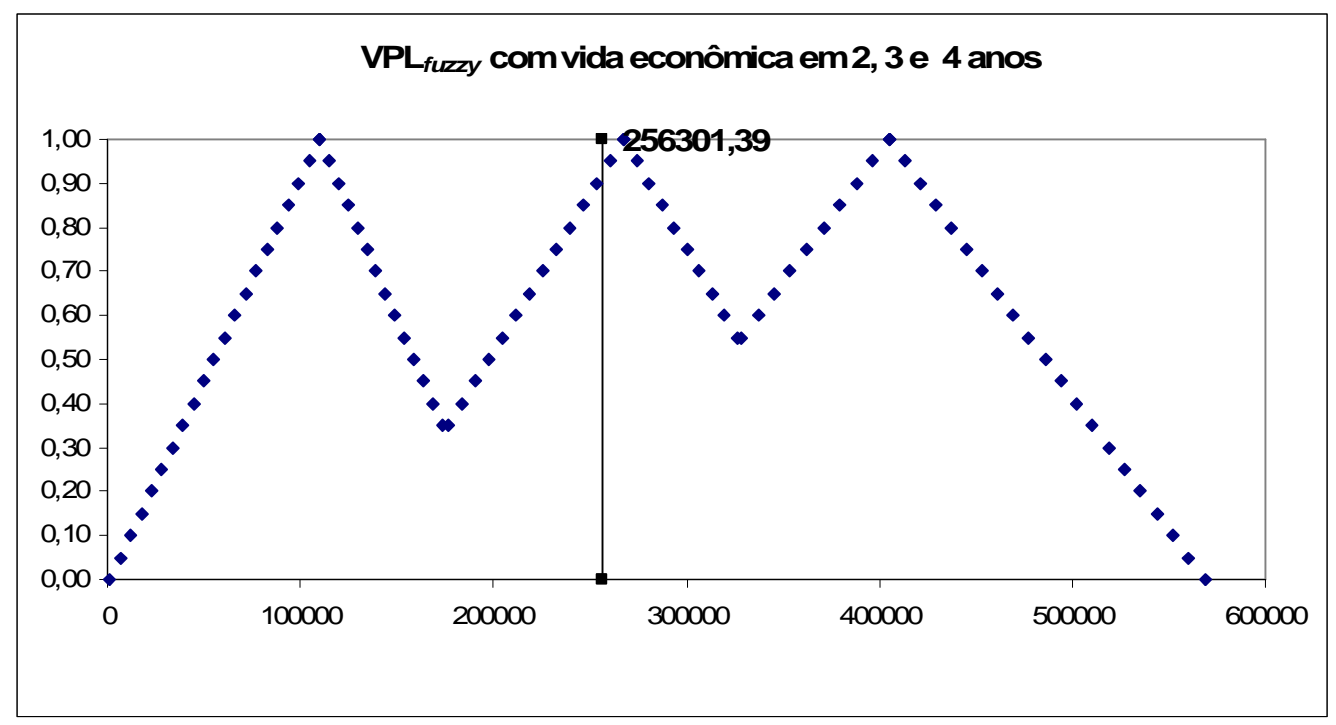

Figura 56 - Defuzzificação proposta por Omitaou e Badiru (2007)

\subsubsection{Considerações Importantes}

Na aplicação do Valor Presente Líquido Fuzzy, a incerteza presente em um investimento é tratada como léxica, ou seja, o modelo é possibilístico e como mostrado ao longo do capítulo não apresenta caráter estatístico. 
O exemplo apresentado é bastante simplificado, visto que o projeto apresenta vida econômica reduzida e a variável chamada Retorno Esperado incorpora as incertezas presentes no fluxo de caixa do investimento. Entre suas contribuições, esta dissertação tratará em seu estudo de caso as variáveis incertas que compõe o fluxo de caixa de maneira independente. Por exemplo: a demanda e o valor do dólar são consideradas variáveis de entrada representadas cada qual por números Fuzzy distintos. Desta maneira as receitas e dispêndios de caixa no período são obtidos através da interação matemática dessas variáveis, que embora aumente substancialmente o cálculo, contribui para a quantificação das incertezas.

O cálculo do Valor Presente Líquido Fuzzy utilizando-se de um número Fuzzy para representar a vida econômica de um investimento pode ser bastante útil, pois permite representar as dúvidas quanto a longevidade do investimento. Entretanto, neste trabalho este artifício não será colocado em prática, visto que tem-se também como objetivo, a comparação da Lógica Fuzzy junto ao método de Monte Carlo. A medida que se adiciona variações ao modelo, mais difícil torna-se a comparação entre as respostas; o que conseqüentemente poderia comprometer o estudo.

Apesar da matemática Fuzzy não ser demasiadamente complexa, seu uso só é viabilizado através de softwares. Além do já citado Fuzzytech, existem softwares específicos para aplicação dos conceitos Fuzzy, como o Matlab, que apresenta um toolbox específico para sua aplicação. Oliveira Júnior et al (2007) cita os softwares desenvolvidos na Universidade de Magdeburg ${ }^{7}$, na Alemanha, como o Nefcon, Nefclass e o Neprox. Trabalhos que usam o Microsoft Excel em sua estruturação também são encontrados.

\footnotetext{
${ }^{7}$ http://fuzzy.cs.uni-magdeburg.de/
} 
Assim como no método de Monte Carlo, para que o resultado seja representativo, a contextualização do cenário econômico deve ser clara e fundamentada nas informações presentes do investimento. A economia mundial apresenta um cenário bastante volátil, de fato isto contribui para que informações presentes se transformem em fatos relativamente diferentes no futuro. No exemplo apresentado as faixas de incerteza são bastante reduzidas, em uma situação real com investimentos de períodos mais longos, pode ser incoerente assumir faixas de incertezas $10 \%$ ou $15 \%$. É evidente que tais variáveis dependem da situação econômica e empresarial de cada investimento.

No próximo capítulo é apresentado o Estudo de Caso, onde Lógica Fuzzy é usada para contextualizar a incerteza, tratada em seu caráter léxico. O Apêndice B apresenta como representar e operar números a formulação utilizando o Microsoft ${ }^{\circledR}$ Excel. 


\section{A APLICAÇÃO E COMPARAÇÃO ENTRE O MÉTODO DE MONTE CARLO E O VPL FUZZY EM UM ESTUDO DE CASO}

\subsection{O PROJETO DE INVESTIMENTO}

Com intuito de promover empiricamente a avaliação dos conceitos apresentados ao longo do trabalho, o método de Monte Carlo e o Valor Presente Líquido Fuzzy serão aplicados em um projeto real de investimento. A parte inicial deste capítulo refere-se a apresentação e estruturação do investimento. A segunda parte destina-se a aplicação dos métodos em discussão. Por fim, são efetuadas as comparações, qualitativas e quantitativas, propostas no capítulo inicial desta dissertação.

Para elaboração de um projeto de investimento é necessário buscar e organizar as informações presentes que envolvem o projeto, organizando-as de maneira sistematizada, e a partir daí, realizar uma avaliação concisa sobre o investimento em discussão. Rebelatto (2004) apresenta a estruturação de um projeto de investimento em cinco etapas. A primeira delas denomina-se análise de mercado. A segunda referese às projeções de engenharia e logística do projeto. Em seguida devem ser estimados os custos e receitas do projeto. No quarto item são observadas as implicações sócioambientais que a execução do projeto trará, e por fim deve ser realizada a avaliação econômico-financeira.

Este trabalho apresenta um projeto de investimento, elaborado conforme os itens descritos. O projeto consiste na criação de uma empresa para a fabricação de máquinas de grande porte para o mercado agroindustrial, com foco central no setor 
sucroalcooleiro, apresentando também boas perspectivas na indústria de papel e celulose. O grupo de investidores envolvidos apresenta experiência neste mercado, tendo atuado na direção de uma metalúrgica de grande porte no setor.

A produção de açúcar e álcool exige uma série de processos logísticos e de transformação. Após a colheita e transporte, o processo industrial é delimitado em várias etapas: a cana deve ser lavada, picada e desfibrada; a partir daí inicia-se o processo de extração do caldo. Em síntese, tal processo consiste na utilização de moendas que esmagam a cana desfibrada, ou através de difusores, que permitem a extração através de lavagens repetitivas.

Após a extração, iniciam-se uma série de processos físico-químicos que permitem a obtenção do açúcar e do álcool. A fonte primária de energia utilizada em todo o processo inerente à operação em uma usina é a queima do bagaço da cana. Através do uso de uma central térmica; um grande volume de água é aquecido gerando vapor, que além de ser diretamente utilizado no processo industrial tem suas propriedades termodinâmicas aproveitadas em sistemas mecânicos para o acionamento de máquinas ou geradores de energia elétrica.

Devido a grande quantidade de processos presentes em uma usina sulcroalcooleira, uma série de máquinas e equipamentos são necessários. Nos próximos itens são apresentados dois exemplos de produtos que visam ser comercializados pelos investidores:

\section{- Caldeiras Aquatubulares}

Uma caldeira aquatubular é um vaso de pressão que contém a água. A caracterísitca técnica mais importante de uma caldeira é sua pressão de trabalho. Em 
caldeiras de baixa e média pressão, à medida que o equipamento recebe calor de uma fonte térmica, a água presente no vaso se torna vapor saturado (FLORES, 2003). Já as caldeiras de alta pressão trabalham com vapor em seu estado superaquecido, apresentando maior eficiência energética, tornado-a mais apropriada para a geração de energia elétrica, o que as tornam um modelo de maior valor agregado. A Figura 57 apresenta um esquema de funcionamento de uma caldeira aquatubular.

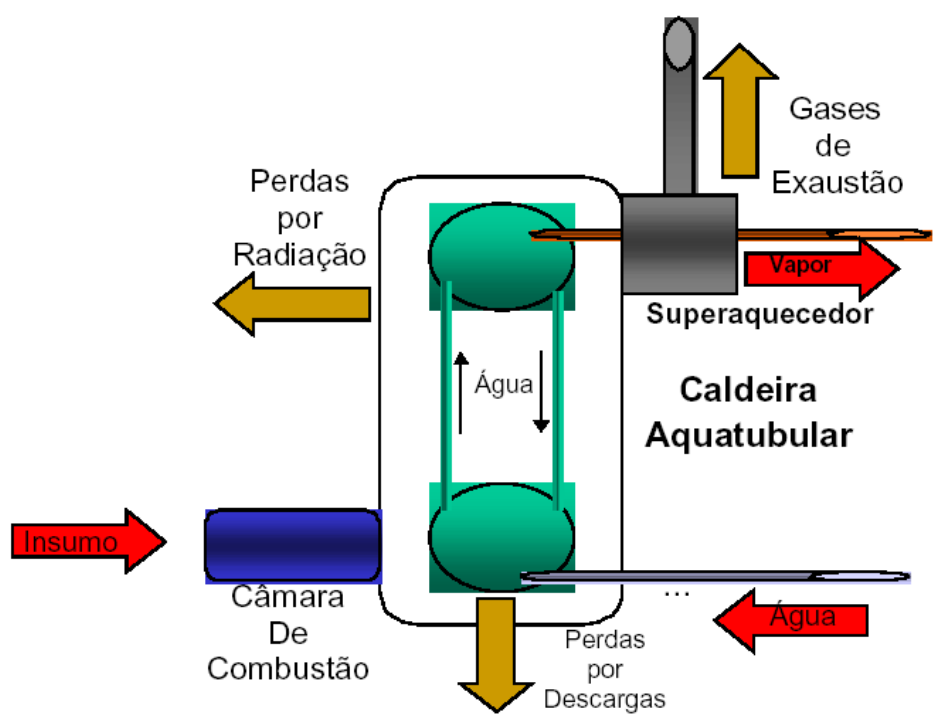

Figura 57 - Esquema de funcionamento de uma caldeira aquatubular Fonte: ALCKMIN et al (2008)

Por meio da queima do insumo (bagaço de cana) na câmara de combustão, obtêm-se energia para a transformação da água em vapor no interior da caldeira (região em verde). Por meio de uma linha de descarga o vapor é direcionado a outras etapas do processo.

Para geração de energia elétrica, o vapor obtido pela queima de bagaço de cana nas caldeiras é direcionado para uma turbina; o vapor superaquecido passa pelos discos da turbina mantendo o eixo central do equipamento em rotação, a energia 
mecânica obtida pela rotação aciona os geradores de energia que através de indução magnética, transformam a energia mecânica em energia elétrica.

\section{- Difusor}

Os difusores são equipamentos responsáveis pela extração do caldo da cana de açúcar. Pelo processo de difusão, o caldo concentrado presente na cana desfibrada é extraído através do contato com a água aquecida.

A Figura 58 apresenta um esquema simplificado do funcionamento de um difusor. A região em azul representa a água de embebição. Na embebição é injetado vapor entre $75^{\circ} \mathrm{C}$ a $90^{\circ} \mathrm{C}$, temperatura apropriada para extração de sacarose.

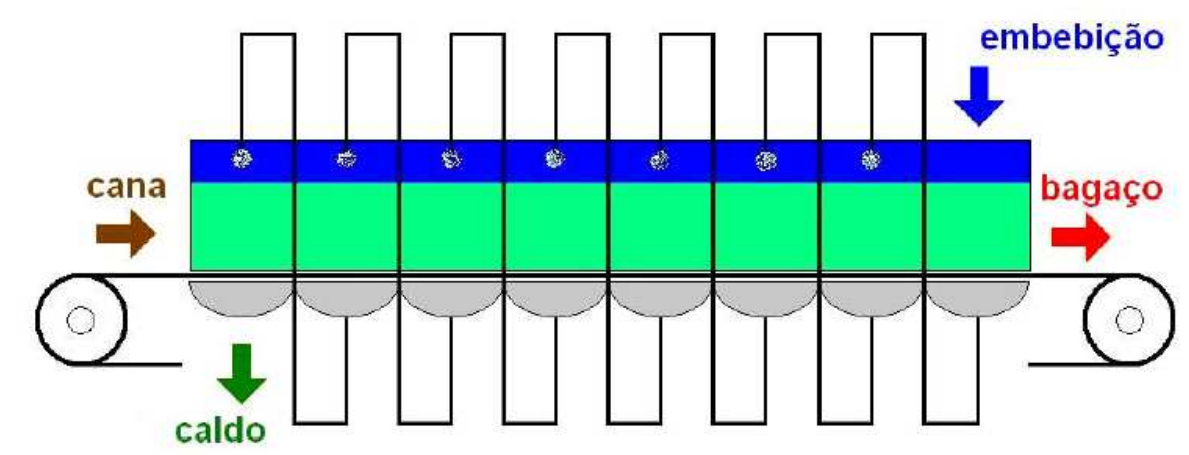

Figura 58 - Esquema de funcionamento de um difusor Fonte: BASTOS NETO (2008)

A região em verde, no esquema da Figura 58, representa a cana de açúcar desfibrada que passa pelo difusor. Pelas canaletas, a embebição percorre o colchão de cana, fazendo com que o concentrado de sacarose deixe as células desfibradas, substância em maior concentração, e se acumule no líquido de embebebição (inicialmente em menor concentração), originando o caldo; uma substância rica em sacarose que é recolhida no captador abaixo do difusor (BASTOS NETO, 2008). 


\subsection{O ESTUDO DE MERCADO}

Um estudo de mercado tem o intuito de captar informações relevantes a um projeto de investimento, relacionando informações econômicas, financeiras e técnicas. Neste tópico é apresentado um panorama geral sobre o mercado, buscando obter informações das perspectivas de crescimento e concorrência no setor, o que contribuirá para quantificação da incerteza inerente ao projeto.

\subsubsection{Aspectos Gerais}

O setor sulcroalcooreiro movimenta $2 \%$ do Produto Interno Bruto (PIB) do Brasil. Esta grande participação na economia nacional está relacionada a posição do país neste seguimento; sendo o maior produtor e exportador de álcool etílico e açúcar do mundo. O setor é considerado o mais antigo da economia nacional, visto que a cana-de-açúcar chegou ao país ainda em seu período colonial e ganhou projeção econômica com a produção de açúcar enviado a Portugal. Apesar de bastante representativo em diversos períodos da economia nacional, o setor só iniciou sua diversificação em 1931, quando o então presidente Getúlio Vargas decretou o acréscimo de 5\% de álcool na gasolina (OLIVEIRA e VASCONCELOS, 2006).

Em 1976 teve início o Programa Nacional do Álcool (Proálcool), marcado por incentivos fiscais significativos que propiciaram desenvolvimento de tecnologia no setor, porém a imagem do programa ficou abalada no fim dos anos 80 com falta do combustível no mercado, visto que a exportação do açúcar era mais lucrativa do que a venda do combustível no mercado nacional. 
Nos últimos anos a participação do setor na economia nacional foi intensificada. Em 2002, com o lançamento dos carros com tecnologia Flex Fuel, esenvolvida pela $\mathrm{Bosch}^{8}$, observou-se significativo crescimento do consumo do álcool combustível no país (OLIVEIRA e VASCONCELOS, 2006). Hoje o número de carros bicombustíveis representa quase 90\% dos carros vendidos no país (RANGEL, 2007).

O álcool produzido a partir da cana-de-açúcar é visto como um produto de grande potencial, por se tratar de um biocombústivel e estima-se que seu consumo deva crescer nos próximos anos. O processo de geração do álcool brasileiro é tomado como uma referência mundial. Quando comparado a processos produtivos que se utilizam do milho, como nos EUA, China e Índia (MSANGI et al, 2006), a tecnologia nacional para produção de álcool mostra-se mais eficiente e com custo mais baixo (ZHANG et al, 2006).

Em 2007 as exportações do álcool nacional alcançaram 3,6 bilhões de litros, um leve crescimento em relação aos 3,4 bilhões exportados em 2006. Os Estados Unidos são os maiores importadores de álcool, com 1,9 bilhão de litros (900 milhões diretamente comprados do Brasil e 1 bilhão comprados de países da América Central), seguidos pela Holanda, com 700 milhões, e Japão, com 380 milhões de litros.

A ascensão do álcool brasileiro tem gerado interesse do mercado internacional, fazendo com que o produto fosse destaque em uma matéria do jornal americano The New York Times que ressaltou a tecnologia brasileira e sua importância para autosuficiência energética do Brasil (ROTHER, 2006).

\footnotetext{
${ }^{8}$ A empresa ganhou o prêmio FINEP por inovação tecnológica por este desenvolvimento.
} 
O interesse norte-americano na agroindústria sucroalcooleira também pode ser observado pela sua inserção no grupo Santelisa Vale, da região de Ribeirão Preto, interior do estado de São Paulo. Em março de 2007, a direção da empresa anunciou uma sociedade com a Global Foods e o Carlyle Riverstone para criar a Companhia Nacional de Açúcar e Álcool (CNAA). A empresa deverá investir R\$ 2 bilhões de reais nos próximos dois anos para erguer quatro usinas. Em julho de 2007, foi a vez do banco americano Goldman Sachs investir 400 milhões de reais no Santelisa Vale (CORREA, 2007).

Com o "boom" do álcool no mundo, o setor sucroalcooleiro do Brasil receberá novos investimentos, que contarão com forte financiamento estatal. Serão aplicados US\$ 19 bilhões até 2012 em pelo menos 86 novas usinas e ampliações, e os empréstimos do BNDES (Banco Nacional de Desenvolvimento Econômico e Social) somarão até R\$ 10 bilhões no período (SOARES, 2007). Em contrapartida o Instituto de Pesquisa Econômica Aplicada do governo (IPEA) criticou a presença do BNDES no setor, alegando instabilidade nos preços do produto, julgando que o mercado ainda é incerto (IPEA, 2008).

Segundo Pessoa (2008), além do álcool, o mercado do açúcar refinado também tem sido diferencial para a indústria sulcroalcooleira. Apesar da diminuição no consumo mundial, os produtores nacionais vêem oportunidades de negócio em países como China e Japão, que apresentam um consumo de açúcar abaixo da média (6 $\mathrm{kg} /$ habitante ano), substancialmente menor do que os Estados Unidos e a União Européia (20 kg/habitante ano).

Junto a comercialização de produtos derivados da cana-de-açúcar, a venda de energia elétrica pelas usinas sucroalcooleiras ao mercado de distribuição é uma fonte de receita potencial. Em 2003 o governo brasileiro criou o Programa de Incentivo às 
Fontes Alternativas (PROINFRA). Tal programa tem como objetivo diversificar a matriz energética brasileira, buscando soluções regionais por meio da implementação de políticas para o desenvolvimento de novas fontes energéticas como a biomassa, pequenas centrais hidroelétricas e aplicações em fontes eólicas. No entanto percebe-se que, apesar de seu potencial, o setor sulcroalcooleiro não apresentou a adesão esperada ao programa. Segundo Souza e Azevedo (2006) o preço de compra pelo MWh pago pela Eletrobrás ainda é considerado pouco atrativo.

Visto um panorama geral sobre o mercado sulcroalcooleiro, a Figura 59 apresenta a quantidade em toneladas produzidas de cana-de-açúcar, desde o ano de 1900 até o ano de 2007.

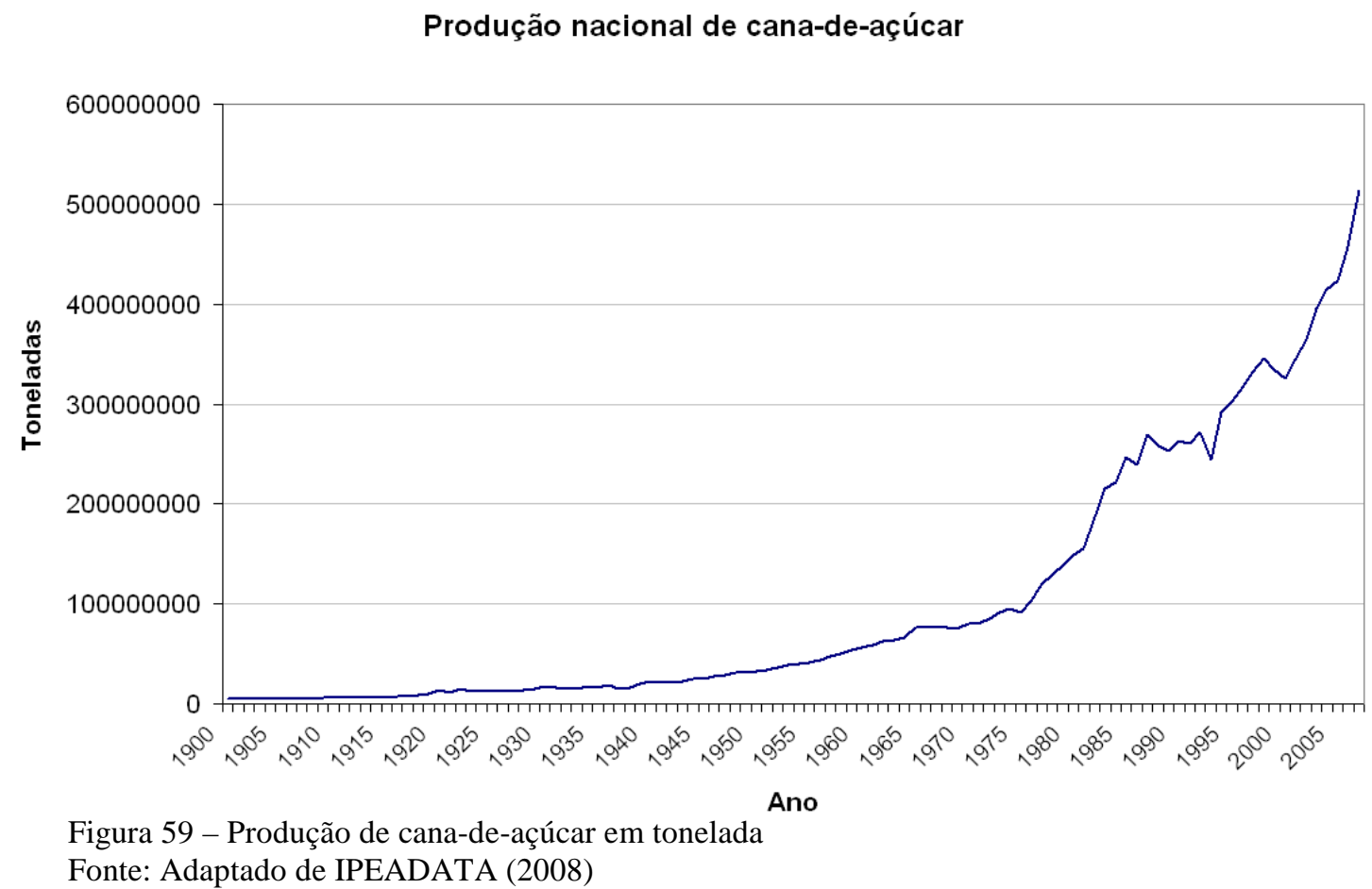

O ano de 2007 foi marcado por uma safra recorde, onde foram produzidas cerca de 514.000.000 toneladas. Para 2008 o IBGE projeta uma produção no setor 9,3 $\%$ maior, superando o valor de 560.000.000 de toneladas (ABDALA, 2007). 
Apesar das boas projeções do IBGE o início do ano de 2008 (período em que está sendo realizada a análise do projeto presente neste trabalho) começou com um sinal amarelo para os produtores e investidores. Ao menos em curto prazo, o mercado do álcool frustrou os que acreditaram nas promessas de novo eldorado verde dos negócios. A euforia de investidores e empresários com o crescimento do setor, iniciada em 2006, arrefeceu com a queda nos preços do produto no mercado interno e com as dificuldades para a exportação, que não se abriu na velocidade alardeada pelo governo; no mercado acredita-se que há excesso de oferta do produto, causada pela safra recorde em 2007. Outro fator de influência foi a produção recorde de combustível a partir do milho nos Estados Unidos que reduziu sua importação do produto (LOBATO e SOARES, 2008).

Segundo informações de empresários, ao menos 25 projetos de implantação de novas unidades industriais foram adiados ou reavaliados. Há, no país, 367 usinas em funcionamento, com a previsão de mais 29 entrarem em operação este ano e um estudo inédito, o BNDES admite a possibilidade de excedente de produção de $10 \%$ até 2010, a depender da evolução do preço da gasolina. A partir daí, projeta-se um longo ciclo de crescimento sustentado, principalmente, pelo mercado interno (LOBATO e SOARES, 2008).

\subsubsection{Mercado Alvo da Empresa}

O grupo de investidores em questão acredita que os possíveis projetos em expansão, criação e reformas de usinas sucrooalcoleiras no Brasil serão valiosas oportunidade de negócios. 
Além de atender ao mercado nacional, a tecnologia brasileira mostra-se propicia à exportação, já que os produtos nacionais também são diretamente aplicáveis ou adaptáveis em sistemas agroindustriais onde o milho é utilizado. O Quadro 5 apresenta uma descrição dos principais mercados em questão:

\begin{tabular}{|c|c|c|}
\hline País / Região & Tecnologia Empregada & $\begin{array}{c}\text { Produção Anual de Etanol } \\
\text { (milhões de litros em 2005) }\end{array}$ \\
\hline Brasil & Cana-de-Açúcar & 16500 \\
\hline EUA & Milho & 16230 \\
\hline China & Milho & 2000 \\
\hline União Européia & Milho & 950 \\
\hline Índia & Milho & 300 \\
\hline Canadá & Milho & 250 \\
\hline Colômbia & Cana-de-Açúcar & 150 \\
\hline Tailândia & Cana-de-Açúcar & 60 \\
\hline Austrália & Cana-de-Açúcar & 60 \\
\hline
\end{tabular}

Quadro 5 - Grandes produtores mundiais de etanol Fonte: MSANG et al (2005)

Os responsáveis pelo projeto de investimento afirmam que, além dos países apresentados no estudo de Msang et al (2005), outros países já aderiam ou deverão aderir à produção de etanol em suas economias. No continente americano tem-se: Argentina, Equador, México, Paraguai, Peru, Venezuela e países da América Central como Nicarágua e El Salvador (onde há forte presença do grupo Cargil). Na África destacam-se a África do Sul, Nigéria e Angola.

\subsubsection{Concorrência no Setor}


No Brasil existem grandes fabricantes de máquinas e equipamentos para as usinas sucroalcooleiras; a maioria deles está concentrada no interior do estado de São Paulo. A estrutura industrial neste segmento apresenta-se bastante verticalizada, fazendo com que as empresas envolvidas trabalhem com produtos ou serviços bastante específicos de engenharia. As parcerias empresarias são bastante contundentes; enquanto parte das empresas são responsáveis pelo desenvolvimento de projetos, outras são responsáveis pela manufatura e aplicação dos produtos.

Algumas parcerias não se apresentam totalmente rígidas, onde é possível encontrar um único fabricante trabalhando simultaneamente com mais de uma empresa responsável pela execução de projetos, sejam elas nacionais ou internacionais.

Os responsáveis pelo investimento consideram quatro grandes fabricantes nacionais, como seus futuros concorrentes diretos. A Figura 60 apresenta uma estimativa realizada pelos investidores sobre a situação atual do marketshare entre as empresas envolvidas:

\section{Marketshare}

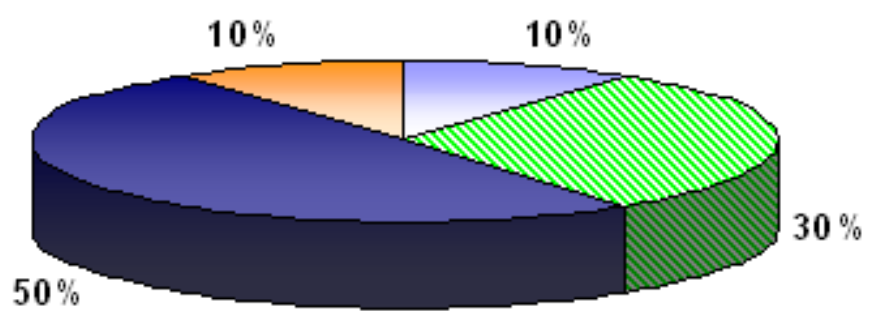

$\square$ Caldema $\square$ Sermatec $\square$ Dedine $\square$ Outras

Figura 60 - Estimativa da distribuição atual do mercado 
Somando-se à concorrência nacional, existe a presença de empresas internacionais no fornecimento de máquinas e equipamentos para produção de açúcar e álcool. À medida que a tecnologia de fabricação de etanol diversifica-se pelo mundo, novas empresas poderão surgir o que poderá aumentar a volatilidade do setor.

Caso o projeto de investimento seja executado, é de se esperar que a empresa enfrente dificuldades para estabelecer-se no mercado, já que seus principais concorrentes mostram-se empresas bem estruturadas. Com o intuito de superar as possíveis dificuldades para a comercialização de seus produtos, o grupo de investidores tem em mente alguns itens estratégicos que deverão delinear a política da empresa em seus primeiros anos de trabalho:

\section{- Prazo de entrega reduzido}

As empresas deste setor foram absorvidas por uma grande demanda do mercado nacional e internacional nos últimos anos. A demanda excedente elevou significativamente o volume de produção do setor, culminando na maioria das vezes em um alto prazo de entrega dos produtos acabados.

Os investidores entendem que trabalhar com prazos mais curtos de entrega será um bom diferencial competitivo para empresa, principalmente para negociações comerciais junto aos clientes.

\section{- Margem de contribuição reduzida frente aos concorrentes}

A margem de contribuição é um indicador de custeio que tem o intuito de represntar as receitas obtidas pela venda de um produto, frente aos custos variáveis 
incorridos pela sua fabricação (MARTINS, 2003). Em termos gerais o conceito margem de contribuição é utilizado para representação do lucro obtido pela venda de determinado produto.

Com intuito de firmarem-se no mercado, os investidores acreditam que será necessário trabalhar com margens menores nos primeiros projetos, oferecendo preços competitivos ao mercado.

\section{- Parcerias empresariais}

Além de um bom relacionamento junto a possíveis parceiros nacionais, o grupo de investidores mantém contato com uma empresa sul-africana que projeta difusores e pretendem buscar novas parcerias com empresas internacionais.

As parcerias entre as empresas são encaradas como uma boa maneira de angariar mercado, já que fortalece a empresa em negociações comerciais e permitem que os produtos fabricados possam ser oferecidos em diferentes mercados.

\subsection{PROJEÇÕES DE ENGENHARIA E LOGÍSTICA DO PROJETO}

\subsubsection{Aspectos Logísticos}

O empreendimento em questão será realizado em Sertãozinho, interior do estado de São Paulo. A cidade apresenta sua economia voltada ao setor sucroalcooleiro contemplando sete usinas e quase 500 empresas em atividade 
(ERENO, 2006). Tal localização propiciará fácil acesso a parceiros, fornecedores e clientes do interior paulista.

Vizinha à cidade de Riberão Preto, a região conta com excelente infraestrutura. O acesso rodoviário é bom, facilitando o fluxo dos produtos até o porto de Santos, principal centro logístico de exportação industrial do país.

\subsubsection{A Engenharia do Projeto}

De acordo com Rebelatto (2004) um projeto de investimento deve compreender um estudo amplo de engenharia que retrate o sistema produtivo da empresa, apresentando informações claras e estruturadas sobre as escolhas por processos de manufatura, equipamentos, capacidade produtiva e definições quanto a fornecedores e mão-de-obra.

O grupo de investidores preferiu não divulgar de maneira completa as informações técnicas do projeto, acreditando que devem ser mantidas como dados sigilosos. Desta forma, este capítulo apresenta exclusivamente as informações consideradas relevantes para a avaliação econômico-financeira do projeto, não se referindo a maneira como foi estruturado e desenvolvido.

O centro fabril foi projetado para que sua capacidade máxima de produção seja de 1560 toneladas por ano de produtos fabricados. Para tal, os investidores têm interesse na compra de um galpão de $2.900 \mathrm{~m}^{2}$ presente em um terreno de $24.600 \mathrm{~m}^{2}$. Além disso, os investidores vêem a necessidade de uma área livre adicional de 10.250 $\mathrm{m}^{2}$ que contribuirá para possíveis expansões, à medida que os resultados do empreendimento sejam positivos. 
A empresa deverá contar inicialmente com 10 funcionários para trabalhar na parte administrativa e de engenharia. Estima-se que serão necessários mais 25 para trabalhar diretamente na produção industrial. Os investidores também deverão comprar máquinas e equipamentos para implementação de seu sistema de manufatura. A Tabela 3 apresenta as estimativas iniciais do projeto: 
Tabela 3 - Estimativas Iniciais do Projeto

\begin{tabular}{|c|c|c|}
\hline & $\begin{array}{c}\text { Valor } \\
\text { Projetado }\end{array}$ & Especificação \\
\hline Galpão & $2900 \mathrm{~m}^{2}$ & $\begin{array}{l}\text { Nele será montado o centro fabril para } \\
\text { manufatura de equipamentos. Também conta } \\
\text { com escritórios para a área administrativa. }\end{array}$ \\
\hline Área Inicial & $24600 \mathrm{~m}^{2}$ & $\begin{array}{l}\text { Importante para logística interna da empresa, } \\
\text { servindo como suporte para o centro fabril na } \\
\text { movimentação de produtos em processamento e } \\
\text { matéria-prima. }\end{array}$ \\
\hline Terreno Adicional & $10250 \mathrm{~m}^{2}$ & $\begin{array}{l}\text { Vizinho ao galpão, será utilizado para uma } \\
\text { possível expansão da empresa. }\end{array}$ \\
\hline $\begin{array}{l}\text { Guincho para } \\
\text { Movimentação }\end{array}$ & 01 & $\begin{array}{l}\text { Será utilizado para movimentação de grandes } \\
\text { cargas no galpão. }\end{array}$ \\
\hline $\begin{array}{l}\text { Máquina Curvadora de } \\
\text { Tubos }\end{array}$ & 01 & $\begin{array}{l}\text { Será utilizado no processo de conformação } \\
\text { mecânica de produtos em processamento. }\end{array}$ \\
\hline Calandra & 01 & $\begin{array}{l}\text { Será utilizado no processo de conformação } \\
\text { mecânica de produtos em processamento. }\end{array}$ \\
\hline Munk & 01 & $\begin{array}{l}\text { Movimentação de material em processamento } \\
\text { em médias distâncias }\end{array}$ \\
\hline $\begin{array}{l}\text { Máquinas leves e } \\
\text { soldadoras }\end{array}$ & --- & $\begin{array}{l}\text { Processamento de material e junção de ligas } \\
\text { metálicas. }\end{array}$ \\
\hline $\begin{array}{l}\text { Material para escritório, } \\
\text { móveis e computadores }\end{array}$ & --- & $\begin{array}{l}\text { Equipamentos diversos para realização de } \\
\text { trabalhos técnicos e administrativos. }\end{array}$ \\
\hline $\begin{array}{l}\text { Número de funcionários } \\
\text { (mão-de-obra direta) }\end{array}$ & 11 & \\
\hline $\begin{array}{l}\text { Número de funcionários } \\
\text { (mão-de-obra indireta) }\end{array}$ & 25 & \\
\hline Capacidade de produção & 1560 ton/ano & \\
\hline Vida econômica do projeto & 15 anos & \\
\hline
\end{tabular}

\subsection{A ESTIMATIVA DE CUSTOS E RECEITAS DO PROJETO}

Baseando-se em informações de engenharia do projeto obtidas junto aos responsáveis pelo investimento, elaborou-se a Tabela 3, que apresenta estimativa sobre o comportamento de receitas e dispêndios de capital que o projeto, caso executado, apresentará: 
Tabela 4 - Estimativa de receitas e custos anuais do projeto

\begin{tabular}{|c|c|c|c|c|}
\hline & & Valor Esperado & $\begin{array}{l}\text { Incerteza } \\
\text { Estimada }\end{array}$ & \begin{tabular}{|c} 
Depreciação \\
Restante
\end{tabular} \\
\hline \multirow{9}{*}{ Investimento } & Galpão & $-R \$ 2.000 .000,00$ & $\pm 3 \%$ & 10 anos \\
\hline & Área Inicial & $-R \$ 2.400 .000,00$ & $\pm 3 \%$ & $\begin{array}{c}\text { não é } \\
\text { depreciável }\end{array}$ \\
\hline & Terreno Adicional & $-\mathrm{R} \$ 1.725 .000,00$ & $\pm 3 \%$ & $\begin{array}{c}\text { não é } \\
\text { depreciável }\end{array}$ \\
\hline & $\begin{array}{l}\text { Guincho para } \\
\text { Movimentação }\end{array}$ & $-\mathrm{R} \$ 100.000,00$ & $\pm 3 \%$ & 10 anos \\
\hline & $\begin{array}{l}\text { Máquina Curvadora } \\
\text { de Tubos }\end{array}$ & $-\mathrm{R} \$ 150.000,00$ & $\pm 3 \%$ & 10 anos \\
\hline & Calandra & $-R \$ 20.000,00$ & $\pm 3 \%$ & 10 anos \\
\hline & Munk & $-R \$ 20.000,00$ & $\pm 3 \%$ & 10 anos \\
\hline & $\begin{array}{l}\text { Máquinas leves e } \\
\text { soldadoras }\end{array}$ & $-\mathrm{R} \$ 100.000,00$ & $\pm 3 \%$ & 10 anos \\
\hline & \begin{tabular}{|l|} 
Material para \\
escritório, móveis e \\
computadores \\
\end{tabular} & $-\mathrm{R} \$ 30.000,00$ & $\pm 3 \%$ & 10 anos \\
\hline \multirow{2}{*}{ Receitas } & $\begin{array}{l}\text { Estimativa de } \\
\text { demanda anual }\end{array}$ & 1200 ton & $\pm 30 \%$ & \\
\hline & $\begin{array}{l}\text { Estimativa de preço } \\
\text { de venda }\end{array}$ & $\mathrm{R} \$ 10.495,00 /$ ton & $\pm 5 \%$ & \\
\hline \multirow{4}{*}{$\begin{array}{l}\text { Custos e } \\
\text { Despesas }\end{array}$} & $\begin{array}{l}\text { Salários e encargos } \\
\text { anuais com mão-de- } \\
\text { obra direta }\end{array}$ & $-\mathrm{R} \$ 672.750,00$ & $\pm 30 \%$ & \\
\hline & $\begin{array}{l}\text { Salários encargos } \\
\text { anuais com mão-de- } \\
\text { obra indireta }\end{array}$ & $-\mathrm{R} \$ 491.556,00$ & $\pm 30 \%$ & \\
\hline & $\begin{array}{l}\text { Gastos anuais com } \\
\text { agua, energia e } \\
\text { telefone }\end{array}$ & $-R \$ 100.000,00$ & $\pm 30 \%$ & \\
\hline & $\begin{array}{l}\text { Custos anuais gerais } \\
\text { de produção (matéria- } \\
\text { prima e consumíveis) }\end{array}$ & -R $\$ 7.623,75 /$ ton & $\pm 5 \%$ & \\
\hline Impostos & $\begin{array}{l}\text { Alíquota de imposto a } \\
\text { ser pago }\end{array}$ & $35 \%$ a.a. & $\begin{array}{l}\text { Não é tratado } \\
\text { como incerto. }\end{array}$ & \\
\hline Valor Residual $^{9}$ & \begin{tabular}{|l} 
Valor Residual do \\
empreendimento
\end{tabular} & $\mathrm{R} \$ 4.725 .000,00$ & $\pm 20 \%$ & \\
\hline $\begin{array}{l}\text { Rentabilidade } \\
\text { Desejada }\end{array}$ & $\begin{array}{l}\text { Taxa mínima de } \\
\text { atratividade (TMA) }\end{array}$ & $15,72 \%$ a.a. & $\pm 6 \%$ & \\
\hline
\end{tabular}

\footnotetext{
${ }^{9} \mathrm{O}$ valor residual do investimento corresponde a soma dos itens Área Inicial e Terreno Adicional da tabela.
} 
As informações contidas na Tabela 4 estão divididas em quatro principais grupos. O primeiro deles, o investimento, representa os ativos necessários para que a empresa seja implantada. Os demais fornecem informações estimadas sobre as receitas e dispêndios de capital que a execução do projeto trará, bem como a rentabilidade desejada do projeto e sua carga tributária.

A coluna incerteza estimada é de fundamental importância para o estudo. Esse indicador apresenta as possíveis variações que influenciarão no fluxo de caixa da empresa no decorrer da vida econômica do investimento. A grande dificuldade para quantificação destas incertezas é que, apesar de existirem informações relevantes sobre o mercado, as mesmas apresentam-se pouco sistematizadas e organizadas, dificultando a aplicação de ferramentas matemáticas ou procedimentais para representá-las numericamente. Desta forma, as faixas de valores incertos foram estipuladas com base em informações de mercado e reuniões efetuadas junto aos investidores, nas quais o feeling e experiência empresarial dos responsáveis pelo projeto apresentaram papel fundamental nestas estimativas.

Observa-se que as estimativas de incerteza para o investimento inicial são variações muito pequenas, isto porque os investimentos já foram cotados e acredita-se que as possíveis alterações possam ocorrer por motivo de negociação ou pela forma de pagamento do ativo. Já as receitas, despesas e custos estimados apresentam uma amplitude maior, visto que uma projeção para quinze anos contém alto grau de imprevisibilidade.

A coluna depreciação consiste em representar contabilmente em quanto tempo um determinado ativo imobilizado perde seu valor durante o uso. As depreciações são importantes, pois são computadas como custos ou despesas nas demonstrações de 
resultados de uma empresa, o que diminui o lucro contábil, valor pelo qual incidem a maioria dos tributos pagos pela empresa (PAMPLONA e MONTEVECHI, 2006).

O próximo tópico deste trabalho destina-se a uma breve consideração sobre as implicações sociais e ambientais que a execução do projeto trará. Posteriormente é iniciada a avaliação econômico-financeira do projeto, que será apresentada por meio da aplicação do cálculo determinístico do Valor Presente Líquido, da simulação de Monte Carlo e do Valor Presente Líquido Fuzzy.

\subsection{AS IMPLICAÇÕES SOCIAIS E AMBIENTAIS DO PROJETO}

Caso o projeto seja realizado, serão criados 35 novos empregos; o quadro de funcionários tende a aumentar a medida com que a empresa atinja bons resultado. Pela comercialização e manufatura dos produtos são esperadas outras contribuições sociais, já que o fluxo de capital junto a clientes e fornecedores deverá impactar positivamente na economia regional.

Quanto as questões ambientais, não são observadas no setor empresas que possuam a certificação ISO 14.001, a qual refere-se a implementação e controle de um Sistema de Gestão Ambiental. Segundo Batalha (2008) tal sistema tem o objetivo de avaliar e melhorar continuamente os processos inerentes a empresa buscando a eliminação dos resíduos descartados durante a vida útil do empreendimento.

O grupo de investidores não entende que a implementação de um sistema de gestão ambiental seja prioridade neste momento, pois os custos com a implementação são altos e não se percebe, neste mercado, exigências por parte de clientes nacionais e internacionais por este tipo de certificação. 


\subsection{O CÁlCULO DO VPL DETERMINÍSTICO PARA A AVALIAÇÃO ECONÔMICO-FINANCEIRA DO PROJETO DE INVESTIMENTO}

Apresentado o projeto de investimento, inicia-se a etapa referente à sua avaliação econômico-financeira. Em geral este tipo de avaliação tem o objetivo de quantificar aos investidores o resultado do investimento. Neste tópico será apresentado o cálculo determinístico do VPL. Este modelo considera os componentes de caixa do investimento valores absolutos, não sendo atribuída nenhuma consideração sobre a incerteza presente. Os valores utilizados para elaboração dos cálculos foram apresentados na Tabela 4.

A primeira etapa para o cálculo do $V P L$ consiste em definir os componentes de caixa do projeto: Investimento Total, Receita Anual Total, Custos e Despesas Anuais Totais, Depreciação Anual Total e Valor Residual. A partir daí, é possível obter o fluxo de caixa ao longo da vida econômica do empreendimento, necessário para obtenção do VPL.

\subsubsection{O Investimento Total}

O Investimento Total consiste na somatória de todos os valores gastos para implementação e funcionamento da empresa:

(Eq. 5.1)

Investimento Total $=$ Galpão + Área Inicial + Terreno Adicional + Guincho para Movimentação + Máquina Curvadora de Tubos + Calandra + Munk + Máquinas leves e soldadoras + Material para escritório, móveis e computadores 


\subsubsection{Receita Anual Total}

Tendo em mente que a comercialização de seus produtos será a única fonte de receita da empresa, a Receita Anual Total é composta pela multiplicação entre Estimativa de Demanda e a Estimativa de preço de venda:

(Eq. 5.3)

Receita Anual Total $=$ Estimativa de Demanda $\times$ Estimativa de preço de venda

$$
\text { Receita Anual Total }=\mathrm{R} \$ 12.594 .000,00
$$

\subsubsection{Custos e Despesas Anuais Totais}

Os Custos e Despesas Anuais Totais representam todos os dispêndios de capital que o projeto trará após sua realização, excluindo-se os impostos a serem pagos:

(Eq. 5.5)

Custos e Despesas Anuais Totais $=[$ Estimativa de Demanda $\times$ Custos gerais de produção (matéria-prima e consumíveis)] + Salários e encargos com mão-de-obra direta + Salários e encargos com mão-de-obra indireta + Água, energia e telefone 


\subsubsection{O Fluxo de Caixa antes dos Impostos}

A partir das estimativas apresentadas sobre o projeto de investimento, é possível calcular o fluxo de caixa anual que o projeto apresentará antes da tributação:

Fluxo de Caixa antes dos Impostos = Receita Anual Total +- Custos e Despesas Anuais Totais

Fluxo de Caixa antes dos Impostos $=\mathrm{R} \$ 2.181 .194,00$

\subsubsection{Depreciação Total Anual}

Apesar de um bom indicador para expor a diferença entre receitas e dispêndios de capitais estimadas para um projeto de investimento, o Fluxo de Caixa antes dos Impostos por si só não é representativo para avaliação de um projeto, já que não leva em consideração as depreciações, amortizações e impostos, os quais apresentarão influência no resultado anual do empreendimento.

As amortizações não fazem parte do estudo, já que os investidores com capital trabalharão exclusivamente com capital próprio, não havendo interesse de usar alguma forma de financiamento ${ }^{10}$ para o projeto. Quanto as depreciações, denominouse um indicador chamado Depreciação Anual Total que consiste em representar

\footnotetext{
${ }^{10}$ Apesar de não haver intuito dos investidores por capital de terceiros, o uso de financiamentos e emissão de títulos de dívida podem ser alternativas interessantes para empresas; os juros pagos em empréstimos e financiamentos são dedutíveis do imposto de renda, o que alguns casos podem ser alternativas para maximização dos resultados financeiros de uma empresa(GITMAN, 2002)
} 
anualmente o quanto os ativos imobilizados perderam seu valor segundo as instruções normativas da Receita Federal (1998).

Conforme apresentado na Tabela 4, os ativos depreciáveis apresentam vida contábil de 10 anos. Assim a parcela de depreciação anual em um período de 1 a 10 anos é calculada por:

(Eq. 5.9)

Depreciação Anual Total $=($ Galpão + Guincho para Movimentação + Máquina

Curvadora de Tubos + Calandra + Munk + Máquinas leves e soldadoras + Material para escritório, móveis e computadores) / 10

Depreciação Anual Total $=-\mathrm{R} \$ 242.000,00$

Anualmente até o décimo ano de vida econômica da empresa, será possível deduzir, para o cálculo do imposto a ser pago, o valor das depreciações do lucro tributável. Pelo escopo do projeto, a partir do décimo primeiro ano esse benefício cessará, fazendo com que o valor pago em impostos seja maior.

\subsubsection{O Fluxo de Caixa após os Impostos}

Utilizando-se do conceito de depreciação é possível calcular o fluxo de caixa que o projeto de investimento apresentará do primeiro ao décimo ano após sua execução. Conforme apresentado na Tabela 4, a alíquota de imposto utilizada será $35 \%$ a.a.: 
(Eq. 5.11)

Fluxo de Caixa após os Impostos (1 a 10 anos $)=$ Fluxo de Caixa antes dos Impostos - Alíquota de Imposto $\times[$ Fluxo de Caixa antes dos Impostos + Depreciação Anual Total]

(Eq. 5.12)

Fluxo de Caixa após os Impostos (1 a 10 anos $)=\mathrm{R} \$ 1.502 .476,10$

Para o cálculo do fluxo de caixa do décimo primeiro ao décimo quinto ano as depreciações foram finalizadas, de maneira que:

(Eq. 5.13)

Fluxo de Caixa após os Impostos (11 a 15 anos $)=$ Fluxo de Caixa antes dos Impostos $-[$ Alíquota de Imposto $\times$ Fluxo de Caixa antes dos Impostos $]$

(Eq. 5.14)

Fluxo de Caixa após os Impostos (11 a 15 anos) $=\mathrm{R} \$ 1.417 .776,10$

\subsubsection{O Cálculo do VPL determinístico}

Organizado os dados que compõem financeiramente o projeto é possível calcular o VPL resultante caso o investimento seja realizado. Utilizando-se a formulação apresentada no capítulo 3 tem-se:

(Eq. 5.15)

$$
V P L=\text { Investimento Total }+\sum_{j=1}^{10}\left[\frac{\text { Fluxo de Caixa após os impostos }(1 \text { a } 10 \text { anos })}{(1+T M A)^{j}}\right]
$$


$+\sum_{j=11}^{15}\left[\frac{\text { Fluxo de Caixa após os impostos }(11 \text { a } 15 \text { anos })}{(1+T M A)^{j}}\right]+\frac{\text { Valor residual }}{(1+T M A)^{15}}$

$$
V P L=\mathrm{R} \$ 2.407 .071,12
$$

O Valor residual do investimento, $\mathrm{R} \$ 4.725 .000,00$, e a $T M A, 15,72 \%$ a.a., foram extraídos da Tabela 4. A taxa mínima de atratividade adotada apresenta valor $4 \%$ maior do que a taxa de juros Selic $^{11}$ média que o mercado apresentou no mês de janeiro de 2008, considerada por muitos investidores como a taxa de remuneração de capital mais segura no mercado financeiro nacional.

O resultado do cálculo do VPL mostra que o investimento é viável. Caso o grupo de investidores realize o projeto, é de se esperar uma remuneração sobre o capital investido de $15,72 \%$ a.a. mais um lucro adicional $\mathrm{R} \$ 2.407 .071,1$.

Apesar do resultado positivo, a aceitação ou não do investimento, baseando-se no resultado do $V P L$ determinístico, pode não ser suficiente para uma análise concisa sobre o investimento. Ao longo de 15 anos os valores que compõem o fluxo de caixa estimado do empreendimento certamente apresentarão variações. Nos próximos tópicos serão apresentados os métodos de avaliação que permitem contemplar a incerteza presente no investimento.

\subsection{A AVALIAÇÃO ECONÔMICO-FINANCEIRA DO PROJETO DE INVESTIMENTO UTILIZANDO A SIMULAÇÃO DE MONTE-CARLO}

\footnotetext{
${ }^{11}$ A Taxa Selic média em Janeiro de 2008 foi 11,72\% a.a. www.bacen.gov.br
} 
Baseando-se no fluxograma apresentado na Figura 12 inicia-se a aplicação do método de Monte Carlo no cálculo do Valor Presente Líquido. O primeiro passo consiste na resolução determinística do problema, apresentada no tópico anterior. Os cálculos foram efetuados por meio de uma planilha eletrônica elaborada no Microsoft ${ }^{\circledR}$ Excel, onde foi estruturada a base de cálculo para a simulação.

\subsubsection{Atribuição de distribuições de probabilidades junto às variáveis independentes}

Após a resolução determinística do modelo, as variáveis que compõem o cálculo do VPL devem ser tratadas como variáveis independentes e em cada uma delas devem ser atribuídas distribuições de probabilidade, as quais têm o intuito de representar as incertezas inerentes ao projeto.

Todas as incertezas serão tratadas como distribuições normais de probabilidade, isto porque não há histórico algum sobre as variáveis que possam ser considerados na análise. Em situações como essa, a opção por distribuições de probabilidade mais sofisticadas ou assimétricas poderia distorcer o resultado, já que estipular os parâmetros que definem o comportamento matemático destas funções não é uma tarefa simples.

A representação das incertezas presentes de maneira estatística foi baseada nos conceitos do teorema de Tchebichev, onde o comportamento de uma distribuição de probabilidade normal é descrito em função de sua média $(\mu)$ e de seu desvio-padrão ( $\sigma$ ) (TRIOLA, 1999), como apresentado na Figura 61. 


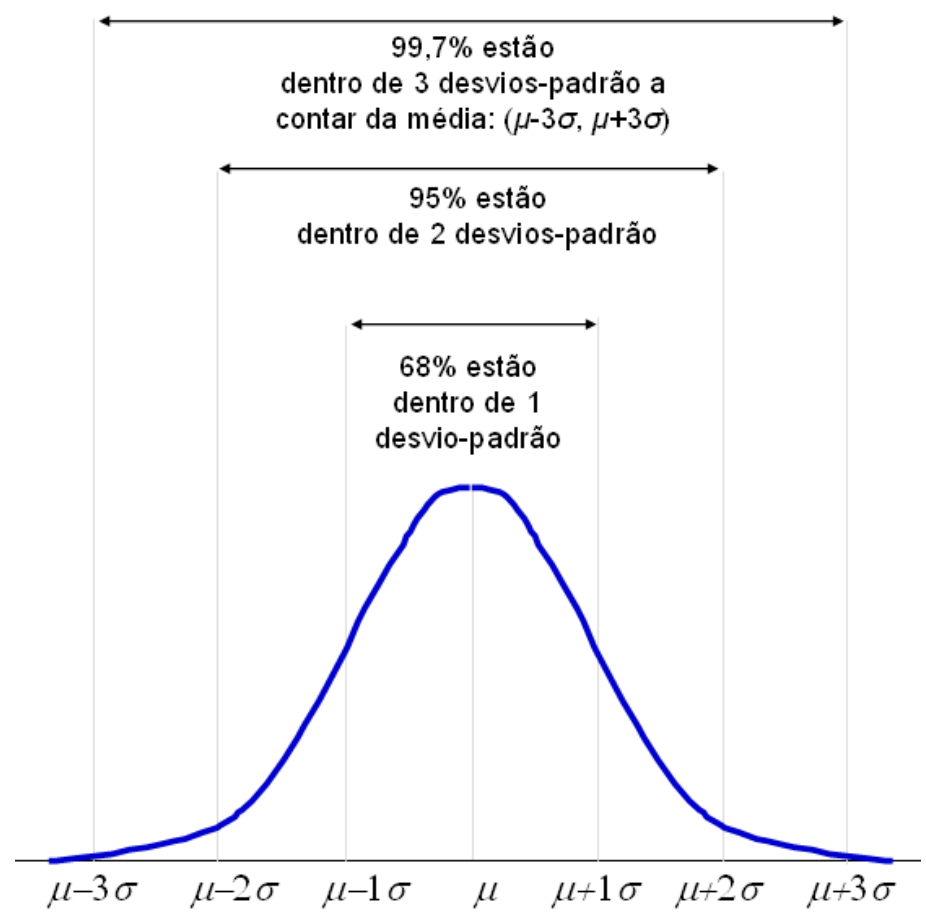

Figura 61- O teorema de Tchebichev ou regra empírica Fonte: Adaptado de TRIOLA (1999)

Quanto maior a faixa de desvios-padrão considerados a partir de um valor médio, maior é a probabilidade de que um elemento de uma amostragem ou população esteja representado dentro desta faixa. Neste contexto admitir-se-á que a faixa de incerteza que compõe cada componente de caixa do projeto de investimento sejam informações que apresentem um intervalo de confiança de $95 \%$.

A faixa de incerteza apresentada na Tabela 4 corresponderá a um intervalo total de 2 desvios-padrão em relação à média $(\mu-2 \sigma, \mu+2 \sigma)$. Assim, para a variável que representa o investimento no Galpão tem-se:

$$
\mu_{\text {Galpão }}=\text { valor esperado do investimento no Galpão }
$$

$$
\mu_{\text {Galpão }}=-\mathrm{R} \$ 2.000 .000,00
$$


(Eq. 5.19)

$$
\begin{aligned}
& \sigma_{\text {Galpão }}=\frac{\left[\left[(1+\text { incerteza estimada mínima }) \times \mu_{\text {Galpão }}\right]-\left[(1+\text { incerteza estimada máxima }) \times \mu_{\text {Galpão }}\right] \mid\right.}{4} \\
& \sigma_{\text {Galpão }}=\frac{\mid[(1-0,03) \times 2000000]-[(1+0,03) \times 2000000)] \mid}{4} \\
& \sigma_{\text {Galpão }}=\mathrm{R} \$ 30.000,000
\end{aligned}
$$

A partir da obtenção de $\mu_{\text {Galpão }}$ e $\sigma_{\text {Galpão }}$ é possível parametrizar a distribuição de probabilidades normal $(N)$ que representa a variável incerta Galpão:

$$
\begin{gathered}
N_{\text {Galpão }}\left(\mu_{\text {Galpão }}, \sigma_{\text {Galpào }}\right) \\
N_{\text {Galpão }}(-2000000,30000)
\end{gathered}
$$

De maneira análoga, o mesmo procedimento deve ser utilizado para obter as distribuições de probabilidade que representarão as outras variáveis incertas do investimento, culminando na Tabela 5: 
Tabela 5 - Variáveis independentes para execução da Simulação de Monte Carlo

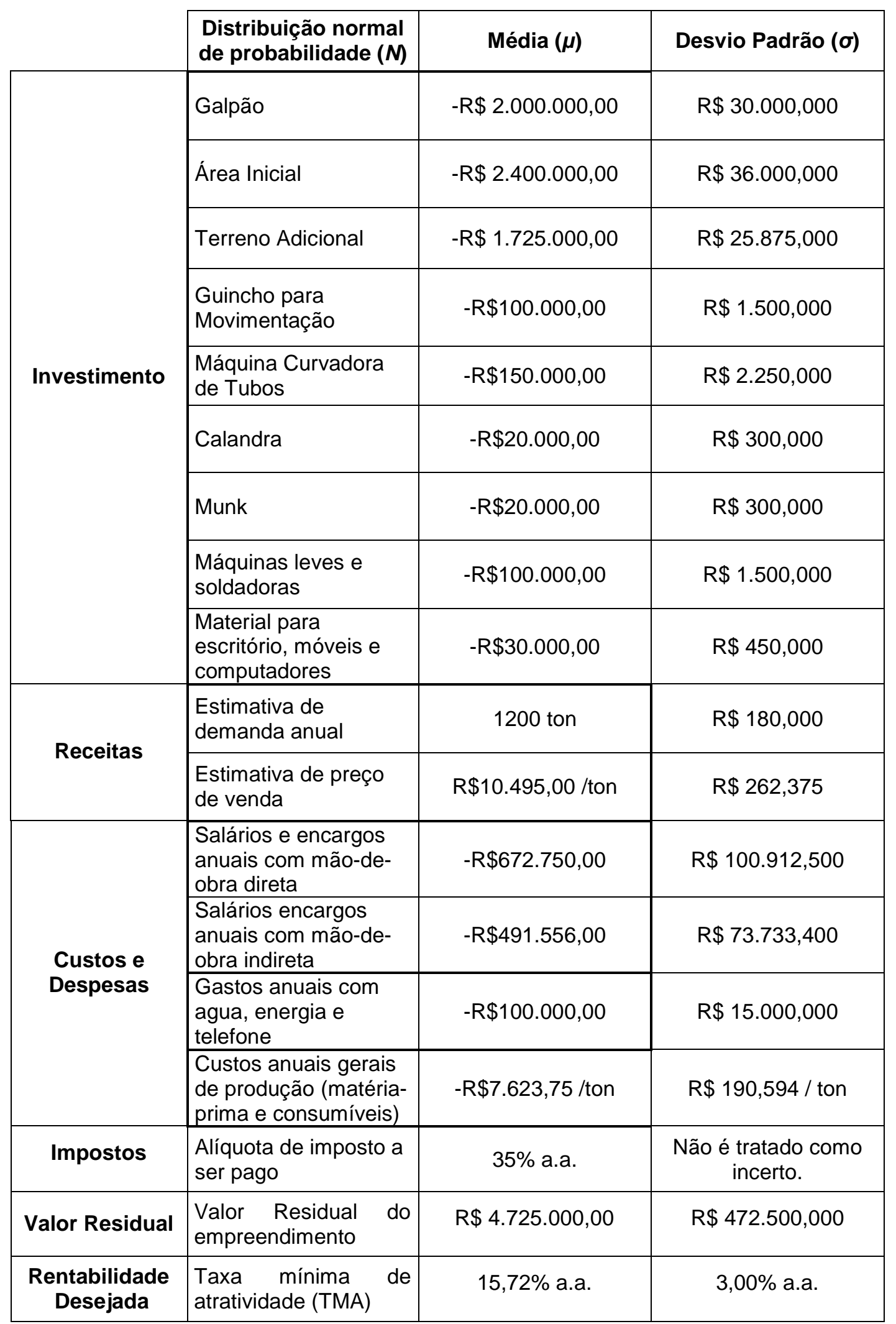


Neste trabalho, toda a operacionalização da simulação de Monte Carlo é realizada por meio do software Crystall Ball. Tal programa funciona acoplado ao Microsoft@ Excel e permite boa interface e aplicabilidade para executar problemas de caráter estatístico onde seja usada a geração de números aleatórios.

Para executar a simulação da variável dependente $V P L$ é necessário atribuir, por meio do software, as distribuições de probabilidade em cada variável independente que compõe o projeto de investimento. A Figura 62 mostra o uso do Crystall Ball para inserção dos parâmetros da distribuição de probabilidade da variável independente Galpão na planilha de cálculo, que se constituem na média, desvio-padrão e intervalo de confiança adotado (95\%).

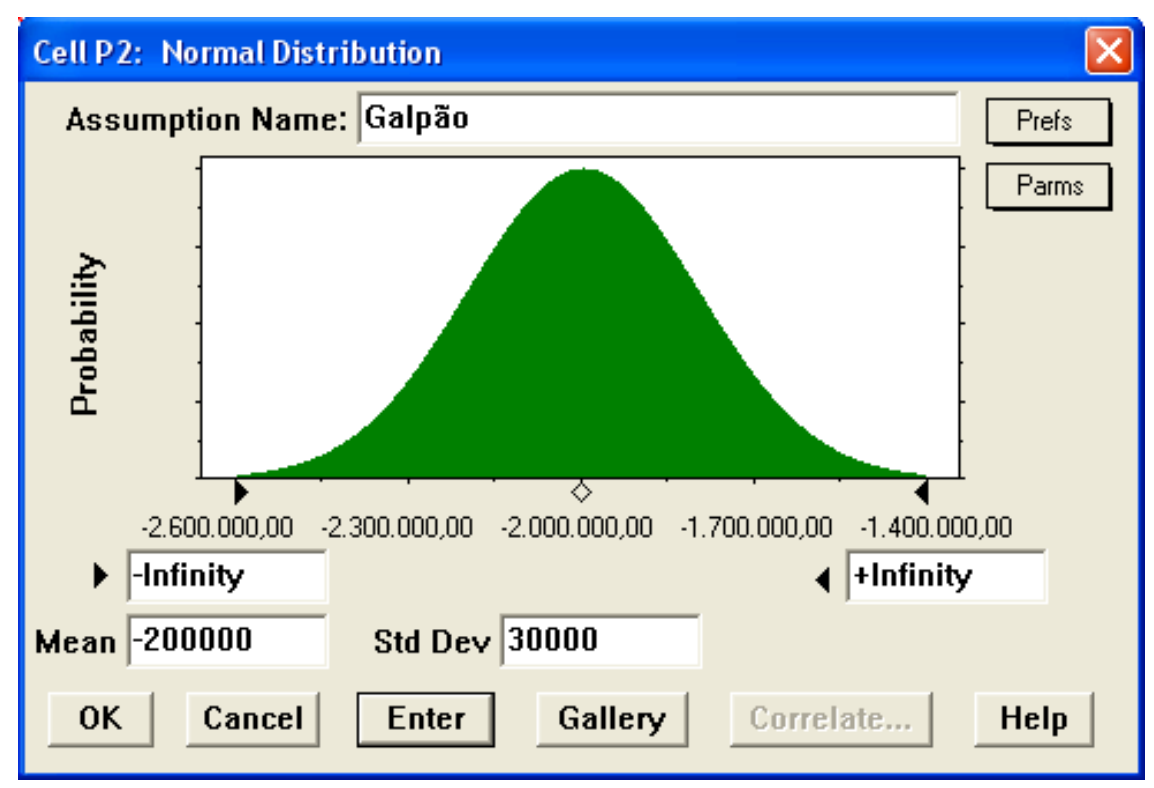

Figura 62- Definição da variável Galpão na simulação utilizando o Crystall Ball

\subsubsection{Atribuição dos números aleatórios e execução da simulação}


Para prosseguir no desenvolvimento da simulação é necessário definir a quantidade de números aleatórios que serão utilizados para calcular a variável dependente. Os números aleatórios serão gerados de maneira que obedeçam às distribuições de probabilidade associadas a cada variável independente.

O Crystall Ball solicita que sejam definidas as quantidades de cenários que serão gerados. Para esta aplicação o número estipulado é de 30.000. Como ao todo existem 17 variáveis independentes, a reposta obtida a partir da simulação será baseada em 510.000 números aleatórios gerados.

Após construída a planilha, definida as distribuições de probabilidade das variáveis independentes e a quantidade de números aleatórios a ser utilizada, a simulação é executada.

\subsubsection{Resultados da simulação}

O resultado da simulação de Monte Carlo é uma distribuição de probabilidades que representa o Valor Presente Líquido do projeto. A Figura 63 apresenta o histograma gerado pela simulação. 


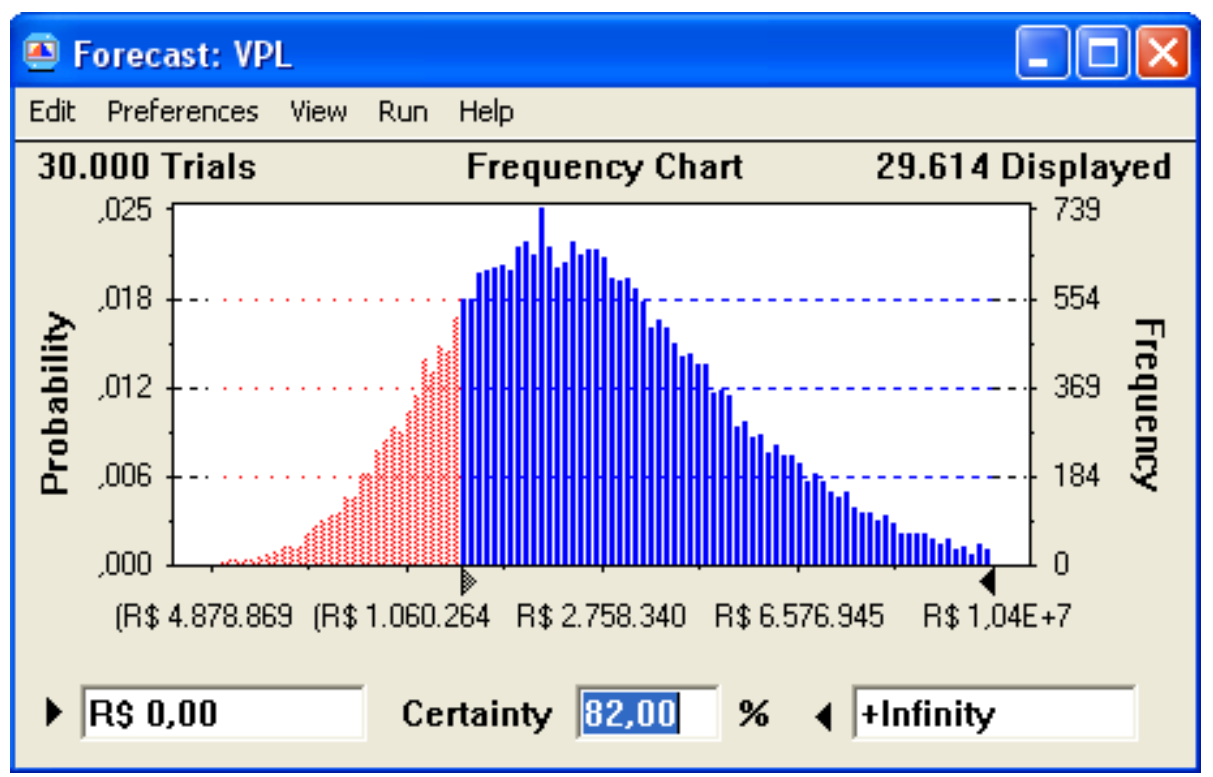

Figura 63 - VPL obtido como resultado da simulação

O software Crystall Ball propicia que a probabilidade cumulativa seja calculada. A probabilidade de que o $V P L$ seja maior ou menor do que 0 (áreas em azul e vermelho no histograma gerado) são informações relevantes pois representam o provável resultado deste investimento.

Pelo indicador Certainly da Figura 63, observa-se que a probabilidade do VPL ser maior do que 0 é $82 \%$. Desta forma a probabilidade de insucesso do empreendimento é:

$$
\begin{gathered}
P(V P L \geq 0)=0,8200 \\
P(V P L<0)=1-0,8200 \\
P(V P L<0)=18,00 \%
\end{gathered}
$$

Além de oferecer o cálculo da probabilidade de sucesso ou insucesso do investimento, o software utilizado permite que seja extraído um grande número de informações estatísticas sobre a simulação. As mais importantes são apresentadas na Figura 64. 


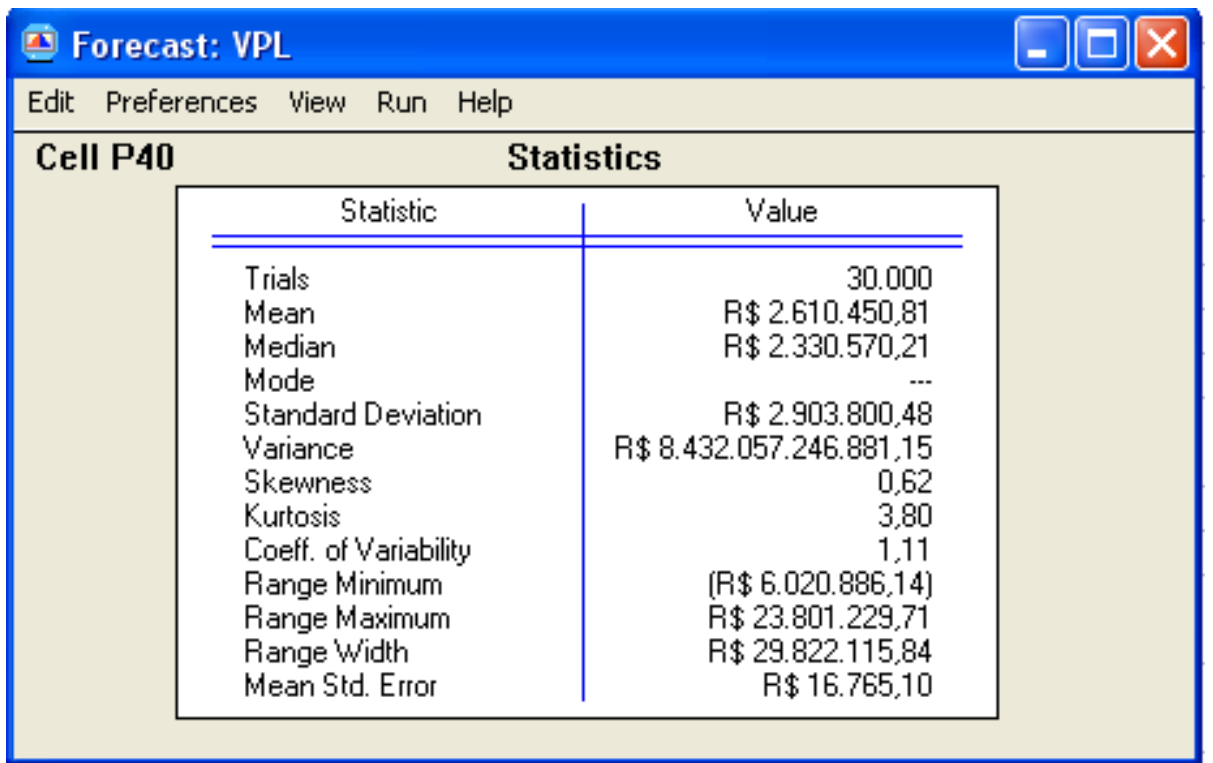

Figura 64 - Indicadores estatísticos obtidos através da simulação

As informações consideradas relevantes para este trabalho são o indicadores Mean, que representa o VPL médio obtido pela simulação, o Range Minimun e o Range Maximun, que representam respectivamente o menor e o maior valor de $V P L$ gerado pela combinação das variáveis independentes durante a simulação.

A Tabela 6 faz um síntese sobre as principais informações obtidas pela aplicação do método de Monte Carlo aplicado à variável $V P L$, que servirá como base para comparação de resultados junto ao $V P L_{f u z z y}$.

Tabela 6 - Resultados obtidos pela aplicação da Simulação de Monte Carlo

\begin{tabular}{|c|c|c|c|c|}
\hline & $\begin{array}{l}\text { Valor mínimo } \\
\left(\text { VPL }_{\text {min }}\right)\end{array}$ & $\begin{array}{l}\text { Valor esperado } \\
\text { (VPL esperado) }\end{array}$ & $\begin{array}{l}\text { Valor máximo } \\
\text { (VPL máx) }\end{array}$ & \begin{tabular}{|c} 
Probabilidade de \\
insucesso
\end{tabular} \\
\hline $\begin{array}{l}\text { Método de } \\
\text { Monte Carlo }\end{array}$ & $-\mathrm{R} \$ 6.020 .086,14$ & $\mathrm{R} \$ 2.610 .450,81$ & $\mathrm{R} \$ 23.801 .229,71$ & $18,00 \%$ \\
\hline
\end{tabular}

Diferentemente dos resultados obtido pela aplicação do $V P L$ determinístico, os resultados obtidos pela aplicação do método de Monte Carlo consideram as faixas de incerteza estimada. Por meio da aplicação deste método é possível obter a informação de que existe probabilidade de insucesso econômico-financeiro do empreendimento, calculada em $18 \%$. Sabe-se que o valor mais provável para o VPL é R $\$ 2.610 .450,81$ 
e se as variáveis se comportarem da pior forma haverá um prejuízo de $-\mathrm{R} \$$ $6.020 .086,14$

A inclusão das incertezas em um modelo de análise apresenta informações relevantes aos investidores e ganham importância em estudos onde são comparados vários projetos de investimento, pois propicia o uso de uma quantidade maior de ferramentas matemáticas para comparação.

A aplicação do método de Monte Carlo apresenta novas informações para a análise que servem de subsídios para a decisão a ser tomada; porém a opção pela realização ou não de um investimento é estritamente pessoal e depende do grau de aversão à incerteza e ao risco de cada investidor. $\mathrm{Na}$ economia poucos são os investimentos tratados como totalmente certos; à medida que a rentabilidade desejada aumenta, os investimentos podem se tornar mais incertos. Caso os investidores acreditem que a probabilidade de insucesso é aceitável o investimento deverá ser realizado. Caso a opinião seja de que esta probabilidade é alta, uma possível opção seria rever a TMA utilizada, e possivelmente decidir por outra alternativa, como por exemplo, investimentos em renda fixa.

\subsection{A AVALIAÇÃO ECONÔMICO-FINANCEIRA DO PROJETO DE INVESTIMENTO UTILIZANDO VPL FUZZY}

Prosseguindo com os métodos para a avaliação econômico-financeira, iniciase a estruturação para o uso do $V P L_{f u z z y}$, que apresenta-se organizada em três etapas: fuzzificação das variáveis de entrada, cálculo e defuzzificação.

Todas as etapas de cálculo foram elaboradas utilizando o Microsoft@ Excel, que embora não apresente nenhuma função específica para aplicação da lógica Fuzzy 
mostrou-se suficiente para a execução do estudo. A opção pelo uso do Excel tem o intuito de contemplar um dos objetivos centrais do trabalho: o de divulgar e promover o uso da matemática Fuzzy em aplicações práticas e acadêmicas da Engenharia de Produção, visto que este software é, sem dúvida, um dos mais utilizados nesta área da engenharia.

\subsubsection{A fuzzificação das variáveis}

Por meio da fuzzificação é possível transformar os conceitos incertos que estão presentes nas variáveis que compõem o investimento em números Fuzzy. As informações sobre cada variável apresentadas na Tabela 4, serão utilizadas como os parâmetros para obtenção dos números Fuzzy.

A variável que representa o investimento no Galpão, por exemplo, apresenta valor esperado em $-\mathrm{R} \$ 2.000 .000,00$ e a incerteza estipulada corresponde a $\pm 3 \%$. A partir destas informações é possível obter o número triangular Fuzzy correspondente:

$$
\text { Galpão }_{f u z z y}=\left(\text { Galpão }_{1}, \text { Galpão }_{2}, \text { Galpão }_{3}\right)
$$

Galpão $_{2}=$ valor esperado do investimento no Galpão

$$
\text { Galpão }_{2}=-\mathrm{R} \$ 2.000 .000,00
$$

$$
\begin{gathered}
\text { Galpão }_{1}=\text { Galpão }_{2} \times(1+\text { incerteza máxima estimada }) \\
\text { Galpão }_{1}=-2000000 \times(1+0,03)
\end{gathered}
$$




$$
\text { Galpão } o_{1}=-\mathrm{R} \$ 2.060 .000,00
$$

$$
\begin{gathered}
\text { Galpão }_{3}=\text { Galpão }_{2} \times(1-\text { incerteza mínima estimada }) \\
\text { Galpão }_{3}=-2000000 \times(1-0,03) \\
\text { Galpão }_{3}=-\mathrm{R} \$ 1.940 .000,00
\end{gathered}
$$

Assim tem-se:

$$
\text { Galpão }_{f u z z y}=(-\mathrm{R} \$ 2.060 .000,-\mathrm{R} \$ 2.000 .000,-\mathrm{R} \$ 1.940 .000)
$$

Utilizando a representação por $\alpha$-cut apresentada na capítulo 4 tem-se:

$$
\begin{aligned}
& \text { Galpão }_{f u z z y}=\left[\text { Galpão }^{l(\alpha)}, \text { Galpão }^{r(\alpha)}\right] \\
& \text { Galpão }^{l(\alpha)}=\left(\text { Galpão }_{2}-\text { Galpão }_{1}\right) \times \alpha+\text { Galpão }_{1}
\end{aligned}
$$

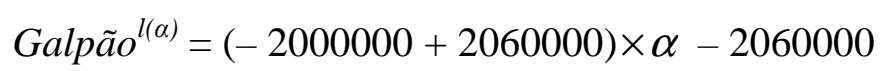

$$
\begin{aligned}
& \text { Galpão }^{l(\alpha)}=60000 \times \alpha-2060000 \\
& \text { Galpão }^{r(\alpha)}=-\left(\text { Galpão }_{3}-\text { Galpão }_{2}\right) \times \alpha+\text { Galpão }_{3} \\
& \text { Galpão }^{r(\alpha)}=-(1940000-2000000) \times \alpha-1940000 \\
& \text { Galpão }^{r(\alpha)}=-60000 \times \alpha-1940000
\end{aligned}
$$

De maneira análoga, o mesmo procedimento deve ser utilizado para obter os valores fuzzificados que representarão as outras variáveis incertas do investimento, culminando na Tabela 7. 
Tabela 7 - Variáveis fuzzificadas para o cálculo do Valor Presente Líquido Fuzzy

\begin{tabular}{|c|c|c|c|}
\hline & Número fuzzy & $I(\alpha)$ & $r(\alpha)$ \\
\hline \multirow{9}{*}{ Investimento } & Galpão & $60000 \times \alpha-2060000$ & $-60000 \times \alpha-1940000$ \\
\hline & Área Inicial & $72000 \times \alpha-2472000$ & $-72000 \times \alpha-2328000$ \\
\hline & Terreno Adicional & $51750 \times \alpha-1776750$ & $-51750 \times \alpha-1673250$ \\
\hline & $\begin{array}{l}\text { Guincho para } \\
\text { Movimentação }\end{array}$ & $3000 \times \alpha-103000$ & $-3000 \times \alpha-97000$ \\
\hline & $\begin{array}{l}\text { Máquina Curvadora } \\
\text { de Tubos }\end{array}$ & $4500 \times \alpha-154500$ & $-4500 \times \alpha-145500$ \\
\hline & Calandra & $600 \times \alpha-20600$ & $-600 \times \alpha-19400$ \\
\hline & Munk & $600 \times \alpha-20600$ & $-600 \times \alpha-19400$ \\
\hline & $\begin{array}{l}\text { Máquinas leves e } \\
\text { soldadoras }\end{array}$ & $3000 \times \alpha-103000$ & $-3000 \times \alpha-97000$ \\
\hline & $\begin{array}{l}\text { Material para } \\
\text { escritório, móveis e } \\
\text { computadores }\end{array}$ & $900 \times \alpha-30900$ & $-900 \times \alpha-29100$ \\
\hline \multirow{2}{*}{ Receitas } & $\begin{array}{l}\text { Estimativa de } \\
\text { demanda anual }\end{array}$ & $360 \times \alpha+840$ & $-360 \times \alpha+1560$ \\
\hline & $\begin{array}{l}\text { Estimativa de preço } \\
\text { de venda }\end{array}$ & $524,75 \times \alpha+9970,25$ & $-524,75 \times \alpha+11019,75$ \\
\hline \multirow{4}{*}{$\begin{array}{l}\text { Custos e } \\
\text { Despesas }\end{array}$} & $\begin{array}{l}\text { Salários e encargos } \\
\text { anuais com mão- } \\
\text { de-obra direta }\end{array}$ & $201825 \times \alpha-874575$ & $-201825 \times \alpha-470925$ \\
\hline & $\begin{array}{l}\text { Salários encargos } \\
\text { anuais com mão- } \\
\text { de-obra indireta }\end{array}$ & $\begin{array}{c}147466,80 \times \alpha- \\
639022,80\end{array}$ & $\begin{array}{c}-147466,80 \times a- \\
344089,20\end{array}$ \\
\hline & $\begin{array}{l}\text { Gastos anuais com } \\
\text { agua, energia e } \\
\text { telefone }\end{array}$ & $30000 \times \alpha-130000$ & $-30000 \times \alpha-70000$ \\
\hline & $\begin{array}{l}\text { Custos anuais } \\
\text { gerais de produção } \\
\text { (matéria-prima e } \\
\text { consumíveis) }\end{array}$ & $381,19 \times \alpha-8004,94$ & $-381.19 \times \alpha-7242,56$ \\
\hline Impostos & $\begin{array}{l}\text { Alíquota de imposto } \\
\text { a ser pago }\end{array}$ & \multicolumn{2}{|c|}{ Não é tratado como incerto. } \\
\hline Valor Residual & $\begin{array}{l}\text { Valor Residual do } \\
\text { empreendimento }\end{array}$ & $4725000 \times \alpha-3780000$ & $-945000 \times \alpha+5670000$ \\
\hline $\begin{array}{l}\text { Rentabilidade } \\
\text { Desejada }\end{array}$ & $\begin{array}{l}\text { Taxa mínima de } \\
\text { atratividade (TMA) }\end{array}$ & $0,060 \times \alpha+0,097$ & $-0,060 \times \alpha+0,217$ \\
\hline
\end{tabular}




\subsubsection{O cálculo do VPL fuzzy $_{\text {f }}$}

Para realização do cálculo é necessário executar algumas operações intermediárias de modo que as variáveis sejam organizadas. Conceitualmente, as operações seguintes seguem o modelo determinístico apresentado no item 5.5.7, porém nos cálculos a seguir as variáveis encontram-se em sua forma Fuzzy.

\section{- Investimento Total}

A primeira etapa consiste em obter um número Fuzzy que represente todo investimento necessário para execução do projeto:

Investimento Total $_{f u z z y}=\left[\right.$ Investimento Total $^{l(\alpha)}$, Investimento Total $\left.^{r(\alpha)}\right]$

(Eq. 5.44)

Investimento Total $^{l(\alpha)}=$ Galpão $^{l(\alpha)}+$ Área Inicial $^{l(\alpha)}+$ Terreno Adicional $^{l(\alpha)}+$ Guincho para Movimentação ${ }^{l(\alpha)}+$ Máquina Curvadora de Tubos $^{l(\alpha)}+$ Calandra $^{l(\alpha)}+$ Munk $^{l(\alpha)}+$ Máquinas leves e soldadoras ${ }^{l(\alpha)}+$ Material para escritório, móveis e computadores $^{l(\alpha)}$

(Eq. 5.45)

Investimento Total $^{r(\alpha)}=$ Galpão $^{r(\alpha)}+$ Área Inicial $^{r(\alpha)}+$ Terreno Adicional $^{r(\alpha)}+$

Guincho para Movimentação ${ }^{r(\alpha)}+$ Máquina Curvadora de Tubos ${ }^{r(\alpha)}+$ Calandra $^{r(\alpha)}$ + Munk $^{r(\alpha)}+$ Máquinas leves e soldadoras ${ }^{r(\alpha)}+$ Material para escritório, móveis e computadores $^{r(\alpha)}$ 


\section{- Receita Anual Total}

Prosseguindo com os cálculos, é necessário obter a receita total que o empreendimento apresentará em sua representação Fuzzy, descrita pelas equações abaixo:

(Eq. 5.46)

Receita Anual Total $_{f u z z y}=\left[\right.$ Receita Anual Total ${ }^{l(\alpha)}$, Receita Anual Total $\left.^{r(\alpha)}\right]$

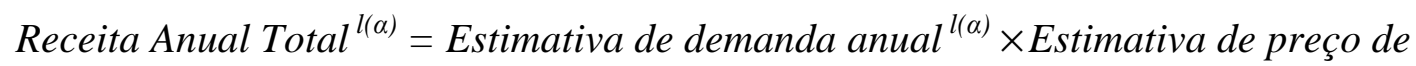
venda ${ }^{l(\alpha)}$

(Eq. 5.48)

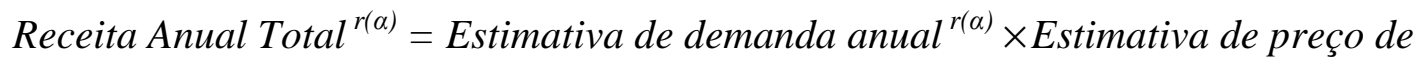
venda ${ }^{r(\alpha)}$

\section{- Custos e Despesas Anuais Totais}

Os custos e despesas totais anuais representam todo dispêndio de capital que serão gerados ao longo da vida econômica do projeto após a sua execução:

(Eq. 5.49)

Custos e Despesas Anuais Totais fuzzy $=\left[\right.$ Custos e Despesas Anuais Totais $^{l(\alpha)}$, Custos e Despesas Anuais Totais $\left.{ }^{r(\alpha)}\right]$ 
(Eq. 5.50)

Custos e Despesas Anuais Totais ${ }^{l(\alpha)}=\left[\right.$ Estimativa de demanda anual ${ }^{l(\alpha)} \times$ Custos anuais gerais de produção (matéria-prima e consumíveis) $\left.{ }^{l(\alpha)}\right]+$ Salários e encargos com mão-de-obra direta ${ }^{l(\alpha)}+$ Salários e encargos com mão-de-obra indireta ${ }^{l(\alpha)}+$ Água, energia e telefone $e^{l(\alpha)}$

(Eq. 5.51)

Custos e Despesas Anuais Totais ${ }^{r(\alpha)}=\left[\right.$ Estimativa de demanda anual ${ }^{r(\alpha)} \times$ Custos anuais gerais de produção (matéria-prima e consumíveis) $\left.{ }^{r(\alpha)}\right]+$ Salários e encargos com mão-de-obra direta ${ }^{r(\alpha)}+$ Salários e encargos com mão-de-obra indireta ${ }^{r(\alpha)}+$ Água, energia e telefone $e^{r(\alpha)}$

\section{- O Fluxo de Caixa antes dos impostos}

Assim como no cálculo do VPL determinístico, o fluxo de caixa antes dos impostos é obtido pela combinação entre receitas e saídas de caixa ao longo da vida econômica do projeto:

(Eq. 5.52)

Fluxo de Caixa antes dos impostos fuzzy $=\left[\right.$ Fluxo de Caixa antes dos impostos $^{l(\alpha)}$,

Fluxo de Caixa antes dos impostos $\left.{ }^{r(\alpha)}\right]$

(Eq. 5.53)

Fluxo de Caixa antes dos impostos ${ }^{l(\alpha)}=$ Receita Anual Total ${ }^{l(\alpha)}+$ Custos e Despesas Anuais Totais ${ }^{l(\alpha)}$ 
Fluxo de Caixa antes dos impostos ${ }^{r(\alpha)}=$ Receita Anual Total ${ }^{r(\alpha)}+$ Custos e Despesas Anuais Totais ${ }^{r(\alpha)}$

\section{- Depreciação Anual Total}

A contabilização da Depreciação Anual Total é obtida pela somatória dos valores investidos em ativos depreciáveis para execução do projeto divididos pelo período de depreciação, neste projeto, de 10 anos:

(Eq. 5.55)

Depreciação Anual Total ${ }_{\text {fuzzy }}=\left[\right.$ Depreciação Anual Total ${ }^{l(\alpha)}$, Depreciação Anual Total $\left.^{r(\alpha)}\right]$

(Eq. 5.56)

Depreciação Anual Total ${ }^{l(\alpha)}=\left(\right.$ Galpão $^{l(\alpha)}+$ Guincho para Movimentação $^{l(\alpha)}+$ Máquina Curvadora de Tubos ${ }^{l(\alpha)}+$ Calandra $^{l(\alpha)}+$ Munk $^{l(\alpha)}+$ Máquinas leves e soldadoras $^{l(\alpha)}+$ Material para escritório, móveis e computadores $\left.^{l(\alpha)}\right) / 10$

Depreciação Anual Total $^{r(\alpha)}=\left(\right.$ Galpão $^{r(\alpha)}+$ Guincho para Movimentação $^{r(\alpha)}+$ Máquina Curvadora de Tubos ${ }^{r(\alpha)}+$ Calandra $^{r(\alpha)}+$ Munk $^{r(\alpha)}+$ Máquinas leves e soldadoras $^{r(\alpha)}+$ Material para escritório, móveis e computadores $\left.{ }^{r(\alpha)}\right) / 10$

\section{- Fluxo de Caixa após os Impostos}


Obtidos os números Fuzzy que representam o valor depreciável dos ativos imobilizados, é possível obter o fluxo de caixa após os impostos. Conforme apresentado, as depreciações são factíveis até o décimo ano de projeto, desta forma o Fluxo de Caixa após os Impostos é representado por dois números Fuzzy distintos: o primeiro se refere ao período de 1 a 10 anos de projeto e o segundo de 11 a 15 anos.

(Eq. 5.58)

Fluxo de Caixa após os Impostos (1 a 10 anos) $)_{\text {fuzzy }}=[$ Fluxo de Caixa após os Impostos (1 a 10 anos $)^{l(\alpha)}$, Fluxo de Caixa após os Impostos $(1 \text { a } 10 \text { anos })^{r(\alpha)}$ ]

Fluxo de Caixa após os Impostos (1 a 10 anos $)^{l(\alpha)}=$ Fluxo de Caixa antes dos Impostos $^{l(\alpha)}$ - Alíquota de Imposto $\times\left[\right.$ Fluxo de Caixa antes dos Impostos ${ }^{l(\alpha)}+$ Depreciação Anual Total $\left.{ }^{l(\alpha)}\right]$

(Eq. 5.60)

Fluxo de Caixa após os Impostos (1 a 10 anos $)^{r(\alpha)}=$ Fluxo de Caixa antes dos Impostos $^{r(\alpha)}$ - Alíquota de Imposto $\times\left[\right.$ Fluxo de Caixa antes dos Impostos ${ }^{r(\alpha)}+$ Depreciação Anual Total $^{r(\alpha)}$ ]

Vale ressaltar que a Alíquota de Imposto não é considerada neste trabalho como uma variável incerta, portanto não é um número Fuzzy. Trata-se de uma constante que multiplica todos os valores obtidos pela a adição entre Fluxo de Caixa antes dos Impostos fuzzy e a Depreciação Anual Total fuzzy:

(Eq. 5.61) 
Fluxo de Caixa após os Impostos (1 a 10 anos $)^{l(\alpha)}=$ Fluxo de Caixa antes dos Impostos $^{l(\alpha)}-0,35 \times\left[\right.$ Fluxo de Caixa antes dos Impostos $^{l(\alpha)}+$ Depreciação Anual

$$
\text { Total } \left.^{l(\alpha)}\right]
$$

(Eq. 5.62)

Fluxo de Caixa após os Impostos (1 a 10 anos $)^{r(\alpha)}=$ Fluxo de Caixa antes dos Impostos $^{r(\alpha)}-0,35 \times\left[\right.$ Fluxo de Caixa antes dos Impostos ${ }^{r(\alpha)}+$ Depreciação Anual

$$
\left.\operatorname{Total}^{r(\alpha)}\right]
$$

A Figura 65 traz a representação gráfica do Fluxo de Caixa após os Impostos (1 a 10 anos) fuzzy:

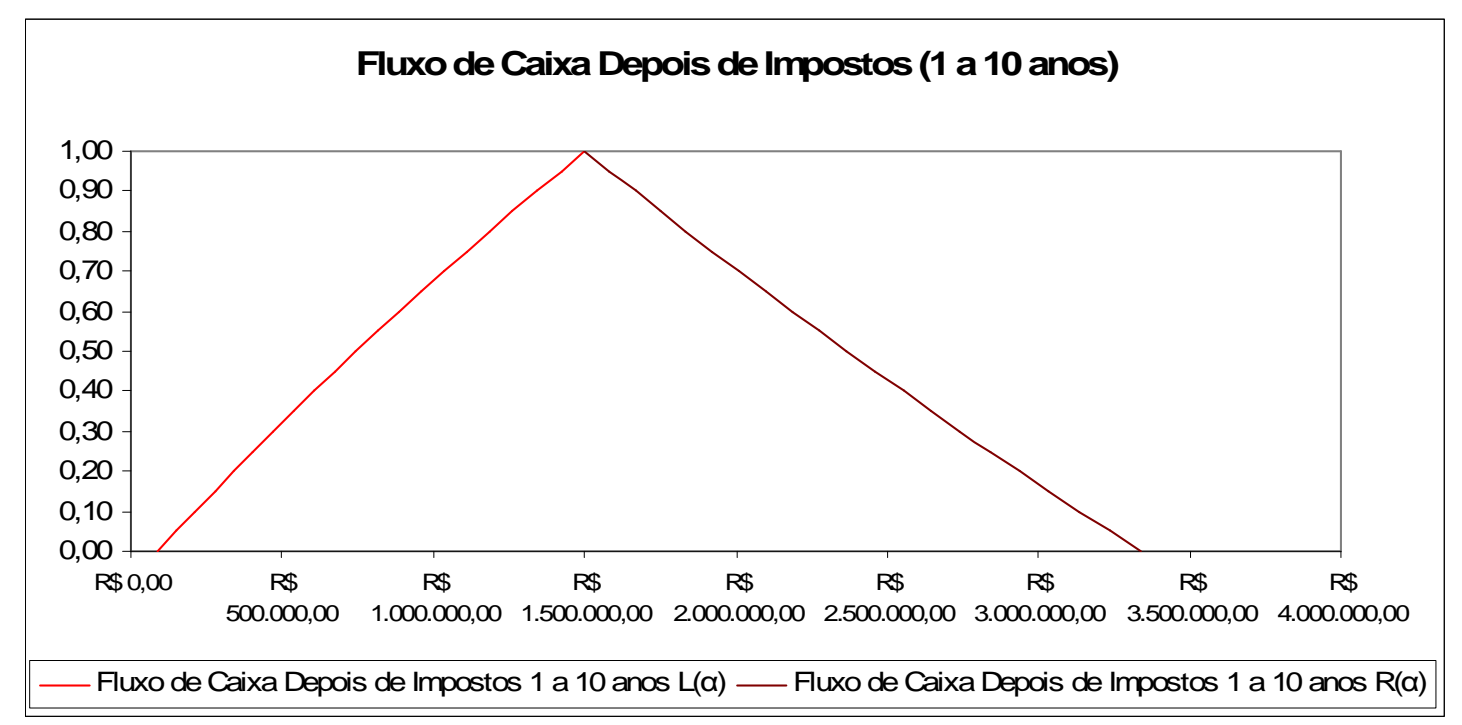

Figura 65 - Fluxo de caixa Fuzzy para o período de 1 a 10 anos

No período entre 11 e 15 anos de investimento, o fluxo de caixa após os impostos é obtido por:

(Eq. 5.63)

Fluxo de Caixa após os Impostos (11 a 15 anos) ${ }_{\text {fuzzy }}=[$ Fluxo de Caixa após os Impostos (11 a 15 anos $)^{l(\alpha)}$, Fluxo de Caixa após os Impostos $(11 \text { a } 15 \text { anos })^{r(\alpha)}$ ] 
(Eq. 5.64)

Fluxo de Caixa após os Impostos $(11 \text { a } 15 \text { anos })^{l(\alpha)}=(1-0,35) \times$ Fluxo de Caixa antes dos Impostos ${ }^{l(\alpha)}$

(Eq. 5.65)

Fluxo de Caixa após os Impostos $(11 \text { a } 15 \text { anos })^{r(\alpha)}=(1-0,35) \times$ Fluxo de Caixa antes dos Impostos $^{r(\alpha)}$

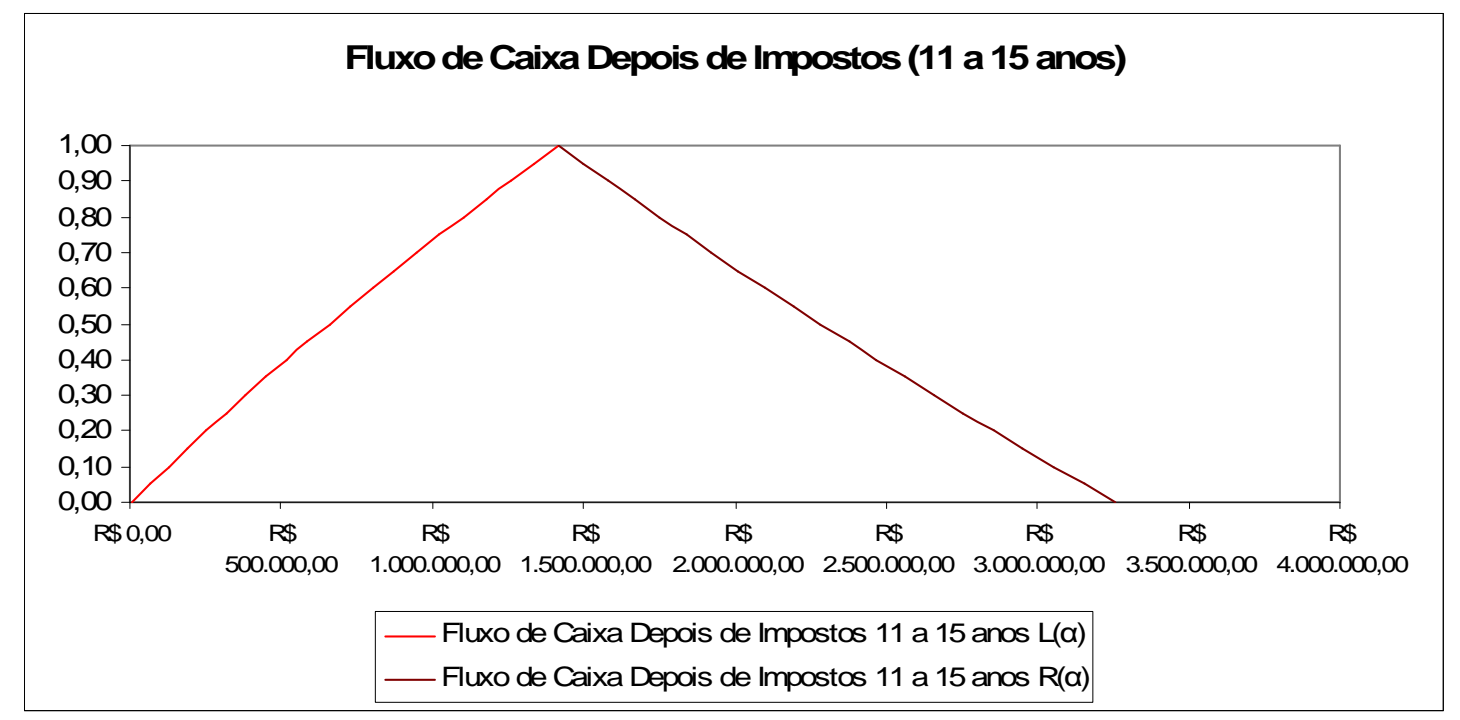

Figura 66 - Fluxo de caixa Fuzzy para o período de 11 a 15 anos

- O Valor Presente Líquido Fuzzy

Obtida a representação Fuzzy para o fluxo de caixa, aplicam-se os conceitos apresentados na equação do capítulo 4:

$$
V P L_{f u z z y}=\left[V P L_{f u z z y}^{l(\alpha)}, V P L_{f u z z y}^{r(\alpha)}\right]
$$


(Eq. 5.67)

$V P L_{f u z z y}^{l(\alpha)}=\left[\right.$ Investimento Total $\left.^{l(\alpha)}\right]+\sum_{j=0}^{10}[\max ($ Fluxo de Caixa após os Impostos $\left.\left.(1 \text { a } 10 \text { anos })^{l(\alpha)}, 0\right) /\left(1+T M A^{r(\alpha)}\right)^{j}\right)+\min ($ Fluxo de Caixa após os Impostos $(1$ a 10 anos $\left.\left.\left.^{l(\alpha)}, 0\right) /\left(1+T M A^{l(\alpha)}\right)^{j}\right)\right]+\sum_{j=11}^{15}[\max ($ Fluxo de Caixa após os Impostos $(11$ a 15 anos $\left.\left.^{l(\alpha)}, 0\right) /\left(1+T M A^{r(\alpha)}\right)^{j}\right)+\min ($ Fluxo de Caixa após os Impostos $(11$ a 15

$$
\text { anos } \left.\left.\left.^{l(\alpha)}, 0\right) /\left(1+\text { TMA }^{l(\alpha)}\right)^{j}\right)\right]+\left[\left(\text { Valor Residual }^{l(\alpha)}\right) /\left(1+\text { TMA }^{r(\alpha)}\right)^{15}\right]
$$

(Eq. 5.68)

$V P L_{f u z z y}^{r(\alpha)}=\left[\right.$ Investimento Total $\left.{ }^{r(\alpha)}\right]+\sum_{j=0}^{10}[\max ($ Fluxo de Caixa após os Impostos $\left.\left.(1 \text { a } 10 \text { anos })^{r(\alpha)}, 0\right) /\left(1+\text { TMA }^{l(\alpha)}\right)^{j}\right)+\min ($ Fluxo de Caixa após os Impostos $(1$ a 10 anos $\left.\left.\left.)^{r(\alpha)}, 0\right) /\left(1+T_{M} A^{r l(\alpha)}\right)^{j}\right)\right]+\sum_{j=11}^{15}[\max ($ Fluxo de Caixa após os Impostos $(11$ a 15 anos $\left.\left.)^{r(\alpha)}, 0\right) /\left(1+T M A^{l(\alpha)}\right)^{j}\right)+\min ($ Fluxo de Caixa após os Impostos $(11$ a 15

$$
\text { anos } \left.\left.\left.^{r(\alpha)}, 0\right) /\left(1+\text { TMA }^{r(\alpha)}\right)^{j}\right)\right]+\left[\left(\text { Valor Residual }^{r(\alpha)}\right) /\left(1+\text { TMA }^{l(\alpha)}\right)^{15}\right]
$$

A Figura 67 traz a representação gráfica do Valor Presente Líquido calculado para este projeto de investimento. 


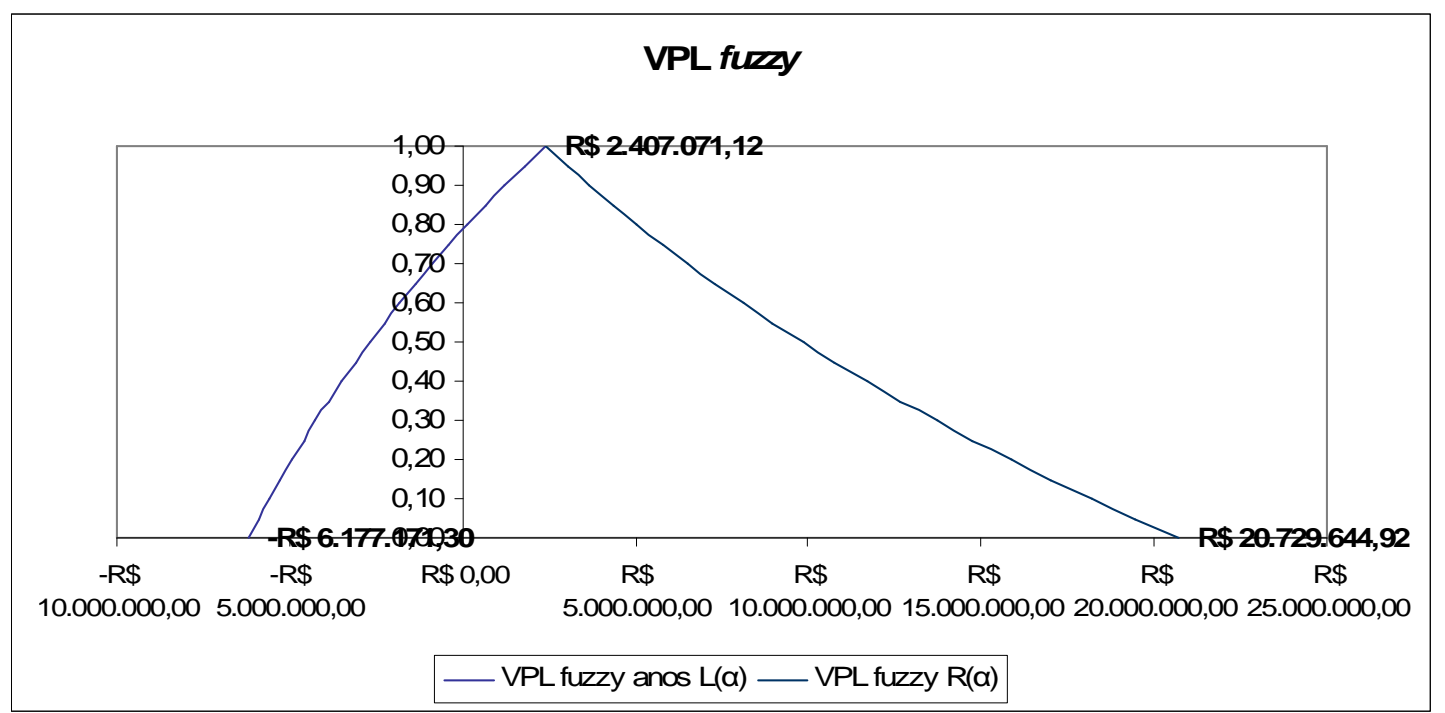

Figura 67 - Valor Presente Líquido Fuzzy do projeto de investimento

\subsubsection{A defuzzificação do Valor Presente Líquido Fuzzy}

\section{- O valor mais possível para o VPL fuzzy}

Para representar as variáveis obtidas em variáveis reais passíveis de interpretação, inicia-se a etapa de defuzificação. Por meio da aplicação do método do Centro da Área é possível obter o valor do $V P L$ de maior possibilidade no domínio real:

$$
V P L^{*}=\frac{\sum_{j=1}^{N} V P L_{f u z z y} \times \mu\left(V P L_{f u z z y}\right)}{\sum_{j=1}^{N} \mu\left(V P L_{f u z z y}\right)}
$$

Em que:

$N$ é o número de iterações a serem realizadas;

$\mu\left(V P L_{f u z z y}\right)$ é a função que descreve a pertinência do $V P L_{f u z z y}$. 
Utilizando-se $N=40$ é o obtido o valor defuzzificado:

$$
V P L^{*}=\mathrm{R} \$ 3.153 .147,04
$$

A Figura 68 representa o valor mais possível obtido pela defuzzificação:

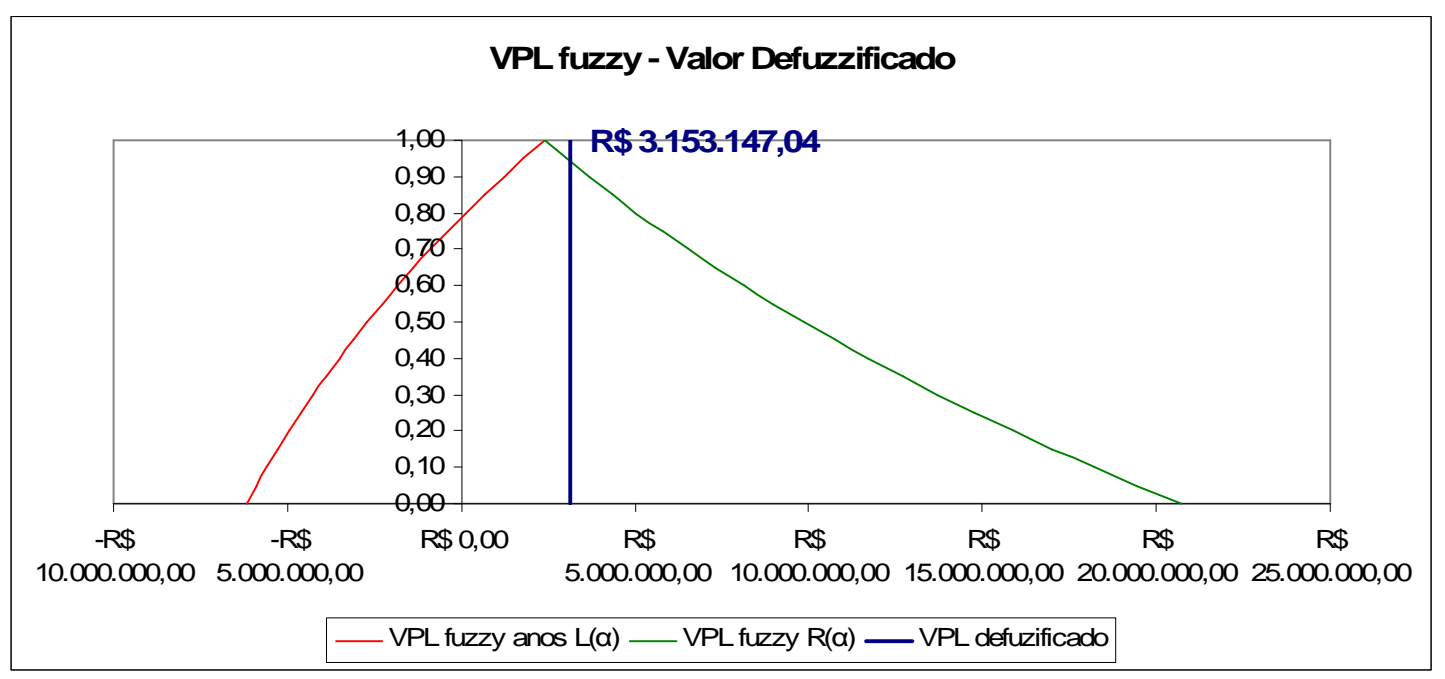

Figura 68 - Defuzzificação do Valor Presente Líquido Fuzzy do projeto de investimento

\section{- Pior e melhor situações possíveis para o investimento}

O pior resultado que o investimento poderá apresentar segundo esta aplicação da lógica Fuzzy é obtida pelo valor de $\alpha$ igual a 0 na função $V P L_{f u z z y}{ }^{l(\alpha)}$. 
$V P L_{f u z z y}^{l(0)}=\left[\right.$ Investimento Total $\left.{ }^{l(0)}\right]+\sum_{j=0}^{10}[\max ($ Fluxo de Caixa após os Impostos $\left.\left.(1 \text { a } 10 \text { anos })^{l(0)}, 0\right) /\left(1+T M A^{r(0)}\right)^{j}\right)+\min ($ Fluxo de Caixa após os Impostos $(1$ a 10 anos $\left.\left.\left.^{l(0)}, 0\right) /\left(1+\text { TMA }^{l(0)}\right)^{j}\right)\right]+\sum_{j=11}^{15}[\max ($ Fluxo de Caixa após os Impostos $(11$ a 15 anos $^{l(0)}$, 0) / $\left.\left(1+T M A^{r(0)}\right)^{j}\right)+\min ($ Fluxo de Caixa após os Impostos $(11$ a 15

$$
\text { anos } \left.\left.\left.^{l(0)}, 0\right) /\left(1+\text { TMA }^{l(\alpha)}\right)^{j}\right)\right]+\left[\left(\text { Valor Residual }^{l(0)}\right) /\left(1+\text { TMA }^{r(0)}\right)^{15}\right]
$$

$$
V P L_{f u z z y}^{l(0)}=-\mathrm{R} \$ 6.177 .171,30
$$

O valor que representa o melhor resultado possível para o projeto de investimento é obtido pela substituição do 0 em $\alpha$ na função $V P L_{f u z z y}{ }^{r(\alpha)}$ :

(Eq. 5.72)

$V P L_{f u z z y}^{r(0)}=\left[\right.$ Investimento Total $\left.{ }^{r(0)}\right]+\sum_{j=0}^{10}[\max ($ Fluxo de Caixa após os Impostos $\left.\left.(1 \text { a } 10 \text { anos })^{r(0)}, 0\right) /\left(1+\text { TMA }^{l(0)}\right)^{j}\right)+\min ($ Fluxo de Caixa após os Impostos $(1$ a 10 anos $\left.\left.\left.)^{r(0)}, 0\right) /\left(1+\text { TMA }^{r(0)}\right)^{j}\right)\right]+\sum_{j=11}^{15}[\max ($ Fluxo de Caixa após os Impostos $(11$ a 15 anos $\left.\left.^{r(0)}, 0\right) /\left(1+\text { TMA }^{l(0)}\right)^{j}\right)+\min ($ Fluxo de Caixa após os Impostos $(11$ a 15

$$
\text { anos } \left.\left.\left.^{r(0)}, 0\right) /\left(1+\text { TMA }^{r(0)}\right)^{j}\right)\right]+\left[\left(\text { Valor Residual }^{r(0)}\right) /\left(1+\text { TMA }^{l(0)}\right)^{15}\right]
$$

$$
V P L_{f u z z y}^{r(0)}=\mathrm{R} \$ 20.729 .644,92
$$

\section{- A possibilidade de insucesso do projeto de investimento}


Como apresentado na Figura 68, o $V P L_{f u z z y}$ contempla valores positivos e negativos, fazendo com que seja necessário o cálculo da possibilidade cumulativa $\left[\mu^{*}\left(V P L_{f u z z y}<0\right)\right]$ para identificar a possibilidade de insucesso do projeto de investimento. Aplicando-se a equação tem-se:

$$
\begin{gathered}
\mu^{*}\left(V P L_{f u z z y}<0\right)=\left|\begin{array}{|}
\int_{-6.177 .171,30}^{0} \mu\left(V P L_{f u z z y}\right) \\
\int_{-6.1729 .644,92}^{20} \mu\left(V P L_{f u z z y}\right)
\end{array}\right| \\
\mu^{*}\left(V P L_{f u z z y}<0\right)=0,2219 \\
\mu^{*}\left(V P L_{f u z z y}<0\right)=22,19 \%
\end{gathered}
$$

A Tabela 8 apresenta as informações obtidas pelo uso do Valor Presente Líquido Fuzzy para avaliação econômico-financeira do projeto de investimento:

Tabela 8 - Resultados obtidos pela aplicação do Valor Presente Líquido Fuzzy

\begin{tabular}{|c|c|c|c|c|}
\cline { 2 - 5 } \multicolumn{1}{c|}{} & $\begin{array}{c}\text { Valor mínimo } \\
\left(V^{1}\right.\end{array}$ & $\begin{array}{c}\text { Valor esperado } \\
\text { min })\end{array}$ & $\begin{array}{c}\text { Valor máximo } \\
\left(\text { VPL }_{\text {esperado }}\right)\end{array}$ & $\begin{array}{c}\text { Possibilidade de } \\
\text { insucesso }\end{array}$ \\
\hline $\mathrm{VPL}_{\text {fuzzy }}$ & $-\mathrm{R} \$ 6.177 .171,30$ & $\mathrm{R} \$ 3.153 .147,04$ & $\mathrm{R} \$ 20.729 .644,92$ & $22,19 \%$ \\
\hline
\end{tabular}

\subsection{A COMPARAÇÃO ENTRE O VPL OBTIDO PELA SIMULAÇÃO DE MONTE}

CARLO E O VPL FUZZY

Conforme apresentado no primeiro capítulo deste trabalho, dois grupos de análises serão elaborados para que seja estruturada a comparação entre os métodos 
apresentados. O primeiro deles refere-se a análises quantitativas, já o segundo destinase a comparações qualitativas.

\subsubsection{Grupo de análises quantitativas}

\section{- A comparação entre os valores obtidos}

A simulação de Monte Carlo aplicada ao VPL e o Valor Presente Líquido Fuzzy apresentam respostas de caráter matemático, o que torna possível confrontar diretamente os valores obtidos pela aplicação de cada um dos métodos. A Tabela 9 apresenta a comparação entre resultados obtidos:

Tabela 9 - Análise numérica comparativa entre os valores obtidos pela aplicação da simulação de Monte Carlo e Valor Presente Líquido Fuzzy

\begin{tabular}{|c|c|c|c|c|}
\hline & $\begin{array}{l}\text { Valor mínimo } \\
\left(\text { VPL }_{\text {min }}\right)\end{array}$ & $\begin{array}{c}\text { Valor esperado } \\
\text { (VPL esperado) }\end{array}$ & $\begin{array}{c}\text { Valor máximo } \\
\text { (VPL máx) }\end{array}$ & $\begin{array}{l}\text { Insucesso do } \\
\text { investimento }\end{array}$ \\
\hline $\begin{array}{l}\text { Método de } \\
\text { Monte Carlo }\end{array}$ & $-\mathrm{R} \$ 6.020 .086,14$ & $\mathrm{R} \$ 2.610 .450,81$ & $\mathrm{R} \$ 23.801 .229,71$ & $18,00 \%$ \\
\hline VPL fuzzy & $-\mathrm{R} \$ 6.177 .171,30$ & $\mathrm{R} \$ 3.153 .147,04$ & $\mathrm{R} \$ 20.729 .644,92$ & $22,19 \%$ \\
\hline $\begin{array}{l}\text { Diferença } \\
\text { Percentual }\end{array}$ & $2,6 \%$ & $20,8 \%$ & $-12,9 \%$ & $4,19 \%$ \\
\hline
\end{tabular}

Tmando como referência os resultados obtidos pelo uso da simulação de Monte Carlo é calculada a linha que apresenta a diferença percentual entre os valores de resposta de cada método.

A variável que apresenta diferença mais significativa é o valor esperado para o $V P L$. Apesar da grande diferença entre os valores obtidos para este indicador, o valor esperado é muitas vezes pouco representativo, pois se trata de um valor único em 
meio a um grande universo de discurso que compreende os prováveis e possíveis resultados do empreendimento. Para um investidor, possivelmente a principal informação obtida pela aplicação dos dois métodos seja a quantificação de insucesso do investimento, cuja a diferença é 4,19\%. Apesar da diferença numérica presente em todos os indicadores obtidos como resposta, cada um dos métodos apresentam informações substancialmente próximas, levando-se em conta que são obtidas por concepções totalmente distintas.

A comparação numérica efetuada entre os resultados obtidos pelo método de Monte Carlo e o $V P L_{f u z z y}$, não permite conclusões exatas sobre qual deles apresenta respostas mais significativas frente à realidade do projeto, visto que o conceito de Valor Presente Líquido exprime os resultados financeiros presentes do projeto a partir projeções que representam o futuro. Desta forma, uma comparação desta natureza seria melhor subsidiada mediante estudos em projetos de investimento já realizados e com vida econômica finalizada, situação diferente da estudada neste trabalho.

\section{- Possíveis variações na aplicação dos métodos}

Mesmo que mantidas todas as entradas do modelo, tanto o método de Monte Carlo como o $V P L_{\text {fuzzy }}$ podem apresentar variações na maneira como são aplicados, podendo gerar algumas diferenças numéricas nas respostas obtidas. No caso da simulação de Monte Carlo, uma possível variação pode ser obtida pela reaplicação do método, já que a simulação ocorre por meio da geração de números aleatórios; em cada vez que o método for aplicado é de se esperar que haja alguma diferença no resultado obtido. 
Neste tópico, além de reaplicado o método, será alterada a quantidade de números aleatórios estipulada; o intuito é de adicionar maior variabilidade à comparação. Na primeira aplicação para o estudo de caso foram utilizados 510.000 números aleatórios, para a próxima simulação a ser apresentada, a quantidade foi aumentada para 1.530.000.

A Tabela 10 sintetiza as informações obtidas pela execução da simulação utilizando-se desta outra proposta de números aleatórios:

Tabela 10 - Comparação numérica entre valores obtidos pela simulação de Monte Carlo em duas diferentes situações

\begin{tabular}{|c|c|c|c|c|}
\cline { 2 - 5 } \multicolumn{1}{c|}{} & $\begin{array}{c}\text { Valor mínimo } \\
\left(\mathrm{VPL}_{\text {min }}\right)\end{array}$ & $\begin{array}{c}\text { Valor esperado } \\
\left(\mathrm{VPL} \text { esperado }^{\circ}\right.\end{array}$ & $\begin{array}{c}\text { Valor máximo } \\
\left(\mathrm{VPL}_{\text {máx }}\right)\end{array}$ & $\begin{array}{c}\text { Probabilidade de } \\
\text { insucesso }\end{array}$ \\
\hline $\begin{array}{c}\text { Método de } \\
\text { Monte Carlo }\end{array}$ & $-\mathrm{R} \$ 6.020 .086,14$ & $\mathrm{R} \$ 2.610 .450,81$ & $\mathrm{R} \$ 23.801 .229,71$ & $18,00 \%$ \\
\hline Reaplicação & $-\mathrm{R} \$ 6.384 .780,34$ & $\mathrm{R} \$ 2.602 .583,00$ & $\mathrm{R} \$ 20.340 .033,88$ & $18,02 \%$ \\
\hline $\begin{array}{c}\text { Erro de } \\
\text { reaplicação }\end{array}$ & $6,1 \%$ & $-0,3 \%$ & $-14,5 \%$ & $-0,02 \%$ \\
\hline
\end{tabular}

A linha Erro de reaplicação apresenta a variação percentual obtida pela reaplicação do método de Monte Carlo quando confrontada com os resultados iniciais, apresentados no tópico 5.6. Observa-se que, apesar de muito sensíveis para alguns indicadores, existe variação dos resultados mesmo quando mantidas as mesmas definições quanto às variáveis independentes do modelo.

Como não é baseado na geração de números aleatórios, Valor Presente Líquido Fuzzy não apresenta variações quanto à reaplicação do método em um mesmo modelo, porém é muito comum o uso de aproximações para seu cálculo, já que este artifício reduz sensivelmente sua complexidade. A aproximação consiste em representar cada número não triangular obtido pelos cálculos em números triangulares. A linha tracejada na Figura 69 representa a aproximação do $V P L_{f u z z y}$ : 


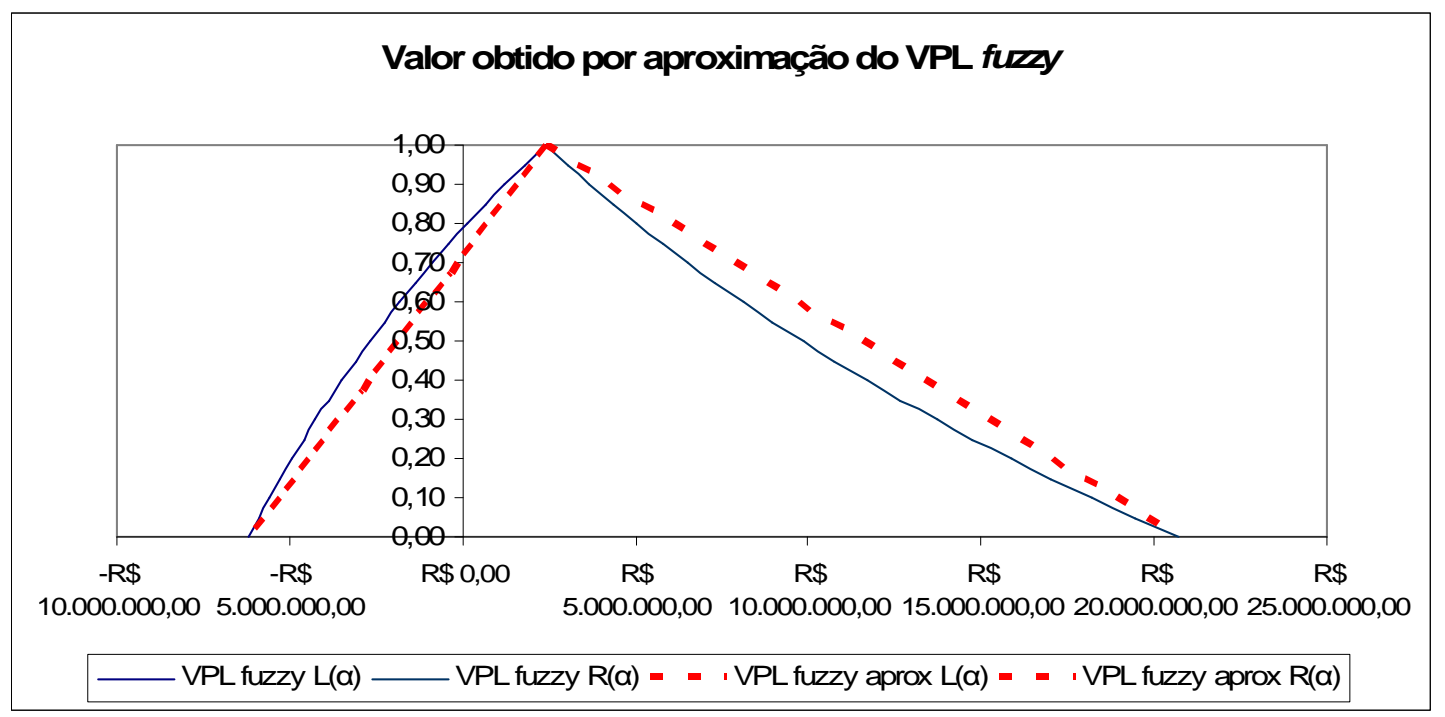

Figura 69 - Valor Presente Líquido Fuzzy obtido por aproximação

Nos trabalhos de Chiu e Park (1994), Sanchez (2003) e Omitaou et al (2007), o uso da aproximação para o $V P L_{f u z z y}$ é considerado matematicamente irrelevante, já que os resultados apresentam variações pouco significativas quando comparado aos cálculos sem aproximação. Vale ressaltar que, nos trabalhos citados, o número de variáveis Fuzzy utilizado é menor que nesta dissertação, que totaliza 17 números Fuzzy representando as variáveis que compõem o investimento.

A Tabela 11 apresenta os resultados obtidos pela defuzzificação do $V P L_{f u z z y}$ aproximado; nela são apresentadas também a comparação numérica frente aos resultados obtidos pelo cálculo sem aproximação.

Tabela 11- Comparação numérica entre valores obtidos pelo cálculo do Valor Presente Líquido Fuzzy efeutado sem aproximação e com aproximação matemática

\begin{tabular}{|c|c|c|c|c|}
\cline { 2 - 5 } \multicolumn{1}{c|}{} & $\begin{array}{c}\text { Valor mínimo } \\
\left(\mathrm{VPL}_{\text {min }} \text { ) }\right.\end{array}$ & $\begin{array}{c}\text { Valor esperado } \\
\left(\mathrm{VPL}_{\text {esperado }}\right)\end{array}$ & $\begin{array}{c}\text { Valor máximo } \\
\left(\mathrm{VPL}_{\text {máx }}\right)\end{array}$ & $\begin{array}{c}\text { Possibilidade de } \\
\text { insucesso }\end{array}$ \\
\hline $\mathrm{VPL}_{\text {fuzzy }}$ & $-\mathrm{R} \$ 6.177 .171,30$ & $\mathrm{R} \$ 3.153 .147,04$ & $\mathrm{R} \$ 20.729 .644,92$ & $22,19 \%$ \\
\hline $\mathrm{VPL}_{\text {fuzzy aprox }}$ & $-\mathrm{R} \$ 6.177 .171,30$ & $\mathrm{R} \$ 3.948 .973,59$ & $\mathrm{R} \$ 20.729 .644,92$ & $16,08 \%$ \\
\hline $\begin{array}{c}\text { Erro por } \\
\text { aproximação }\end{array}$ & $0,0 \%$ & $25,4 \%$ & $0,0 \%$ & $-6,11 \%$ \\
\hline
\end{tabular}


Observa-se que a aproximação gera um erro considerável no indicador de resposta mais importante; a possibilidade de insucesso do investimento, que passa de $22,19 \%$ para $16,08 \%$. Pelo grande número de ferramentas computacionais disponíveis a pesquisadores e aplicadores da lógica $F u z z y$, entende-se que a prática de aproximações para o cálculo do $V P L_{f u z z y}$ não deve ser utilizada, pois exprime diferença no resultado.

Embora os resultados obtidos pela reaplicação da simulação de Monte Carlo não tenha apresentado diferenças significativas, quando comparada ao seu resultado original, uma possível vantagem do uso do $V P L_{f u z z y}$ sem aproximação para com a simulação é sua independência à aleatoriedade, pois sempre que mantidas as mesmas entradas o resultado de cálculo é o mesmo.

\subsubsection{Grupo de análises qualitativas}

As análises qualitativas presentes no trabalho têm o intuito de proporcionar diversas comparações sobre a aplicabilidade da simulação de Monte Carlo e o Valor Presente Líquido Fuzzy não por suas respostas numéricas, mas sim pela compilação dos conceitos que envolvem cada um dos métodos.

- A facilidade em representar a incerteza presente no investimento como uma entrada para o modelo de cálculo

Para a execução da simulação de Monte Carlo, as variáveis incertas que compõem um investimento devem ser estruturadas por meio de distribuições de 
probabilidade, o que requer certo conhecimento em estatística, sobretudo quando temse o intuito de utilizar representações assimétricas para tais variáveis.

A lógica Fuzzy é fundamentada na existência de imprecisão, incerteza e definições qualitativas. A representação da incerteza presente nas variáveis que compõem o investimento por números triangulares Fuzzy é uma tarefa de natureza matemática bastante simplificada, pois para que seja efetuada a fuzzificação de uma variável presente no investimento, basta definir os vértices do triangulo que compõem o número Fuzzy. Apesar de não terem sido utilizadas durante o estudo de caso, se necessário o uso de variáveis assimétricas, basta deslocar o vértice do triangulo de pertinência igual a 1 dentro do universo em discurso.

\section{- A viabilidade de execução dos cálculos pertinentes em cada modelo}

Por se tratar de um método utilizado em um grande número de estudos estatísticos, as simulações de caráter estocástico, como a de Monte Carlo, podem ser executadas por diversos softwares no mercado. O Microsoft ${ }^{\circledR}$ Excel, por exemplo, apresenta diversos tipos de funções lógicas e da matemática, que permitem construir modelos de simulação sem grandes dificuldades.

Quando realizadas em softwares específicos, como o Crystall Ball, a facilidade para a execução das simulações é ainda maior. Além disto, estes aplicativos apresentam um grande número de informações estatísticas para a análise da variável simulada, embora a maior parte delas não seja representativa em situações onde a variável independente é o Valor Presente Líquido para um investimento.

Os modelos baseados em lógica Fuzzy por sua vez, constituem-se em concepções mais recentes e pouco conhecidas em algumas áreas da engenharia. São 
escassos os softwares específicos que permitem simplicidade ao cálculo do Valor Presente Líquido Fuzzy ou que sejam estruturados para aplicações diretas na área financeira. Na maioria das aplicações faz-se necessário a estruturação passo a passo do problema, tornando sua execução relativamente trabalhosa.

Dentre os softwares mais utilizados para aplicação da lógica Fuzzy descata-se o Matlab, o qual apresenta uma barra de ferramentas específica que permite a construção de sistemas e modelos de inferência ou cálculo. Apesar de propiciar ao usuário a construção de trabalhos complexos, a utilização deste software requer bons conhecimentos sobre programação, o que restringe seu uso.

O cálculo do Valor Presente Líquido Fuzzy apresentado no estudo de caso, fora executado pelo Microsoft ${ }^{\circledR}$ Excel. Como tal aplicativo não apresenta nenhuma função específica que contemple a lógica Fuzzy, a execução do trabalho deu-se de maneira bastante trabalhosa, visto que não foram encontrados, dentro da pesquisa bibliográfica realizada, trabalhos que mostrassem como representar as variáveis Fuzzy por meio daquele software.

Para a execução do cálculo do $V P L_{f u z z y}$ foram construídas quatro pastas de trabalho. A primeira delas, referente a fuzzificação das variáveis de caixa do investimento, constituída por 22 planilhas. A segunda, elaborada para a realização de cálculos de depreciação dos ativos, constituída por 8 planilhas. A terceira constitui os cálculos de impostos a serem pagos pela empresa, totalizando 5 planilhas. Por fim, a quarta pasta de trabalho, destinada aos cálculos referentes a defuzzificação das variáveis, constituída por 10 planilhas. Os arquivos em Excel elaborados para o cálculo estão gravados no CD em anexo a esta dissertação, servindo como mecanismo de consulta e aprendizado para pesquisadores interessados em aplicações da lógica Fuzzy. 


\section{- Facilidade de assimilação da resposta calculada pelos modelos matemáticos}

Conforme apresentado no grupo de análises quantitativas, os resultados obtidos, tanto pelo método de Monte Carlo como pelo Valor Presente Líquido Fuzzy apresentam respostas que pode ser parametrizadas e comparadas. Desta forma não há grande diferença sobre o tipo de resposta obtida, já que a aplicação de ambos os métodos pode apresentar respostas equivalentes.

\section{- Aplicabilidade junto ao estudo de caso efetuado}

O estudo de caso presente neste trabalho refere-se a criação de uma nova empresa; não há referência histórica ou conjunto de dados que possa servir como base para obtenção dos valores que compõem o fluxo de caixa. Pelas concepções apresentadas no capítulo 2, a situação que contempla o investimento é de incerteza. Uma situação de risco, apesar de conceitualmente próxima a de incerteza, é delineada quando existem dados que permitam relacionar situações passadas com projeções futuras.

O método de Monte Carlo, conforme definição de Casarotto Filho e Kopittke (2002), é adequado para situações de risco, onde, por meio de dados existentes sobre o investimento em questão, é possível obter distribuições de probabilidade que representem as variáveis independentes do projeto. Existem ferramentas estatísticas que permitem a associação de uma série de dados para compor informações sob o futuro, como os testes de aderência e as regressões lineares.

Quando não se dispõe de dados que permitam o uso de ferramentas estatísticas, ou acredita-se que o comportamento passado não apresenta relação com o 
comportamento de variáveis no futuro, uma das poucas alternativas é trabalhar junto às estimativas que representem o projeto de investimento.

Para análises de projetos de investimento sob condição de incerteza, estipular distribuições de probabilidade associadas a cada uma das variáveis presentes é uma tarefa difícil já que, em geral, não há informações concretas sobre o comportamento das variáveis, o que interfere diretamente em um dos pontos centrais das teorias que acercam a estatística; a análise de dados.

No projeto de investimento apresentado a incerteza presente é mensurada por conceitos não estatísticos, baseados em definições bastante subjetivas onde factivelmente, a imprecisão pode estar presente. Essencialmente a teoria Fuzzy é voltada para o desenvolvimento de conceitos e técnicas que permitam quantificar fontes de incerteza e imprecisão de natureza não estatística e de difícil mensuração; fato com que fez que tal teoria fosse aplicada com bastante sucesso em diversas da engenharia. Desta forma, acredita-se que os conceitos que envolvem a aplicação do Valor Presente Líquido Fuzzy sejam mais adequados para a avaliação de investimentos onde a condição presente é de incerteza.

A aceitação de um investimento deste porte, na grande maioria das vezes, não é realizada com base exclusiva de resultados em indicadores. Uma avaliação econômico-financeira tem o intuito de proporcionar a investidores maiores subsídios para decisões a serem tomadas, porém vale a ressalva que em um ambiente complexo sobre um investimento; o conhecimento de mercado, contatos empresariais, capacidade técnica são fatores relevantes para a execução ou não de um projeto.

O próximo capítulo destina-se a apresentar as considerações finais sobre os métodos em estudo, promover uma revisão geral sobre o que fora exposto ao longo do 
trabalho e por fim, esboçar possíveis trabalhos futuros que possam contribuir com as discussões apresentadas. 


\section{CONSIDERAÇÕES FINAIS}

As incertezas são características presentes em investimentos correntes do mercado financeiro e também em projetos de investimento com escopo definido. A dificuldade em se estimar, com exatidão, as varáveis de caixa presentes a qualquer investimento está ligada a imprevisibilidade futura e alta volatilidade econômica e tecnológica que o atual cenário internacional apresenta. Mesmo em curto prazo, eventos naturais, políticos e econômicos apresentam grande influência em fatores decisivos no resultado de empresas e grupos de investidores.

As análises determinísticas de investimentos podem ser falhas; à medida que há presença de incerteza em um projeto, os resultados obtidos por estimativas exatas, em muitos casos, não representam a realidade do investimento, o que pode contribuir diretamente para que gestores ou investidores tomem decisões equivocadas sobre a alocação de capital.

Os métodos que permitem aos investidores considerar a incerteza junto a um investimento apresentam-se como alternativas de apoio à decisão. O método de Monte Carlo, em seu caráter estatístico, permite com que as variáveis presentes sejam consideradas por meio de distribuições de probabilidade. Embora tal alternativa seja dificultada em situações onde não existem dados passados referentes às variáveis presentes, este método tem sido bastante utilizado ao longo dos anos, seja em trabalhos científicos ou em aplicações em práticas empresariais.

A lógica Fuzzy, conforme apresentado ao longo do trabalho, prescreve uma nova alternativa para aplicações onde existe incerteza. O uso de uma função de pertinência contínua permite quantificar de maneira estruturada a incerteza presente 
em um sistema ou modelo, de forma a representá-la como um número ou conjunto nebuloso onde suas fronteiras não são rígidas.

O Valor Presente Líquido Fuzzy constitui-se em método para a avaliação econômico-financeira que utiliza a associação de números difusos ou nebulosos, o que permite representar a incerteza presente em um investimento por seu caráter léxico. $\mathrm{O}$ uso de números Fuzzy contempla todos os valores possíveis que compõem a variável em questão, onde tais valores podem apresentar intensidades diferentes. Este tipo de representação mostrou-se propícia para análises onde não existiam clareza das variáveis a serem utilizadas, fazendo-se necessário a utilização de estimativas, em certos casos até intuitivas.

Ao decorrer do trabalho e sobretudo após da execução do estudo de caso, percebeu-se que o Valor Presente Líquido Fuzzy contribui significativamente para avaliação de investimentos sob condição de incerteza, já que pode trazer informações relevantes aos que buscam decisões otimizadas, considerando o uso de faixas de incerteza em seu cálculo. Como resposta da aplicação, são fornecidas estruturas matemáticas Fuzzy que, por meio do conceito de defuzzicação, são transformadas em indicadores passíveis de interpretação.

A concepção da lógica Fuzzy mostra-se diferente dos conceitos estatísticos que envolvem a execução de uma simulação de Monte Carlo. Por meio de observações quantitativas e qualitativas buscou-se realizar uma comparação entre os dois métodos.

\subsection{RESULTADOS OBTIDOS}

O objetivo geral deste trabalho consistira em avaliar a aplicabilidade do Valor Presente Líquido Fuzzy como instrumento de avaliação de projetos de investimento, a 
partir da comparação feita junto ao método de Monte Carlo. O capítulo 5 foi dedicado à comparação: por meio da aplicação em uma situação real de investimento foram obtidos resultados que puderam ser discutidos. Em termos gerais observou-se que as respostas obtidas pelos dois métodos convergem para um cenário relativamente próximo, apesar de observadas diferenças consideráveis em alguns dos indicadores obtidos.

Dentre as comparações qualitativas observou-se maior facilidade da Lógica Fuzzy para a representação de variáveis incertas; a utilização das faixas de incerteza por meio de números triangulares Fuzzy mostrou-se conceitualmente simples, sendo bastante apropriada na transformação de dados estimados e intuitivos em valores matemáticos que se associassem às incertezas presentes.

Apesar de muito relevante, a aplicação do Valor Presente Líquido Fuzzy em seus moldes atuais exige relativo conhecimento sobre a lógica em questão, visto que o mercado ainda não dispõe de ferramentas computacionais que permitam sua aplicação em situações de maneira simplificada, necessitando em muitos casos de softwares específicos para sua aplicação. Neste trabalho o uso do Microsoft Excel® teve o intuito de aproximar a Lógica Fuzzy a um dos aplicativos computacionais mais utilizadas no mercado. Apesar de não conter nenhuma ferramenta específica para o uso de números Fuzzy, os cálculos foram considerados satisfatórios, já que atenderam as exigências matemáticas necessárias.

Quanto à adequação conceitual ao estudo de caso realizado, o uso da lógica Fuzzy está bem alinhado a situação avaliada, pois não se dispõe de informações que permitam grandes considerações sobre o comportamento econômico do projeto de investimento apresentado. 


\subsubsection{A incerteza e o projeto de investimento avaliado}

Durante a realização do estudo de caso, uma das tarefas de maior dificuldade fora a busca por estimativas de faixas de incerteza que representassem o projeto de investimento em análise. A definição de faixas de incerteza que não englobem as possibilidades futuras faz com que a resposta obtida pela aplicação do modelo de cálculo seja inútil e, conseqüentemente, possa levar investidores e gestores a conclusões deturpadas sobre o projeto de investimento.

Com o intuito de realizar uma avaliação econômico-financeira que representasse a variabilidade futura do projeto, optou-se pela utilização de faixas de incerteza elevadas, em que alguns componentes de caixa chegaram a apresentar valores com variação percentual de $60 \%$. Um valor alto, porém adequado em vista da imprevisibilidade e da baixa capacidade de mensuração do comportamento futuro das variáveis envolvidas.

A taxa de desconto utilizada no projeto de investimento fora estipulada baseada em discussão com o grupo de investidores. Seu valor fora referenciado na taxa Selic média do mês de janeiro de 2008: 11,72\% a.a. Segundo os investidores, a realização do projeto de investimento só se torna viável caso sua rentabilidade supere a taxa básica de juros nacional em 4\%. Desta forma:

$$
\begin{gathered}
T M A=(\text { Selic Janeiro } / 2008)+4 \% \\
T M A=15,72 \% \text { a.a. }
\end{gathered}
$$


A expectativa do pesquisador responsável pela avaliação é que o valor da taxa de juros básica da economia nacional para os próximos 15 anos, seja estimada em 6\% acima ou abaixo do valor apresentado em março de 2008. Desta forma:

$$
\begin{gathered}
\text { TMA }=(\text { Selic Janeiro } / 2008+4 \%) \pm 6 \% \\
T M A=15,72 \pm 6 \% \text { a.a. }
\end{gathered}
$$

A inclusão deste raciocínio como entrada para os modelos de cálculo, fizera com que as repostas obtidas (valor mínimo, valor máximo, valor esperado, possibilidade ou probabilidade de insucesso) levassem em conta flutuações estimadas nos juros da economia nacional.

\subsubsection{A importância da avaliação de investimentos}

As contribuições da avaliação de um projeto de investimento vão além dos resultados econômico-financeiros que possam ser inferidos. O sucesso de um empreendimento depende de fatores políticos, econômicos, estratégicos e operacionais. A construção de um projeto sistematizado permite a gestores e investidores angariarem um grande número de informações decisivas, como a atuação da concorrência, perspectivas de mercado, entre outras: o que pode contribuir para a definição da estratégia e política empresarial a serem seguidas, caso o investimento seja realizado.

As avaliações econômico-financeiras constituem-se em um mecanismo de apoio a decisão; à medida que seja possível oferecer modelos de cálculo que representem a realidade futura de um investimento, mais apropriadas e menos incertas 
podem se tornar as decisões tomadas. Tendo em vista a quantidade de informações passíveis de coleta e sistemas para aplicação, presentes na chamada era digital, o adequado uso da informação em busca melhores resultados empresarias, em quaisquer áreas, não deve ser considerado um diferencial, mas sim uma exigência futura incisiva no sucesso empresarial.

\subsubsection{Contribuições para o grupo de pesquisa}

O grupo de pesquisa em economia e finanças do SEP - Departamento de Engenharia de Produção da Escola de Engenharia de São Carlos, ao longo de 8 anos tem apresentado diversos trabalhos, nacionais e internacionais, que visam criar ou aprimorar métodos e aplicações para a engenheira econômica, a gestão econômica e a gestão de custos.

Desde a criação do grupo, muitos temas e métodos foram trabalhados, como as Redes Neurais Artificiais, a Análise por Envoltória de Dados, os Sistemas de Custeio Dinâmicos, a Teoria das Opções Reais entre outros. Apesar da variabilidade técnica e temática das pesquisas já realizadas, a presente dissertação é o primeiro trabalho do grupo a utilizar a Lógica Fuzzy.

O início das aplicações da Lógica Fuzzy na área financeira é bastante recente, o que faz acreditar que pouco de seu potencial tenha sido explorado. Com o intuito de promover este trabalho a um material para informação e consulta para realização de trabalhos futuros, buscou-se realizar a revisão bibliográfica de forma abrangente; a apresentação de conceitos foi colocada de forma lógica e seqüencial, expondo-se um número grande de figuras e ilustrações para maior facilidade de assimilação. 


\subsubsection{Contribuições para o pesquisador}

Apesar de não se apresentar demasiadamente complexos, os conceitos que envolvem a lógica Fuzzy não se caracterizam pela obviedade; acredita-se que a escolha deste tema de pesquisa contribuiu sensivelmente para desenvolvimento do raciocínio analítico e do poder de assimilação do autor. Em vista ao grande número de publicações relacionadas aos chamados sistemas inteligentes realizadas anualmente, é de se supor que a execução deste trabalho contribuirá conceitualmente, ao autor, para a busca por novas e mais elaboradas pesquisas, não se restringindo a Lógica Fuzzy, mas também ao alcance de outros métodos, como as redes neurais, os sistemas NeuroFuzzy e os Algoritmos Genéticos.

Além dos conceitos que envolvem a Lógica $F u z z y$, a execução do presente trabalho tornou necessária a pesquisa em outras áreas do conhecimento. A engenharia econômica, a gestão financeira e a estatística mostram-se áreas valorizadas e importantes no meio empresarial e acadêmico, firmando-se também como um possível universo de atuação profissional para o pesquisador.

\subsubsection{Dificuldades encontradas}

A busca de informações diversas para elaboração de uma dissertação vem acompanhada de dificuldades, sejam elas de caráter conceitual ou prático. No caso em específico da Lógica Fuzzy, os trabalhos encontrados em pesquisas realizadas apresentam-se conceituados em universos específicos referentes à suas aplicações, caracterizadas em diversas áreas da engenharia como a de controle e de computação. Por se tratar de um dissertação referente a engenharia de produção, foi necessário 
estruturá-la em uma linguagem compactuada com a área, com a adaptação de parte dos conceitos referenciados.

Vale a ressalva de que a linguagem matemática utilizada nas representações que envolvem a Lógica Fuzzy carece muito em padronização e que este fato dificulta sensivelmente a compreensão de grande parte dos trabalhos pesquisados, aumentando o tempo de estudo dedicado. Para elaboração desta dissertação, buscou-se uma representação matemática modernizada, já utilizada em trabalhos nacionais e internacionais como os de Nicoletti e Camargo (2004); Banholzer (2005); Omitaou e Badiru (2007).

As áreas financeiras são tratadas com extremo sigilo pela direção das empresas em geral, fato que dificulta a execução de pesquisas e estudos relacionados. O estudo de caso tornou-se quase uma exigência para este trabalho, já que acreditavase que a comparação entre os métodos apresentados seria melhor avaliada ao entorno de uma situação real de investimento. Apesar de sua importância, a aplicação em uma situação prática quase foi inviabilizada, já que a primeira empresa que havia se comprometido em fornecer informações necessárias preferiu não divulgá-las. Desta forma, o estudo de caso foi realizado em uma segunda empresa, a qual se mostrou bastante receptiva e informativa. Embora a necessidade da aplicação prática tenha sido suprida nesta dissertação, muitos pesquisadores apresentam dificuldades na busca por situações reais, fazendo-se necessária esta menção.

Por fim, apesar das dificuldades para execução de uma dissertação, a satisfação obtida e o conhecimento adquirido fazem com que as barreiras encontradas sejam minimizadas. O Brasil, apesar dos significativos avanços em pesquisa e desenvolvimento, ainda é muito dependente das instituições de ensino superior para seu avanço cultural e tecnológico visto que, ao contrário de outros países que 
produzem conhecimento, a presença da iniciativa empresarial neste seguimento ainda é restrita, o que ressalta a importância de dissertações e teses construídas ano após ano.

\subsection{SUGESTÕES PARA TRABALHOS FUTUROS}

A facilidade do acesso à informação dos dias atuais gera oportunidades de pesquisas vastas fazendo com que os trabalhos possam ser ampliados, tornando-se muito abrangentes. Ao longo da elaboração de uma dissertação de mestrado, emerge ao pesquisador a necessidade de capacidade analítica e senso crítico, importantes para delinear e delimitar um trabalho científico de modo que não sejam perdidos de vista os objetivos envolvidos. Em paralelo, uma série de limitações e possíveis melhorias ao trabalho executado tornam-se visíveis. Este tópico trata das idéias que surgiram no decorrer desta dissertação e, acredita-se, possam orientar novos trabalhos de pesquisa, dentro da Engenharia de Produção.

\subsubsection{Melhorias na composição do Valor Presente Líquido Fuzzy}

O método conceitual que compreende o Valor Presente Líquido Fuzzy apresentado neste trabalho restringiu-se ao uso de números triangulares. Um possível trabalho que poderia complementar o modelo descrito, seria baseado na inclusão de mais tipos de números Fuzzy ao cálculo.

Em princípio, parece não haver grandes problemas em tipos de números Fuzzy cuja função de pertinência compreende um único valor em sua normalidade $(\mu=1)$, 
como os números em formato de sino, já que nestes casos a definição de cada lado da função $F u z z y[l(\alpha)$ e $r(\alpha)]$ é natural. Acredita-se que a maior dificuldade estaria associada a utilização de números Fuzzy onde a normalidade esteja compreendida em uma faixa de valores, como nos números trapezoidais. Nestes casos, uma alternativa seria a definição de uma representação matemática por $\alpha$-cut que permitisse trabalhar tais números por funções $l(\alpha)$ e $r(\alpha)$, dividindo a região normalizada.

\subsubsection{Melhorias na quantificação de incertezas}

Uma lacuna que este trabalho traz é relativo a como as incertezas devem ser parametrizadas, para que sejam inclusas aos modelos cálculo do valor presente líquido. As definições quanto às incertezas consideradas no estudo de caso apresentam certa fragilidade estrutural, pois dependem excessivamente de conhecimento e opinião de mercado dos investidores responsáveis pelo projeto, fazendo-se necessário o uso de amplitudes altas para definição dos valores numéricos que representarão as variáveis incertas.

Quanto mais incertas as variáveis de entrada, maior será a amplitude numérica das respostas obtidas pela aplicação do modelo, fazendo com que mecanismos que levem a redução dos parâmetros que definem as faixas de incerteza possam contribuir significativamente ao apoio a decisão. Dois tipos de pesquisa distintos são sugeridos para a busca de novas contribuições a este tema:

\section{- A uso de ferramentas qualitativas para delineamento da incerteza}


A Engenharia de Produção dispõe de métodos qualitativos para análise de problemas de concepção complexa. Dentre os mais difundidos, destacam-se o Failure Mode Effect Analysis (FMEA) e o Quality Function Deployment (QFD), muito utilizados nas áreas de produção, projeto e qualidade de grandes corporações industriais.

Tais ferramentas ganharam projeção com a ascensão da filosofia Lean Production, do Sistema Toyota de Produção e mais recentemente, do Lean Six Sigma. Em síntese o FMEA e o QFD familiarizam-se por relacionar diversas informações qualitativas e trabalhá-las, de maneira lógica e procedimental, utilizando-se de conceitos matemáticos bastante simplificados.

Acredita-se que estudos que visem à utilização de conceitos presentes em tais métodos, para a contextualização de informações e cenários de investimento poderão promover melhores interpretações quanto às incertezas presentes em um projeto, contribuindo para a definição de faixas de incerteza menos amplas.

\section{- O uso de Sistemas Neuro-Fuzzy para delineamento da incerteza}

Seguindo para uma linha de pesquisa mais computacional, a aplicação de sistemas denominados Neuro-Fuzzy também poderá contribuir para a melhor quantificação de incertezas em investimentos. As Redes Neurais são conhecidas pelo alto poder de associação de dados, enquanto a Lógica Fuzzy é caracterizada por sua capacidade de mensuração de variáveis inexatas, fazendo com que estes sistemas híbridos propiciem a associação de um grande número de informações quantitativas e qualitativas.

Em situações onde não se dispõe de informações que permitam projeções futuras sobre as principais variáveis de caixa em um projeto de investimento, uma 
possível alternativa poderia ser a utilização de dados macroeconômico junto a informações qualitativas que considerassem perspectivas específicas sobre o empreendimento. Este conjunto de informações quando trabalhadas por meio de cálculos e inferências nos sistemas Neuro-Fuzzy, poderia gerar repostas que exprimissem a incerteza referente a importantes variáveis de um projeto de investimento

As variáveis obtidas pela aplicação de um Sistema Neuro-Fuzzy poderiam ser mantidas em seu estado fuzzificado, que por sua vez seriam entradas diretas para um modelo de cálculo do Valor Presente Líquido Fuzzy. É evidente esta sugestão incorpora um sistema de cálculo bastante complexo que possivelmente possa não ser explorado em um único projeto de pesquisa, mas possa se tornar factível ao longo de trabalhos complementares.

\subsubsection{Estruturação de softwares ou planilhas de cálculo para maior facilidade de} aplicação

Conforme já ressaltado ao longo do trabalho, o crescimento das aplicações da Lógica Fuzzy na área financeira poderá ser elevado, à medida com que os aplicativos disponíveis apresentem uma interface prática e amigável a gestores e investidores. Desta forma acredita-se que um trabalho focado ao desenvolvimento de softwares que venham preencher esta lacuna sejam de grande valia, sobretudo pelo apelo comercial que possam apresentar.

Para o desenvolvimento de um software específico realmente efetivo, mesmo antes das definições quanto ao padrão de interface a ser seguido, diversas questões devem estar pré-determinadas: quais funções matemáticas oferecidas? que tipo de 
situações financeiras poderão ser trabalhadas pelo uso do aplicativo? serão necessários treinamentos preliminares para sua utilização?

Assim como no item anterior, o desenvolvimento de um trabalho desta natureza mostra-se complexo, fazendo-se acreditar que sua realização exija um grupo de pesquisadores experientes no tema, composto também por pessoas com elevado conhecimento em linguagens de programação.

Uma alternativa mais simplificada, e não menos importante para este problema de pesquisa, poderia ser a utilização da linguagem de programação intitulada Visual Basic for Applications (VBA). Trata-se da linguagem interna de programação dos aplicativos do pacote Microsoft Office ${ }^{\circledR}$, os quais apresentam um editor específico para criação de rotinas utilizadas na automatização de tarefas repetitivas.

O editor de VBA poderia ser utilizado para a criação de uma barra de ferramentas no Microsoft Excel® que permitisse a automatização de tarefas referentes ao uso da Lógica Fuzzy. Este artifício ainda permitiria que as diversas funções de cálculo e lógica oferecidas pelo Excel pudessem ser utilizadas normalmente por um usuário.

\subsubsection{Sistemas de apoio a decisão para decisões de curto e curtíssimo prazo}

A economia globalizada, ao longo dos anos, tem se mostrado bastante oscilante com a formação de grandes grupos e uma possibilidade ilimitada de mercados a se investir. Em períodos muito curtos de tempo podem ocorrer variações consideráveis em valores cambiais, no preço do petróleo ou outras commodities. 
Embora muitas empresas tentem reduzir seu ambiente de incerteza por meio de heading e contratos firmados junto a fornecedores e clientes, as possibilidades de prejuízos em decisões de curto prazo são bastante factíveis.

Nas negociações comerciais realizadas por indústrias de produtos seriados, por exemplo, ocorrem situações onde devem ser definidos preços de venda com informações baseadas em indicadores econômicos e financeiros diários. Acredita-se que pesquisas relacionadas ao uso de números triangulares Fuzzy para representar as variáveis e compor o preço de seus produtos poderão trazer consideráveis contribuições às decisões a serem tomadas.

Outra aplicação possível da Lógica Fuzzy para situações em curto prazo seria a criação de um sistema de apoio a decisão, ou mesmo um sistema especialista, para o gerenciamento de fundos agressivos de ações. Tais fundos são possibilidades de investimento oferecidas por bancos de varejo e são caracterizados pela busca de altos índices de rentabilidade, aumentando a incerteza presente.

Os gestores destes fundos, além de trabalharem com ações de alta variabilidade, realizam grandes volumes de negociação, seja buscando a redução de prejuízos ou a realização de lucros em períodos onde seus ativos apresentam alta valorização. Por meio de um sistema de inferência Fuzzy seria possível considerar o preço de ações e investimentos de renda fixa disponíveis no mercado, fuzzificados por meio de indicadores qualitativos (muito baixo, baixo, normal, alto, muito alto). Por meio da inferência Fuzzy, seria possível a composição de uma carteira otimizada para o fundo em análise.

\subsubsection{Sistema de apoio a decisão para a análise de crédito}


As análises para concessão de crédito a pessoas físicas são atividades muito importantes para as instituições financeiras; a decisão de conceder crédito ou não envolve questões como inadimplência e taxa de juros a ser cobrada.

Em instituições onde há alto índice de inadimplência, muitas vezes é necessário elevar política de juros proposta para a concessão de empréstimos, fazendo com que prejuízos causados pelo não pagamento de clientes sejam cobertos. Em contrapartida, quanto maior a taxa de juros cobrada pela instituição financeira, menor será sua demanda, visto que no mercado talvez sejam encontradas taxas menores, em concorrentes. Desta forma, quanto mais certeiras as análises, melhores os resultados obtidos pela empresa.

Para que seja possível as análises estatísticas e regressões, uma série de questionamentos são realizados, como faixa etária, renda mensal, quantidade de dependentes, etc. Um Sistema Neuro-Fuzzy poderia ser utilizado para este tipo de avaliação, conjugando variáveis quantitativas e qualitativas.

\subsubsection{Sistema de avaliação social de projetos}

Talvez uma das maiores dificuldades na avaliação de um projeto de investimento seja quanto às contribuições sociais ou mesmo sócio-ambientais que sua execução possa causar. Uma possível alternativa para este problema seria a criação de um sistema de inferência Fuzzy baseando-se em indicadores padronizados de entrada como, por exemplo, número de empregos gerados e a quantidade de $\mathrm{CO}_{2}$ lançada ao meio ambiente. Como resposta do sistema poderia ser obtido um indicador numérico que representasse as contribuições sociais ou ambientais que a execução do projeto traria, fazendo-se possível a comparação entre projetos. 


\subsubsection{A utilização da lógica Fuzzy para precificação de opções}

Em sua grande maioria, os modelos desenvolvidos para precificação de opções financeiras, como o de Black-Scholes caracterizam-se pela utilização da estatística para representar a variabilidade do ativo a que opção se refere. Acredita-se que o uso de números Fuzzy neste tipo de representação seria uma técnica interessante. Uma pesquisa poderia ser desenvolvida para explorar este tema, facilitada pelo fato de que as informações necessárias (valor de mercado de ações e opções) para comparações em situações reais entre o modelo de Black-Scholes e o modelo a ser desenvolvido, apresentam-se amplamente disponíveis.

A Teoria das Opções Reais (TOR) consiste em um método em destaque, tema de pesquisas e publicações para avaliação de projetos de investimentos. Tal método caracteriza-se por permitir ao cálculo do VPL maior flexibilidade, já que torna possível considerar o investimento inicial em um projeto como uma opção de compra, contemplando situações onde dispêndio de capital não precisa ser totalizado em seu início. O uso de um modelo de precificação de opções utilizando-se de números Fuzzy poderia ser utilizado em conjunto com o Valor Presente Líquido Fuzzy, fazendo com que as aplicações da TOR contemplassem também a incerteza em variáveis presentes ao investimento.

\subsubsection{Possíveis aplicações da lógica Fuzzy em outras áreas da engenharia de produção}


Não se restringindo às sugestões relacionadas as áreas de economia e finanças, a parte final desta dissertação é dedicada a mais duas sugestões de pesquisas que podem ser englobadas em outras áreas, dentro da Engenharia de Produção.

\section{- Pesquisa Operacional}

A Pesquisa Operacional é a área da Engenharia de Produção referente a aplicação de métodos científicos a problemas complexos no auxílio a tomada de decisão, tais como projetar, planejar e operar sistemas em situações que requerem alocações eficientes de recursos escassos (BATALHA, 2008). Em suas aplicações mais comuns, destacam-se os problemas de otimização executados por meio do uso de sistemas numéricos. Acredita-se que o uso de números Fuzzy como entradas de tais sistemas permitiria agregar o conceito de incerteza as variáveis presentes, como por exemplo, variações em processos de transformação dentro de um problema de alocação de recursos em um complexo de manufatura.

\section{- Planejamento e controle da produção}

Os sistemas denominados Enterprise Resource Planning (ERP) permitem a integração de várias (ou todas) as base de dados que acercam uma empresa (SLACK et al, 2002). Dentre as funções que tais sistemas apresentam é o planejamento e controle da produção.

Por meio de informações firmadas junto ao departamento de vendas de uma empresa inicia-se a programação da produção ou serviço, gerando o chamado Plano Mestre de Produção, que por sua vez, apresenta as ordens de fabricação diária ou semanal dos sistemas de produção e manufatura. Em tais ordens estão definidos o 
prazos de entrega, material utilizado e as quantidade de cada produto que devem ser produzidas.

Um ERP, no entanto, trabalha em seu sistema de cálculo valores absolutos, porém no meio industrial, grandes variações podem ser originadas devido a falta de material, atraso em fornecimentos internos ou externos, presença de refugos, etc.

A utilização de um ERP que utilize as variáveis de entrada para a programação da produção representada por números Fuzzy, possivelmente poderá apresentar ganhos, pois à medida que seja possível obter um Plano Mestre de Produção melhor ordenado, mais adequadas as empresas de manufatura poderão estar de uma das suas principais metas: a de conseguir trabalhar da maneira mais próxima possível a sua programação, cumprindo datas e quantidades estipuladas. 


\section{APÊNDICE A}

O objetivo deste tópico é apresentar de maneira simplificada a execução de uma simulação baseada no método de Monte Carlo, utilizando o Excel e Crystall Ball.

\section{- Exemplo}

Obter a distribuição de probabilidades Receita Total, resultante do produto entre Preço de Venda e a Demanda. Em que:

Preço de Venda: $\mu_{\text {preço }}=\mathrm{R} \$ 10.495,00$ e $\sigma_{\text {preço }}=\mathrm{R} \$ 262,375$

Demanda: $\mu_{\mathrm{demanda}}=1200$ e $\sigma_{\text {demanda }}=180$

\section{- Representação no Excel}

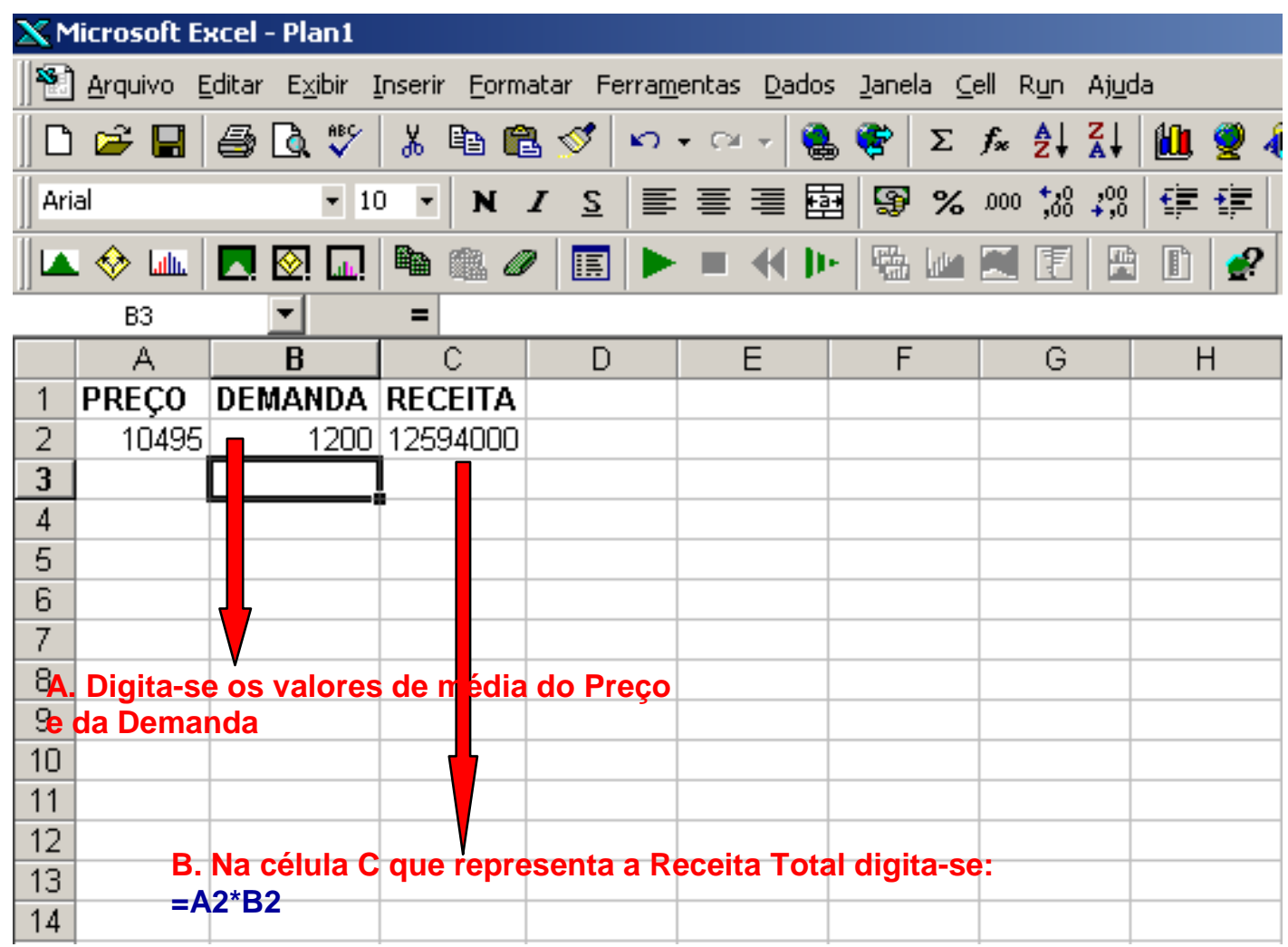


- Associação das distribuições de probabilidade às variáveis independentes

\section{B. Deve-se clicar no botão Define Assumption do Crystall Ball}

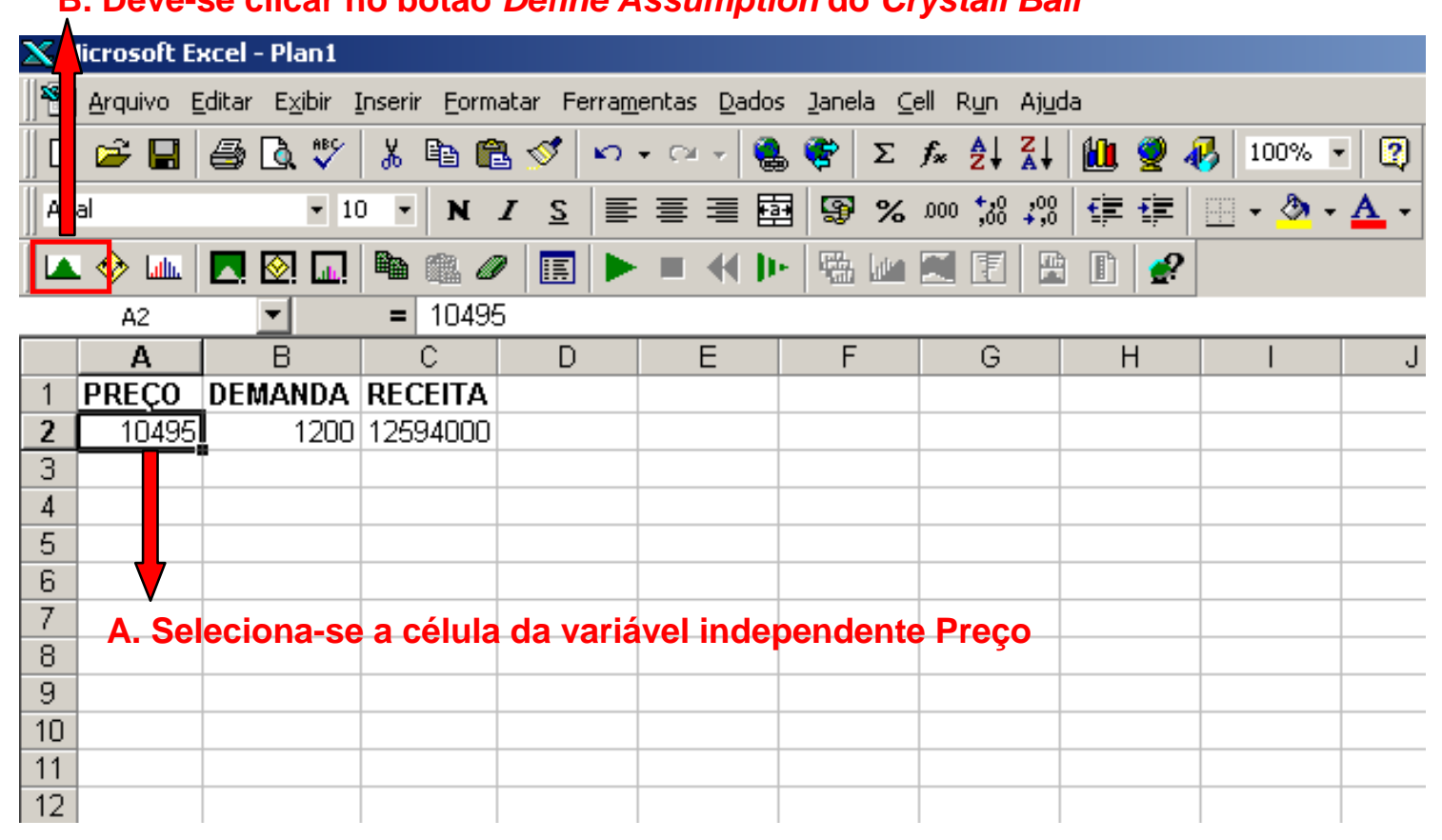

\section{Deve neste exemplo a distribuição é a normal}

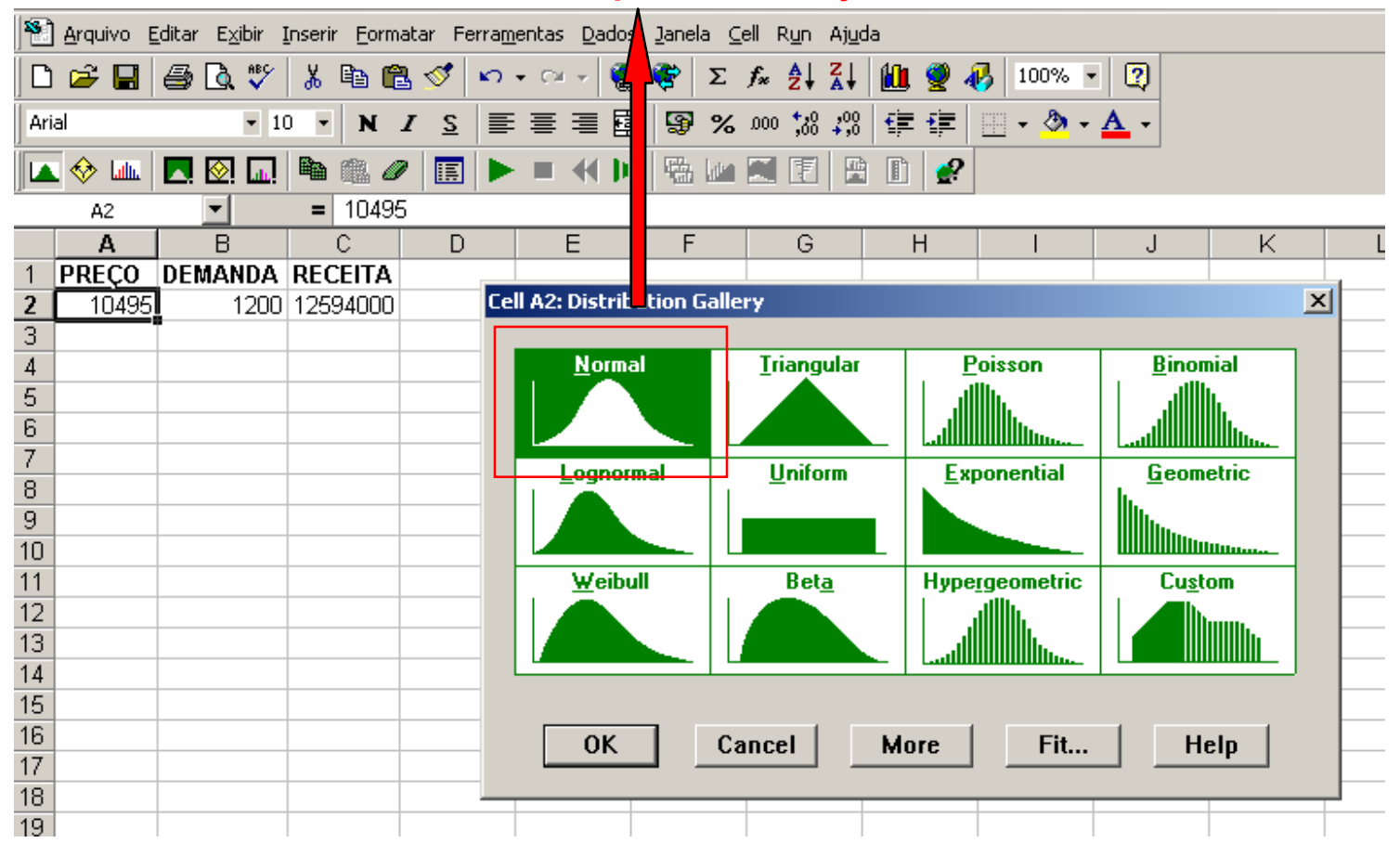




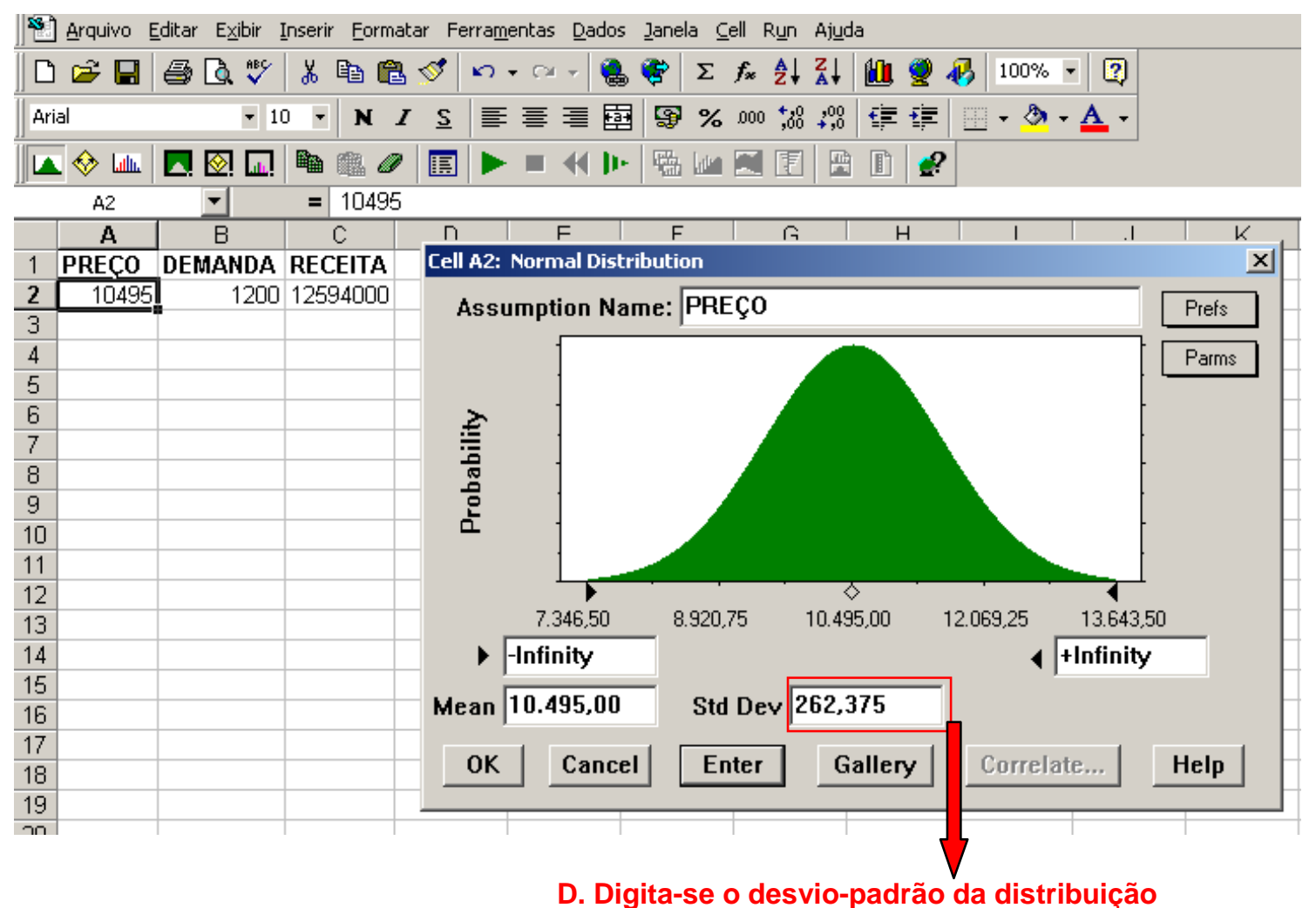

De maneira análoga o mesmo procedimento é realizado com a variável

\section{Demanda.}


- Definição da Variável Dependente

B. Deve-se clicar no botão Define Forecast do Crystall Ball

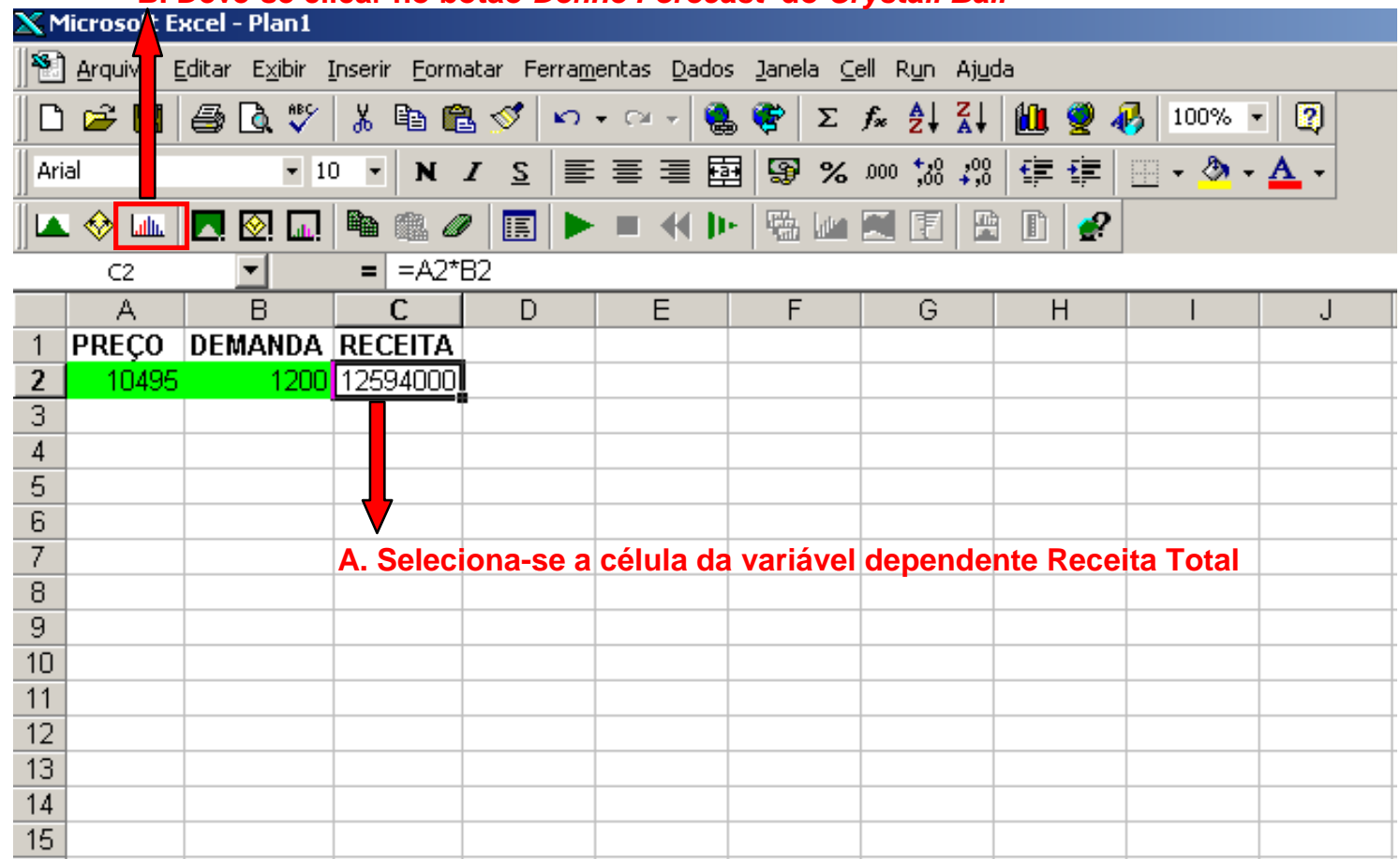




\section{- Execução da simulação}

A. Deve-se clicar no botão Run Preferences do Crystall Ball XMicrosoft Excel - Plan1

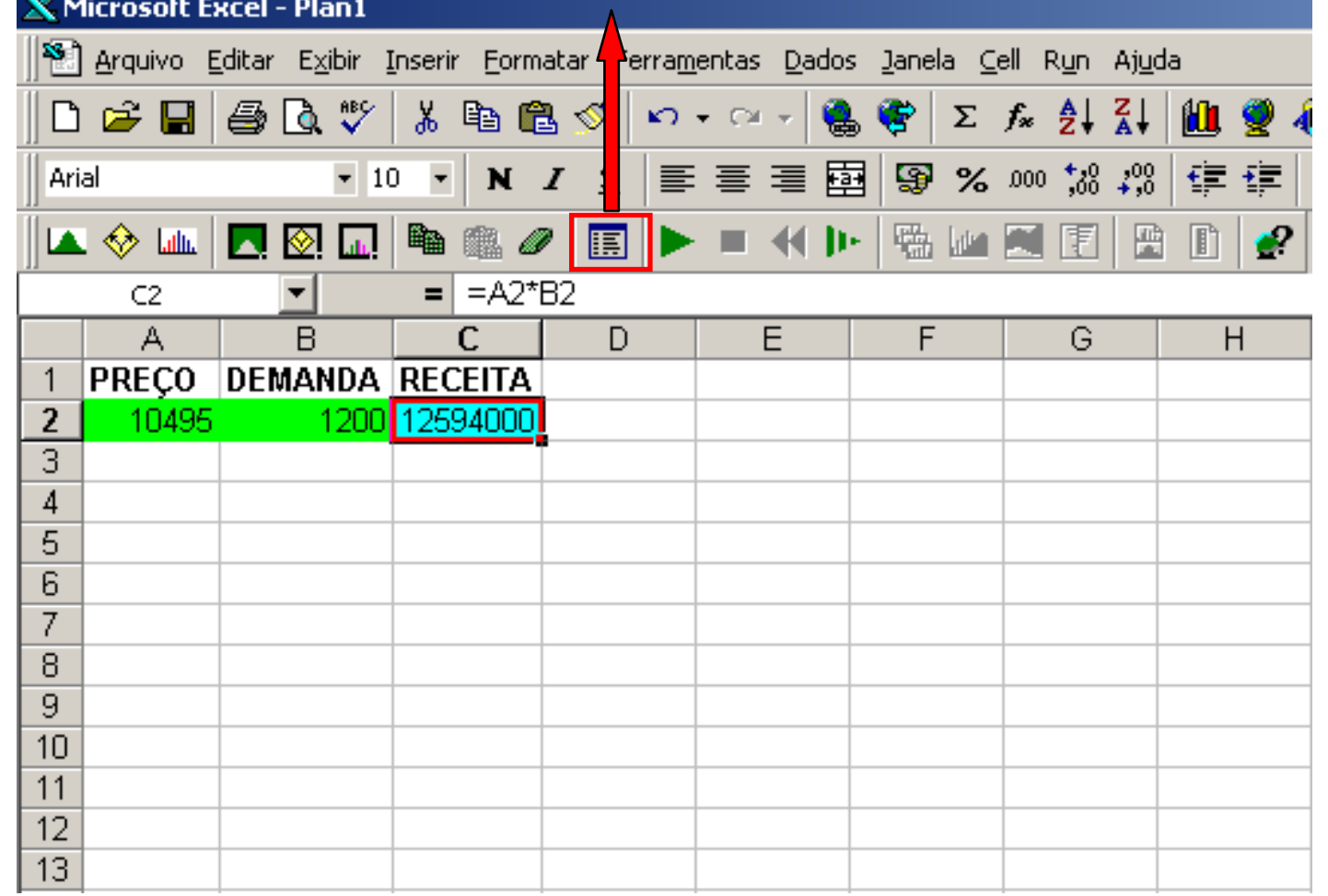

B. Define-se o número de genários a ser utilizado

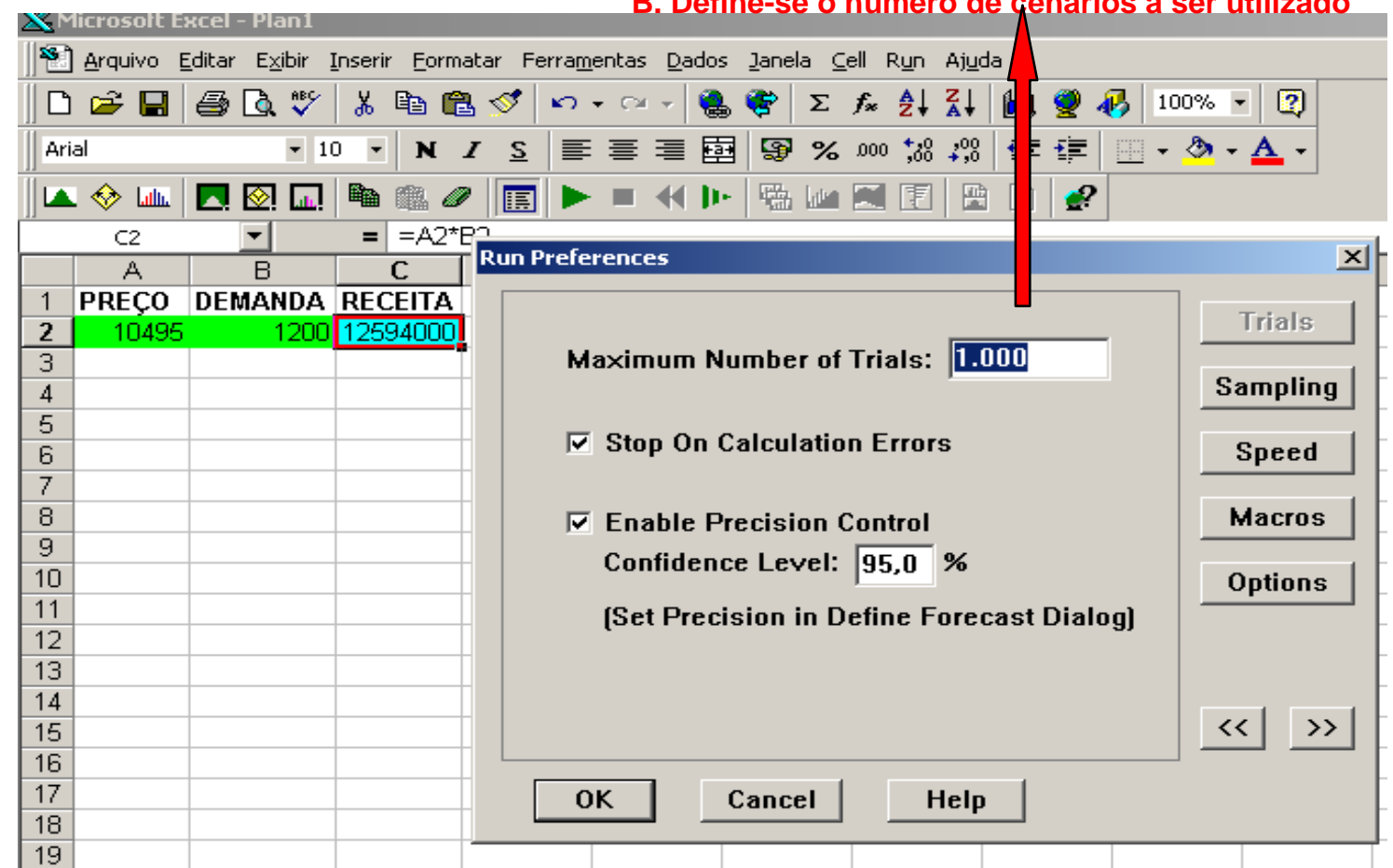




\section{Simulação deve ser executada}

\section{Microsoft Excel - Plan1}

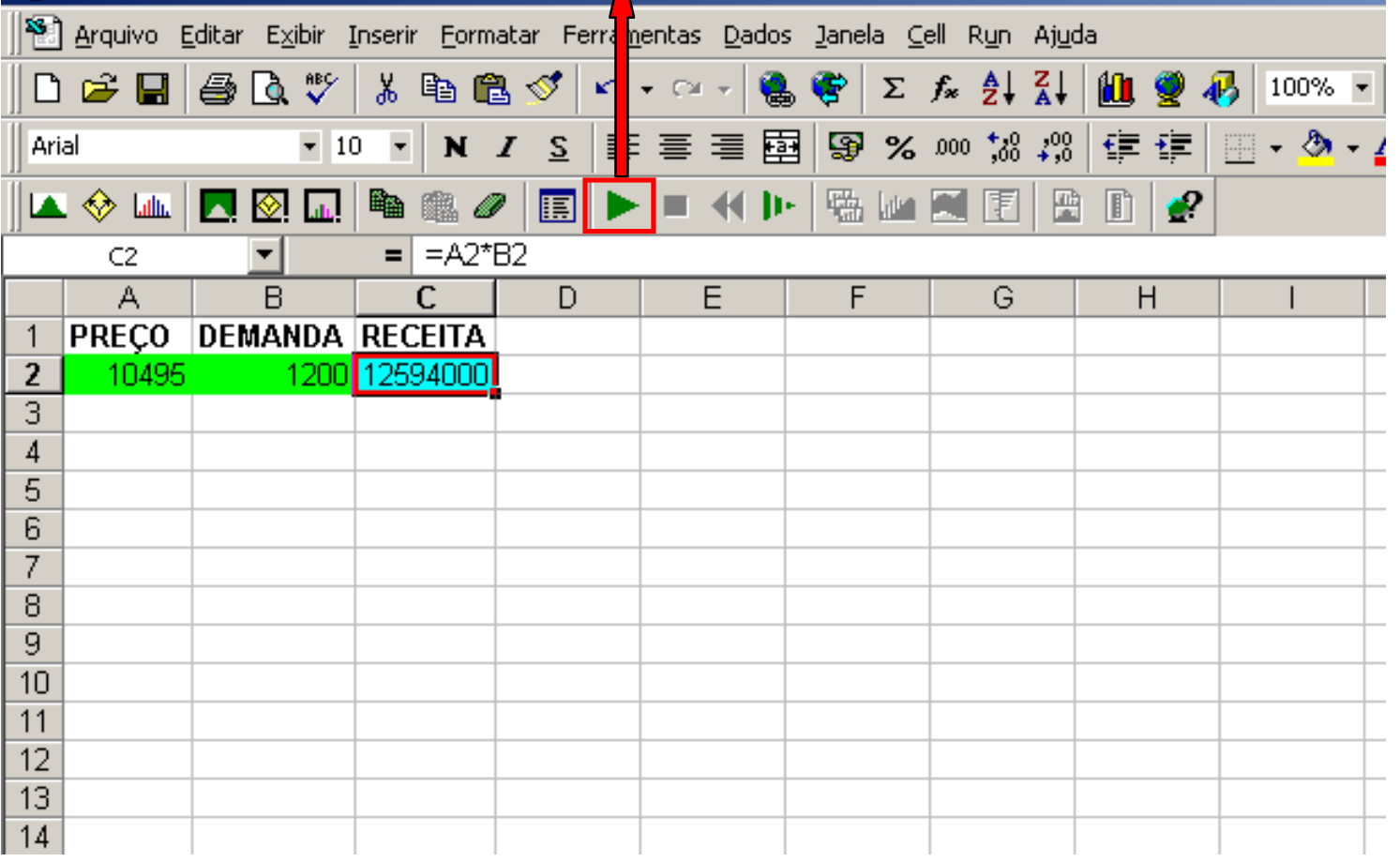

D. Obtêm a variável RECEITA simulada

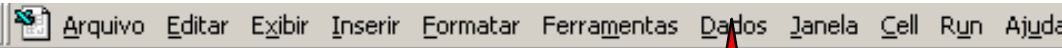

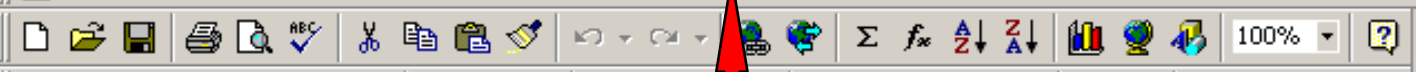

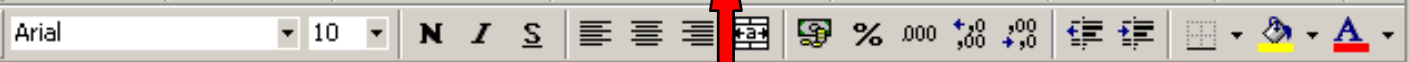

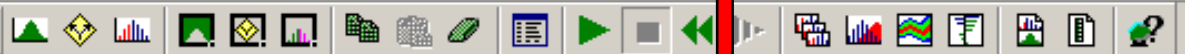

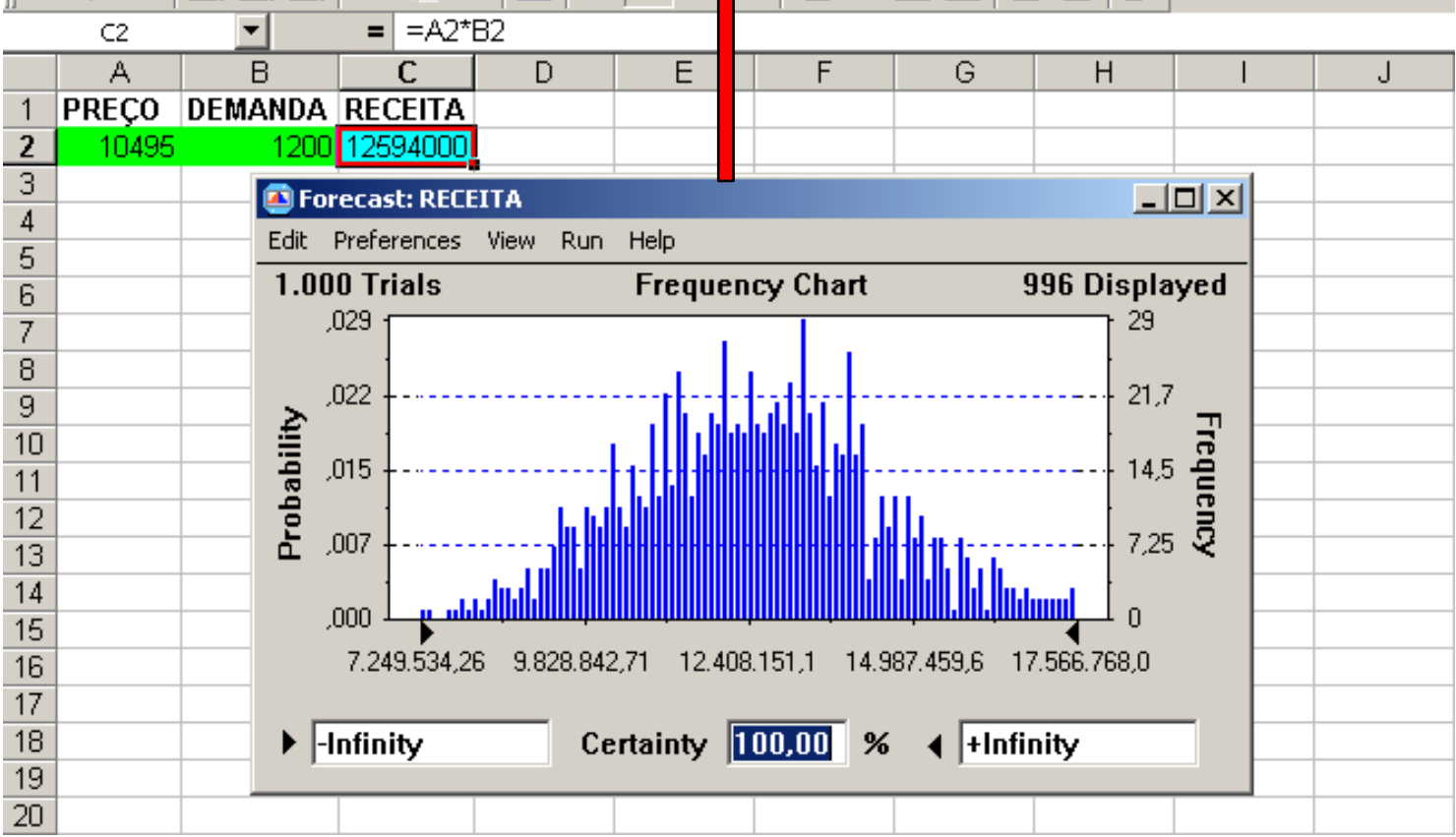




\section{APÊNDICE B}

O objetivo deste tópico é apresentar de maneira simplificada de como, definir, realizar cálculos e representar números Fuzzy utilizando o Microsoft@ Excel:

\section{- Exemplo}

Calculo do número Fuzzy Receita Total, resultante da multiplicação dos números triangulares Fuzzy Preço de Venda e Demanda. Em que:

$$
\text { Preço de Venda }=(\mathrm{R} \$ 9.970,25, \mathrm{R} \$ 10.495,00, \mathrm{R} \$ 11.019,75)
$$

$$
\text { Demanda }=(840,1200,1560)
$$

\section{- Representação por $\alpha$-cut}

Representação necessária para que sejam efetuados os cálculos (seu equacionamento é apresentado no item 4.2.4 deste trabalho):

$$
\begin{gathered}
\text { Preço de Venda }{ }^{l(\alpha)}=(524,75 \times \alpha+9970,25) \\
\text { Preço de Venda }{ }^{r(\alpha)}=(-524,75 \times \alpha+11019,75) \\
\text { Demanda }^{l(\alpha)}=(360 \times \alpha+840) \\
\text { Demanda }^{r(\alpha)}=(-360 \times \alpha+1560)
\end{gathered}
$$




\section{- Representação no Excel}

1. Cria-se uma planilha. A coluna A é destinada para descrever a função de pertinência. Cada função $(L$ e $R)$ dos números Fuzzy é representada por uma coluna diferente.

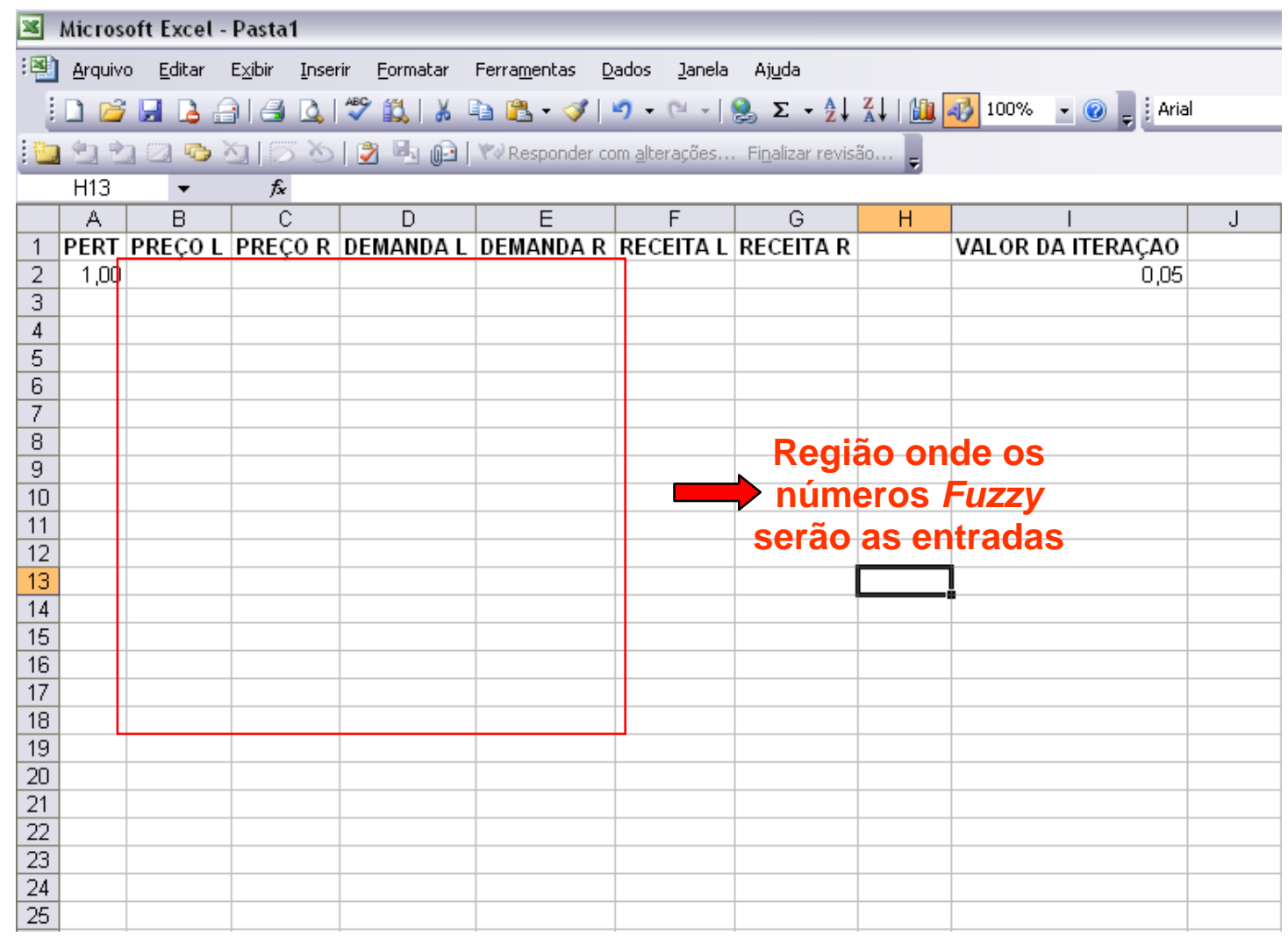


2. Define-se a função pertinência baseando-se nas iterações definidas.

\begin{tabular}{|c|c|c|c|c|c|c|c|c|c|}
\hline \multicolumn{10}{|c|}{ Microsoft Excel - Pasta1 } \\
\hline \multirow{3}{*}{\multicolumn{10}{|c|}{ 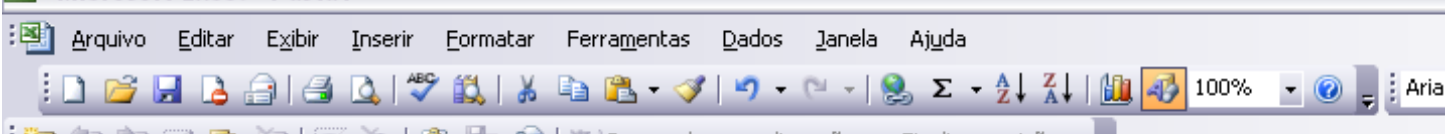 }} \\
\hline & & & & & & & & & \\
\hline \multicolumn{9}{|c|}{ 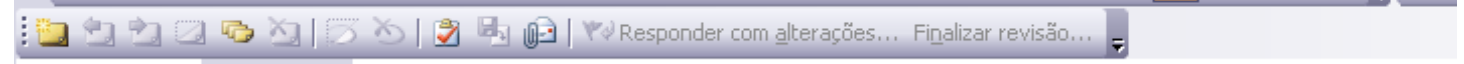 } & \\
\hline \multicolumn{10}{|c|}{$\mathrm{B} 2 \quad-\quad f_{x}$} \\
\hline & A & $\mathrm{B}$ & $\mathrm{C}$ & D & $\mathrm{E}$ & $\mathrm{F}$ & G & $\mathrm{H}$ & 1 \\
\hline 1 & PERT. & PRECO L & PREÇO R & DEMANDA L & DEMANDA R & RECEITA L & RECEITA R & & VALOR DA ITERAÇAO \\
\hline 2 & 1,00 & & & & & & & & 0,05 \\
\hline 3 & 0,95 & & & 1. Digita-s & e na célul & & & & \\
\hline 4 & 0,90 & & & & 32 & & & & \\
\hline 5 & 0,85 & & & $=A 2$ & $-\$ 12 \$$ & & & & \\
\hline 6 & 0,80 & & & & & & & & \\
\hline 7 & 0,75 & & & & & & & & \\
\hline 8 & 0,70 & & & & & & & & \\
\hline 9 & 0,65 & & & & & & & & \\
\hline 10 & 0,60 & & & & & & & & \\
\hline 11 & 0,55 & & & & & & & & \\
\hline 12 & 0,50 & & & B. Utiliza- & se do rec & urso de & & & \\
\hline 13 & 0,45 & & & - clat & complat: & & & & \\
\hline 14 & 0,40 & & & & ocompret & & & & \\
\hline 15 & 0,35 & & & chega-se & até o valc & or 0,00 d & & & \\
\hline 16 & 0,30 & & & & ertinência & & & & \\
\hline 17 & 0,25 & & & & & & & & \\
\hline 18 & 0,20 & & & & & & & & \\
\hline 19 & 0,15 & & & & & & & & \\
\hline 20 & 0,10 & & & & & & & & \\
\hline 21 & 0,05 & & & & & & & & \\
\hline 22 & 0,00 & & & & & & & & \\
\hline \multicolumn{10}{|l|}{23} \\
\hline \multicolumn{10}{|l|}{24} \\
\hline 25 & & & & & & & & & \\
\hline
\end{tabular}


3. Digitam-se as funções representadas por nas colunas respectivas.

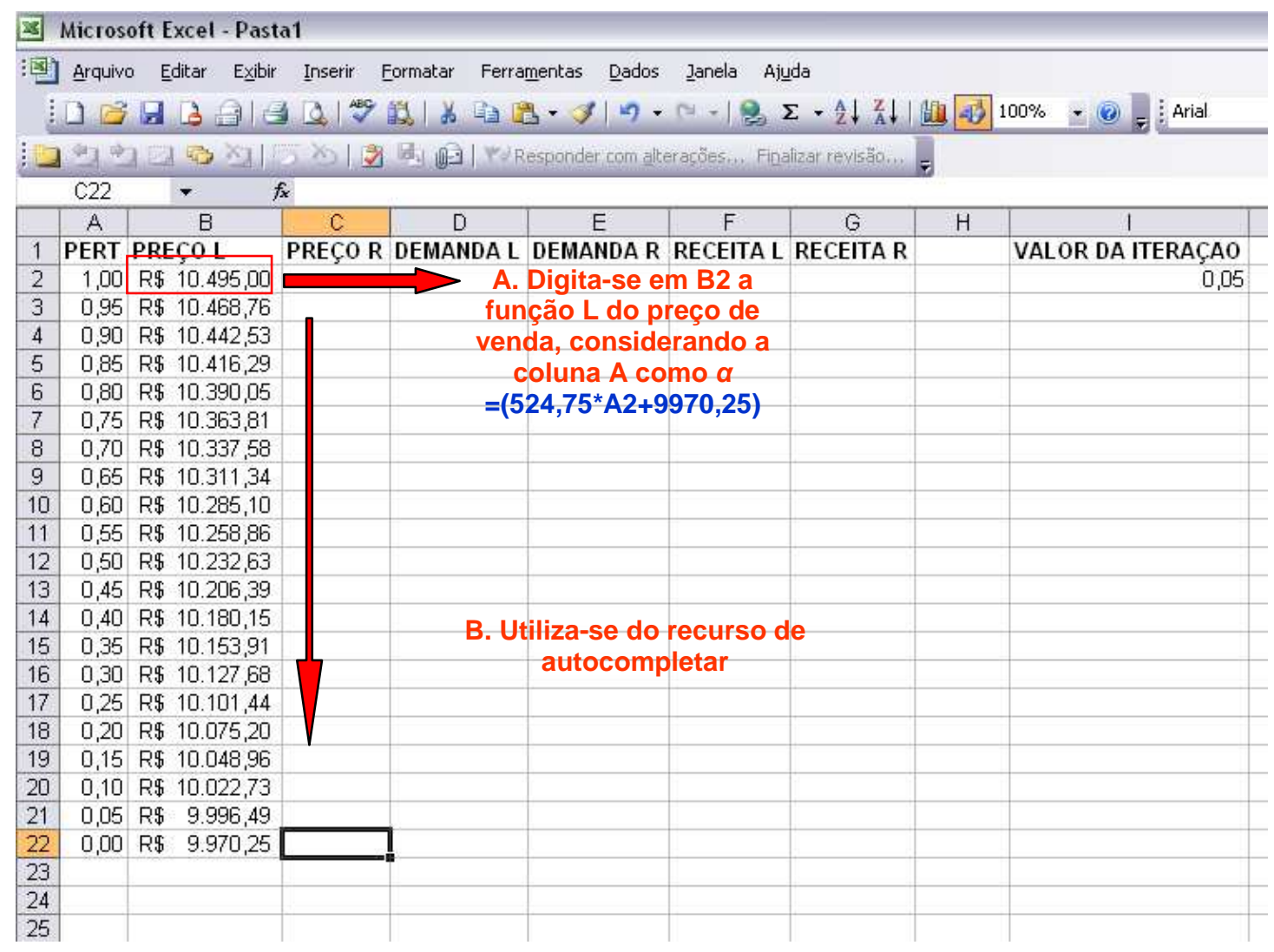


4. De maneira análoga, são preenchidas as outras funções.

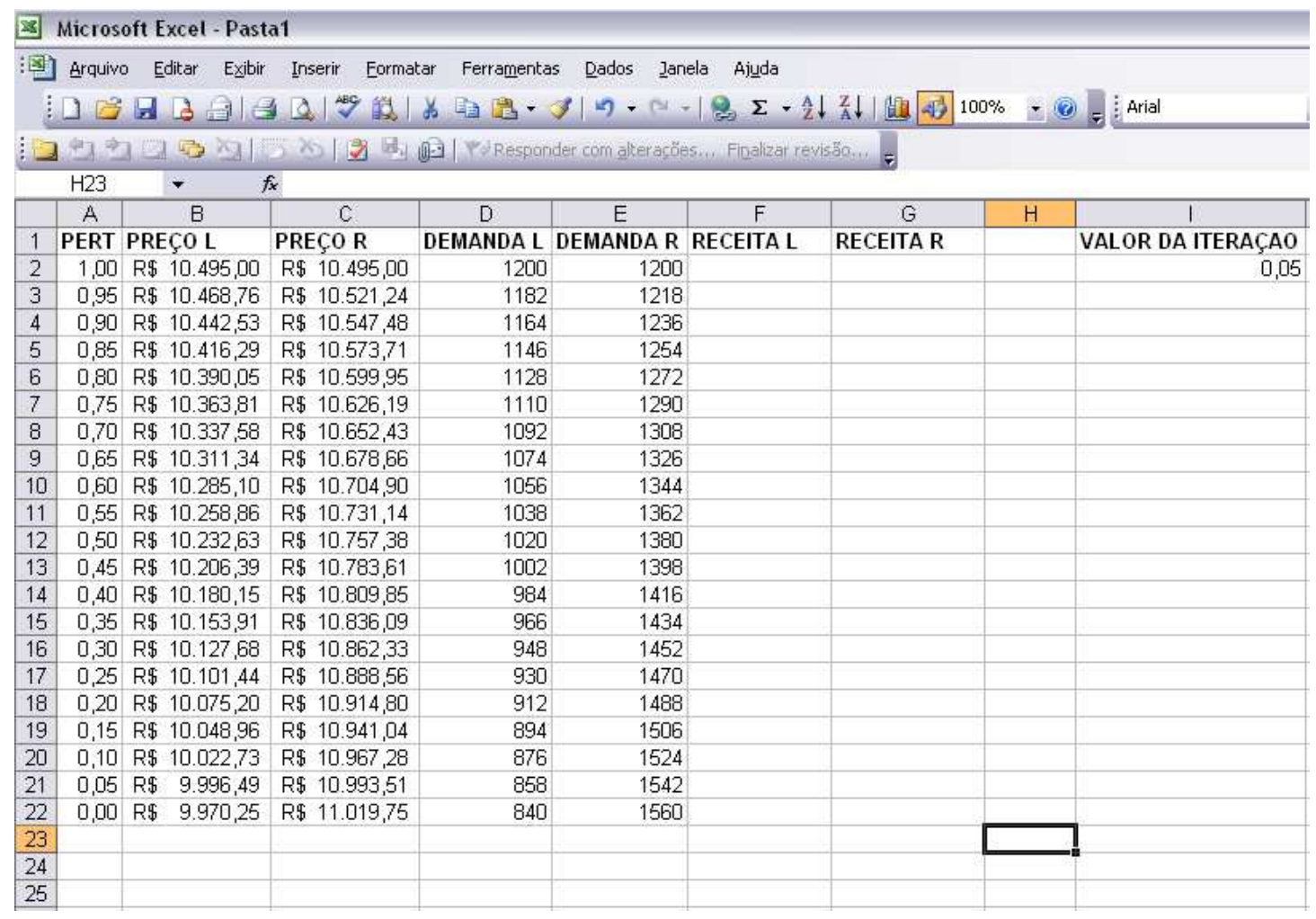


- Cálculo da Receita Total Fuzzy

Conforme apresentado no item 4.2.5 deste trabalho, multiplicação Fuzzy é obtida pela multiplicação das funções pertinência, de forma que:

$$
\begin{aligned}
& \text { Receita Total }^{l(\alpha)}=\text { Preço de Venda } \\
& \text { Receita }^{l(\alpha)} \times \text { Total }^{r(\alpha)}=\text { Preço de Venda } \\
&
\end{aligned}
$$

Utilizando-se o Excel tem-se o número Fuzzy Receita Total, resultante da multiplicação:

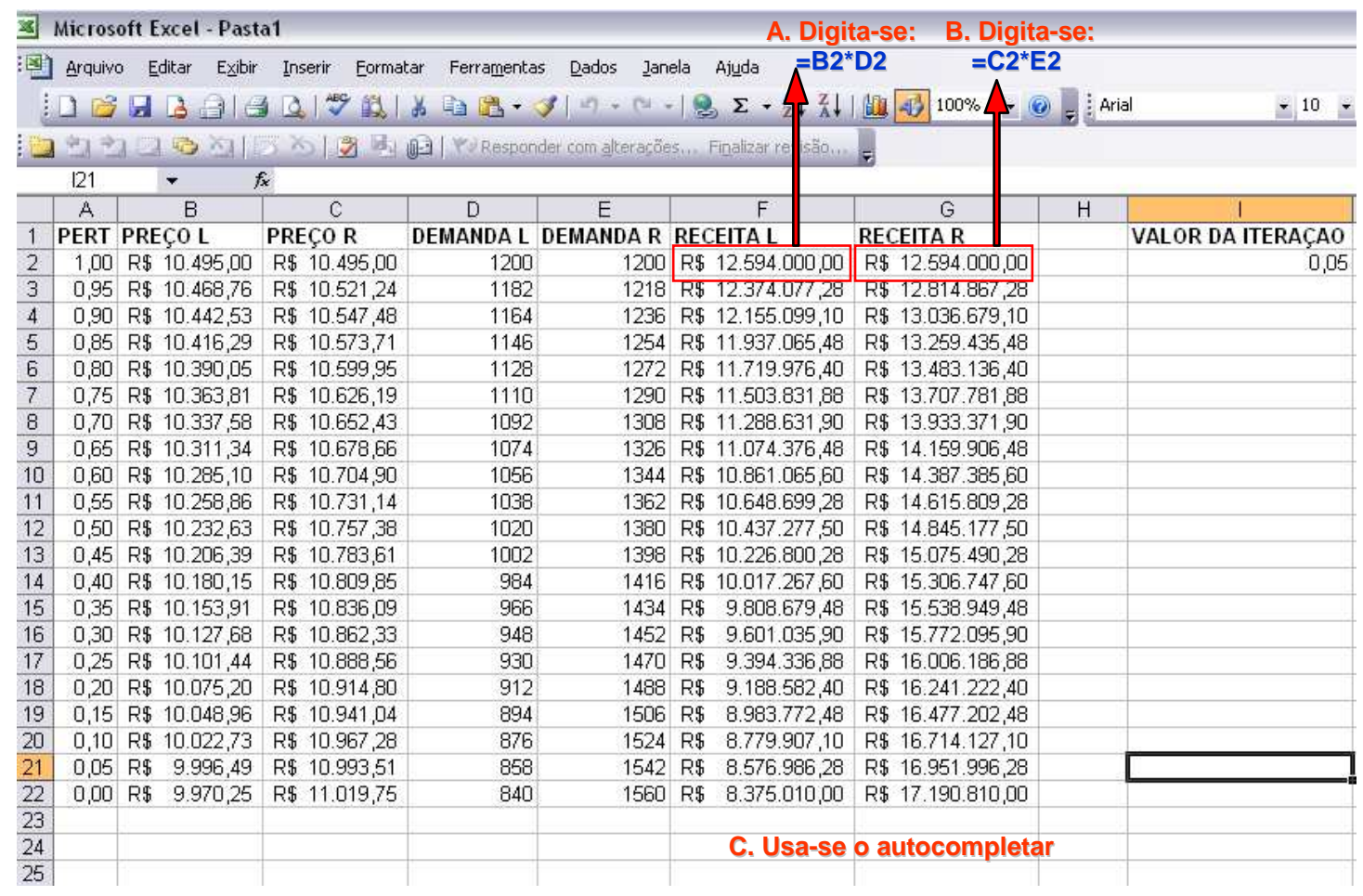




\section{- Representação gráfica}

1. Para representar graficamente o número Fuzzy obtido deve ser usado um gráfico de dispersão.

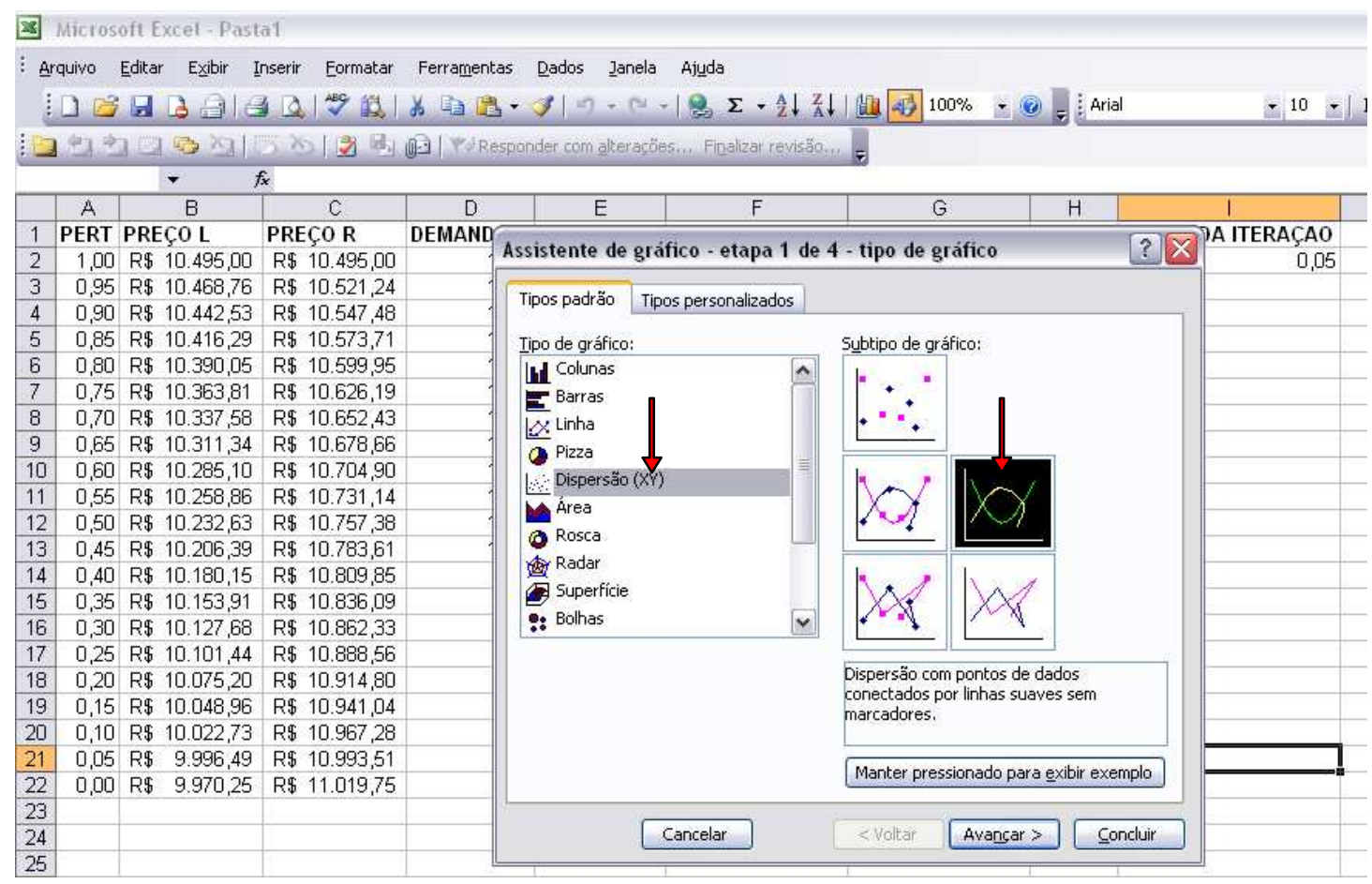

2. Insere-se a função L da variável no menu do gráfico.

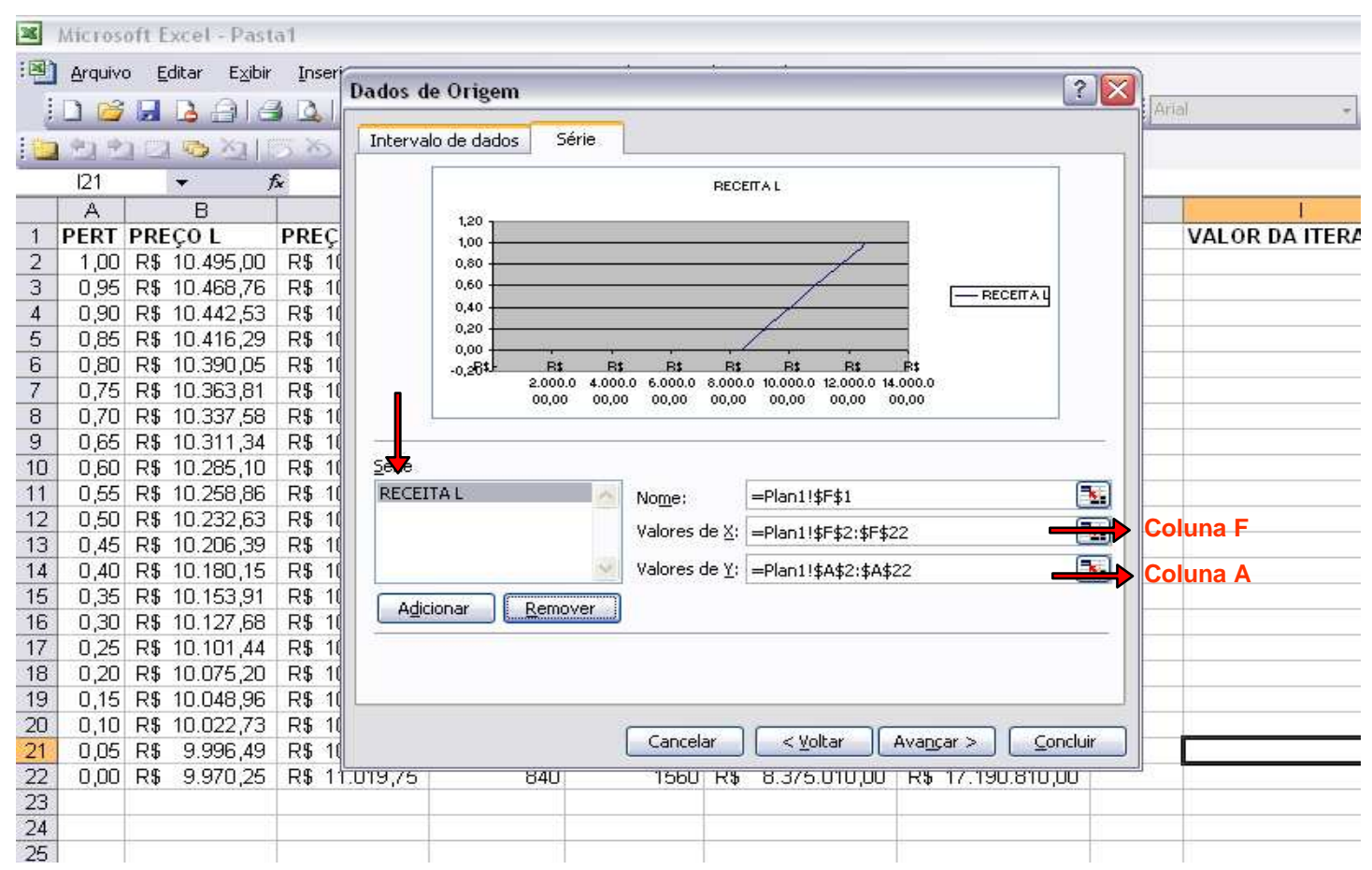


3. Insere-se a função R da variável no menu do gráfico.

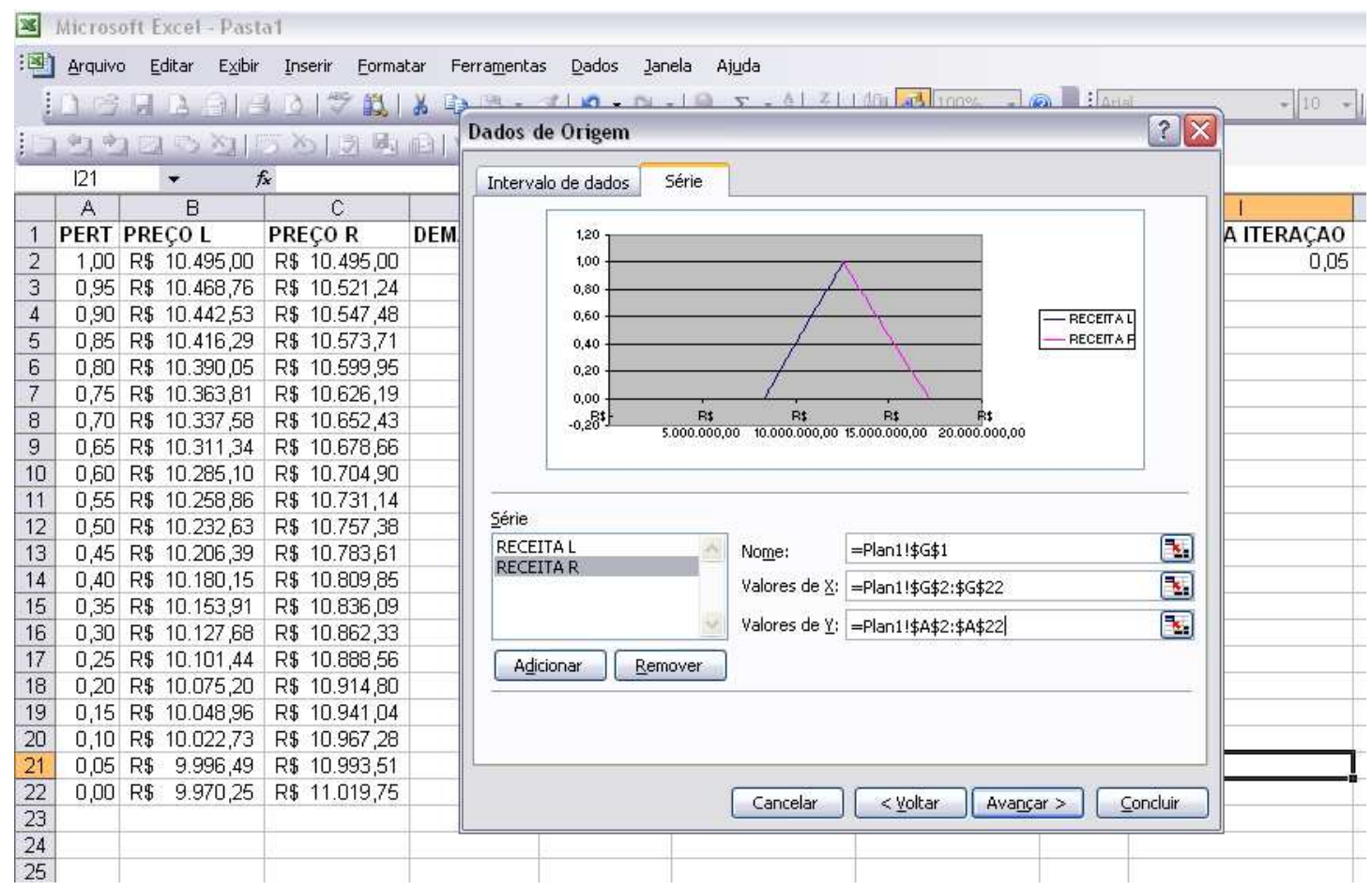

\section{Obtêm-se o gráfico.}

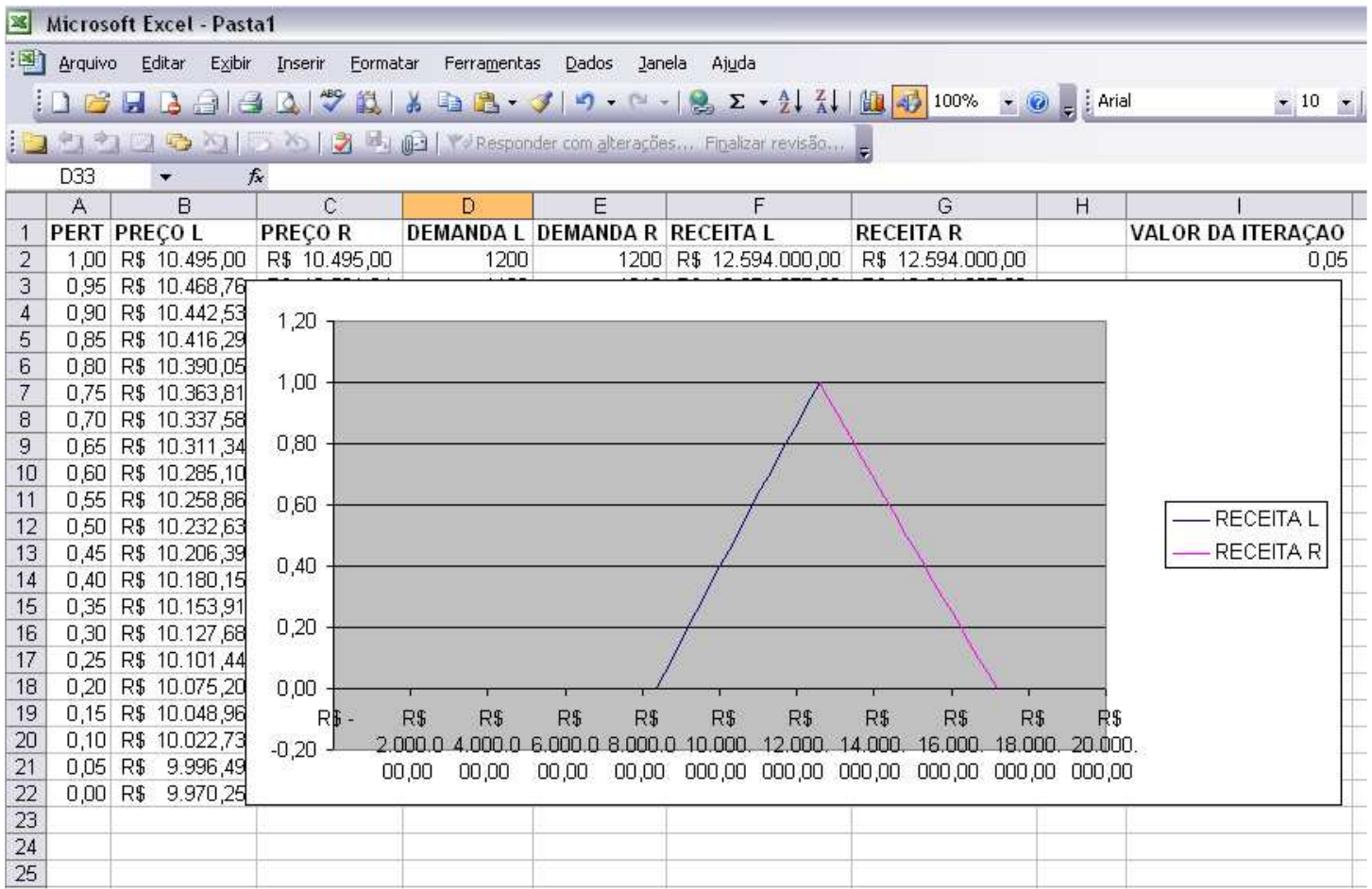




\section{REFERÊNCIAS BIBLIOGRÁFICAS}

ABDALA, V. Produção de cana-de-açúcar deve aumentar 9,3\% no ano que vem, diz IBGE. Agência Brasil, Dezembro de 2007.

http://www.agenciabrasil.gov.br/noticias/2007/12/10/materia.2007-12$\underline{10.6405334294 / \text { view }}$

ABEPRO - Associação Brasileira de Engenharia de Produção - XXVII Encontro nacional de engenharia de produção - ENEGEP http://www.abepro.org.br/indexsub.asp?ss=8 consultado em novembro de 2007.

ALCKMIN, G; GOLDBERG, J.; BARRETO, D. Eficiência energética na gestão ambiental. Secretaria do Meio Ambiente - Governo do Estado de São Paulo. http://146.164.33.61/termo/cogeracao/EFICI\%CANCIA\%20ENERG\%C9TICA\%20N A\%20GEST\%C3O\%20AMBIENTAL.pdf consultado em janeiro de 2008.

ARAÚJO, C.E.G - Algoritmos genéticos híbridos sem delimitadores de rotas para problemas de roteirização de veículos. 89p. Dissertação (Mestrado) - Escola Politécnica, Universidade de São Paulo, São Paulo, 2008.

BALARINE, O.F. O uso de análise de investimentos em incorporações imobiliárias. Revista Produção, São Paulo, ABEPRO vol.14 julho/dezembro 2004.

BANHOLZER, I.E.G. Proposta para interpretação da taxa interna de retorno através do calculo fuzzy. 93p. Dissertação (Mestrado) UNIFEI, Itajubá, 2005.

BATALHA, M. O. Introdução à engenharia de produção. Rio de Janeiro: Elseiver, 2008.

BASTOS NETO, A.O. Aspectos da extração de sacarose de cana-de-açúcar por difusão. UNI-SYSTEMS

http://uni-systems.locaweb.com.br/images/online/arq_Catalogo\%20portu.pdf consultado em janeiro de 2008.

BARREIROS, F.A.M. Projeto de investimento: uma análise estratégica a partir do conceito de cadeia de suprimentos. 221p. Dissertação (Mestrado) - Escola de Engenharia de São Carlos, Universidade de São Paulo, São Carlos, 2003.

BORBA J.A.B \& DILL R. Análise de rentabilidade de empresas: uma abordagem baseada na lógica nebulosa (fuzzy logic). RAC-Eletrônica, São Paulo ANPAD vol. 1 janeiro/abril 2007.

BRANDÃO L. Apostila de análise de projetos e avaliação de empresas. PUC, Rio de Janeiro, 2007. 
BREALEY, R.A.; MYERS, S.C. Princípios de finanças empresarias. 5.ed. Lisboa. McGraw-Hill, 1998.

CASAROTTO FILHO, N. C. \& KOPITTKE, B. H. Análise de Investimentos: matemática financeira, engenharia econômica, tomada de decisão, estratégia empresarial. 9.ed. São Paulo: Atlas, 2000.

CHIU, C.Y.;PARK, C. S.; Fuzzy cash flow analysis using present worth criterion; The Engeneering Economist 1994 - volume 39, no 2 (113-137).

CORREA, C. O clã do etanol. Revista Exame. Editora Abril, São Paulo, agosto de 2007.

http://portalexame.abril.com.br/revista/exame/edicoes/0899/mm_2007/m0135376.htm $\underline{1}$

CORREIA NETO, J.F; MOURA, H.J.; e FORTE, S.H.C.A. Modelo prático de previsão de fluxo de caixa operacional para empresas comerciais considerando os efeitos do risco, através do método de Monte Carlo. Revista Eletrônica de Administração, Porto Alegre, UFRGS vol.8 n. 3, junho 2002.

ERENO, D. Sertãozinho, usina de inovações. Revista Pesquisa FAPESP, edição 128 - Outubro, 2006. São Paulo.

FEITOSA, H.A \& PAULOVICH, L. Um prelúdio à lógica. São Paulo, Editora UNESP, 2005.

FLORES, L.F.V.; Apostila do curso de sistemas e centrais térmicas. UNIFEI, Itajubá, 2003.

FUZZYTECH $^{\circledR}$. 5.60c IA-S5 Demo Copyright ${ }^{\circledR}$ 1991-2006

GAVIRA, M. O. A simulação computacional como uma ferramenta de aquisição de conhecimento. Dissertação (Mestrado) - Escola de Engenharia de São Carlos, Universidade de São Paulo, São Carlos, 2003.

GIL, A.C. Como elaborar projetos de pesquisa. São Paulo: Atlas, 1987.

GILL-LAFUENTE, A.M. Fuzzy logic in financial analysis. Nova York, Springer Verlag, 2005.

GITMAN, L. J. Princípios de administração financeira. 10. ed. São Paulo: Pearson Addisson Wesley, 2004.

GUTIÉRREZ, I. Fuzzy numbers and net present value. Scand. J. Mgmt, Vol 5 No. 2, pp.149-159, 1989. 
IPEA - Instituto de Pesquisa Econômica Aplicada. Exibição de notícia. http://www.ipea.gov.br/003/00301009.jsp?ttCD_CHAVE=2246 consultado em janeiro de 2008.

IPEADATA. Produção anual de cana-de-açúcar.

http://www.ipeadata.gov.br/ipeaweb.dll/ipeadata?SessionID=1639907358\&Tick=121 6527590421\&VAR_FUNCAO=SubmeterFormulario\%28\%27frmMain \%27\%2C\%27 Series\%3FSessionID\%3D1639907358\%26Text\%3Dcana\%26Tick\%3D12165275904 21\%27\%29\%3B\&Mod=M consultado em fevereiro de 2008.

KALATIZS, A.E.G. Avaliação de investimentos envolvendo risco: uma abordagem probabilística. Apostila do curso de finanças corporativas aplicada. Escola de Engenharia de São Carlos, Universidade de São Paulo, São Carlos, 2006.

KASSAI, J.R. Uma abordagem matemática e contábil do retorno do investimento. Caderno de estudos em administração, São Paulo, FIPECAFI, vol.14, julho/dezembro 1996.

KREUZER, H.; 2000. General report. Twentieth congress of large dams, Vol.1, Question 76, Beijing China.

LAW, A.M.; KELTON, W.D. Simulation modeling and analysis. 3. ed. Boston: McGraw-Hill, 2000.

LIMA, M.S.O. (2007). O gás natural como alternativa energética para a indústria têxtil: vantagem competitiva ou estratégia de sobrevivência? Dissertação (Mestrado) - Escola de Engenharia de São Carlos, Universidade de São Paulo, São Carlos, 2007.

LOBATO, E.; SOARES, P. Álcool frustra investidores e produtores. Folha de São Paulo, 20/01/2008. São Paulo.

MALERBA, E.P.M. Desenvolvimento e aplicação de uma ferramenta computacional de apoio à decisão em análise de investimentos sob condições de risco - uma automação do método de monte carlo. 136p. Dissertação (Mestrado) UNIFEI, Itajubá, 2003.

MARCONI, M.A; LAKATOS. E.M. Técnicas de pesquisa. São Paulo: Atlas, 1982.

MARTINS, E. Contabilidade de custos. 9. ed. São Paulo: Atlas, 2002.

MEDEIROS, S. Método para analise de projetos em unidades de conservação, usando lógica fuzzy. Dissertação (Mestrado) UFSC, Florianópolis, 2003. 
MEIRELES, J.L.F. A teoria das opções reais como instrumento de avaliação de projeto de investimentos. 117p. Dissertação (Mestrado) - Escola de Engenharia de São Carlos, Universidade de São Paulo, São Carlos, 2004.

MONTGOMERY D.C.; RUNGERG.C. Estatística aplicada e probabilidade para engenheiros. 2. ed. Rio de Janiero: LTC, 2003.

MSANGI, M.; SULSER, T.; ROSEGRANT, M.; VALMONTE SANTOS, R. Global scenarios for biofuels: impacts and implications. Farm Policy Journal, Vol. 4 No. 2, May Quarter 2007.

NOVA, A.M.O.P. (1980); Geração de números aleatórios em computador. Algumas aplicações. Primeiro CPI - Congresso Português de Informática. Braga, Portugal.

NICOLETTI, M.C.; CAMARGO, H.A. Fundamentos da teoria dos conjuntos fuzzy. (Série Apontamentos). São Carlos: Edufscar, 2004.

OLIVEIRA, M.; VASCONCELOS, Y. Uma história de sucesso e polêmicas. Revista Pesquisa FAPESP, edição 122 - Abril, 2006. São Paulo.

OLIVEIRA JÚNIOR, H.A. Lógica difusa: aspectos práticos e aplicações. Rio de Janeiro: Interciência, 1999.

OLIVEIRA JÚNIOR, H.A, CALDEIRA, A.M.; MACHADO, M.A.S.; SOUZA, R.C.; TRANSCHEIT, R. Inteligência computacional aplicada à administração, economia e engenharia em matlab. São Paulo: Thomson Learning 2007.

OMITAOMU, O.A; BADIRU A. Fuzzy present value analysis model for evaluating information system projects. The Engineering Economist, Volume 52, Issue 2 April 2007 , pages $157-178$.

PACIFICO, O. (2003). Substituição do ativo permanente como vantagem competitiva: estudo de caso no cluster da laranja no município de bebedouro. $102 \mathrm{p}$. Dissertação (Mestrado) - Escola de Engenharia de São Carlos, Universidade de São Paulo, São Carlos, 2003.

PAMPLONA E.O.; MONTEVECHI, J.A.B. Apostila do curso de engenharia econômica 2. UNIFEI, Itajubá, 2005.

PAMPLONA E.O.; MONTEVECHI, J.A.B. Apostila do curso de engenharia econômica avançada. UNIFEI, Itajubá, 2006.

PESSOA, A. Cana-de-açúcar.

http//www.mre.gov.br/Itamaraty/web/port/economia/agrc/producao/cana consultado em fevereiro 2008. 
PLLANA, S. History of Monte Carlo method.

http//www.geocities.com/CollegePark/Quad/2435 consultado em maio de 2007.

PINTO O.P.F. Desenvolvimento de uma ferramenta de análise de decisão para suprimento de uma refinaria de petróleo através de uma rede de oleodutos. Dissertação (Mestrado) UFSC, Santa Catarina, 2001.

RANGEL, C. Carros flex puxam recorde na produção de álcool. Terra economia. Dezembro de 2007.

http://invertia.terra.com.br/sustentabilidade/interna/0,,OI2180117-EI10426,00.html

RECEITA FEDERAL. Instrução Normativa SRF. $\mathrm{n}^{\circ}$ 162, de 31 de dezembro de 1998 DOU de 07/01/1999, pág. 5.

REBELATTO, D.A.N. Projeto de investimento: com estudo de caso completo na área de serviços. BARUERI: Manole, 2004.

ROSA, F.H.F.P.; PEDRO JÚNIOR, V.A. Gerando números aleatórios. Laboratório de Matemática Aplicada - Instituto de Matemática e Estatística, Universidade de São Paulo, São Paulo, 2002.

ROSS, S.A.; WESTERFIELD R.W.; JORDAN B.D. (2002); Administração financeira. 2. ed. São Paulo. Atlas 2002.

ROSS, S.A.; WESTERFIELD R.W.; JAFFE, F.F. (2000); Princípios de administração financeira. 2. ed. São Paulo. Atlas 2000.

ROTHER, L. With big boost from sugar cane, Brazil is satisfying its fuel needs. The New York Times, 2006-04-10. http://www.nytimes.com/2006/04/10/world/americas/10brazil.html?_r=1\&pagewante $\underline{\mathrm{d}=1 \& \mathrm{sq}=\text { Bush\%20Brazil\%20ethanol\&st=nyt\&scp=5\&oref=slogin }}$

SANCHES, A.L. Avaliação econômica de projetos de investimento em condições de incerteza utilizando números triangulares fuzzy. 221p. Dissertação (Mestrado) UNIFEI, Itajubá, 2003.

SANTOS, M.P. Apostila de introdução a simulação discreta. UERJ, Rio de Janeiro, 1999.

SHAMBLIN, J.E.; STEVENS G.T. Pesquisa operacional. São Paulo: Atlas 1979.

SHAW, I.S.; SIMÕES, M.G. Controle e modelagem fuzzy. São Paulo: Edgar Blütcher, 1999.

SILVA, W.F. Contribuição da simulação de Monte Carlo na projeção de cenários para a gestão de custos na área de laticínios. Dissertação (Mestrado) UNIFEI, Itajubá, 2004. 
SILVA FILHO, B.S. Curso de controladores lógicos programáveis. Apostila. Laboratório de Engenharia Elétrica. UERJ, Rio de Janeiro, 2007.

SLACK, N.; CHAMBERS, S.; JOHNSTON, R. Administração da produção. 2. ed. São Paulo: Atlas, 2002.

SOARES, P.; Investimento em álcool chega a US\$19 bi até 2012. Folha de São Paulo, 17/07/2007. São Paulo.

SOUZA, Z.J.; AZEVEDO, P.F.; Geração de energia elétrica excedente no setor sulcroalcooleiro: um estudo a partir de usinas paulistas. RER - Revista Economia e Sociologia, Rio de Janeiro, vol. 44, nº 02, p. 179-199, abr/jun 2006.

THOMPSON JÚNIOR, A. Tomada de decisões sob condições de incerteza, risco e incerteza. Porto Alegre: Universidade Federal do Rio Grande do Sul, 1995.(Texto didático, n.6).

VON ALTROCK, C.; Fuzzy logic \& neurofuzzy application in business \& finance, Pretince Hall PRT-Upper Sadle River, New Jersey 07458-1995.

TORRES, O.F.F. Fundamentos da engenharia econômica e da análise de projetos. São Paulo: Thomson Learning 2006.

TRIOLA, M.F. Introdução à estatística. 7 ed. Rio de Janeiro: LTC, 1999.

VIEIRA, C.E.C.; RIBEIRO, C.C.R.; SOUZA, R.C. Geradores de números aleatórios. PUC-RioInf.MCC22/04. PUC, Rio de Janeiro, junho de 2004.

ZADEH, L.A. Fuzzy sets. Information and control vol 8, 1965.

ZANG, Z.; VEDENOV, D.; WETZSTEIN, M. Can the U.S. ethanol industry compete in the alternative fuels' market? Southern Agricultural Economics Association Meetings Mobile, Alabama, February 4 - 6, 2007. 